\title{
LA ALEXITIMIA EN LA ARTRITIS REUMATOIDEA
}

\author{
Helena Lunazzi
}

Tesis de Doctorado

Facultad de Humanidades y Ciencias de la Educación UNIVERSIDAD NACIONAL DE LA PLATA 2006

DIRECTOR DE TESIS: Doctor Gregorio Klimovsky CO-DIRECTORA DE TESIS: Doctora Liliana Schwartz TESISTA: Psicóloga Clínica Helena Ana Lunazzi 


\section{INDICE}

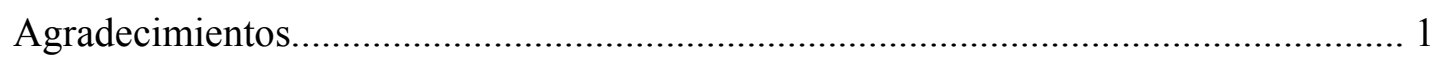

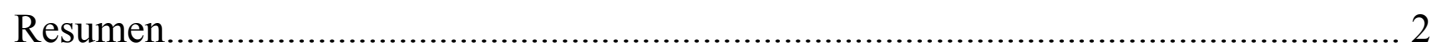

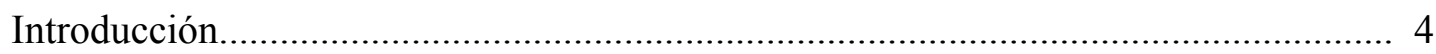

Capítulo 1 Marco Teórico................................................................................... 15

1.1. Patologías Psicosomáticas............................................................................. 16

1.2. Status de los síntomas de los enfermos psicosomáticos........................................ 21

1.3. Psiconeuroinmunoendocrinología................................................................... 24

1.4. Los afectos en la salud y la enfermedad. …………………………………... 30

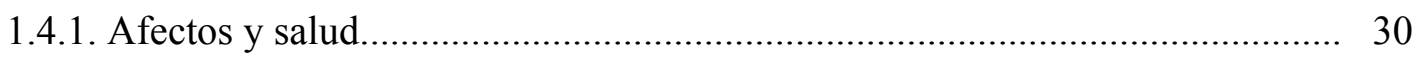

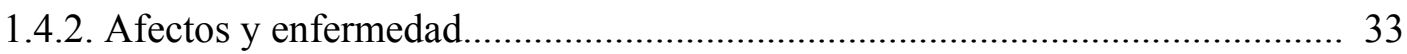

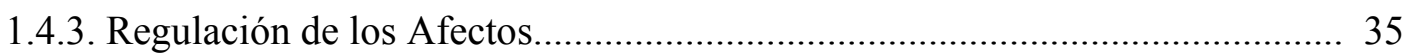

1.5. ¿Cómo comprender las rupturas de la Salud y los desarrollos patológicos?....... 41

1.5.1. Modelos Explicativos.................................................................................... 41

1.5.2. Modelos de déficit: El Modelo Psicosomático de Pierre Marty....................... 44

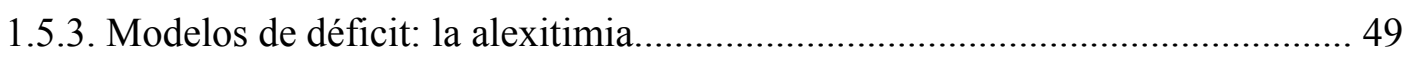

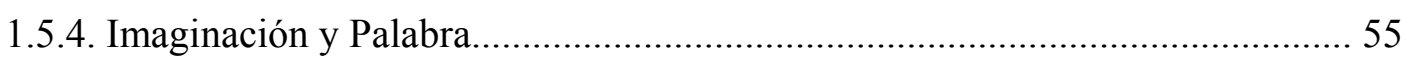

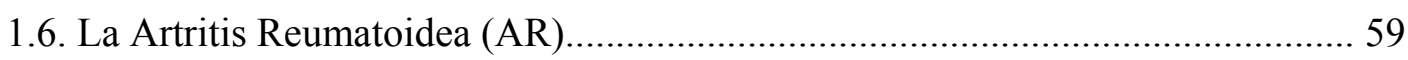

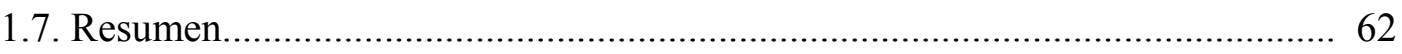

Capítulo 2 Estado de la Cuestión................................................................................. 66

PARTE I : 2. 1. Alexitimia, Personalidad y Cultura................................................ 68

2.1.1 El constructo Alexitimia y la personalidad................................................... 68

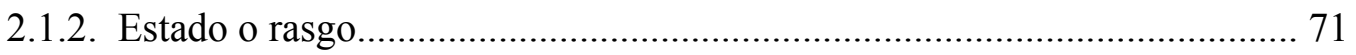

2.1.3. Alexitimia y mecanismos de defensa............................................................ 76

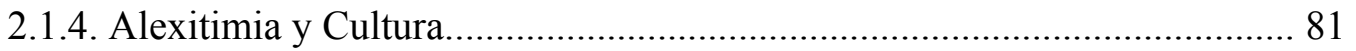

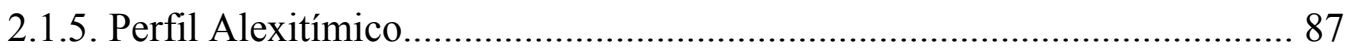

2.1.6. Resumen 
PARTE II 2.2. La Evaluación de la Alexitimia

91

2.2.1. Instrumentos de evaluación de la alexitimia. Desarrollo de la Escala Toronto de Alexitimia TAS (TAS26) 91

2.2.2. Técnica Rorschach. 105.

2.2.3. Contribución de la Técnica Rorschach en el campo hospitalario. 109

2.2.4. Resumen de los hallazgos Rorschach en Medicina Psicosomática..... 111

2.2.5. Estudios Rorschach en alexitimia. 112

2.2.6. Obstáculos metodológicos que pueden limitar la validez de los estudios Rorschach en Alexitmia 116

2.2.7. Propuesta de evaluación Rorschach de la alexitimia. 117.

PARTE III 2.3. Investigaciones y evaluaciones en la Artritis Reumatoidea (AR)... 121 2.3.1. Evaluación de la Artritis Reumatoidea mediante las Escalas Toronto de Alexitimia (TAS y TAS-20)

2.3.2. Evaluación de la alexitimia en la Artritis Reumatoidea mediante el Rorschach,

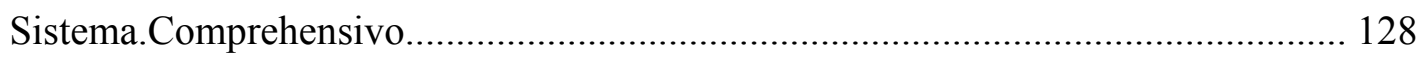

PARTE IV 2.4. Síntesis de la Revisión del Estado de la Cuestión ........................... 132

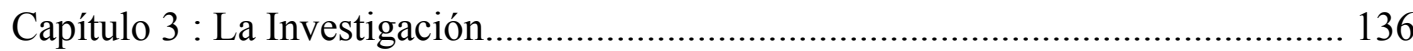

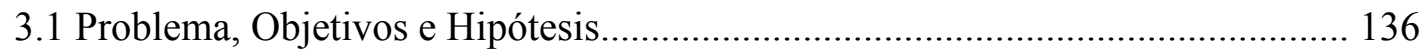

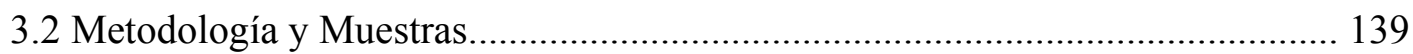

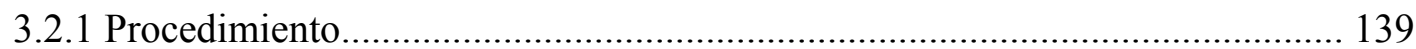

3.2.2 Composición y obtención de las Muestras..................................................... 143

3.2.3 Características de la Muestra I, Artríticos Reumatoideos (AR)...................... 144

3.2.4 Selección, Codificación y Observaciones sobre las muestras.......................... 149

Capítulo 4. Resultados de la Escala Toronto de Alexitimia.................................... 151

4.1 Escala Toronto de Alexitimia (TAS26) ......................................................... 152

4.2 Composición de las Muestras y Resultados de las Muestras I y II.................. 152

4.3 Composición de las Muestras y Resultados de las Muestras I y III................ 157 
4.5. Estudio Cualitativo de la TAS .......................................................................... 165

4.6. Discusión de Resultados TAS ............................................................................. 166

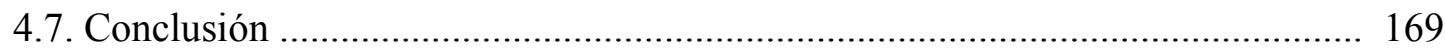

Capítulo 5 : Resultados Obtenidos en la Técnica Rorschach (SC)........................ 171

5.1. Indicadores de Alexitimia en Rorschach (M. W. Acklin y E. Bernat).

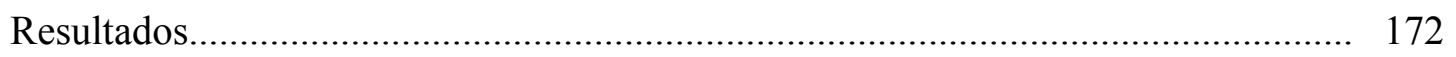

5.2. Significado de las siglas utilizadas en los cuadros........................................... 175

5.3. Indicadores ampliados de alexitimia en el Rorschach......................................... 182

5.4. Comparaciones entre las muestras, reagrupándolas según niveles de años

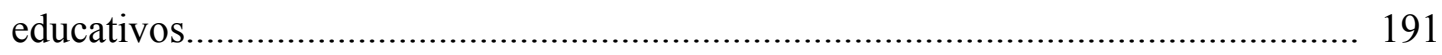

5.5. Investigación de variables asociadas al EA>6 ............................................... 200

5.6 Discusión de Resultados............................................................................... 202

5.7. Síntesis de resultados y Conclusión:..................................................................... 204

Capítulo 6: El empleo de multimétodos y el entrecruzamiento de resultados 207

6.1 Ventajas de la Aplicación conjunta de la Escala Toronto de Alexitimia (TAS26) y la Técnica Rorschach (S.C.) para la evaluación concurrente del constructo alexitmia... 208

6.2 Los perfiles psicológicos. 217

6.3. Perfil psicológico de la Muestra I (Pacientes de artritis reumatoidea -AR), alexitímicos tanto en TAS26, como en el Rorschach (S.C.) 220

6.4. Perfil psicológico de la Muestra II (No-Pacientes de nivel socioeconómico medio bajo), no alexitímicos en la TAS26, y alexitímicos en el Rorschach (S.C.). 221

6.5. Perfil psicológico de la Muestra III (No-Pacientes con años educativos iguales o superiores a 15 años), no alexitímicos en la TAS 26, y no alexitímicos en el Rorschach (S.C.). 
7.1. Revisión de las problemáticas desarrolladas previamente y de las respuestas obtenidas, mediante la aplicación de los instrumentos de evaluación de la

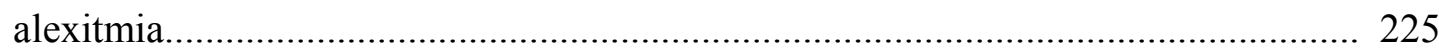

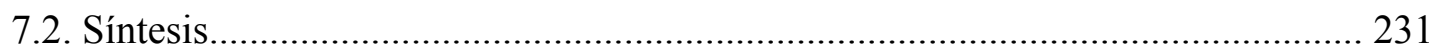

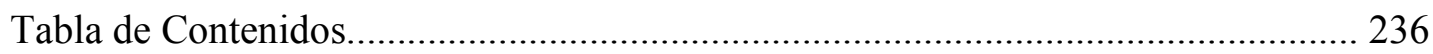

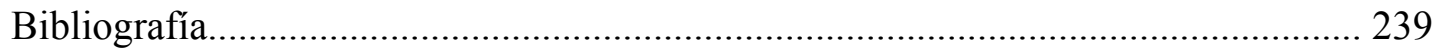

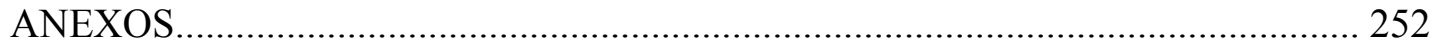

Anexo 1. Planillas de composición demográfica y variables Rorschach de las tres muestras utilizadas: muestra I, muestra II y muestra III.

Anexo 2 : Elaboración estadística.

Prof. María Inés Urrutia (CesPI - centro de estudios estadísticos para la investigación. Universidad Nacional de la Plata)

Anexo 3 : La Escala de Realidad y Fantasía (RFS)

Resultados en las muestras I, II y III, según niveles de presencia de alexitimia definitiva, indeterminada y ausente.

Anexo 4: El involucramiento en las respuestas (R- engagement) evaluado en cada protocolo. resultados en las muestras I, II y III

Anexo 5: La Confiabilidad de la codificación entre codificadores de la muestra de 506 nopacientes argentinos.

elaborada por Thomas Shaffer, Ph. D., A.B.P.P. 


\section{AGRADECIMIENTOS}

Deseo agradecer profundamente al Dr.Gregorio Klimovsky su incondicional apoyo y confianza.

A la Dra. Liliana Schwartz, cuya exhaustiva y eficaz revisión de los manuscritos, en mucho ha contribuido a la mejora de los mismos.

Al Dr.Piero Porcelli, autor de una obra fundamental para el avance de la investigación en Rorschach y Psicosomática, que me posibilitó el acceso a los más recientes desarrollos del tema.

A la Dra. Shira Tibon quien con amable deferencia, supervisó mis avances en el uso de la Escala de Realidad y Fantasía (RFS).

Al Dr. Gregory Meyer, que se mantuvo cordialmente accesible para la discusión sobre los avances y resultados del índice de Involucramiento de Respuesta (R-engagement).

A la Prof. María Inés Urrutia compañera incansable en la elaboración estadística de los resultados.

Al Dr. Thomas Shaffer que aportó el estudio de la confiabilidad intercodificadores de la muestra normativa representativa del Gran La Plata.

Al Hospital Rodolfo Rossi de la Plata que puso a mi disposición la muestra de pacientes de su Servicio de Reumatología.

Asimismo hago extensiva mi gratitud a los pacientes y no-pacientes, todos voluntarios, que accedieron a colaborar en la investigación.

A todos los colegas y amigos que me alentaron en la prosecución de esta Tesis.

A mis hijas, que con respeto y afecto, me brindaron su apoyo y contención en las muchas horas de dedicación y esfuerzo que demandó este estudio.

Helena Lunazzi, 20 de abril de 2006 


\title{
UNIVERSIDAD NACIONAL DE LA PLATA
}

\author{
ABSTRACT \\ LA ALEXITIMIA EN LA \\ ARTRITIS REUMATOIDEA \\ por Helena Lunazzi
}

La alexitimia -sin palabras para los afectos- es un desorden en la regulación de los afectos conceptualizado e investigado en las últimas décadas. Se caracteriza por la dificultad en comunicar los sentimientos, en diferenciarlos de las sensaciones corporales, por la pobreza de la vida de fantasía y por la cognición orientada hacia problemáticas concretas en el mundo externo. Descripta originariamente en los enfermos psicosomáticos, actualmente se reconoce en los trastornos por estrés postraumático, adicciones, personalidades impulsivas y en muchos cuadros psiquiátricos de difícil tratamiento. No se ha comprobado la presencia significativa desde el punto de vista probabilístico de la alexitmia en la artritis reumatoidea (AR), una enfermedad psicosomática autoinmune de importante distribución poblacional. Establecer diferencialmente su presencia en los casos precisa el diagnóstico y orientación psicoterapéutica por parte del equipo de salud.

Con el objetivo de investigar la alexitimia en la AR y evaluarla empíricamente mediante las técnicas Escala Toronto de Alexitimia (TAS26) y Rorschach (Sistema Comprehensivo), se desarrolla esta tesis. Se utilizó un dispositivo de multimétodos, por considerarlo el más apropiado para la evaluación del constructo. Las técnicas se aplicaron a tres muestras seleccionadas de pacientes y no-pacientes, en un total de 180 casos que permitieron la contrastación de los indicadores y variables en juego. 
Para la adecuada contrastación de los resultados de las muestras se obtuvieron los estadísticos descriptivos normativos en 506 no-pacientes de entre 18 y 65 años de edad y del mismo contexto cultural, para la Técnica Rorschach. Se emplearon recientes desarrollos en la investigación de indicadores Rorschach de alexitimia. Se estudió la asociación entre presencia de alexitimia y las variables nivel socio-económico y años educativos, y la validez concurrente de las Técnicas empleadas en el diagnóstico de la alexitmia. Finalmente se comprueban, se refutan y se proponen indicadores nuevos para la evaluación Rorschach (SC) de la alexitimia.

En los enfermos psicosomáticos se señala a la alexitmia como un déficit, pues al reducir la significación emocional de la información proveniente del mundo interno y externo, interfiere en el reconocimiento de situaciones con una gran carga emocional, excitatoria y dañina sobre el organismo, y más ampliamente, con el proceso de autoorganización y reorganización del organismo en su historia y ambiente.

Se aspira a que reconocer en los enfermos de $A R$ la presencia de alexitmia permita contribuir al diseño de las estrategias apropiadas para las intervenciones del equipo de salud. 


\title{
Introducción
}

\author{
Llamamos cuerpo al pedazo del alma que \\ se percibe con los cinco sentidos
}

WILLIAM BLAKE

Los resultados de la investigación que vamos a presentar de inmediato ponen de manifiesto dramáticamente el nudo problemático que inspira el trabajo que desarrollaremos.

El cardiólogo David Sheps, director de cardiología de la Universidad de Tennessee y sus colaboradores, luego de una investigación realizada en 196 personas fallecidas que padecían enfermedades en las arterias coronarias, señalaron que en realidad, y en contra de lo que se piensa, en el caso de las enfermedades cardíacas las características psicológicas por lo general se asocian con la muerte. «Es muy preocupante-indicó Sheps-que los pacientes casi nunca sienten síntomas de estrés, no saben que están estresados y ahí es donde creemos que radica el peligro». Sus conclusiones, entre otras, fueron publicadas en Archives of Surgery de la American Medical Association (agosto 1999) en el artículo Lo que mata es el estrés o El estrés puede matar en silencio a los pacientes cardíacos, denunciando que el estrés psicológico produce más accidentes vasculares en los cardíacos que el estrés físico. Apuntamos aquí que el término 'estrés' designa a la sobrecarga de demandas o estímulos emocionales internos y externos que no se alcanzan a reconocer o a afrontar saludablemente. Los pacientes ignoran cuáles son las situaciones de su ambiente que los afectan y desconocen los mensajes de tensión, cansancio, desazón, rabia, etcétera, que en su interior los presionan.

Nos preguntamos entonces, ¿cómo logran apropiarse de ese saber las personas capaces de reconocer en sus síntomas la relación con su propia subjetividad? y, entonces, ¿Cuáles son las referencias que separan a los sujetos incapaces de integrar a sus síntomas o 
manifestaciones de enfermedad somática, las condiciones psicológicas que, concomitantemente, las agravan o alivian?

Cuando los pacientes reconocen sus síntomas con relación al, o como expresión del sufrimiento psíquico, aunque no sepan conscientemente los lazos de asociación, hablamos del síntoma investido. Postulamos que contar con esta capacidad otorga condiciones de acceso a tratamientos y es promesa de modificaciones. En peor condición se hallarían aquellos sujetos en los que la enfermedad somática es asumida como «marca», como que «algo anda regular» en el órgano afectado, pero no en la subjetividad.

La idea de que los afectos se relacionan con la personalidad y la enfermedad, y que, especialmente cuando se hallan en niveles excesivos, pueden influir negativamente sobre la salud mental y corporal, es muy antigua y ha sido expresada tanto por médicos como por filósofos desde la antigüedad. Hipócrates (siglo IV a. C.) describió los temperamentos humanos como el resultado de cuatro orientaciones emocionales básicas (sanguínea, colérica, flemática y melancólica), resultantes de la preponderancia de ciertos fluidos corporales (sangre, flema y varios tipos de bilis), y atribuyó al exceso de bilis negra la causa principal de la enfermedad mental.

Contamos en el presente con importantes teorizaciones respecto de cómo la falta de disposición y recursos para la elaboración psíquica puede reconocerse particularmente en los llamados enfermos «psicosomáticos».

Pierre Marty, principal representante de la Escuela Psicosomática de París, explica que, como conclusión de sus investigaciones psicoanalíticas iniciadas en la década del sesenta con pacientes que sufrían cefalalgias -inhibición dolorosa del pensamiento-, ciertos aspectos psicosomáticos de la tuberculosis cerebral y otros casos en los que había hallado «pensamiento operatorio» y carencias funcionales psíquicas, fue centrando su atención en los procesos de formación de representaciones propias del preconciente. Llegó así a desarrollar el concepto de «mentalización», con el cual construyó una nueva nosología psicopatológica. También Marty nos aporta la elaboración de los principios básicos de las somatizaciones, cuando plantea que los acontecimientos vitales provocan excitaciones en 
nuestros instintos y pulsiones, y que esas excitaciones deben encontrar vías de descarga -a través de lo sensorio motriz- o de elaboración psíquica -a través de la mentalización- para no volverse excesivas. «El exceso de cargas o, excitaciones acumuladas, constituiría el terreno básico de las somatizaciones» (Marty, 1993).

Desde el punto de vista neurológico, hoy en día son muy claras las pruebas clínicas que hacen visibles las consecuencias alarmantes del exceso de excitaciones (estrés) sobre el tejido nervioso, en las tomografías por emisión de positrones (PET). Consecuencias alarmantes que Selye, autor del concepto de estrés como síndrome general de adaptación, sólo pudo anticipar en sus animales de laboratorio.

Desde otra vertiente, pero en notable coincidencia con los enfoques de la Escuela Psicosomática de París, P. Sifneos y J. C. Nemiah, investigadores bostonianos, como corolario de abundantes trabajos previos, en 1974 emplearon el vocablo griego alexitimia, que significa 'ausencia de verbalización de afectos o sentimientos'. El concepto alexitimia es un constructo hipotético derivado del trabajo clínico con pacientes psicosomáticos. Dichos autores observaron que los pacientes psicosomáticos se caracterizaban por: a) pensamientos con bajos niveles de abstracción; b) pobre capacidad para fantasear; c) relaciones interpersonales rígidas y estereotipadas; d) gran resistencia a aceptar las interpretaciones psicoanalíticas tradicionales. P. Sifneos y J. C. Nemiah aluden con dichos rasgos (por ejemplo «poca abstracción») a la característica disposición de estos pacientes por los abordajes utilitarios y concretos de los hechos, con escasa introspección. Dicho rasgo, como notamos, fue. el llamado pensamiento «operatorio», descripto previamente por P. Marty, M. de M'Uzan y P. David, en 1963 (Marty y de M’Uzan, 1963)

Una caracterización aceptada (Taylor et al., 1997) considera que la alexitimia denuncia que la palabra no representa la vida afectiva del sujeto. Consiste en un desorden de la regulación y mediación de los afectos entre la fisiología, el soma y los procesos cerebrales de la mente, lo cual constituye un importante factor de riesgo en las enfermedades psicológicas y físicas, hallándose implicada en los cuadros psicosomáticos, 
cuadros antisociales, abuso de sustancias, desorden por pánico y otras enfermedades. Todos estos cuadros comparten la escasa integración de los sentimientos a la mente y la conducta.

El déficit del procesamiento cognitivo de las emociones -definido por Sifneos en 1973 como déficit neurológico de las vías conectivas entre la corteza y el sistema límbicoen la llamada alexitimia primaria es susceptible de verificarse en las pruebas de laboratorio y de inducirse experimentalmente. Dicho déficit también es manifiesto en la alexitimia secundaria, así llamada por Sifneos (1995), que se desarrolla aun cuando las bases y conexiones neurológicas están intactas. La alexitimia secundaria, verdadera o cristalizada como rasgo de la personalidad, en cambio, se atribuye a falencias tempranas en el vínculo materno, cuando la madre carece de la capacidad de representarse las emociones del bebé y por ello tampoco es capaz de verbalizarlas (Winnicott, 1979; Liberman, 1983; Mc Dougall, 1987; Bion, 1965, 1992). Esas carencias maternas interferirían en el proceso normal del bebé de reconocer y expresar sus propias emociones.

También se ha descripto una alexitimia secundaria, como respuesta adaptativa a traumas y enfermedades. Esta respuesta «adaptativa», en la cual las emociones intensas no se reconocen ni verbalizan puede ser transitoria, ya que se trataría de un sujeto, sólo situacionalmente alexitímico (Freyberger, 1977).

Además se señalan, desde otro nivel de análisis, variables culturales propicias para el desarrollo de la alexitimia secundaria.(Casullo, 1994; Paez y Casullo, 2000).

El constructo alexitimia, entonces, recupera y enfatiza el valor de la palabra como producción simbólica capaz de representar las sensaciones y mediar con las vicisitudes del soma. Muestra especial interés teórico y práctico para el reconocimiento y abordaje de los pacientes psicosomáticos.

El término psicosomático ha sido utilizado tanto en el campo médico como psicoanalítico para referirse a una serie de trastornos orgánicos en los que era reconocida como esencial la incidencia de los factores psíquicos. Queda expreso que los factores de la 
personalidad son manifiestos, pero necesariamente también en la enfermedad deben constatarse lesiones y disfuncionalidades en los órganos. Es decir, se hallarán asociados componentes orgánicos, genéticos, inmunitarios, etcétera. Citamos como ejemplos clásicos al asma, la úlcera, la hipertensión, la artritis reumatoidea, el hipertiroidismo y la psoriasis. A pesar de que los factores psíquicos claramente inciden en la aparición y el desarrollo de la enfermedad, esto es «ignorado» por el paciente, que trata a su cuerpo como un escenario ajeno de sí mismo. Contrariamente a la implicancia de unión entre la mente y el cuerpo que el vocablo psicosomático parece indicar, el cuerpo queda escindido o disociado de la mente. Debemos aclarar que los clínicos reconocen como esencial la incidencia de los factores psíquicos, mientras que los pacientes psicosomáticos manifiestan con el cuerpo sus efectos.

Plantearse la actividad indisoluble entre la mente, el cuerpo y su ambiente ha requerido, por otra parte, la revisión de postulaciones epistemológicas unicausalistas vigentes en enfoques propios de ciertos campos médicos. Actualmente la medicina se encuentra con la necesidad de replantear esquemas, paradigmas y abordajes que tradicionalmente han marcado su definición como ciencia. Entre tales cambios, surge la Psiconeuroinmunoendocrinología (PNIE), como una de las principales neoconceptualizaciones. En psiconeuroinmunoendocrinología las relaciones entre los cuatro sistemas de control que tiene el organismo humano -el psicológico, el neurológico, el inmunológico y el endocrinológico- se ven definitivamente integrados como un todo. Sus aportes resultarán indispensables para la comprensión del problema que nos ocupa.

El desarrollo y funcionamiento saludable del ser humano implica un flexible y fino fenómeno adaptativo, donde el ambiente puede afrontarse haciendo uso de las capacidades neurobiológicas propias que permiten no sólo el rechazo o la huída de los factores potencialmente agresores o destructivos sino su reconocimiento, afrontamiento y resolución conveniente y creativa para el sujeto. El amplio concepto de funcionamiento defensivo, tanto en el campo médico (sistema inmune) como en el psicoanalítico (operaciones defensivas del yo) es aquí específicamente significativo. 
Los autores del modelo integrativo en PNIE que describen las interacciones entre los factores psicosociociales y biológicos en la etiología y progresión de las enfermedades han empíricamente demostrado que «La forma en que un individuo interpreta y responde a su ambiente determina su respuesta al estrés, influye en sus conductas saludables, contribuye a su respuesta inmune y neuroendócrina y puede, por último, afectar el desenlace saludable» (Lutgendorf y Constanzo, 2003).

Carentes de o limitados en sus recursos para reconocer mediante la palabra sus estados subjetivos y las demandas del ambiente, ¿podrían entonces los enfermos psicosomáticos influir saludablemente en la evolución de su enfermedad? La presencia de alexitimia, si bien esperable, ¿en qué proporción se hallaría presente en una determinada enfermedad psicosomática?, ¿sería posible intervenir terapéuticamente mejor, conociendo la cualidad particular del déficit en cada caso?

Nos ha interesado profundizar en la investigación empírica de estas preguntas, conocer si efectivamente la alexitimia se hallaría presente en un cuadro psicosomático específico. De ser así, su alcance, sus límites, las variables que podrían afectar la presencia de alexitimia.

Para ello, vamos a estudiar una enfermedad clasificada como psicosomática, sobre la cual no se han realizado investigaciones suficientemente rigurosas respecto de la presencia de alexitimia: la Artritis Reumatoidea (AR). La AR es una enfermedad autoinmune, inflamatoria, crónica, en la cual el daño a los tejidos articulares puede no sólo provocar deformidad sino invalidez.. La Artritis reumatoidea atrajo nuestro interés en razón de las características especiales manifiestas en nuestros estudios previos con enfermedades psicosomáticas y por la ausencia de investigaciones evaluativas satisfactorias hasta el presente.

Siempre hemos considerado a las técnicas de evaluación psicológica como instrumentos preciosos, capaces de reconocer y estimar distintos funcionamientos de la personalidad. Hemos sostenido, además, que el valor de las técnicas requiere del adecuado 
juicio clínico del psicólogo, quien deberá integrar sus distintos aportes, reconocer las variables en juego y describir dimensiones estructurales y dinámicas en esta personalidad única, en su tiempo y contexto.

La evaluación psicológica disfruta actualmente, afortunadamente, de «nuevo respeto científico, aplicaciones y enfoques», dice R. Clay en un artículo publicado en el Monitor on Psychology el 1 de enero del 2006, en el que analiza varios focos de la disciplina y cita un estudio publicado en el 2001 en el American Psychologist (Vol. 56, n. ${ }^{\circ}$ 2: 128-165), donde un grupo de trabajo sobre Evaluación Psicológica de la Sociedad Americana de Psicólogos (APA) comparó la validez de los test psicológicos con la de los test médicos, tales como las imágenes por resonancia magnética, frotis del Papanicolau, electrocardiogramas y muchos más. Los resultados obtenidos, sorprendentes y esclarecedores, establecieron que los test psicológicos generalmente predicen o muestran, consecuencias con una eficacia semejante a la que obtienen los test médicos. Clay señala los importantes desarrollos logrados en la disciplina y, particularmente, destaca como un hecho significativo el aumento de los pagos desde 2006 para los servicios de evaluación en los Estados Unidos.

Utilizaremos en la investigación que nos proponemos dos técnicas de evaluación psicológica, reconocidas internacionalmente: la Escala Toronto de alexitimia (TAS26) (Taylor y Bagby, 1987) y la Técnica de Rorschach, provista de rigor psicométrico y amplia base empírica, mediante el Sistema Comprehensivo (Exner, 1974). Seleccionamos estas técnicas por su capacidad para evaluar cada una en forma independiente el mismo constructo, la alexitimia. Abordaremos, de este modo, el empleo complementario y concurrente de ambas técnicas para evaluar la alexitimia.

Es importante señalar aquí que, por primera vez en nuestro país, los resultados de la Técnica Rorschach se compararán con los estadísticos descriptivos de no-pacientes propios de nuestra cultura. Implementamos este laborioso recaudo metodológico con los objetivos de contar con normas poblacionales argentinas y evitar los posibles sesgos que hubiera ocasionado la comparación con poblaciones extranjeras (Allen, 2000, 2004), (Constantino, 1995), (Dana, 1993, 1995, 1998, 2002), (Franchi, 1999), (Lunazzi , 2002), (Meyer, 2002). 
La construcción de las normas de referencia de la Técnica Rorschach para nuestra población en 506 no-pacientes entre 18 y 65 años de edad (Lunazzi y col., 2005), es el fruto del proyecto de investigación 11/H 266 acreditado por la Universidad Nacional de La Plata, que desarrollamos en el período 1999 a 2003.

Utilizamos, para la presente Tesis, una muestra de 60 pacientes de Artritis Reumatoidea (AR), obtenidos en el Servicio de Reumatología de un gran hospital público, el Hospital R. Rossi, de La Plata. La sometimos al análisis de la correlación de los resultados respecto de otras dos muestras (120 casos) de no-pacientes equiparadas demográficamente. Nos proponemos neutralizar la presencia de variables que pudieran afectar y confundir los resultados, por ejemplo el nivel socioeconómico y los años educativos.

Mundialmente se realizan numerosos estudios, por ejemplo acerca de la respuesta al dolor en la AR, pero se carece de referencias específicas y fundadas sobre las características psicológicas del cuadro, en particular de su capacidad para reconocer, describir y modular la emoción del dolor. El aporte de esta investigación sobre la regulación afectiva, interesa para conocer las características del funcionamiento psíquico en la delimitación del cuadro que nos ocupa: la artritis reumatoidea (AR). Si el médico pudiera disponer de información y orientación acerca de las características psicológicas, podría anticipar mejor comprensión, brindar mejor tratamiento, e implementar oportunamente cuidados disciplinarios e interdisciplinarios. De este modo, la transferencia a la comunidad, de los resultados obtenidos, reviste un valor práctico.

Esta investigación responde también, como contribución a nuestras preocupaciones profesionales. Los psicólogos, en tanto profesionales del campo de la salud, nos hallamos frecuentemente conmovidos por hechos o sucesos que implican amenazas, o daños a la salud física o mental de la comunidad. Confrontados con esos problemas, intentamos hacer aportes desde nuestra disciplina, mediante intervenciones asistenciales, de investigación o de prevención, que desarrollamos en nuestros distintos ámbitos de ejercicio profesional. 
En síntesis: motivados por contribuir desde nuestra disciplina a la solución de los acuciantes problemas de la salud, calidad de vida y sobrevida de nuestra población, desarrollamos este trabajo con los recursos disponibles más actuales. Concebimos la evaluación psicológica en su aplicación diagnóstica, como un recurso confiable, válido y necesario, que debe ser integrado en los equipos de salud con el objetivo de identificar y reconocer, en cada paciente, su disponibilidad y características, de modo de volver a las intervenciones terapéuticas las más eficaces posibles.

Vamos a ocuparnos de investigar una patología autoinmune, de importante incidencia demográfica: la artritis reumatoidea (AR). Mediante la aplicación conjunta de técnicas de evaluación psicológica específicas, estudiaremos la presencia y funcionamiento de alexitimia. Constructo teórico y operativo, elaborado en las últimas décadas, cuya identificación permitirá reconocer las singulares características psicológicas de los pacientes. Utilizaremos un cuidadoso diseño metodológico, mediante el análisis de muestras de pacientes y no-pacientes, cuya descripción haremos más adelante.

Durante el desarrollo del trabajo que introducimos retomaremos y profundizaremos las muchas cuestiones aquí enunciadas. Nos guían los objetivos de:

1. Delimitar y precisar la relación entre la alexitimia y la AR.

2. Validar, en el caso de la AR, el uso de dos técnicas distintas: TAS26 y Rorschach, para el diagnóstico de la alexitimia, analizando sus aportes concurrentes en el diagnóstico.

3. Contribuir con los resultados de la investigación, al trabajo del psicólogo, en los equipos de salud.

\section{Interés del presente tema de Tesis}

En atención a todo lo expuesto previamente, estimamos que el interés del tema es de carácter múltiple, interés que a continuación puntualizaremos:

Frente a los importantes problemas y límites que plantean los tratamientos a las enfermedades y padecimientos humanos, tanto físicos, psíquicos o sociales, la alternativa de la intervención en la prevención y tratamiento aparece como prometedora, aunque no por ello sencilla. Clásicamente, prevención alude a pre-ver dispositivos y cuidados antes de 
que un cuadro patológico se constituya o instale. Poder prever y poder intervenir, a su vez, implica un conocimiento acabado de las enfermedades, las condiciones que intervienen etiológicamente, sus formas de trasmisión, los medios que las favorecen y los recursos posibles para neutralizar, combatir o eliminar su aparición. En consecuencia, reconocer y evaluar la presencia, magnitud o ausencia de alexitimia en los pacientes de AR permitiría ofrecer una información cuantitativa y cualitativa de utilidad en la comprensión y manejo de los pacientes.

Desde el punto de vista del psicodiagnóstico diferencial, interesa el reconocimiento de las características especiales de este cuadro psicosomático. Disponer de criterios diagnósticos diferenciales, enriquece al conocimiento técnico y a la comprensión teórica, hechos que a su vez contribuyen a las precisiones pronósticas y a la indicación de los tratamientos que correspondan.

Señalemos también la posible utilidad metodológica del uso concurrente de técnicas disímiles, el Rorschach y la TAS 26, para los datos que, hasta ahora, las técnicas informan independientemente. El uso conjunto de distintas técnicas de evaluación de un mismo constructo, al arrojar luz de distinta forma sobre sus caras complementarias, promete enriquecer y profundizar tanto el conocimiento de la alexitimia, como el de las técnicas en símismas.

El estudio y comportamiento de las variables modulación o regulación de las emociones propias de la alexitimia, a través de la AR, que concitan tanta atención en la actualidad, ofrecerá aportes a la comprensión teórica de los respectivos conceptos y su asociación con la salud y con la enfermedad.

Nos proponemos investigar la intervención de variables tales como nivel socioeconómico y años educativos, para despejar y controlar, la posible asociación que tales variables pueden presentar con la alexitimia. Incorporaremos los más recientes desarrollos de indicadores elaborados en técnica Rorschach, como la Escala de Realidad y 
Fantasía (RFS, Tibon, 2000) y la Capacidad para involucrarse en las Respuestas (R-eng, G. Meyer, 1997), para probar su pertinencia.

La investigación que vamos a realizar se ha planteado mediante una muestra de pacientes y una de control de no-pacientes, demográficamente homologados y evaluados según los baremos del propio contexto cultural (Gran La Plata, 506 no-pacientes). Tales propiedades no sólo neutralizan los sesgos provenientes de realizar comparaciones entre las muestras locales y los baremos de poblaciones extranjeras, sino que permitirán comparar con pacientes de AR, recolectados en otros contextos culturales, siguiendo la metodología del Rorschach, Sistema Comprehensivo ${ }^{1}$.

La profundización en las características del funcionamiento psicológico asociado a la AR permitirá, en suma, la transferencia de conocimiento útil para el tratamiento y prevención interdisciplinario de la enfermedad y su evolución.

En síntesis, este trabajo constituirá un aporte de sumo interés para el tema. Por un lado, como avance en la comprensión de la vida afectiva en esta enfermedad y por otro, por los conocimientos obtenidos de la metodología evaluativa que se propone y las aplicaciones consecuentes. Esta adquisición de conocimiento derivará a su vez en transferencia apta, para instrumentar en los tratamientos del padecimiento. Tal contribución se plasmará tanto en la asistencia al paciente, como en la asistencia de la relación médico-paciente.

\footnotetext{
${ }^{1}$ Actualmente (2005) se hallan acreditados en la Sociedad Internacional de Rorschach 33 países cuyas Asociaciones realizan su evaluaciones empleando el Sistema Comprehensivo.
} 


\title{
Capitulo 1
}

\section{MARCO TEÓRICO}

\author{
El comedor y la biblioteca de mis recuerdos eran \\ ahora, derribada la pared medianera, una sola \\ gran pieza desmantelada, con uno que otro \\ mueble. No trataré de describirlos porque no \\ estoy seguro de haberlos visto, pese a la \\ despiadada luz blanca. Me explicaré. Para ver \\ una cosa hay que comprenderla. El sillón \\ presupone el cuerpo humano, sus articulaciones y \\ partes; las tijeras el acto de cortar ¿que decir de \\ una lámpara o de un vehículo? el salvaje no \\ puede percibir la biblia del misionero; el pasajero \\ no ve el mismo cordaje que los hombres de a \\ bordo. Si viéramos realmente el universo tal vez \\ lo entenderíamos.
}

JORGE LUIS BORGES (El libro de arena)

Para presentar y desarrollar esta Investigación necesitamos, en primera instancia, delimitar teóricamente algunas nociones y conceptos que han sido utilizados para cumplimentar este trabajo. Es nuestro fin tornar comprensibles las distintas puntualizaciones, que realizamos ya que las mismas, se pueden "leer", desde distintas concepciones teóricas y/o disciplinas. Abordaremos el examen de dichas nociones, según el plan de exposición que continúa:

\subsection{Patologías Psicosomáticas}

1.2. Status de los síntomas de los enfermos psicosomáticos.

\subsection{Psiconeuroinmunoendocrinología}

1.4. Los afectos en la salud y la enfermedad.

1.4.1. Afectos y salud.

\subsubsection{Afectos y enfermedad}

\subsubsection{Regulación de los Afectos}

1.5. ¿Cómo comprender las rupturas de la Salud y los desarrollos patológicos?

\subsubsection{Modelos Explicativos}


1.5.2. Modelos de déficit: El Modelo Psicosomático de Pierre Marty

1.5.3. Modelos de déficit: la alexitimia.

1.5.4. Imaginación y Palabra

1.6. La Artritis Reumatoidea (AR)

1.7. Resumen

\subsection{Patologías Psicosomáticas}

Las patologías llamadas psicosomáticas desafortunadamente cobran día a día un lugar de mayor protagonismo, tanto por su variedad como por el aumento de su incidencia negativa en la salud de las poblaciones en general. A las siete enfermedades llamadas «clásicas»: asma, úlcera, colitis, hipertensión, artritis, eccema e hipertiroidismo, se han agregado los trastornos de la alimentación, la vulnerabilidad a patologías oncológicas, las colagenopatías, nuevas patologías autoinmunes, la vulnerabilidad y desorganización frente al estrés en su forma crónica o traumática, la psoriasis, etcétera. En especial, las patologías cardiovasculares, como es de público conocimiento, han ascendido al primer lugar entre las causas mundiales de mortandad. En nuestro país más de cien mil personas fallecen al año por alguna afección cardíaca (Consultor de Salud, 8 de agosto de 1997, N. ${ }^{\circ}$ 176: 5).

A pesar de que el término psicosomático no es simple, ha pasado al vocabulario cotidiano. Para el sentido popular, como para la comunidad médica, el concepto habitual consiste en asimilar lo psicosomático a lo psíquico. Aquellos pacientes designados así, son considerados falsos enfermos, más o menos histéricos, eventualmente hipocondríacos, o simuladores. Delante de un síntoma somático, decir «es psicosomático» resulta en negarle toda fuente orgánica, es decir su causalidad corporal. Si el síntoma parece organizado en el seno de una enfermedad manifiesta en los órganos y en las pruebas de laboratorio, la locución «es una enfermedad psicosomática» prejuzga su origen psíquico y su status de condición incierta. Sin embargo, para que la enfermedad «psicosomática» se instale y 
desarrolle es preciso que entren en juego componentes orgánicos, genéticos, inmunitarios, etcétera, que se podrán observar en los análisis de laboratorio.

El sentido común encuentra a menudo concebible que ciertos acontecimientos como la pérdida de un ser querido, o un fracaso sentimental o profesional puedan crear las condiciones de desarrollo de una enfermedad somática. En todos esos sucesos, la noción de psicosomático es regularmente asimilada a la de causalidad psíquica. Es también plausible aceptar que un estado de tensión psíquica pueda desencadenar una migraña, un dolor de columna, o cólicos, por ejemplo, y hasta incriminar al psiquismo en el desencadenamiento de infartos de miocardio o de úlceras; o de igual modo, entender que una lesión difusa o localizada en el cerebro, o la ingesta de psicofármacos o de sustancias tóxicas que actúan sobre el cerebro sean capaces de modificar las emociones que se vivencian o las conductas que expresan. Sin embargo, tales conclusiones podrían implicar que se asume cierta polarización entre lo orgánico y lo psíquico, o alguna creencia de subordinación entre ellos, más que enfatizar su interacción.

Podríamos decir respecto de la pareja psique-soma, que, en realidad, conforma algo así como una mezcla indisoluble, pero en la cual los dos términos presentan estrategias de abordaje, características que dificultan acceder a su verdadera integración y mutuo compromiso.

La división cartesiana mente-cuerpo ahondó la distinción entre esas dos dimensiones que originaron más y mayor focalización y especialización, corriendo el riesgo de considerarse estancas (Canteros, 2003). Somos, sin embargo, en tanto seres humanos, expresión somática, ya que el cuerpo es nuestro sostén y medio. En grado diverso nuestro sostén somático se lesiona, afecta o perturba, y podemos caer enfermos, restablecernos o devenir y configurar modos de expresión y funcionamiento reconocibles en la llamada clínica de la expresión somática. La expresión somática, tanto como la psíquica, forma parte de las potencialidades y capacidades que todos tenemos para regular las alternativas y demandas de las excitaciones internas y externas en el curso de la vida. Los seres humanos somos seres de la comunicación, y nuestra capacidad de comunicación está íntimamente ligada a nuestra capacidad de expresión somática. Lo que damos a escuchar en el decir, y a ver en el actuar es indisociable de la participación de nuestros músculos faciales, de la tonalidad 
de la voz, de la tonicidad de nuestros movimientos, de nuestro cuerpo. Los sucesos vitales en los que intervenimos se sostienen o acompañan en y con los estados del cuerpo, tanto en lo que se dice como en lo que no se encuentra expresado verbalmente. Como sostiene Rosine Debray: «¿Cómo disociar lo que se dice de quién lo dice?» (Debray, 1996: 15). Sólo cuando la expresión somática adopta un lugar sintomático privilegiado y estable, comprometiendo la salud de los órganos o de su funcionamiento, nos hallamos frente a los llamados «cuadros psicosomáticos».

El término psicosomático ha sido utilizado tanto en el campo médico como en el psicoanalítico para referirse a una serie de trastornos orgánicos en los que era reconocida como esencial la incidencia de los factores psíquicos. A pesar de que el término psicosomático, en apariencia, subraya la básica unidad psique-soma del ser humano, en realidad alude a pacientes que al mostrar un serio daño corporal se manifiestan como si negaran o no tuvieran registro psíquico del mismo. Al decir psicosomático se trata de un modo de funcionamiento que se caracteriza por el no reconocimiento de la dimensión psíquica, dimensión que no se encuentra ligada a lo somático. Para D. Winnicott (Winnicott, 1979) ésta es la verdadera enfermedad. Para ilustrar esta situación podemos ejemplificar con la característica posición de los sujetos obesos: se los describe como muy adaptados y carentes de la angustia del registro de su sobrecarga, se dice de ellos «que padecen de cordura y no padecen su gordura» (Liberman, 1991), se relacionan con su propio cuerpo como si fuera de algún modo «ajeno». En realidad, la condición de la salud es la integración de ambas realidades, la psíquica y la corporal, en la experiencia del sujeto. Las características mencionadas, cierta desarticulación entre lo somático y lo psíquico, son las condiciones de vulnerabilidad, pero aunque implícitas no son exclusivas para el desarrollo de una enfermedad orgánica. Podríamos decir que, en el caso de las enfermedades psicosomáticas, los factores psíquicos en juego son necesarios, pero no suficientes. Para que la enfermedad se instale y desarrolle es preciso que intervengan componentes orgánicos, genéticos, inmunitarios, etcétera.

Son determinantes, para desarrollar una enfermedad psicosomática típica, los factores genéticos y hereditarios, pero, paralelamente, se encuentran aportes que acentúan dimensiones de la personalidad: $a$ ) enferman quienes tienen determinados perfiles de 
personalidad, por ejemplo el descripto Tipo A entre los $\operatorname{cardíacos}^{1}$; o $b$ ) los que tienen tipos específicos de conflictos, esta última postura ilustrada por Ángel Garma (Garma, 1957), de la escuela kleiniana argentina, Flanders Dunbar en Chicago (Dunbar, 1955), y más recientemente entre nosotros, con el mismo énfasis, L. Chiozza (Chiozza, 1970). En el campo del psicodiagnóstico, autoras como Lydia Burde y Elisabeth Sorribas (Burde y Sorribas, 1993) han sostenido, además, el reconocimiento de ciertas posiciones fantasmáticas características en los enfermos psicosomáticos.

Cuando hacemos referencia entonces a «cuadro psicosomático» quedan excluidas las «manifestaciones somáticas» o los «síntomas somáticos», ocasionales y normales modos de expresión por medio del cuerpo de todos los seres humanos (Debray, 1996). Tomemos en cuenta que ellos, sin embargo, no conforman dinámicas estables, largamente consolidadas en el curso de la vida. Tampoco en las «manifestaciones somáticas», por ejemplo cambios ocasionales de la presión arterial, o cólicos digestivos en situaciones especiales, se halla el compromiso característico del conjunto de la personalidad, ni la lesión del órgano.

Reconoceremos, en cambio, a los pacientes que verdaderamente conforman un cuadro psicosomático de modo abarcativo y típico, cuando utilizan la enfermedad para darse identidad: «soy diabético», «soy cardíaco», «yo soy asmático».

Creemos importante, sin embargo, señalar que la incidencia de factores psíquicos vuelve decisiva la intervención de los psicoterapeutas para la prevención, atención o remisión de la enfermedad. A su vez, las intervenciones terapéuticas avaladas por una comprensión amplia de las enfermedades se benefician adquiriendo mayor precisión (Ricart, Cohen, Alfonso, Hoffman, Quiñónez, Cohen, Indyk, 2002), (Crofford, Casey, 1999), (Rice, Pisetsky, 1999), (Schanberg, Sandstrom, 1999).El equipo constituido por J. Kielcolt Glaser, L. Mac Guire, T. Robles y R. Glaser, luego de una revisión de las investigaciones realizadas desde 1939 en medicina psicosomática en la cual analizaron la modulación psicológica de la función inmune según la duración de los estresores y sus características,

\footnotetext{
${ }^{1}$ El patrón Tipo A incluye un sentido de urgencia, competitividad, agresividad, impaciencia, exigencia excesiva de logros, voz vigorosa y manierismos psicomotores. Fue descripto inicialmente por Friedman y Rosenman en 1959, y concitó mucho interés en las décadas posteriores.
} 
la psicopatología, la personalidad, las relaciones interpersonales y particularmente la respuesta del sistema inmune a las intervenciones psicoterapéuticas habitualmente de carácter conductual, afirman: «actualmente disponemos de suficientes datos como para concluir que la modulación inmune puede llevar a cambios saludables reconocibles, las evidencias directas más fuertes para registrar se hallan en las enfermedades infecciosas y en la curación de las heridas» (Kielcolt Glaser, Mac Guire, Robles, y Glaser, 2002). 


\subsection{Status de los síntomas de los enfermos psicosomáticos.}

Hemos dicho que es importante la intervención del psicólogo en estas enfermedades. Sin embargo es necesario anticipar, que si abordamos enfermos psicosomáticos nos hallamos en un campo de intervención dificultosa, especialmente por la relación que establece el paciente con su sintomatología. Si el problema, por ejemplo, es la hipertensión o el asma, el que habla, se muestra y da a ver y a cuidar es el cuerpo, no el sujeto. Para el sujeto se trata de procesos ajenos a su propia vida afectiva: simplemente son «denuncias» de que algo anda mal orgánicamente. ¿Podemos entonces, llamar síntomas a los malestares propios de los enfermos psicosomáticos?

Diferenciamos este tipo de relación de las manifestaciones del enfermar como signos o marcas, pero en ausencia de síntoma investido. Es decir, esto último, cargado de significado subjetivo, aunque este significado pueda ser desconocido.

Reservaremos el uso del término 'síntoma' al propio de la teoría psicoanalítica. La Medicina, en cambio, utiliza también el concepto de signo y se distingue síntoma de signo. Como síntoma se entiende, en Medicina, cualquier modificación anormal en los órganos, o en las funciones o comportamientos normales, las que se considerarán indicaciones de la presencia de patología. El signo (por ejemplo, el de Babinsky) no es visible, como los síntomas, pero se lo obtiene mediante estimulación e igualmente indica presencia de alteración, o patología.

Haremos entonces a continuación una revisión breve del uso del concepto de síntoma desde el punto de vista psicoanalítico, entendiéndolo dinámicamente, como efecto del conflicto psíquico. Este concepto de síntoma supone suficiente integración entre los procesos de la mente y el cuerpo; dimensiones que -recordamos- se hallan disociadas en los psicosomáticos.

S. Freud, en 1916, fue terminante al enunciar que «el síntoma somático está desprovisto de sentido», al distinguir las neurosis actuales, en las cuales el síntoma está localizado anatómicamente y no cede a la interpretación de lo reprimido ${ }^{2}$, de las psiconeurosis de

\footnotetext{
${ }^{2}$ Corresponde a lo que describimos como enfermedad psicosomática, enfermedad ajena al sujeto, radicada en el cuerpo como algo ajeno de sí mismo (Nota de la autora).
} 
defensa, cuyo modelo es la histeria de conversión, en la cual la interpretación de lo reprimido lleva a la disolución del síntoma. Freud mantuvo su afirmación durante toda su obra. También J. Lacan en 1960, al hablar del fenómeno psicosomático, señaló que no integra la cadena significante por ser efecto de una forclusión. Se trataría de algo del orden de la marca, que no tuvo por destino su borramiento, o represión, en términos freudianos. Sin embargo Lacan, sobre el final de su enseñanza en la Conferencia de Ginebra (Lacan, 1997), insistió en que sólo por medio del trabajo del inconciente «se podrá revelar algo del goce específico fijado a la marca, que da lugar al síntoma somático». Queda abierta así la posibilidad de que, al menos en ciertos casos, la intervención analítica podría ser apropiada, postura con la que coincidimos. Lo hacemos porque la descripción de las enfermedades psicosomáticas que hemos ofrecido es válida, particularmente como modelo teórico. Empero también, debemos considerar la necesaria heterogeneidad psicológica de todos los casos, los cuales a menudo comparten y discrepan en algunos rasgos de los modelos. Como veremos en detalle más adelante, es posible observar organizaciones psíquicas psicosomáticas que disponen de ciertos recursos de elaboración psíquica (mentalización). Como ilustra la Escuela Psicosomática de Paris y hemos tenido oportunidad de comprobar en nuestra propia experiencia, una franja dentro de los enfermos psicosomáticos, que dispone de mejores niveles de mentalización, se beneficia claramente mediante el trabajo analítico.

Si consideramos a la enfermedad en relación con la estructura psíquica subjetiva del que la padece, será más grave la consecuencia cuando el sujeto se halle restringido en sus recursos de acomodación y respuesta. En este caso hablamos de limitación para «mentalizar», es decir, elaborar la representación psíquica, por ejemplo del efecto del estrés. Dicha representación le permitiría organizarse: estimar, posponer, mediar, regular las acomodaciones y respuestas que le resulten más adecuadas.

Adelantando un poco el concepto de «mentalización», que profundizaremos más adelante (Modelo de Pierre Marty), cuando hay en los sujetos severas limitaciones para mentalizar, la inscripción de la sobrecarga de excitaciones excesivas y negativas se efectúa en el cuerpo, a menudo de modo no reversible. Al respecto, es útil que diferenciemos los dos caminos extremos, seguidos por las violencias estresantes: su elaboración sintomática 
o su carácter de «marca», es decir, una manifestación del cuerpo, pero en la que el sujeto no habla.

Estos términos pueden ser confusos, ya que se puede considerar a la hipertensión, por ejemplo, como un «síntoma» de estrés. Y no es así, porque el sujeto que padece de hipertensión permanece ajeno, meramente constatando y tratando de controlar medicamentosamente lo que su sistema circulatorio expresa. En este caso, más bien se tratará de una «marca» impresa que habla desde el daño a los órganos, articulaciones, tejidos, con escasa posibilidad de ser asumido como problema subjetivo.

Reservamos entonces, el concepto de "marca" a lo no investido o no subjetivado. Empleamos el término «síntoma» para el síntoma investido, en términos psicoanalíticos, a la formación de compromiso producto de la interacción intrainstancias. El sentido del síntoma es susceptible de ser descifrado en transferencia mediante el dispositivo psicoanalítico y su instalación psicopatológica puede ser modificada mediante la interpretación y reconocimiento consciente. 


\subsection{Psiconeuroinmunoendocrinología}

El reconocimiento de los problemas y los resultados acumulativos de numerosas investigaciones, con características como la que citamos anteriormente, desarrollada por el equipo de Kielcolt Glaser, fueron reflejando una concepción integradora respecto del organismo humano, y determinaron que actualmente la medicina se encuentre con la necesidad de replantear esquemas, paradigmas y abordajes que tradicionalmente han marcado su definición como ciencia. Entre tales cambios surge la Psiconeuroinmunoendocrinología (PNIE), como una de las principales neoconceptualizaciones. Es entonces que las relaciones entre los cuatro sistemas de control que tiene el organismo humano: el psicológico, el neurológico, el inmunológico y el endocrinológico, se ven definitivamente integrados como un todo, en activa relación con el ambiente.

La PNIE pretende estudiar a la enfermedad como el resultado de la ruptura de todo un sistema. Tradicionalmente, cada especialidad médica entiende a la enfermedad sólo parcialmente, parcialidad producida por un pensamiento unicausal y simplista. El ser humano es una complejidad de sistemas que nosotros dividimos para entender, pero no debemos perder de vista el concepto de que el todo es más que la suma de las partes. La preservación de la especie y la autopreservación son siempre influenciadas por la interacción con el medio.

Nos dice Andrea Márquez López Mato (Márquez López Mato, 2004; pág. 14) que: «La PNIE recupera entonces la versión holística de la medicina hipocrática pero sin olvidar la singularidad de cada ser. Sólo en la interacción del hombre biológico, psicológico y social con su medio se entiende que no hay enfermedades sino enfermos». Y más adelante explica: «La PNIE debe inclinarse hacia la demostración de hechos verificables, cuantificables y reproducibles como ostenta la ciencia y el pensamiento racional cartesiano (sensatez), pero sin dejar de lado otras formas intuitivo simbólicas (sensación y sentimientos) de percepción de la realidad», afirmando entonces que: «La mente surge como parte del cuerpo con el fin de poder integrar lo que siento y pienso con el cómo actúo desde y hacia el medio ambiente que me rodea, con el cual interacciono» (Márquez López Mato, 2004; pág. 10) y continúa: «Planteamos incluso la incompletud de este nuevo 
paradigma relacional proponiendo un nuevo modelo a repensar donde se incluyera no sólo la indivisibilidad cuerpo-mente sino el espíritu. En este sentido es de vital importancia recordar que la mente trasciende el cerebro; que la mente es, al decir de Fisher, nuestro maestro argentino de psiquiatría biológica, no sólo el cerebro sino también su producto. Cuerpo, mente, espíritu, en el orden que cada uno quiera darle acorde con su sistema de creencias, están indisolublemente integrados en mi persona como ser único e irrepetible.» (Márquez López Mato, 2004; pág. 11).

Hoy se sabe que cada uno de los componentes que forman la PNIE es capaz de interrelacionarse con otro, o bien actuar sobre sí mismo (automodulación) mediante todos los idiomas PNIE. Así debemos comprender que citoquinas, neuropéptidos, neurotransmisores y hormonas pueden actuar o ser sintetizados en cualquiera de los tres sistemas implicados (cerebro, hipófisis, tejidos glandulares y células del sistema inmune). Todos los órganos que forman el sistema PNIE poseen receptores específicos para las diferentes sustancias biológicas que permiten la interrelación de los subsistemas implicados. Así la Psiconeuroinmunoendocrinología comprende el estudio de los mecanismos regulatorios y de control del organismo.

El sistema PNIE está constituido por distintos subsistemas con bases anatómicas y funcionales propias interrelacionadas. Así podemos hablar de un sistema psicológico, uno neurológico, uno endocrino y uno inmunológico, en constante interacción con su medio y en el cual la mente juega a su vez, recursivamente, un activo rol. De este modo, la mente intervendría en tanto proceso recursivo, es decir, aquellos propios de los productos capaces, a su vez, de afectar al productor. Los autores del modelo integrativo en PNIE que describen las interacciones entre los factores psicosociociales y biológicos, en la etiología y progresión de las enfermedades han empíricamente demostrado que «Cómo un individuo interpreta y responde a su ambiente determina su respuesta al estrés, influye sus conductas saludables, contribuye a su respuesta inmune y neuroendocrina y puede por último afectar el desenlace saludable» (Lutgendorf y Constanzo, 2003). Se comprobó claramente así una afirmación a veces difícil de creen : no son los hechos como tales los que producen estrés sino los significados que los sujetos atribuyen a sus percepciones. De este modo sabemos, que lejos de intentar modificar sólo la realidad externa, se trata de modificar también, los esquemas cognitivos con que se la aborda. 
Sin pretensión de exhaustividad, cabe mencionar a dos autores que anticiparon en sus épocas a la disciplina PNIE: F. Alexander, en la década del cuarenta, y H. Selye, en 1956 (Selye, 1992).

F. Alexander, psiquiatra y psicoanalista norteamericano, preocupado por conceptualizar el proceso de enfermar, propone la posición más integradora que se conoció en su época. Postuló relaciones dinámicas entre varios componentes: a) un tipo específico de conflicto, más b) una predisposición particular del cuerpo llamado factor somático X, más c) una situación actual de conflicto (Alexander, 1950).

Hans Selye (Selye, 1992) por su parte, en 1956 introdujo científicamente el concepto de estrés y del Síndrome General de Adaptación. Lo definió «como el estado que se manifiesta por un síndrome específico, constituido por todos los cambios no específicamente inducidos en un sistema biológico». Se basó en pruebas experimentales de laboratorio con animales, y estableció así las bases para el reconocimiento de la interfaz de efectos orgánicos sobre el tejido nervioso y los órganos a causa de factores no materiales como, por ejemplo, la frustración y el miedo. No es específica la causa (pueden ser variadas), ni tampoco la respuesta del órgano: hay una manifestación sistémica, por ejemplo: el miedo, en las ratas, en 24 horas simultáneamente provocó la disminución del timo y de los nódulos linfáticos a la mitad de su peso, cambió de color la corteza suprarrenal por hipersecreción de corticoides, úlceras con hiperkemia y hemorragias en el estómago (Selye, 1992).

Puede sernos útil recordar que el término 'estrés' fue acuñado por el británico especialista en construcción de puentes Robert Hooke en el siglo XVII, quien lo utilizó por primera vez para referirse a la resistencia de los materiales respecto de la carga a la que eran sometidos. Evocamos este antecedente, pues instala en nuestra comprensión la necesidad de ligar estrés con un trípode de agentes o componentes: la carga, el «terreno» (puente) y el modo en que ese terreno expresa su efecto (hundimiento, rajadura, ruptura, debilitamiento, etcétera), es decir los estresores, la estructura subjetiva con su atravesamiento temporo-vincular y sus modos peculiares y propios de expresión o resistencia. 
Selye definió al estrés «como un estado que se caracteriza por un síndrome general de adaptación, que es la manifestación somática de un trabajo de adaptación general». Reconociendo la complejidad del concepto, Selye lo resume afirmando: «el estrés es la velocidad de desgaste vital».

Para aclarar este concepto complejo, Selye evoca a Hipócrates, quien hace veinticinco siglos ya conocía el estrés y distinguió la presencia de dos fenómenos frente a la enfermedad: el sufrimiento y el trabajo de la enfermedad. El trabajo de la enfermedad se opone al sufrimiento, es una reacción. Todos los agentes que actúan sobre el organismo o cualquiera de sus partes ejercen efectos dobles, acciones específicas sobre el órgano y respuestas de acomodación y resistencia ante el estímulo. Explica:

"Por una vía no del todo conocida marcha un estímulo desde la zona afectada hasta la hipófisis anterior comunicando el estrés. Siendo probable que el primer mediador de la defensa hormonal no sea siempre el mismo: en algunas ocasiones, puede ser una descarga de adrenalina, en otras una liberación de metabolitos tisulares tóxicos del tipo de la histamina, un impulso nervioso e incluso, deficiencias súbitas en algún componente importante del organismo, tal como la glucosa. [...] Agentes muy variados son los causantes de enfermedades, por ejemplo un trauma, una quemadura, una excitación nerviosa, una infección, una alergia, etc."

Lo que fue realmente renovador del hallazgo de Selye, y lo que justifica el espacio que le dedicamos, fue, precisamente, anticipar cómo las emociones afectaban el cuerpo. Demostró en los estudios histológicos de sus animales de prueba que el miedo y la frustración producían daños irreversibles sobre sus órganos.

Actualmente, «La Biología, la Medicina y la Psicología han incorporado el término estrés -fuerza que deforma los cuerpos o provoca tensión-, entendiendo a la fuerza, como el proceso o mecanismo con el cual el organismo mantiene su equilibrio interno, adaptándose a las exigencias, tensiones e influencias a las que se expone en el medio en el que se desarrolla» (Pérez-Jáuregui, 2000; pág. 16). 
Para Lazarus y Folkman (1984) (citado por Pérez-Jáuregui, 2000: pág. 17): «El estrés es una relación entre la persona y el entorno, que es percibido por la persona como impuesta o excediendo sus recursos y poniendo en peligro su bienestar».

Podemos retomar entonces, en síntesis, el significativo aporte de H. Selye, ¿Qué es el estrés? Las respuestas no específicas, que implican notable esfuerzo y desgaste de un organismo al enfrentar adaptativamente a agentes variados que vulneran y sobrecargan su resistencia. Vemos aquí las bases del concepto de cargas excitatorias excesivas no moduladas que será explicado por el psicoanalista P. Marty, como su propuesta para la explicación del desencadenamiento de las enfermedades psicosomáticas, que profundizaremos más adelante en este capítulo.

Por lo tanto de la Psiconeuroinmunoendocrinología podemos concluir que:

a) Contamos con notables progresos en neurobiología respecto de la interacción cuerpo $><$ cerebro $><$ ambiente.

b) Las tomografías por emisión de positrones permiten visualizar los daños que produce el estrés en el tejido nervioso. Llamamos estrés a la sobrecarga emocional de origen interno y externo que soporta el organismo.

c) Se postulan procesos de regulación básica entre pautas neurales innatas (tallo cerebral e hipotálamo) que preservan la supervivencia mediante procesos neurales-bioquímicos entre el cerebro, las glándulas endocrinas y los órganos que tienen a cargo la función metabólica asegurando la homeostasis del sistema interno y el sistema inmune que protege al organismo de los microdepredadores (virus, bacterias, parásitos). La regulación que ejerce el organismo intenta preservar la homeostasis.

d) También intervienen en los circuitos reguladores sistemas como el límbico, modificables o influíbles por la experiencia del individuo y asociados con la regulación de las emociones, impulsos y sentimientos. 
e) A su vez, el hipotálamo y las estructuras interrelacionadas están regulados no sólo por señales neurales y químicas procedentes de otras regiones del cerebro, sino también por señales químicas que surgen en diversos sistemas corporales.

f) La vida depende de que estos procesos bioquímicos se mantengan dentro de un rango adecuado, puesto que las desviaciones excesivas de este rango en puntos clave del perfil compuesto pueden producir enfermedad o muerte.

g) El estrés mental crónico, un estado relacionado con el procesamiento en numerosos sistemas cerebrales a nivel de la necorteza, del sistema límbico y del hipotálamo, parece conducir a la sobreproducción de una sustancia química que afecta la función inmunológica. El resultado final es que el cuerpo es más vulnerable a la infección cuando una vía de entrada principal está peor defendida.

h) La tristeza y la ansiedad pueden alterar en forma notable la regulación de las hormonas sexuales. La congoja, que es otro estado que depende del procesamiento a nivel cerebral, conduce a una depresión del sistema inmune, de manera que los individuos son más propensos a la infección y a desarrollar distintos tipos de cáncer. 


\subsection{Los Afectos en la salud y la enfermedad.}

\subsubsection{Afectos y salud.}

Vamos ahora a indagar y revisar conceptos teóricos básicos para nuestro trabajo:

1. ¿Qué son los afectos y los sentimientos? ¿Cómo se relacionan con la percepción, la palabra y los procesos mentales como la imaginación y la reflexión?

2. ¿Cuál es su intervención saludable? ¿De qué modo la falta de articulación y regulación de los afectos se relacionaría con el enfermar? El concepto de afectos proviene del latín afficere así como el de emoción, emovere y literalmente expresan 'afectar' o 'mover' en tanto la cualidad propia de la experiencia emocional en la cual somos movidos, invadidos por distintas experiencias psíquicas que mantienen su correlato con el cuerpo.

Entre la lista de las emociones contamos el amor, el odio, la angustia, la alegría, el miedo, la vergüenza, la ternura, la culpa y otras. Aunque no existe un consenso absoluto sobre la definición de emoción, hay una acuerdo generalizado acerca de que la respuesta emocional humana implica tres sistemas o conjuntos de procesos interrelacionados: a) Procesos neurofisiológicos (sistema nervioso autónomo y activación neuroendocrina); $b$ ) Procesos expresivos conductuales y motores (por ejemplo expresión facial, llanto, cambios de la postura y tono de la voz, etcétera); y c) un sistema cognitivo-vivencial (reconocimiento subjetivo e información verbal del estado vivencial como sentimiento). La palabra sentimiento alude a la dimensión subjetiva cognitivo-vivencial de las emociones. Las emociones refieren al aspecto neurofisiológico y expresivo-conductual motor. Cuando decimos afectos abarcamos estados compuestos que incluyen las tres dimensiones, cognitivos y vivenciales, fisiológicos, expresivos y conductuales (Taylor, 1997).

El neurólogo A. Damasio (Damasio, 2003), para analizar la producción de sentimientos y el registro de ellos, se vale de ejemplos que propone al lector, tales como, evocar estar en un lugar muy agradable, por ejemplo una tranquila y bella playa. Así dice que «los sentimientos en el más puro y estrecho sentido del vocablo, son la idea del cuerpo de cierta manera», y continúa, «en esta definición usted puede sustituir "idea" por "pensamiento" o “percepción”» (2003: pág. 85), y avanza aún más, proponiendo: «mi hipótesis entonces, 
presentada como una definición provisional es que un sentimiento es la percepción de un cierto estado del cuerpo junto con la percepción de un cierto modo de pensamiento y pensamientos en relación con ciertos temas». Los sentimientos emergen cuando la cabal acumulación de los detalles mapeados en el cerebro alcanzan un cierto nivel. Señala que, desde otra perspectiva, la filósofa Susanne Langer capturó la naturaleza de ese momento de emergencia diciendo que, cuando la actividad de alguna parte del sistema nervioso alcanza un «punto crítico», el proceso «se siente». Los sentimientos son una consecuencia de cambios en el proceso de homeostasis, el siguiente escalón en la cadena. Y Damasio explica (2003: pág. 87):

"Como yo lo veo, el origen de las percepciones que constituyen la esencia de los sentimientos es claro: hay un objeto general, el cuerpo, y hay muchas partes de ese cuerpo que están continuamente mapeadas en un número de estructuras cerebrales. Los contenidos de esas percepciones también son claros: varios estados del cuerpo perfilados por los mapas que representan el cuerpo a lo largo de un rango de posibilidades. Por ejemplo, las micro y macro estructuras de los músculos tensos tienen un contenido diferente de las de los músculos relajados. Lo mismo se aplica al corazón cuando late rápido o lento, y para la función de otros sistemas, como el respiratorio y el digestivo, cuyas actividades pueden seguir tranquila y armoniosamente o con dificultad y coordinación pobre."

El autor que estamos citando, para responder a la pregunta «¿Quiénes pueden tener sentimientos?» (Damasio, 2003: pág. 109), realiza una revisión sobre las capacidades y funcionamientos de los organismos inferiores, tales como las plantas; toma en cuenta también sus investigaciones con pacientes lesionados cerebralmente (1996), y nos ofrece una conclusión muy importante para nuestro trabajo: puede tener sentimientos «un organismo que no sólo tenga cuerpo sino que pueda representar su cuerpo en su mente».

Y en relación con los efectos saludables y adaptativos que la conexión con los propios sentimientos aporta al organismo humano, dice (2003: pág. 178): 
"Cuando los sentimientos se vuelven conocidos por uno mismo (self), dentro del organismo que los posee, los sentimientos mejoran y amplían el proceso de darle curso a la propia vida. La maquinaria por detrás de los sentimientos capacita las correcciones biológicas necesarias para sobrevivir ofreciendo explícita y relevante información sobre el estado de los diferentes componentes del organismo en cada momento. Los sentimientos designan los mapas neuronales relacionados, con una estampilla que dice:“¡marcar eso!”.

Antonio Damasio, coincidentemente con G. Taylor (mencionado antes), precisa: «las emociones son las manifestaciones que el organismo da a ver, mientras que los sentimientos representan su correlato subjetivo íntimo» (Damasio, 2003: pág.100) y «Haciendo nosotros un retorno completo al reclamo de Spinoza de que el cuerpo y la mente son atributos paralelos de una misma sustancia. Los separamos bajo el microscopio de la biología porque queremos saber cómo esa sustancia trabaja, y cómo se generan dentro de ella las formas del cuerpo y la mente. Después de investigar la emoción y los sentimientos con relativo aislamiento, podemos en un momento de quietud reunirlos nuevamente como afectos» (Damasio, 2003: pág. 133).

Se podría sintetizar diciendo que los sentimientos son necesarios, porque ellos son el nivel mental de expresión de las emociones, y lo que se halla debajo de ellos. Así, sostiene: «Solamente en ese nivel mental de los procesos biológicos y a la clara luz de la conciencia, hay suficiente integración del ahora, el pasado y del futuro anticipado. Sólo en este nivel es posible a las emociones crear, mediante los sentimientos, la reflexión sobre uno mismo como sujeto» y afirma: «La solución efectiva de problemas no comunes requiere de flexibilidad y de alto poder informativo, la alianza de todo lo que los procesos mentales pueden ofrecer, y las reflexiones que los sentimientos pueden ofrecer» (Damasio, 2003: pág. 178).

Los afectos, cognitivamente, se extienden en funciones tales como atención, memoria, imaginación, representación y comunicación. Los afectos nos permiten evaluar, validar y apreciar los objetos de los cuales dependemos, y a su vez permitirles a ellos, una vez internalizados en nosotros, crecer con nosotros (Grotstein, 1997). 


\subsubsection{Afectos y enfermedad}

Desde la antigüedad se expuso la idea de que los afectos, en particular cuando se hallan en niveles excesivos y masivos, o no modulados, pueden influir negativamente sobre la salud mental y corporal.

A Hipócrates (siglo IV a. de C.), padre de la medicina, se le atribuye la descripción de los temperamentos humanos como el resultado de cuatro orientaciones emocionales básicas (sanguínea, colérica, flemática y melancólica), resultantes de la preponderancia de ciertos fluidos corporales (sangre, flema y varios tipos de bilis), y atribuyó al exceso de bilis negra la causa principal de la enfermedad mental.

En la era grecorromana, por ejemplo, Ascelepíades atribuyó el trastorno mental a la perturbación emocional. Galeno clasificó a las pasiones como la sexta causa no natural de enfermedad. Platón relacionó la «locura erótica» con el amor humano. Cicerón describió las cuatro principales «perturbaciones»o «pasiones» (tristeza, miedo, alegría y libido), todas ellas capaces de ser moderadas por la razón, pero que podrían, si se volvieran excesivas, provocar la enfermedad del alma. Refiriéndose al tratamiento de los trastornos mentales, Aristóteles aconsejó el uso de la catarsis, incluyendo música, vino y afrodisíacos para aliviar las emociones o pasiones conflictivas (Mora, 1967).

En la Edad Media, conceptos más primitivos aún, como la influencia del diablo o de brujas, se invocaron como causa de comportamientos humanos perturbados. En el siglo XVI el interés por las emociones se enfatizó nuevamente cuando Johann Weyer rechazó la creencia en la brujería, y especialmente con el abordaje de Paracelso, quien otorgó a las pasiones un rol patogénico, tanto en las enfermedades físicas como mentales.

A principios del siglo XVII, Wright en 1601, citado por Taylor (1997), afirmó que las pasiones engendran humores que pueden alterar la estructura del cuerpo y su funcionamiento, y que, a la vez, los humores incitan pasiones. Identificó como sede de las pasiones al corazón, el cual sería saludablemente estimulado por la alegría moderada, pero si la alegría se volviera excesiva podría dilatar el corazón y producir incluso una muerte súbita. Las pasiones negativas, como la tristeza, el miedo y la desesperación, fueron 
consideradas por Wright aún más peligrosas para el cuerpo, pues podían constreñir el corazón.

Rather (1965: 156) menciona que Robert Burton en 1621 enfatizó los factores emocionales como causas de la enfermedad mental e identificó al cerebro como la parte afectada del cuerpo.

Luego, Rather indica que numerosos científicos se ocuparon del tema, como T. Willis, $\mathrm{T}$. Sydenham, W. Harvey, W. Falconer y en especial T. Gaub, quien en 1763 describió los efectos dañinos sobre el cuerpo de las emociones perturbadoras como la rabia excesiva, el duelo, el miedo y el terror no expresados, además del amor no retribuido y la alegría excesiva. También discutió los efectos benéficos de la esperanza, la alegría, el amor y la tranquilidad; y destacó también el valor terapéutico de expresar emociones reprimidas y de la modulación de las emociones mediante el correcto razonamiento.

Notemos que T. Gaub en 1763 anticipó así, la noción moderna de que la regulación de las emociones a través de ciertos recursos cognitivos, tiene una influencia reguladora en el funcionamiento del cuerpo.

Recientemente, se ha demostrado mediante la tomografía por emisión de positrones (PET), cómo las trasmisiones nerviosas registran y descargan emociones en el cerebro ${ }^{3}$. En sentido opuesto, se ha demostrado empíricamente cómo mediante la mente es factible regular el funcionamiento del cuerpo, por ejemplo elevar o descender la temperatura corporal $^{4}$.

\footnotetext{
${ }^{3}$ «Actividad eléctrica en la fibra nerviosa», serie de la BBC El poder de la mente, emisión del 12 de diciembre de 2004.

${ }^{4}$ Dr. Herbert Benson, Universidad de Harvard. Serie Conexión Discovery, emisión del 3 de febrero de 2005.
} 


\subsection{La Regulación de los Afectos.}

Vamos a detenernos en el concepto de regulación que, veremos, puede atravesar con familiaridad los desarrollos de la psiconeuroinmuendocrinología; en la concepción de la Escuela Psicosomática de París y también en los obstáculos para el funcionamiento sano del organismo determinados por la presencia de alexitimia (Taylor, 1997).

Regulación alude a una noción económica y dinámica: económica porque implica cambios energéticos, y dinámica porque comprende desplazamientos, distribuciones y juegos de fuerzas. En la revisión histórica que realizamos en los párrafos previos (2.1.), las relaciones entre las emociones y la salud de la mente y el cuerpo se expresaban mayormente en términos de equilibrio entre emociones negativas y positivas, así como en cuán efectivamente estaban reguladas, por ejemplo, la capacidad de modificar y aminorar una carga emocional excesiva, en el caso de poder reconocerla a través de los sentimientos.

En biología existe el principio de autorregulación, que puede aplicarse también a las emociones, y que es un principio básico para todos los organismos vivientes. El principio de autorregulación proviene de los trabajos de Claude Bernard y Walter Cannon sobre los mecanismos homeostáticos que regulan y mantienen la constancia de las condiciones en el medio interior de un organismo. Este principio se extiende más allá de los sistemas fisiológicos para abarcar también sistemas conductuales, ambientales y ecológicos, como lo reconoce la teoría general de los sistemas. De modo muy amplio así se sostiene el reconocimiento, más que de causas lineales o aún el de interacción dualística, de una vasta red de componentes en mutua relación (Márquez López Mato, 2004: 14).

En este campo son concluyentes las afirmaciones de Antonio Damasio, de las cuales reproducimos párrafos cruciales que nos advierten de los progresos neurobiológicos respecto de la interacción cerebro, cuerpo, ambiente y de su regulación. Dice A. Damasio:

"Más sobre regulación básica: las pautas neurales innatas que parecen más críticas para la supervivencia se mantienen en circuitos del tallo cerebral y del hipotálamo. Este último es un actor clave en la regulación de las glándulas endocrinas entre ellas la hipófisis, la tiroides, las adrenales y los órganos reproductores, todos los cuales producen hormonas y en la función del sistema inmune. La regulación endocrina que depende de sustancias químicas liberadas 
al torrente sanguíneo y no de impulsos neurales, es indispensable para mantener la función metabólica y administrar la defensa de los tejidos biológicos contra los microdepredadores tales como virus, bacterias y parásitos.

La regulación biológica relacionada con el tallo cerebral y con el hipotálamo está complementada por controles en el sistema límbico. No es aquí el lugar indicado para analizar la intrincada anatomía y la detallada función de este considerable sector del cerebro, pero debe señalarse que el sistema límbico participa también en la promulgación de impulsos e instintos y tiene un papel especialmente importante en las emociones y los sentimientos. Sin embargo, sospecho que, a diferencia del bulbo raquídeo y del hipotálamo, cuya circuitería es en mayor parte innata y estable, el sistema límbico contiene a la vez una circuitería innata y circuitería modificable por la experiencia del organismo siempre en evolución."

Y más adelante:

"En consecuencia, como cabría esperar, existe una interacción cerebro-cuerpo bien documentada, y quizá podamos espigar relaciones mente-cuerpo menos visibles. Considere el lector el siguiente ejemplo: el estrés mental crónico, un estado relacionado con el procesamiento en numerosos sistemas cerebrales a nivel de la necorteza, del sistema límbico y del hipotálamo, parece conducir a la sobreproducción de una sustancia química, un péptido relacionado genéticamente con la calcitonina, o PRGC, en terminales nerviosas de la piel. Como resultado, el PRGC recubre en exceso la superficie de las células de Langerhans, unas células relacionadas con el sistema inmune cuya función es capturar agentes infecciosos y entregarlos a los linfocitos, de manera que el sistema inmune pueda contrarrestar su presencia. Si están completamente recubiertas de PRGC, las células de Langerhans quedan incapacitadas y ya no pueden realizar su función de guardianes. El resultado final es que el cuerpo es más vulnerable a la infección, ahora que una vía de entrada principal está peor definida. Y existen otros ejemplos de interacción mente cuerpo: la tristeza y la ansiedad pueden alterar de forma notable la regulación de las hormonas sexuales, lo que no sólo produce cambios en el impulso sexual, sino también variaciones en el ciclo menstrual. La congoja, que es otro estado que depende del procesamiento a nivel cerebral, conduce a una depresión del sistema inmune de manera que los individuos son más propensos a la infección y, ya sea como resultado directo o no, tienen más probabilidades de desarrollar distintos tipos de cáncer. Se puede morir de un corazón roto.”

Seguimos compartiendo los desarrollos de Damasio, que esclarecen las interacciones cuerpo, mente, afectos y precisan el funcionamiento de regulación: 
La influencia contraria, la de sustancias químicas procedentes de cuerpo sobre el cerebro, también ha sido observada, desde luego. No es ninguna sorpresa que el tabaco, el alcohol y las drogas (las médicas y las que no lo son) penetran en el cerebro y modifican su función, con lo que alteran la mente. Algunas de las acciones de las sustancias químicas del cuerpo caen directamente sobre las neuronas o sus sistemas de soporte; algunas son indirectas, a través de neuronas mediadoras neurotransmisoras localizadas en el tallo cerebral y en el prosencéfalo basal, que ya se han comentado anteriormente. Al disparar, estos pequeños conjuntos de neuronas pueden transmitir una dosis de dopamina, norepinefrina, serotonina o acetilcolina a regiones extendidas del cerebro, incluidas las cortezas cerebrales y los ganglios basales. Puede imaginarse la disposición como un conjunto de dispositivos de riego por aspersión bien diseñados, cada uno de los cuales suministra su sustancia química a determinados sistemas y, dentro de dichos sistemas, a circuitos determinados con tipos y cantidades concretas de receptores. Los cambios en la cantidad y distribución de sustancia difundida por uno de estos transmisores, o incluso cambios en el equilibrio relativo de los transmisores a un lugar determinado, pueden influir de manera rápida y profunda sobre la actividad cortical y dar origen a estados de depresión o de exaltación, incluso de manía (véase el capítulo 7). Los procesos del pensamiento pueden hacerse más lentos o más rápidos; la profusión de imágenes rememoradas puede reducirse o aumentar; la creación de combinaciones nuevas de imágenes puede acrecentarse o suprimirse. La capacidad de concentrarse en un determinado contenido de la mente fluctúa de acuerdo con esto.”

En suma, luego de este recorrido vemos que los afectos, emociones y sentimientos son intrincables y de igual status, compañeros de la vida mental cognitiva y son funcionalmente indivisibles, holísticos respecto de cómo interactúan. Los distintos traumas vitales desinvestidos, en ausencia de afectos, fantasmas, o actividad proyectiva para ser representados y transitados, derivan en un aumento y acumulación de tensión. Siguiendo a P. Marty, la desorganización de las defensas que dependen de la organización psíquica influye sobre las defensas biológicas.

Los afectos e impulsos son los adjetivos calificativos de las experiencias, los que le dan su significado emocional. Consecuentemente, los afectos -necesariamente epifenómenos de base biológica- incluyen una dimensión cognitiva, experiencial y conductual, que a su vez es capaz de modificar los funcionamientos fisiológicos (Intebi y Zukerfeld, 2000; Lutgendorf y Constanzo, 2003; Sang-Ahm y Young-Joo, 2005; Rosmond, 2005). Consiste entonces en un proceso recursivo, entendiendo como tal a aquel en el cual el producto ejerce un efecto productor sobre el sistema que lo produce. 
Vamos a detenernos ahora en un autor psicoanalítico, cuya interesante contribución ofrece una comprensión de las organizaciones mentales deficitarias y un modelo holístico para el entendimiento de la vida afectiva. Se trata de J. Grotstein, (Grotstein, 1986, 1990) quien en su prefacio al libro Desórdenes en la regulación de los afectos (Taylor, Bagby y Parker, 1997), plantea que actualmente las emociones, los afectos y los sentimientos son compañeros constantes de la vida mental cognitiva y podemos evaluar como interactúan unos con otros desde el punto de vista de su status separado pero igual. Pero debemos también, enfatiza Grotstein, considerar que ellos están tan intrínsecamente relacionados que son funcionalmente indivisibles, «holísticos». Si quisiéramos separarlos por un momento y comparar el pensamiento abstracto con el sentimiento puro, una característica interesante rápidamente se hará visible, explica:

"Los pensamientos ocupan la tercera o cuarta dimensión de espacio y tiempo, en términos de extensión, profundidad, duración y sucesión linear. Pertenecen, como nos ha advertido Bion $(1962,1963)$, al campo sensual de la percepción. Los proto-afectos, por otro lado, no son sensuales y pueden ser sin tiempo, caóticos, sin dimensionalidad, sin límites, infinitos y eternos: por ejemplo, no tienen ni pasado ni futuro, ni tienen espacio. Mientras que la ansiedad puede adaptativamente prepararnos anticipando peligros en el futuro, en contraste, el pánico es dramático, en su terrorífica inmediatez, sin dirección y vivido como infinito. Por su parte, lo que Freud nos recordaba desde la perspectiva de la hegemonía de los impulsos instintivos, acerca de que el trauma psíquico representaba la irrupción de los impulsos en el yo, nosotros hoy sabemos que el contenido inconciente temido no son tanto los impulsos, sino el caos, el infinito, las pre-concepciones no modificadas inherentes a la mente, lo que Bion denomina «elementos beta», los datos no mentalizados de la experiencia humana, y todos ellos están debajo de la sombrilla proto-afectiva, esto es lo que constituye el agente potencialmente amenazante".

En estos desarrollos sobre el tema de lo infinito y carente de todo límite, el autor que venimos siguiendo se refiere a un número de recientes y diferentes contribuciones, sin embargo, convergentes como las de Bion, quien habla de «las transformaciones de los elementos beta en elementos O», de Lacan con su «Registro de lo Real», de Kauffman y Prigogine, con sus «teoría del caos y la complejidad», los antecedentes de «la cosa en sí misma» de Kant, o el «caldero hirviente» de Freud. Todos estos autores aluden al territorio de la verdad última, de la realidad absoluta, de lo inefable, aquel que la imaginación y la simbolización de la mente humana jamás podrá alcanzar. Y en una dimensión menos 
universal, también caben aquí los traumas tempranos escindidos e impensables para el psiquismo.

Y acercándonos a lo que más adelante explicitaremos, la función de la alexitimia, Grotstein plantea que «Tanto los analistas como los terapeutas saben desde larga data que sus pacientes generalmente tienen miedo de sus sentimientos, tanto de experimentarlos como de saber sobre ellos. El constructo alexitimia ofrece una comprensión parcial sobre este miedo. Si los sentimientos no pueden ser procesados, entonces los sentimientos, en lugar de significar los estados internos, automáticamente se vuelven el horror que normalmente sólo designarían. Por lo tanto volverse conciente de los propios sentimientos, implica el riesgo del desencadenamiento de avalanchas de brutales proto-afectos». Así postula Grotstein, «Como consecuencia, los sujetos no preparados para lidiar con los afectos (los alexitímicos) deben instigar una coartación de la cascada de afectos, que de otro modo podría inundarlos, como vemos en algunos de los síntomas asociados con la alexitimia, tales como anhedonia, pobreza de la fantasía, de la imaginación y de la vida onírica» 5 .

Por ello, la teoría del afecto, con otras palabras, consiste en el estudio de cómo nosotros somos personalmente afectados por los acontecimientos, y al mismo tiempo nuestra capacidad para establecer la importancia y el significado de esos sentimientos para nuestra propia vida, en términos de evaluación cognitiva, comprensión, planificación, adaptación, etcétera.

Como corolario de su pensamiento Grotstein explicita un nuevo modelo holístico, como un intento para comprender la complejidad de la nueva concepción sobre la regulación afectiva, en la cual «afecto $<->$ cognición $<->$ percepción $<$ - $>$ sensación $<->$ conducta pueden ser expresados tanto con las flechas reversibles y simultáneamente sin ellas, como si fueran holísticamente un solo conjunto» (Grotstein, 1997: XVI).

Notemos que así como los afectos son objeto de acciones regulatorias, también juegan un importante rol en la organización del funcionamiento mental y conductual. Como expresa G. Taylor (Taylor y otros, 1997: 4, y citado por Rather, 1965): «Los afectos, aunque están

\footnotetext{
${ }^{5} \mathrm{El}$ autor también plantea que podría tratarse de un defecto del proceso primario, semejante al que postula que ocurre en la esquizofrenia.
} 
sin embargo enraizados en la biología, son generalmente vistos como estados compuestos que incluyen tanto componentes cognitivos y vivenciales o experienciales como fisiológicos, conductuales y expresivos (Dodge y Garber, 1991). Por lo tanto, los procesos cognitivos tales como atención, juicio, representación mental, imaginación, mecanismos de defensa, sueños y comunicación verbal se hallan también implicados en el procesamiento y regulación de los afectos (Izard y Kobak, 1991; Rachman, 1980; Salovey, Hsee y Mayer, 1993). Y mientras los afectos están sujetos a acciones regulatorias se ha vuelto crecientemente evidente que los propios afectos juegan un importante rol en la organización del funcionamiento mental y la conducta (Ciompi, 1991; Emde, 1988; Fridja, 1986).

Por su parte, coincidentemente, G. Taylor, preguntándose sobre las relaciones de las emociones y la mente (psyche), plantea que se trata de componentes dentro de los ordenamientos jerárquicos de subsistemas regulándose recíprocamente. Cita a Ciompi (Ciompi, 1991) quien conceptualiza a la psyche como «una estructura jerárquica compleja de sistemas de referencia cognitivos y afectivos, que son generados por acciones concretas repetitivas. Esos sistemas tienen sus correspondientes sistemas neurológicos operativos, que almacenan en su estructura las experiencias pasadas y regulan pensamientos, sentimientos y conducta. Es decir, los afectos y sus equivalentes neurobiológicos con funciones movilizadoras, integradoras y organizativas, las cuales están siempre acompañadas por cogniciones. Aún más, a través de las conexiones descendentes de los sistemas hipotálamico y límbico, los afectos siempre involucran todo el cuerpo, como se evidencia en los cambios fisiológicos tales como alteraciones en el ritmo cardíaco, la presión de la sangre y el tono muscular» (Taylor, 1997: 228).

Vemos entonces a través de la revisión que acabamos de considerar, afirmaciones y fundamentos de muy importantes consecuencias para nuestro trabajo:

1. Describen la forma en que las emociones interactúan y afectan el cerebro y la vida.

2. Postulan la consecuencia destructiva de cargas de excitaciones excesivas acumuladas (estrés) no reguladas. 
3. Enfatizan que las emociones se conciben en el modelo de regulación, no como un fenómeno psicológico que causa cambios en el cuerpo, sino como parte de la respuesta biológica de un organismo como un todo a los acontecimientos ambientales, tales como los percibe.

4. Cognición y afecto operan en la interfaz del cuerpo y la mente, favoreciendo los procesos de autoorganización y autopreservación.

\section{5. ¿Cómo comprender las rupturas de la Salud y los desarrollos patológicos?}

\subsubsection{Modelos Explicativos}

Si bien encontramos un acuerdo amplio acerca de qué son las emociones, los sentimientos y acerca de cómo se reconoce su funcionamiento armonioso en las vidas saludables, al acercarnos al campo de las patologías en general podrían describirse dos grandes posturas explicativas para comprender las rupturas de la salud. Ellas enfatizan, por un lado, ya sea factores que desde afuera agreden al organismo, o, por otro, la presencia de vulnerabilidades y disfuncionalidades propias del mismo organismo. Estas disfuncionalidades promoverían la inestabilidad o ruptura de la salud.

El primer modelo explicativo es llamado «agresológico». En él se postulan agresiones provenientes del ambiente tales como virus, bacterias, impactos traumáticos (Engels, 1955), la teoría del estrés (Selye, 1956) enfatizando la sobrestimulación nociva, o la Psiconeuroinmunología, de desarrollo más reciente (Kiecolt-Glazer y Glazer, 1992), cuando da cuenta de las situaciones traumáticas tempranas.

El otro modelo, llamado «de déficit», enfatiza, en cambio, la composición genética y el funcionamiento deficitario orgánico o psíquico. Entre ellos hallamos, desde el campo de la neurología, al déficit del procesamiento cognitivo de las emociones definido por Sifneos en 
1973, como déficit neurológico de las vías conectivas, entre la corteza y el sistema límbico, en la llamada alexitimia primaria. También en la alexitimia secundaria, ( que se desarrolla aún cuando las bases neurológicas están intactas, como dijimos anteriormente ${ }^{6}$ ), Taylor (1998) plantea, como resultante de la presencia de alexitimia elevada que, si se compromete al cuerpo como receptáculo de cargas pulsionales que no han sido «procesadas mentalmente» se producirían muchas enfermedades psicosomáticas cuando exhiben modos cronificados o caracterológicos de la existencia humana. Si la vía de descarga del monto pulsional es, en cambio, la acción, la conducta impulsiva, de modo amplio su forma resultante serían los cuadros psicopáticos y las adicciones (Maldavsky, $1992 \mathrm{a}, 1992$ b).

En dirección semejante, otros autores desde el campo psicoanalítico plantean el déficit por patología del preconciente. Déficit que determinaría carencia de la vida fantasmática, vida operatoria y desorganización somática. En esta línea son fundacionales los desarrollos de P. Marty y M. de M’Uzan, de la Escuela de Psicosomática de París, desde el año 1963. Nos referiremos luego más extensamente a esta teorización.

También, dentro de la teoría deficitaria pueden citarse otros destacados aportes de autores psicoanalíticos, como los de Sami Alí (1979, 1993), D. Liberman (1991), D. Maldavsky (1992) y J. McDougall (1987). Esta autora, en especial, destaca las falencias traumáticas del rol materno respecto del desinvestimiento representacional del cuerpo del bebé.

Dentro de los grandes polos que representan los modelos agresológico y deficitario, caben posiciones que propician definidamente alguna de las vertientes, y otras son mayormente interactivas. Incluso dentro de la genética, ciertas posturas responsabilizan de determinados efectos a los genes, y otras a los factores propiciatorios que desde el ambiente activan o no el protagonismo de ciertos genes.

Como mencionamos en la introducción, los postulados actuales de la Psiconeuroinmunoendocrinología plantean posiciones superadoras de las polarizaciones previas, y sostienen la constante e íntima interacción entre la cualidad y funcionalidad de

\footnotetext{
${ }^{6}$ Remite a Introducción.
} 
los sistemas PNIE según la vulnerabilidad o integridad de las dimensiones conductuales y el medio ambiente en el mantenimiento de la salud de la calidad de vida.

El siguiente Modelo Biopsicosocial (Lutgendorf y Constanzo, 2003) permite visualizar el conjunto de componentes en continua interacción que han de considerarse cuando el equipo de salud recibe a un paciente:

a) Procesos Psicosociales: Diferencias individuales (optimismo, hostilidad, afectos negativos). Estado de ánimo (depresión, ansiedad). Recursos (afrontamiento, red vincular, religión, esperanza, proyecto). Otros (reacción al estrés).

b) Factores biológicos: genéticos, hereditarios, edad, sexo, raza, exposición a los virus (HIV, papiloma, influenza), toxinas, daños, tratamientos médicos. Conductas saludables, hábitos: sueño, dieta, ejercicio, exposición al sol, controles médicos, alcohol, drogas, cigarrillo, conductas sexuales, vacunas. Estrés cotidiano: agudo, crónico, traumático, estatus socioeconómico, sucesos traumáticos tempranos.

c) Intervenciones de la Psicología de la Salud: psicoterapia, terapia cognitiva, relajación, hipnosis, ejercicio, meditación, red vincular, manejo cognitivo conductual del estrés, higiene del sueño. Mecanismos:

- Neuroendócrinos: (Ejes hipotálamo-hipófiso-adrenal, hipotálamohipófiso-gonadal, etcétera) Adrenalina-Noradrenalina-Ocitocina-CortisolDopamina, 5-hidroxitriptamina (serotonina)-Estrógeno, TestosteronaHormona de crecimiento, Prolactina, etcétera.

- Inmunológicos: Respuesta inmune celular. Células citotóxicas naturales (NK), linfocitos $\mathrm{T}$ citotóxicos, otros. Citokinas de tipo T helper 1 y $\mathrm{T}$ helper 2 . Interleukina 6, Factor de crecimiento transformante $\beta$. Mecanismos Humorales. Factor de crecimiento del endotelio vascular. Factores de reparación de heridas.

d) Vulnerabilidad, Resiliencia.

e) Comienzo de los síntomas.

f) Progresión. Exacerbación. Recuperación de calidad de vida.

g) Sobrevida. Calidad de vida. 
Cabe aquí mencionar a S. Freud, quien con su concepto de Series Complementarias (al que aludiremos más adelante) anticipó notablemente estas conceptualizaciones actuales.

\subsubsection{Modelos de déficit: el Modelo Psicosomático de Pierre Marty}

En los años cincuenta y sesenta el funcionamiento psicosomático era un enigma para los psicoanalistas que luego formaron la Escuela Psicosomática de París: P. Marty, Michael Fain, Michel de M'Uzan y Christian David. Ellos elaboraron los conceptos de insuficiencia de los mecanismos neuróticos y de regresión somática o defensa somática. Realizaron un verdadero «retrato robot» del paciente psicosomático, acuñando un concepto que tomó un valor paradigmático en esta nueva clínica: el de Pensamiento Operatorio. Este concepto devino, para la psicosomática, lo que la histeria es a la neurosis, y el delirio a la psicosis. El concepto de pensamiento operatorio parece organizar a su alrededor un conjunto de datos clínicos que testimonian un profundo desequilibrio del funcionamiento mental más ampliamente aún que el de la economía psicosomática. Las fallas de la vida fantasmática y onírica asociadas a la carencia expresiva de los afectos y al sobreinvestimiento de los procesos secundarios definirían clínicamente la organización clínica de estos pacientes. Desde el punto de vista psicosomático, estos dos órdenes de fenómenos retuvieron la atención: la importancia del comportamiento y el desarrollo de la somatización. Un comportamiento muy activo y hasta eficiente, desligado de la representación del propio cuerpo y realidad psíquica, establecería las características identificatorias del desarrollo de la somatización.

Los desarrollos que desde 1963 inició Pierre Marty han devenido en la teorización psicoanalítica más vigente y reconocida. Las principales características de su vasta obra, en el seno de la llamada Escuela Psicosomática de París, consisten en ser el inventor de una nueva clínica. El llamado modelo psicosomático de Pierre Marty (1979) desarrolló los conceptos fundamentales que formaban parte previamente de la experiencia de todo psicoanalista, que abordara pacientes psicosomáticos. El pensamiento operatorio, la depresión esencial, la desorganización progresiva, la organización alérgica esencial y las neurosis de comportamiento son entidades clínicas que se han integrado merced a su obra a 
la herencia teórico-clínica de los psicoanalistas, los que previamente encontraban estos “obstáculos en la cura”, ausentes de teorización posible.

La práctica psicoterapéutica de P. Martu y colaboradores de la Escuela Psicosomática de París, ha ampliado el abanico y ha contribuido a reformular las indicaciones y contraindicaciones de las curas psicoanalíticas. Podríamos preguntarnos: ¿qué clase de modelo teórico es?, ¿psicoanalítico?, ¿biológico?, ¿psicológico?, ¿otro? La respuesta es que es «original y único en su concepción: es psicosomático» (Smadja, 1995).

La definición del campo epistemológico de la psicosomática plantea siempre numerosos problemas de lógica científica. Para los investigadores el concepto de psicosomático es, en efecto, demasiado general, se relaciona con coordenadas múltiples y variables y no se deja aprehender fácilmente por un diseño tradicional de investigación.

La pareja psico-soma aparece así, según vimos al comienzo, como una mezcla indisoluble en la cual los dos términos que se hallan en una verdadera combinación o compromiso, son abordados por metodologías que los separan. Puede así constatarse que aun en los modelos teóricos que intentan abarcar ese compromiso, la dificultad para pensar el hecho psicosomático de otra manera que una concepción de o «todo psíquico»o «todo biológico», conduce tanto a impasses, como a la dificultad de superar ese antagonismo.

En el decir de Claude Smadja (Smadja, 1995):

"La situación de la psicosomática, a caballo de dos campos semánticos y en el registro de funcionamientos notablemente diferentes, uno biológico y otro psíquico, plantea un problema en el cual todo modelo teórico debe confrontarse y explicitar lo que él debe explicar. En el centro de esas contradicciones figura la cuestión del monismo, la mayor parte de los investigadores, ya sean biologistas o psicoanalistas, concuerdan hoy en admitir la noción de monismo material somato-psíquico. No obstante los unos y los otros divergen en cuanto a la noción de monismo de funcionamiento. En la comunidad de los biologistas se tiende a pensar, en efecto, que el psiquismo es un hecho de evolución y que sus propiedades proceden de las coordenadas morfogenéticas del cerebro. Por lo contrario, en las comunidades de los psicoanalistas se insiste sobre los modos radicalmente diferentes de funcionamiento económico entre la vida psíquica y la vida de las funciones somáticas. Aquí el dualismo se impone." 
El problema mente-cuerpo constituye una cuestión de larga data, y se vincula con aspectos desarrollados en la filosofía, en especial en el campo de la filosofía de la mente. En la actualidad se estudia la cuestión con enfoques que entrecruzan filosofía, ciencia y lingüística. Los planteos se sitúan tanto en posiciones irreconciliables como en otros casos, en posiciones con matices. En una posición se rehúsa reconocer la realidad psíquica (monismo material) y en otra el dualismo de sustancia ${ }^{7}$. Como esta problemática excede el marco del presente trabajo la vamos a omitir.

La ausencia de explicación unívoca, así como la diversidad de los puntos de vista para considerar por tratarse de una enfermedad psicosomática -es decir aquéllas en las que se conjugan por lo menos factores genéticos, hereditarios, psicológicos y emocionales-, nos orientan en el ánimo de no realizar un enfoque reductivo a la revisión de las hipótesis posibles que desde una perspectiva psicodinámica, permitan describir los procesos y las vicisitudes del desarrollo de la regulación de los afectos, que se harán manifiestos en la alexitimia. Tendremos presente, por otra parte, las enseñanzas pioneras que nos aportó S. Freud con su concepto de «series complementarias» ${ }^{8}$ (Freud, 1916-1917) en el que destaca la interacción constante entre las bases biológicas y experiencias tempranas (reales o fantaseadas) de los sujetos y las experiencias (vivencias o acontecimientos actuales) sufridas en la interacción con el medio durante su desarrollo.

A la ampliación y enriquecimiento del punto de vista económico freudiano se agrega en el modelo de la Escuela Psicosomática de París, una nosografía psicosomática basada en la capacidad de mentalización. Esta noción, que es también de orden económico, ordena su clínica. El concepto de mentalización, con criterio evolucionista, se desliga de las

\footnotetext{
${ }^{7}$ Aporte de la Dra. Alicia Gianella.

${ }^{8}$ Serie complementaria: Término utilizado por Freud para explicar la etiología de la neurosis y superar la alternativa que obligaría a elegir entre factores exógenos o endógenos: estos factores son, en realidad, complementarios, y cada uno de ellos puede ser tanto más débil cuanto más fuerte es el otro, de tal forma que el conjunto de los casos puede ser ordenado dentro de una escala en la que los dos tipos de factores varían en sentido inverso; sólo en los dos extremos de la serie se encontraría un solo factor. La idea de Serie Complementaria es afirmada por Freud en Lecciones de Introducción al Psicoanálisis (1916-1917). Al principio ello sucede en relación con el problema del desencadenamiento de la neurosis: desde el punto de vista etiológico, no se trata de elegir entre el factor endógeno -representado por la fijación-y el factor exógeno -representado por la frustración-; ambos varían entre sí en razón inversa, para que se desencadene la neurosis, puede ser suficiente un trauma mínimo en el caso de que la fijación sea intensa, y viceversa. Por otra parte, la fijación puede a su vez dividirse en dos factores complementarios: constitución hereditaria y experiencias infantiles. El concepto de serie complementaria permitiría situar cada caso dentro de una serie, según la parte relativa que corresponda a la constitución, a la fijación infantil y a los traumatismos ulteriores. Freud utiliza principalmente el concepto de serie complementaria para explicar la etiología de la neurosis, pero también puede aplicarse a otros sectores en que interviene igualmente una multiplicidad de factores que varían en razón inversa entre sí (Laplanche y Pontalis, 1971).
} 
referencias a cuadros psicopatológicos y facilita las respectivas indicaciones psicoterapéuticas. De este modo, en conformidad con su modelo teórico, el conjunto de la clínica es visto según los mismos principios evolutivos, tomando como eje el nivel de la mentalización. Así Marty distingue cuatro grandes conjuntos nosográficos, que corresponden aproximadamente, pero sin superponerse, con las entidades psicopatológicas tradicionales, siguiendo un principio de jerarquización con relación al examen del psiquismo o de la mentalización de cada paciente. El concepto de mentalización se vincula con el estudio de la vida de las representaciones, en sus dos dimensiones -cualitativa y cuantitativa-; y con el sistema funcional en el cual ellas se desarrollan: el preconciente. Acerca de la mentalización, Bergeret señala: «La actividad fantasmática no constituye más que una parte del trabajo efectuado por el psiquismo para “ordenar", "dominar" (maitrisser) la energía pulsional y la excitación ligándola y derivándola. Esta elaboración psíquica se confunde con el advenimiento del proceso secundario y los procesos de pensamiento» (Bergeret, 1992: 258).

Siguiendo a Bergeret, definimos mentalización como proceso y función de la elaboración mental. Esta elaboración es progresiva y tiene por fin:

-disminuir el impacto desorganizador de los estímulos externos e internos (representantes pulsionales), ligándolos y desviándolos a través de un método que no es solamente económico sino que constituye también una operación de sentido (significante).

-diferir, anticipar y aun reemplazar la satisfacción pulsional. -mantener la constancia de un objeto pulsional a través de sus ausencias y cambios, de allí el desarrollo representacional que lo internaliza y lo vuelve figura significante.

Pierre Marty desarrolla una nosografía regulada por la eficacia del funcionamiento de la mentalización y describe la secuencia temporal activa que liga al traumatismo con el desencadenamiento de una depresión esencial, originando la consecuente desorganización somática, secuencia susceptible de reorganización, cuando la cualidad de la mentalización lo permite. 
La mentalización no es una definición simple y unívoca. Pueden existir, en un mismo sujeto, modos bien mentalizados y pensamiento operatorio.

Puede haber una brusca pérdida del valor funcional del preconciente o, al revés, un paciente que sólo se expresa somáticamente puede acceder al desarrollo de la mentalización -tratamiento psicoanalítico especializado mediante-, mentalización suficiente como para cargar al síntoma de sentido, representarlo, ponerlo en palabras.

Pierre Marty (1996) plantea:

\begin{abstract}
"Nuestros estudios sobre las cefalalgias, la inhibición dolorosa del pensamiento, y de ciertos aspectos psicosomáticos de la tuberculosis cerebral han atraído nuestra atención sobre diversos aspectos de carencias funcionales psíquicas. Primero constatamos la existencia del «pensamiento operatorio»; después, la distinción entre las insuficiencias fundamentales y las insuficiencias puestas en evidencia por las desorganizaciones ha centrado nuestro trabajo sobre los movimientos del preconciente y sobre la formación de representaciones, desembocando en conjunto sobre la noción de mentalización. [...] Finalmente, se elaboró un principio rudimentario de las somatizaciones, que puede expresarse así: - los acontecimientos de nuestra vida provocan excitaciones en nuestros instintos y pulsiones; - esas excitaciones deben encontrar vías de tránsito o de descarga, de modo de no acumularse y volverse excesivas, su acumulación consiste en la principal causa de las somatizaciones. Existen dos vías principales de tránsito y de descarga para las excitaciones, una puede parcialmente compensar a la otra, la elaboración mental (mentalización) y la expresión sensoriomotriz."
\end{abstract}

Sus estudios sobre psicosomáticos los llevaron a innovaciones teóricas, actualmente de gran vigencia. Así conceptualizaron el déficit por patología del preconciente, el cual determinaría carencia de vida fantasmática, vida operatoria y desorganización somática (Marty y De M' Uzan, 1963). Los distintos traumas vitales desinvestidos, en ausencia de afectos, fantasmas, actividad proyectiva para ser representados y transitados, derivan en un aumento y acumulación de tensión. Siguiendo a P. Marty, la desorganización de las defensas que dependen de la organización psíquica influye sobre las defensas biológicas.

Encontramos en este marco teórico, dentro de los modelos de déficit, con sus nociones de mentalización y desorganización defensiva, las referencias conceptuales que mejor se aplican a nuestro estudio de la AR. 
Cuando, justamente, constatamos alexitimia, se vuelven manifiestas las falencias en los procesos de mentalización. Vamos a continuación a presentar los desarrollos conceptuales correspondientes al constructo alexitimia.

\subsubsection{Modelos de déficit: la alexitimia.}

\section{La alexitimia. Alexitimia Primaria y Secundaria.}

Nuestro acercamiento al tema de la alexitimia surgió de los resultados hallados en nuestros trabajos de investigación. Con la intención de aportar a una comprensión más amplia de los cuadros psicosomáticos, investigamos la problemática de los trastornos alimentarios: la obesidad y el sobrepeso crónico (Lunazzi y col., 1996). Se trata de trastornos poco reconocidos socialmente como tales, a pesar de su notable aumento y manifestación. Según las últimas encuestas ${ }^{9}$ en los Estados Unidos, el país que ha generado más riquezas y más mecanismos de ahorro, la proporción de obesos en la población ha aumentado del $30 \%$ al $40 \%$ en los últimos veinte años. Tendencia en aumento que se comprueba, sin embargo, también en América latina y en nuestro país ${ }^{10}$.

El hecho reconocido de que los tratamientos basados solamente en dietas alimenticias muestran fracaso en el largo plazo, subraya la necesidad de un reconocimiento del sobrepeso crónico como un fenómeno en el que a la sobrecarga adiposa corporal se hallan asociados factores genéticos, ambientales, vinculares, afectivos y sociales. Por ello, manifiesta el anclaje de modos organizativos profundos de la personalidad dentro de los cuadros psicosomáticos. Nuestros trabajos mediante técnicas de evaluación, (Lunazzi, García de la Fuente, Elías y Kosak, 1997; Lunazzi, 1999 a, Lunazzi 2001 a, Lunazzi, 2001 b, Lunazzi, 2005 a) permitieron definir al Sobrepeso Crónico como un fenómeno complejo, multifocalmente abordable, al cual subyacen dinámicas psíquicas muy profundas, asociadas a otros factores igualmente poderosos. De esta definición deriva la pertinencia de un abordaje preventivo y asistencial en equipos transdisciplinarios. En especial, observamos que reconocer en estos pacientes la presencia de alexitimia definiría

\footnotetext{
${ }^{9}$ VII Congreso Internacional de Obesidad, Toronto, septiembre de 1995.

${ }^{10}$ Consultor de Salud. Informe del Congreso Nacional de Obesidad. Marzo de 2000.
} 
estrategias de atención discriminadas que deberían considerarse en los planes de tratamiento.

P. Sifneos y J. C. Nemiah, como corolario de abundantes trabajos previos, en 1974 emplearon el vocablo griego alexitimia, que significa «ausencia de verbalización de afectos o sentimientos». El concepto alexitimia es un constructo hipotético derivado del trabajo clínico con pacientes psicosomáticos. Dichos autores observaron que los pacientes psicosomáticos se caracterizaban por: $a$ ) pensamientos con bajos niveles de abstracción; $b$ ) pobre capacidad para fantasear; $c$ ) relaciones interpersonales rígidas y estereotipadas; $d$ ) gran resistencia a aceptar las interpretaciones psicoanalíticas tradicionales. P. Sifneos y J. C. Nemiah aluden con dichos rasgos, por ejemplo «poca abstracción» a la característica disposición de estos pacientes por los abordajes utilitarios y concretos de los hechos, con escasa introspección. Dicho rasgo fue llamado pensamiento operatorio y descripto previamente por P. Marty, M. de M’Uzan y P. David en 1963 (Marty y de M’Uzan, 1963).

En cuanto a la «resistencia a aceptar interpretaciones psicoanalíticas», recordemos que las interpretaciones intentan en el aquí y ahora del vínculo terapéutico, en transferencia, reconocer experiencias emocionales del pasado que permanecían previamente inconscientes. Esta resistencia es comprensible si recordamos el estilo concreto, poco imaginativo y reflexivo característico de esos pacientes. Como su nombre lo indica, la ausencia de verbalización de afectos o sentimientos empobrece la profundidad de las experiencias, simplificándolas principalmente a sus aspectos materiales o concretos.

Una caracterización aceptada considera que la alexitimia es un desorden de la regulación y mediación de los afectos entre la fisiología, el soma y los procesos cerebrales de la mente, que constituye un importante factor de riesgo en las enfermedades psicológicas y físicas, hallándose implicado en los cuadros psicosomáticos, cuadros antisociales, abuso de sustancias, desorden por pánico y otras enfermedades. Todos estos cuadros comparten la escasa integración de los sentimientos a la mente y la conducta (Haviland, Sonne, Kowert, 2004), (Lunazzi, 2003).

El déficit del procesamiento cognitivo de las emociones, definido por Sifneos en 1973 como el déficit neurológico de las vías conectivas entre la corteza y el sistema límbico en la llamada alexitimia primaria, es susceptible de verificarse en las pruebas de laboratorio y 
de inducirse experimentalmente. Dicho déficit también es manifiesto en la alexitimia secundaria, así llamada por Sifneos (1995), desarrollada aún cuando las bases y conexiones neurológicas están intactas como respuesta adaptativa a traumas y enfermedades. Esta respuesta adaptativa, en la cual las emociones intensas no se reconocen ni verbalizan puede ser transitoria, ya que se trataría de un sujeto sólo situacionalmente alexitímico. La alexitimia secundaria, verdadera o cristalizada como rasgo de la personalidad, en cambio, también se atribuye a falencias tempranas en el vínculo materno, cuando la madre carece de la capacidad de representarse las emociones del bebé y por ello tampoco de verbalizarlas (Winnicott, 1979; Liberman, 1983; McDougall, 1987; Bion, 1965, 1992). Esas carencias maternas interferirían en el proceso normal del bebé de reconocer y expresar sus propias emociones.

También existen modelos social-cognitivos explicativos de la alexitimia secundaria, que señalan las características de ciertas culturas que no estimulan la manifestación afectiva (Casullo, 1994; Páez, 2000). En la misma dirección, en una investigación que realizamos sobre las variables relacionadas con la alexitimia, hallamos que el nivel socioeconómico medio-bajo está asociado con uno de los factores que se evalúan en el constructo ${ }^{11}$ (Lunazzi, 2000): el uso de la fantasía. Los voluntarios no pacientes de nivel socioeconómico medio bajo muy significativamente utilizan menos la vida de fantasía, respecto de las muestras de no pacientes con las que se los compararon.

Si revisamos las citas originales de Sifneos (1995: 30) respecto de las formas de alexitimia, dice:

"Como lo mencioné anteriormente introduje el término alexitimia para describir los déficits afectivos. Distingo dos tipos de alexitimia según sus bases etiológicas, tales como se las puede concebir teóricamente. Pienso que la alexitimia primaria está etiológicamente ligada a déficits neurobiológicos, tales como las malas conexiones de las regiones límbicas y neocorticales. La alexitimia primaria aparece claramente como un déficit de los sentimientos y no de las emociones. Por ejemplo en el caso en el cual los dos sistemas no están conectados, un estímulo arribando al núcleo de la amígdala suscitará emociones

\footnotetext{
${ }^{11}$ Respecto de este último aspecto, la influencia cultural sobre la alexitimia, en una investigación que realizamos (Lunazzi, 2000 a), hallamos que los sujetos con nivel económico medio bajo no mostraban diferencias estadísticamente significativas en el puntaje total de alexitimia evaluado con la TAS y respecto de las muestras normativas. Sí, en cambio, fue estadísticamente significativo que el tercer factor (disposición para fantasear o imaginar) que compone la evaluación de la alexitimia, apareció disminuido en este grupo.
} 
tales como el miedo o la cólera, las cuales en ausencia de todo aporte de imágenes y pensamientos provenientes del neocórtex serán expresadas bajo la forma de reacción de combate o huída. La observación de pacientes refractarios que han sufrido una comisurectomía o una hemisferectomía, han corroborado la tesis de la etiología neurológica de la alexitimia primaria. Como consecuencia de esas intervenciones quirúrgicas que han interrumpido las comunicaciones en el interior del cerebro, estos pacientes presentaron características alexitímicas que no estuvieron presentes en ellos previamente. Evidentemente las emociones provenientes de la amígdala no podían alcanzar las regiones neocorticales para crear imágenes, imaginaciones y pensamientos ni utilizar el lenguaje para expresarlas. Es más, la alexitimia primaria puede resultar de factores genéticos predisponentes como lo demostró en Noruega un estudio con gemelos monocigotas. La alexitimia secundaria, por lo contrario, no parece tener un origen neurológico. Una experiencia traumática devastadora sufrida en la edad preverbal puede dejar al niño incapaz de expresar sus emociones por medio del lenguaje. De otro modo, adultos que no eran alexitímicos sino víctimas de shocks producidos por el medio ambiente tales como catástrofes naturales, pueden desarrollar para sobrevivir una alexitimia característica. Ellos rehusaron más tarde abandonar esos rasgos de carácter, medio de su supervivencia, aún cuando ya no les eran útiles. La «parálisis» de los sentimientos que se menciona tan frecuentemente en la literatura que concierne al holocausto se refiere a este mecanismo. En fin, las reacciones socioculturales o psicodinámicas bajo la forma de uso excesivo de los mecanismos de negación o de represión pueden igualmente hallarse en el origen de una alexitimia secundaria".

El investigador H. Freyberger (1977) ha difundido el término alexitimia secundaria para designar una reacción habitual, particularmente en los pacientes sometidos a diálisis y hospitalizaciones en terapia intensiva, consistente en bloquear la comunicación de sus sentimientos. Este tipo de manifestación puede permanecer instalado en la personalidad o remitir.

La intervención de los psicoterapeutas, dijimos, es muchas veces decisiva en el campo psicosomático para la prevención o remisión de la enfermedad, o menos ambiciosamente, para obstaculizar su agravamiento. En particular, es imprescindible en aquellos graves casos donde la sobrevida del paciente depende de su capacidad de adherencia al tratamiento $^{12}$. De modo claro, P. Sifneos afirma (1995: 32):

\footnotetext{
${ }^{12}$ IX Congreso Nacional de Psicodiagnóstico. XVI Jornadas Nacionales de A.D.E.I.P.: Dr. L. Benasayag, Dr. R. Diez, Psic. H. Lunazzi (2005) Identidad, historia y transformación en la práctica de la integración en Psiconeuroinmunoendocrinología (PNIE).
} 
"Los trastornos alexitímicos no se encuentran solamente en asociación con las enfermedades psicosomáticas, sino que se encuentran igualmente en los pacientes que sufren de síndrome de estrés post traumático (PTSD), en drogadictos, alcohólicos crónicos, anorexia y bulimia mental y en los sociópatas. Es interesante que las deficiencias afectivas bajo la forma de alexitimia aparecen en un gran abanico de especialidades médicas, en medicina interna, cirugía, neurología, psiquiatría tanto como en psicología. Este hecho nos da la ocasión de estudiar y de comprender las interrelaciones entre esas especialidades médicas, las que tienen todas por fin aliviar los sufrimientos elaborando juntas diferentes tipos de intervención terapéutica. Por ejemplo, va de sí, que un paciente padeciendo una úlcera sin alexitimia tendrá necesidad únicamente de un régimen médico apropiado. En revancha, una úlcera péptica alexitímica tendrá necesidad de un tratamiento medicamentoso tópico y de una ayuda psicológica destinada a reducir la hiperactividad del sistema nervioso autónomo debida al trastorno alexitímico".

Habida cuenta de lo dicho por Sifneos, aparece con claridad la importancia de la intervención del psicólogo, tanto en la discriminación diagnóstica de la alexitimia, para establecer su presencia y cualidad, cuanto en la implementación de los tratamientos psicoterapéuticos pertinentes que su ausencia o presencia conlleva.

Otorgando respaldo a nuestro objetivo nos resultó muy estimulante el señalamiento de G. J. Taylor, director de los programas de investigación y evaluación de la alexitimia de la Universidad de Toronto, respecto de las consecuencias prácticas sobre los tratamientos de los pacientes que presenten alexitimia. En un artículo publicado en 1994: El constructo alexitimia: conceptualización, validación y relación con dimensiones básicas de la personalidad (Taylor, 1994) ha expresado:

"A pesar de que el constructo alexitimia fue derivado de observaciones hechas inicialmente con pacientes de enfermedades psicosomáticas «clásicas», recientes estudios han confirmado la impresión clínica de que la alexitimia está estrechamente asociada también con numerosos desórdenes psiquiátricos escasamente comprendidos y de difícil tratamiento.

Propongo que esos trastornos psicosomáticos y psiquiátricos sean reconceptualizados como desórdenes de la regulación de las emociones. La propuesta está avalada por la evidencia empírica que informa que la alexitimia está asociada positivamente con emocionalidad negativa, en forma negativa con emocionalidad positiva y negativamente con la dimensión de la personalidad apertura a la experiencia, la cual acompaña características de la personalidad que juegan un importante rol en la regulación de los afectos. Esta 
conceptualización y los resultados de las investigaciones tienen importantes implicaciones terapéuticas ${ }^{13}$."

En dirección a la afirmación de G. J. Taylor contamos con numerosos antecedentes que mencionan la imprescindible intervención del psicólogo en los equipos de salud, entre los cuales citaremos algunos. Respecto de la falta de adherencia a los tratamientos en enfermedades autoinmunes (Ricart, Cohen, Alfonso, Hoffman, Quiñónez, Cohen, Indyk, 2002) manejo la respuesta al estrés y de control del dolor (Crofford y Casey, 1999), (Schanberg y Sandstrom, 1999), (McCain, 1996), (Crofford y Demitrack, 1996), (Wolfe y Potter, 1996) y en tratamientos psicoterapéuticos de los alexitímicos (Krystal, 1993: 318), (Lutgendorf y Constanzo, 2003).

La alexitimia consiste, entonces, en un constructo que representa una configuración de déficits en la capacidad de procesar las emociones: déficit para distinguir sentimientos de manifestaciones corporales, déficit en la capacidad de comunicar los sentimientos, para imaginar y fantasear, para vincularse introspectivamente. Revelaría, a través de ese fracaso de procesamiento cognitivo, la contraparte del funcionamiento sano, propio del individuo normal. En consecuencia, investigarla y estudiarla ayudaría a iluminar el significado de la vida emocional en la salud y en la enfermedad.

Investigadores argentinos recientemente se han referido a la alexitimia, expresando que: «Consideramos que aunque el constructo se refiere a problemáticas de varias décadas, su valor nos sugiere el de los vinos añejos, que requieren tiempo y conocimiento para saborearlos» (Sivak, Wiater, Lolas, 1997:pág. 174).

Pensamos que la necesaria inversión «de tiempo y conocimiento» para utilizar valiosamente la noción de alexitimia es muy acertada. Se trata de un trastorno cognitivo

\footnotetext{
${ }^{13}$ Los conceptos de emocionalidad negativa en terapias conductuales aluden a la presencia de depresión, ansiedad, actitudes de rechazo y no colaboración. La emocionalidad positiva refiere, en cambio, a la presencia de estado de ánimo constructivo, colaborador y optimista. En cuanto a la dimensión apertura de la experiencia designa la disposición a explorar y afrontar las experiencias de modo amplio y profundo o, por lo contrario, simplificador. En especial, la dimensión de la personalidad «apertura a la experiencia» constituye una de las cinco grandes áreas o polaridades en el estudio de la personalidad, en un modelo reciente de evaluación de la personalidad llamado Modelo de los Cinco Factores o FFM (Five Factors Model). Estas cinco polaridades son: a) estabilidad versus neuroticismo; b) extraversión versus introversión; c) constricción versus labilidad; d) cordialidad versus antagonismo y e) apertura versus cerrazón a la experiencia. (Sendin, 2000: 267).
} 
serio y deficitario de la simbolización y de la expresión afectiva. A pesar de que se la define de un modo aparentemente rápido y claro, sin embargo, amerita diferenciarla de posiciones voluntarias en los sujetos del tipo «el que habla pierde» o de mecanismos neuróticos defensivos, como la intelectualización y el aislamiento en sujetos con una gran riqueza imaginativa y afectiva, que no deben confundirse con los alexitímicos.

\subsubsection{Imaginación y Palabra}

Sin extendernos en un tema que refleja la construcción fundamental del ser humano y que hace al ser humano, su hacer palabra, brevemente, ateniéndonos a nuestro objetivo presente, anticiparemos que la palabra provee el recurso de elaborar la angustia y los afectos, volviéndolos material de representación ${ }^{14}$.

Los procesos de mentalización operan sobre la base de la producción de palabra representante. Lo que no alcanza nombre, o sea, palabra que lo represente, no existe para la mente.

H. Krystal plantea, en su libro, que «en cada estadio psicosexual hay una elaboración de la riqueza de las soluciones en la fantasía, las cuales modifican la urgencia de los impulsos. A medida de que las habilidades verbales se desarrollan como parte de la elaboración de las fantasías, la precisión y efectividad de las palabras demuestran que el lenguaje es la vía preferida para manejar los afectos. Así cada etapa psicosexual, cada crisis psicosexual, cada incremento en relaciones, conceptos y modalidades significativas promueve la verbalización y desomatización de los afectos y su regulación» (Krystal, 1993: pág. 49).

Es notable la revisión que ha realizado Leff, en múltiples estudios que incluyen investigaciones internacionales sobre las relaciones étnicas y los patrones lingüísticos, que sugieren que la cultura en los territorios desarrollados conlleva una mayor diferenciación de las emociones. Por ejemplo, Krystal cita un estudio realizado por Leff en 1973, en el cual demostró que «la naturaleza de la propia experiencia está determinada por la

\footnotetext{
${ }^{14}$ Remito al lector al texto de L. Schwartz Hablar lo Verbal, 1996.
} 
disponibilidad de palabras para describirla. Usó la falta de diferenciación de ciertos colores: en los lenguajes de las islas del Pacífico se carece de la distinción entre verde y azul; entre los Navajo disponen de una sola palabra para el marrón y el gris; y la gente Shona no distingue entre rojo y púrpura, y todas esas poblaciones carecen de la diferenciación entre esos colores» (Krystal, 1993: pág.58).

Pero cómo llegamos a disponer, o no, de palabra para representar los sucesos afectivos de nuestra vida psíquica implica un largo derrotero.

M. Klein (1940), a partir del modelo original de Freud de los impulsos instintivos inició una importante contribución al formular una epigénesis del procesamiento o regulación de los afectos. Concibió que en las primeras etapas de su vida, el bebé desea preservar el placer en su ego, evacuando en el objeto los sentimientos dolorosos y la ansiedad persecutoria, a través de los mecanismos de disociación e identificación proyectiva, en la llamada posición esquizo-paranoide. A medida de que el desarrollo del bebé progresa, se vuelve más capaz, contando con la ayuda del objeto, para tolerar y alojar sus propios sentimientos. Tal logro constituye alcanzar la posición depresiva. Este término tanto describe un período donde clínicamente puede reconocerse el cambio en el bebé, que responde a la integración de sentimientos negativos y positivos que habitan el mismo objeto. Dice al respecto Grotstein (1997, XV): «Se podría decir que el bebé es inicialmente alexitímico, dado su nivel de desarrollo, pero si cuenta con una normal maduración alcanza la lexitimia». Para comprender esta «normal maduración» necesitamos, siguiendo el surco de M. Klein, adentrarnos en las contribuciones de W. Bion $(1959,1962)$ y particularmente también de D. W. Winnicott (1953). Bion concibe el modelo del continente/contenido, en el cual el procesamiento cognitivo y emocional de la madre (función alpha, reverie) de los sentimientos brutos de malestar proyectados del bebé son trasformados por ella en interpretaciones discriminadas gentilmente, comunicadas con palabras, de modo que el bebé pueda ir aprendiendo de ellas sobre su repertorio afectivo.

Por su parte, D. W. Winnicott ${ }^{15}$ refiere las primeras formas elementales de regulación afectiva, propia de los primeros meses de la vida. Señala que, si bien inicialmente la

\footnotetext{
${ }^{15}$ En esta línea, también otros autores como Gaddini, Bolwby y Tustin.
} 
presencia de un cuidador seguro y empático será la precursora de la regulación de los estados de satisfacción-insatisfacción del bebé, ellos mismos desarrollan algunas conductas independientes de autorregulación emocional: chupar sus dedos o el pulgar, rascar partes de su cuerpo, menearse, tocar partes del cuerpo del cuidador o de su ropa, o de algún juguete, y los llamó objetos sensación. Tales objetos, a través del ritmo motor y la experiencia sensorial táctil, propone, son modos de preservar en el bebé la ilusión de unidad con su madre. Estos objetos sensación serían la precondición de lo que posteriormente llamará objeto transicional o fenómeno transicional. En 1953 Winnicott llamó al objeto transicional la «primera creación» del niño, o acto imaginativo. El objeto transicional emerge aproximadamente entre los 4 y 6 meses de vida y alcanza su cima a los 18 meses. Consiste en un objeto especial, tal como un juguete suave o peludo, una pequeña sabanita, un trozo de madera que el bebé ha elegido y repetidamente busca en sus momentos de malestar, especialmente en situaciones ansiosas relacionadas con la separación de la madre. Utilizado por el niño como autocontentamiento, el objeto transicional ejerce una destacada actividad de regulación afectiva.

Winnicott, y otros autores posteriormente, consideran a la relación entre el bebé y una madre empática como la matriz imprescindible para el desarrollo gradual de la imaginación y de las capacidades creativas. Aunque la creación del objeto transicional está inicialmente relacionada con las propiedades olfativas y táctiles del objeto (suavidad, olores de leche y otros de la madre), el niño gradualmente dota al objeto transicional con sentido, lo convierte en un símbolo significante de la madre y preserva el vínculo con ella en su ausencia. Desde estas raíces y ayudado por la maduración de las funciones y estructuras neocorticales, la capacidad imaginaria del niño evoluciona hasta crear una imagen mental de la madre ligando la representación a palabra, creando fantasías, sueños, intereses y juegos que van mucho más allá de las imágenes producto de los objetos externos. Son conocidas las actividades de creación de amigos imaginarios que muchos bebés y niños usan para inducir afectos tranquilizadores o placenteros, o para modular situaciones amenazantes. Estas capacidades juegan un rol muy reconocido en el desarrollo de la personalidad y en la autorregulación afectiva durante toda la vida. Capacidades para fantasear e imaginar, que como hemos señalado, se hallan muy restringidas en los alexitímicos. 
La vida imaginaria implica un conjunto de conceptos y funciones interrelacionados en procesos de representación y elaboración mental o mentalización. Incluyendo la capacidad para crear una fantasía, la capacidad para usar esa fantasía a fin de la autorregulación afectiva o como defensa, la construcción de una síntesis de percepciones y recuerdos en la imagen mental de una persona o cosa que no está presente, la capacidad para mantener el registro de nuestro mundo interno de representaciones mentales como opuesto al mundo externo de percepciones sensoriales, la proyección a futuro. Si bien las habilidades verbales se desarrollan como parte de la elaboración de las fantasías, la precisión y efectividad de las palabras vuelven al lenguaje, la vía preferida para expresar los afectos, siempre en íntima alianza con la vida imaginaria.

No disponer de palabra para la propia vida afectiva refleja la carencia representacional de cómo nuestros afectos afectan nuestras relaciones y de cómo, a su vez, los afectos que se mueven en el ambiente e interacciones nos afectan ahora y en nuestra historia.

Por lo tanto, y de acuerdo a lo desarrollado anteriormente, podemos afirmar que la alexitimia, entonces, refleja un desorden importante en la regulación de los afectos, y constituye un importante factor de riesgo en las enfermedades del tipo que fueran, particularmente en los trastornos somatoformes, de la alimentación, abuso de sustancias, ataque de pánico, sociopatías y psicosomáticas, pues al reducir la circulación y significación de la información proveniente de las señales del mundo interno y del externo, interfiere con el proceso de autoorganización y reorganización del organismo en su historia y su ambiente.

El principio antes mencionado de la homeostasis y su regulación incluye en el ser humano la capacidad sana para autorregular sus emociones y para recuperarse cuando sufre lesiones o enfermedades. Establecer la presencia de alexitimia implicaría constatar el déficit o fractura de las naturales interrelaciones cognitivas, experienciales, fisiológicas y expresivas de la vida afectiva, con su consecuente efecto patológico. Asimismo, la ponderación de su presencia y cualidad orientaría los modos de intervención y abordaje del paciente. 


\subsection{La Artritis Reumatoidea (AR)}

En las investigaciones que llevamos a cabo en enfermos psicosomáticos y alexitimia (Lunazzi, García de la Fuente, Elías y Kosak, 1997; Lunazzi, 1999 a; Lunazzi, 2001 a; Lunazzi, 2001 b; Lunazzi, 2005 a); nos llamaron la atención ciertos hallazgos diferenciales encontrados en la artritis reumatoidea y la falta de estudios rigurosos de evaluación psicológica en esta enfermedad Ello nos motivó a centrar y profundizar nuestro estudio en este particular grupo de pacientes, intentando construir un aporte a la comprensión de su funcionamiento psicológico que pudiera ser de utilidad para su tratamiento. La posibilidad de establecer la presencia o ausencia de alexitimia y su ponderación en estos pacientes prometía contar con una noción clara y cuantificable para proponer en el trabajo transdisciplinario.

La AR fue clasificada en un tiempo entre las siete enfermedades psicosomáticas clásicas, dados sus componentes genéticos, orgánicos y psicológicos. Actualmente es conocida en su calidad de enfermedad autoinmune. Se considera que la enfermedad se inicia con una respuesta inmune anormal contra un virus común o bacteria, la cual entonces se vuelve autoperpetrada (Baker, 1987). Las reacciones inflamatorias se instalan en el cuerpo, especialmente en las articulaciones, produciendo su deformación y rigidez. Se realizan múltiples estudios para acceder al conocimiento de las causalidades asociadas a las enfermedades autoinmunes. Como señala una fuente consultada, poco se ha avanzado desde los comienzos en ese sentido y «a pesar de que la AR debe incluir algún desequilibrio en la regulación inmunológica, exactamente por qué el sistema inmunitario de una persona pierde la capacidad para diferenciar entre las macromoléculas propias y las ajenas se desconoce» (Schoenfeld y Schwartz, 1984), (citado por Taylor y col., 1997).

Del mismo modo que en otras enfermedades autoinmunes, como la colitis ulcerosa de aparición juvenil o el Tipo I de diabetes mellitus, un alto porcentaje de pacientes con AR informan haber experimentado experiencias muy estresantes emocionalmente previas al desencadenamiento o manifestación de la enfermedad. En otro grupo de casos, no se informan, o el paciente desconoce la presencia de experiencias estresantes. Tal desconocimiento no es sorprendente, ya que hemos mencionado anteriormente el característico escaso reconocimiento de los pacientes psicosomáticos respecto de sus propios sentimientos y procesos psicológicos. 
La artritis reumatoidea es una afección autoinmune ${ }^{16}$, en la cual, en una descripción simple, el sistema inmunológico ataca crónicamente al propio tejido articular. Sus síntomas característicos son: $a$ ) la rigidez prolongada de las articulaciones al despertar y $b$ ) inflamación, dolor y tumefacción de las articulaciones (principalmente manos y pies) en forma simétrica. Habitualmente, como anticipamos, la afección se desencadena tras alguna situación de gran estrés. Si no es tratada en forma adecuada y precoz, puede dar lugar al daño y la deformación permanente de las articulaciones, evolucionando hasta que el paciente se vea impedido de realizar sus tareas cotidianas y las personales más íntimas ${ }^{17}$. El pronóstico a largo plazo para los pacientes que presentan la enfermedad es reservado. Muchos pacientes se enfrentan con una incapacitación creciente y muerte prematura. El promedio de duración probable de la vida de una persona puede acortarse entre tres y siete años. Las formas severas de la AR pueden conducir a la muerte de 10 a 15 años antes de lo previsto. El diez por ciento de las personas que lo padecen están, después de 20 años, severamente incapacitadas y no pueden desarrollar sus actividades cotidianas mínimas, como comer y vestirse. Se diagnostica sobre la base de los síntomas generales del paciente, el historial médico, examen físico, radiografías y análisis de sangre en el laboratorio. Los criterios para diagnosticarla incluyen la inflamación, el dolor y la tumefacción de múltiples articulaciones, rigidez articular matinal prolongada, evidencia radiográfica de la erosión de la articulación, nódulos característicos (bultos de tejidos) de la piel y evidencia de un anticuerpo, llamado el factor reumatoide, que se encuentra en la sangre de aproximadamente el $80 \%$ de los enfermos adultos. El diagnóstico precoz y el tratamiento agresivo son necesarios para demorar el menoscabo funcional y los daños irreversibles a las articulaciones ${ }^{18}$.

\footnotetext{
${ }^{16}$ La Artritis Reumatoidea (AR) es una enfermedad inflamatoria crónica que se caracteriza por la infiltración de células T y B, macrófagos y neutrófilos en el revestimiento sinovial y en el fluido de los espacios periarticulares. Las quemokinas actúan como ligaduras para los receptores fuertemente relacionados con las quemokinas, los cuales se expresan en distintas poblaciones de leucocitos incluyendo las células tipo recolectadas en las articulaciones (Quiñónez, Ahuja, Jiménez, Schaefer, Garavito, Rao, Chenaux, Reddick, Kuziel, 2004). En las enfermedades autoinmunes, el sistema inmunológico se equivoca en el reconocimiento de lo propio y toma como extrañas a células de su organismo, destruyéndolas. Según el tipo de las células destruidas, la enfermedad será una diabetes juvenil, una tiroiditis, etcétera (Soler, 1997: 73).

${ }^{17}$ Informe relativo al Congreso Panamericano de Reumatología (Panlar 2002, Aruba). La Nación, 30 de junio de 2002 .

${ }^{18}$ Informe sobre Salud. El Día, 31 de julio de 2002.
} 
En la Argentina ${ }^{19}$ padecen AR 500.000 personas. Si bien el desarrollo de nuevas clases de agentes farmacológicos antirreumáticos con menor grado de toxicidad consiste en la indicación sustancial y promisoria para este cuadro psicosomático, también lograr una mayor comprensión del funcionamiento emocional que lo precede y acompaña, tal como puede conceptualizarse mediante el constructo alexitimia, mucho podría aportar a las reflexiones preventivas y a las estrategias terapéuticas. Las intervenciones psicoterapéuticas prometen ofrecer beneficios en cuanto a la mejor disposición de los pacientes para aceptar los tratamientos médicos, las vicisitudes de la enfermedad y, en general, su calidad de vida. (Sang-Ahm y Young-Joo, 2005; Rosmond, 2005; Sepa, Frodi, Ludvigsson, 2002).

La investigación de la presencia de alexitimia en esta enfermedad crónica, autoinmune, discapacitante, en la cual se produce la erosión de los cartílagos, de los huesos y de las articulaciones del cuerpo, que afecta al 1\% de la población adulta del mundo, constituye el sustento de la presente Tesis. Tratamos de establecer la presencia de limitaciones en la regulación de los afectos, característica de la alexitimia en el interjuego psico-biológico social en el que está comprometido todo el organismo.

\footnotetext{
${ }^{19}$ Datos de la Secretaría de Salud del Gobierno de la Ciudad de Buenos Aires. La Nación, 29 de octubre de 2000.
} 


\subsection{Resumen}

El recorrido de autores que realizamos nos facilita conocer las definiciones sobre la vida afectiva, su enraizamiento en el cuerpo y la contribución adaptativa que el reconocimiento de las propios sentimientos aporta. Reconocemos así el lugar de los afectos en la salud y cómo las consecuencias patológicas que conllevan tanto su disociación como los déficits de regulación.

Los desarrollos de los autores de la Escuela Psicosomática de París nos ofrecen los instrumentos conceptuales capaces de describir las posibles diferentes formas de presentación, según su grado de mentalización, de los pacientes psicosomáticos, en nuestro caso de artríticos reumatoides. Nos ofrecen también, con la explicación de montos excesivos de cargas excitatorias acumuladas, las bases teóricas para entender las consecuencias patológicas del fracaso de las posibilidades de mentalización y descarga sensoriomotriz.

Nos aportan, con el concepto de mentalización la comprensión del trabajo que se desarrolla saludablemente en la mente que posee esa capacidad para regular las excitaciones, ligándolas a palabra y representaciones, que le permitirán disminuir, derivar y simultáneamente conservar la constancia de los objetos (relaciones objetales) ${ }^{20}$.

En lo pertinente al constructo alexitimia, que provee al status de la palabra como articuladora en la interfaz del cuerpo y de la mente, contamos con los desarrollos teóricotécnicos elaborados por P. Sifneos, sobre bases neurobiológicas y cognitivas. Nos facilita, desde otra disciplina, conceptos con notable parentesco con los desarrollados por la escuela francesa. Disponemos del trabajo de sus discípulos M. Bagby y G. Taylor, quienes continuaron con la operacionalización del constructo, al elaborar-como veremos- las Escalas Toronto para la evaluación de la alexitimia, cuyos factores responden a las limitaciones del trabajo de mentalización y al pensamiento operatorio descripto por Marty.

\footnotetext{
${ }^{20}$ Cuando decimos relaciones objetales no hacemos referencia meramente a relaciones interpersonales, sino a la actividad fantasmática inconciente que las acompaña.
} 
Nos es particularmente promisoria la conceptualización de G. Taylor, quien acuña el particular significado de la alexitimia como déficit en la regulación de los afectos. Facilita, de este modo, los puentes teóricos apropiados para situar nuestras preocupaciones en el marco de los problemas e investigaciones propios de las enfermedades psicosomáticas tales como las comprende y trata la Psiconeuroinmunoendocrinología, y el interés de las intervenciones de los psicólogos.

Los antecedentes mencionados, y en especial la propuesta del Prof. G. J. Taylor, relativa a la importancia de la intervención del psicólogo en el equipo de salud, constituyen las bases para el desarrollo del presente proyecto de tesis: la alexitimia en la Artritis Reumatoidea.

Cuando constatamos alexitimia, se vuelven manifiestas las falencias en los procesos de mentalización que podrán operacionalizarse en los indicadores de nuestras técnicas de evaluación psicológica

Contamos entonces con nociones psicológicas, psiconeuroinmunológicas y metapsicológicas en referencia a la alexitimia.

Por lo tanto, enmarcaremos el estudio de la alexitimia en la AR, en las citadas contribuciones teóricas.

En síntesis:

1. La palabra sentimiento alude a la dimensión subjetiva cognitivo-vivencial de las emociones. Las emociones refieren al aspecto neurofisiológico y expresivo conductual-conductual motor. Cuando decimos afectos abarcamos estados compuestos, que incluyen dimensiones cognitivas, vivenciales, fisiológicas, expresivas, conductuales.

2. Los afectos están intrincablemente unidos a la vida mental y cognitiva, y podemos ver cómo interactúan: son funcionalmente indivisibles, holísticos. 
3. Los afectos son los adjetivos de las experiencias, los que le dan significado, y las experiencias dejan el rastro de su significado afectivo. Son objeto de acciones regulatorias y juegan un importante rol en la organización del funcionamiento mental y conductual.

4. Bajo la forma de sentimientos, son experimentados y percibidos; y consisten en las percepciones de estados corporales, a su vez, con contenidos temáticos. Este es un proceso recursivo: es posible a partir de un tema desencadenar una percepción, un sentimiento y las respuestas fisiológicas que como emoción o impulsos conlleva.

5. Puede tener sentimientos un organismo que no sólo tenga cuerpo, sino que pueda representar su cuerpo en su mente. Requiere la posibilidad de palabra investida por la actividad de mentalización.

6. Los sentimientos capacitan las correcciones biológicas necesarias para sobrevivir, ofreciendo explícita y relevante información sobre el estado de los diferentes componentes del organismo en cada momento. Permiten que los procesos biológicos adquieran nivel mental, la reflexión sobre uno mismo como sujeto y la integración del presente, el pasado y la anticipación del futuro. El proceso de elaboración mental de las excitaciones ligándolas a palabra representativa se llama mentalización.

7. La idea de que los afectos (sentimientos y emociones), cuando se hallan en niveles excesivos o no modulados, pueden afectar negativamente la salud mental y corporal, reconocida desde la antigüedad, puede hoy contar con fundamentos teóricos y pruebas clínicas con capacidad de objetivarlo.

8. Cuando los afectos no son adecuadamente representados y transitados derivan en un aumento y acumulación de tensión. La desorganización de las defensas que dependen de la organización psíquica influye sobre las defensas biológicas. Los enfermos psicosomáticos se caracterizan por la exclusión en la mente de la representación del propio cuerpo. 
9. El constructo alexitimia opera en la interfaz del cuerpo y la mente y permite reconocer la cualidad del proceso de mentalización particular a cada caso. Establecer la presencia de alexitimia en la AR, implicará constatar el déficit o fractura de las naturales interrelaciones, cognitivas, experienciales, fisiológicas y expresivas de la vida afectiva, con su consecuente efecto patológico.

10. La psiconeuroinmunología es una disciplina dentro de la medicina que sostiene la constante e íntima interacción entre la cualidad y funcionalidad de los sistemas psicológico, neurológico, inmunológico y endocrinológico, en la vulnerabilidad o integridad de las dimensiones conductuales y el medio ambiente. En el mantenimiento de la salud o de la calidad de vida y particularmente en la calidad de la sobrevida. 


\title{
Capitulo 2
}

\section{ESTADO DE LA CUESTIÓN}

\begin{abstract}
No tener es el comienzo del deseo, entonces el hecho de tener, el de poseer, tal cual expresáis vos tan exhaustivamente... no es el poseer de esa forma...¿culpable? Ahora podéis hablar, pero haced el favor de mantener la misma pose, pues debemos hacer un nuevo intento... Nadar, querido amigo, no me interpretáis bien. En literatura, ¿quién puede creer haber entendido nada? Todos morimos solos. Fijaos cuando pronunciáis la palabra avaricia, cuando decís el verbo tener, sentid con cuánto gusto vuestros dientes superiores acarician vuestro labio inferior; así se produce el sentido, pues nuestro cuerpo forma, crea el signifcado de las palabras.. Lo hacen nuestros sentidos ¡avidos!, amigo mío, tan ansiosos por poseer el ser como la boca por poseer la lengua. Interpretadme mejor: no encuentro pecado en amar lo que tenemos, pues de hecho no poseemos nada, salvo lo que nos posee -nuestra lengua por ejemplo- ¡no poseemos nada!
\end{abstract}

RICHARD HOWARD (Avaricia)

El constructo alexitimia constituye un vasto y promisorio territorio, que ofrece una perspectiva enteramente nueva y rica sobre cómo las emociones influencian la salud física y mental. Contamos con un importante acuerdo teórico, proveniente de los campos Neurobiológico, Psicoanalítico y de la Psiconeuroinmunoendocrinología, acuerdo también ,avalado empíricamente.

A continuación vamos a revisar las investigaciones que se han desarrollado sobre distintas dimensiones de interés para el problema que nos ocupa. El recorrido de los resultados de los trabajos, promete establecer los puntos de acuerdo y controversia y las bases actualizadas, a partir de las cuales vamos a referir nuestra propia investigación. Vamos a dividir la exposición en tres partes: Parte I: Alexitimia, Personalidad y Cultura, 
Parte II: La Evaluación de la Alexitimia y Parte III: el tópico específicamente referido a la Artritis Reumatoidea (AR). La Parte IV , presentara la síntesis de la revisión de la cuestión desarrollada.

\section{PARTE I : 2. 1. ALEXITIMIA, PERSONALIDAD Y CULTURA.}

2.1.1 El constructo Alexitimia y la personalidad.

2.1.2. Estado o rasgo.

2.1.3. Alexitimia y mecanismos de defensa.

2.1.4. Alexitimia y Cultura.

2.1.5. Perfil Alexitímico.

2.1.6. Resumen.

\section{PARTE II 2.2. LA EVALUACIÓN DE LA ALEXITIMIA}

2.2.1. Instrumentos de evaluación de la alexitimia. Desarrollo de la Escala Toronto de Alexitimia TAS (TAS26)

2.2.2. Técnica Rorschach.

2.2.3. Contribución de la Técnica Rorschach_en el campo hospitalario.

2.2.4. Resumen de los hallazgos Rorschach en Medicina Psicosomática.

2.2.5. Estudios Rorschach en alexitimia.

2.2.6. Obstáculos metodológicos que pueden limitar la validez de los estudios Rorschach en Alexitmia.

2.2.7. Propuesta de evaluación Rorschach de la alexitimia.

PARTE III: 2.3. Investigaciones y evaluaciones en la Artritis Reumatoidea (AR).

2.3.1. Evaluación de la Artritis Reumatoidea mediante las Escalas Toronto de Alexitimia (TAS y TAS-20)

2.3.2. Evaluación de la alexitimia en la Artritis Reumatoidea mediante el Rorschach, Sistema.Comprehensivo

PARTE IV 2.4. Síntesis de la Revisión del Estado de la Cuestión 


\section{PARTE I : 2.1. Alexitimia, Personalidad y Cultura.}

\subsubsection{El constructo Alexitimia y la personalidad.}

Como hemos expuesto en el capítulo anterior,Alexitimia (etimológicamente, ausencia de palabras para expresar emociones) es un constructo hipotético multidimensional formulado por P. Sifneos y P. Nemiah en 1973 para describir una compleja constelación de manifestaciones cognitivo-afectivas observadas en pacientes con enfermedades psicosomáticas. Algunas de sus características, como el llamado «pensamiento operatorio», habían sido estudiadas por otros investigadores previamente ( $\mathrm{P}$. Marty en 1963).

La alexitimia puede ser entendida también como un estilo cognitivo peculiar del lenguaje y los pensamientos. Actualmente, puede entenderse como «un déficit en la regulación de las emociones» (Taylor, 1987).

Los sujetos alexitímicos no se caracterizarían tanto por una incapacidad para experimentar o sentir los estados emocionales y expresarlos, sino más bien por una dificultad en diferenciarlos y verbalizarlos.

Acentuando que la alexitimia es también un trastorno comunicativo, F. Lolas (Lolas, 1981, 1997) reformuló el concepto de alexitimia como una ausencia de significados emocionales compartidos en situaciones reales, más que como una simple disminución de expresiones afectivas.

Ciertos autores (Freyberger, 1977) conciben a la alexitimia como una reacción o estado, pasajero o permanente, subsecuente a situaciones muy estresantes.

Algunas críticas han sostenido que la alexitimia puede simplemente ser explicada por diferencias sociales y culturales respecto de la expresividad emocional (Borens y col., 1977; Kirmayer, 1987; Prince, 1897; Prince, 1987), ( cuestión que analizaremos) o también por dificultades de comunicación específicas de la relación entre el médico y los pacientes (Musaph, 1974) citado por Parker (Taylor, Parker y Bagby, 1997). 
Otros consideran a la alexitimia como una defensa contra el conflicto neurótico (Hogan, 1995; Knapp, 1983; Wilson y Mintz, 1989) más que una forma de déficit afectivo, (como lo han propuesto, Sifneos (1994) y Nemiah (1977). Algunos incluso dicen «no acordar»o «no creer» en el concepto de alexitimia, equivocándose al no reconocer que los constructos no existen en el sentido de las cosas materiales, sino que representan hipótesis sobre las cuales los científicos del comportamiento se apoyan para explorar el pensamiento y la conducta humana (Wallace, 1988).

Dice J. Parker (1997: pág. 70) que dada la «plétora de medidas que han sido desarrolladas por los investigadores empleando el enfoque multitudimensional a la personalidad, no es sorprendente que ese amplio abanico de constructos haya sido usado para estudiar la alexitimia y su relación con la estructura de la personalidad. En algunas de las primeras investigaciones se encontró que la alexitimia no estaba relacionada con numerosos rasgos de la personalidad, entre ellos neuroticismo, ansiedad (rasgo), represiónsensitización y el patrón de conducta tipo A, propio de personalidades competitivas en exceso, (Fava, Baladro y Osti, 1980; Martín y Pihl, 1986; Mendelson, 1982; Schiraldi y Beck, 1988). Es probable, sin embargo, que esos resultados reflejen errores de medida más que las verdaderas relaciones entre la alexitimia y esos diversos rasgos de personalidad, puesto que la alexitimia fue medida con cuestionarios autoadministrados que posteriormente se supo- carecían de confiabilidad y validez, tales como el SSPS, la forma revisada del SSPS, y el MMPI-A».

Parker revisa, también, cuidadosos estudios de tipo prospectivo, que apuntaron a evaluar la relación de alexitimia con ansiedad y desórdenes depresivos. Estos estudios tienen particular importancia, pues indagan si la alexitimia evalúa aspectos de la neurosis o la depresión, o si constituye un único constructo de la personalidad. Se realizaron estudios antes y después de trascurrido un tiempo de tratamiento de los síntomas que requirieron atención. La ansiedad y la depresión disminuyeron luego de períodos considerables, por ejemplo seis meses, pero no hubo reducción en la media de alexitimia. Concluye: «La comparación de los puntajes de los test antes y después de los tratamientos mostraron reducciones estadísticamente significativas en ansiedad, rasgo, estado y depresión, pero no hubo cambio significativo en la media del puntaje de alexitimia» (Parker, Taylor y Bagby, 1997:pág. 73). Afirma que, como conclusión de otra cantidad de estudios realizados de modo prospectivo en pacientes adictos, pacientes con enfermedades médicas y pacientes 
psiquiátricos se constata que la alexitimia no es una respuesta secundaria simple que acompaña estados ansiosos o depresivos.

Se hicieron, también, como señalamos, investigaciones para establecer las relaciones entre alexitimia y el modelo de los tres factores de Eynseck, evaluados con el cuestionario de personalidad de Eynseck (EPQ). Revisando la cuestión de que en ciertas circunstancias no ha sido claro si la condición del estado influencia la respuesta con la cual se mide el rasgo, se podría esperar que los alexitímicos manifiesten una tendencia al distress emocional (como ansiedad y depresión) ya que la alexitimia, teorizada como un desorden de la regulación afectiva, refleja un déficit en los procesos cognitivos y regulación de las emociones (menciona a Lane y Schwartz, 1987). Por otra parte, uno podría esperar una relación inversa entre alexitimia y disforia si la alexitimia funcionara como una defensa, tal como numerosos investigadores sugirieron (p. 71). Prestemos atención al siguiente párrafo en la contribución de J. Parker: «A pesar de que los alexitímicos son capaces de informar distress (malestar emocional) cuando contestan a preguntas muy específicas, altamente estructuradas, en los cuestionarios autoadministrados (tales como el Inventario Beck de Depresión), los interrogatorios intensivos en las entrevistas clínicas revelan que ellos saben muy poco sobre sus propios sentimientos y en la mayoría de las instancias son incapaces de vincularlos con memorias, fantasías o situaciones especificas». La dificultad que experimentan las personas alexitímicas para distinguir entre diversos estados afectivos fue descripta en un estudio (p. $65^{1}$ ), que citamos por su interés.

La cita es $n^{\circ} 22^{1}$ Aunque la mayor parte del soporte de la validez del constructo alexitimia se basa en estudios de análisis factorial y correlacional para demostrar la validez consensual, se han realizado también enfoques experimentales. Estos son necesarios para predecir cómo diferirán las personas que obtengan un puntaje alto respecto de los que obtengan un puntaje bajo en la escala. Aplicando este enfoque plantearon la hipótesis de que "los individuos que puntuaran alto en la TAS deberían tener más dificultad para distinguir entre sus diferentes estados afectivos, que los que puntuaban bajo". Esta predicción fue evaluada mediante datos recolectados por M. Acklin en 131 pacientes referidos al servicio externo de psiquiatría en un gran hospital metropolitano en Honolulu, Hawai.

Acklin administró numerosas pruebas, entre ellas el POMS, que consiste en 65 ítems según una escala de 5 puntos, diseñada para medir 6 estados afectivos o de ánimo, derivados mediante análisis factorial. Ellos son: tensión-ansiedad; depresión-abatimiento (dejection); vigor-actividad; fatiga-inercia y confusión-perplejidad (bewilderment). Sólo las cinco emociones negativas se usaron en nuestro análisis. Consistentemente con nuestra predicción, los pacientes que puntuaron alto en el rango alexitímico (TAS26 $\geq 74 ; \mathrm{N}=54$ ) no mostraron variaciones significativas en la escala POMS, mientras que los pacientes en el rango no alexitímico $(\leq 62)$, mostraron diferencias significativas (Bagby et al., 1993). Los grupos no diferían en edad o en nivel de sintomatología y funcionamiento, tal como la evalúa el Eje 5 de la Escala Global de Funcionamiento DSMIII-R. 
Rubino confundió al Neuroticismo - una dimensión de la personalidad-con el desorden psiconeurótico - diagnóstico psiquiátrico-, y según expone J. Parker, ignoró una cantidad de estudios que sugerían la independencia de la alexitimia de la patología psiconeurótica. Finalmente, Parker (1997: pág. 72) sostiene que el análisis factorial de ítems combinados entre medidas de alexitimia y depresión aportó evidencia de que la alexitimia es un constructo separado y distinto del de depresión (Parker et al., 1991: a).

\subsubsection{Estado o rasgo.}

Para profundizar en los problemas enunciados, continuaremos respecto de su relación con la personalidad: la alexitimia, ¿se trata de un rasgo o de un estado?

Haremos referencia en este punto a la revisión exhaustiva realizada por M. Bagby y G. Taylor (1997), quienes señalan: «A pesar de que hay consenso sobre los rasgos clínicos y la definición del constructo alexitimia, ha habido controversia y debate respecto de si es o no un rasgo de personalidad estable, un estado transitorio asociado a la perturbación psicológica asociada con una enfermedad aguda o alguna otra situación estresante, o también una respuesta de afrontamiento frente a una enfermedad crónica» (citan a Ahrens y Deffner, 1986).

Se acepta la distinción entre alexitimia primaria (de origen biológico, para Sifneos) y alexitimia secundaria, sin lesión cerebral, pero igualmente duradera y que muestra funcionamientos estables en la personalidad.

Parecería, por otra parte, que la alexitimia puede ser considerada como una característica de intensidad variable, o como un estado transitorio del pensamiento y de las modalidades de expresión. También se ha descripto una forma secundaria, que aparece en pacientes con una situación de riesgo vital (diálisis, cáncer) y en situaciones de catástrofe.

(Continúa cita 22) Otro estudio investigó la predicción de que los alexitímicos diferirían de los que no lo son en la manera en que responden a los estímulos que activan emociones. La predicción sostenía que los alexitímicos, a causa de su reducida capacidad cognitiva de procesar las emociones, serían más distraídos y con menor capacidad de atender las tareas presentes. Se utilizó una forma modificada del test de nombrar los colores de Stroop (1935), y se comprobó que los alexitímicos fueron mucho más lentos para nombrar los colores asociados con emociones que el grupo no alexitímico, aunque no difirieron en su capacidad para nombrar colores emocionalmente neutros. Luego de enumerar otros estudios, concluyen que ellos pueden no sólo proveer soporte para el constructo alexitimia, sino que también ayudan a explicar la asociación entre alexitimia y ciertos desórdenes médicos y psiquiátricos. 
En estas condiciones, podemos pensar que es una respuesta adaptativa ante la angustia suscitada por el suceso traumático. Esta forma de la alexitimia puede ser transitoria, cuando es una reacción ante una enfermedad, o permanente, por ejemplo cuando es posterior a un suceso altamente traumático. Respecto de la controversia sobre si es un estado o un rasgo, Freyberger (1977) y otros, observaron constricción de la expresión emocional y de la actividad imaginativa en algunos enfermos clínicamente enfermos sujetos de hemodiálisis o transplante de órganos- y en otros que están transitoriamente sufriendo algún estado amenazante para la vida y se hallan en unidades de cuidados intensivos. Freyberger llamó a este fenómeno parecido a la alexitimia alexitimia secundaria, e informó que podía instalarse de modo permanente en pacientes cuya enfermedad se volvía crónica. Estudios recientes de pacientes sujetos a transplante de riñón o hemodiálisis han confirmado que el desarrollo de características alexitímicas no es infrecuente, como respuesta a estos procedimientos tan estresantes. Parece ser una estrategia protectora, mediante el empleo defensivo de la negación (Fukunishi, 1992; Fukunishi, Saito y Osaki, 1992b).

Sifneos $(1988,1994)$ utiliza el término alexitimia secundaria en un modo diferente del de Freyberger, y se refiere a las características alexitímicas resultantes de detenciones evolutivas, traumas psicológicos masivos -tempranos en la infancia o más tardíos en la vida-, factores socioculturales y psicodinámicos. La contrapone a la alexitimia primaria, que, como dijimos, atribuye a un déficit neurobiológico.

La etiología de la alexitimia probablemente implica múltiples factores, que incluyen variaciones constitucionalmente heredadas en la organización del cerebro y deficiencias tempranas en el medio familiar y social. Además, los traumas masivos no sólo pueden sobrecargar al yo e inducir una regresión del funcionamiento afectivo, sino que también afectan de modo durable cambios en la excitabilidad neuronal, que pueden contribuir a las manifestaciones clínicas de la alexitimia. También, las detenciones en el desarrollo o la regulación de los afectos en la temprana infancia generalmente se vuelven rasgos persistentes, que duran a lo largo de la vida.

Distinguiremos entre la alexitimia como rasgo estable, independientemente de la etiología, y la alexitimia como situacionalmente dependiente, que corresponde al concepto 
de alexitimia secundaria de Freyberger. Muchos estudios confirman que la alexitimia no es un estado, como a continuación revisaremos.

Una nueva tendencia en investigación con alexitimia se está imponiendo, cada vez con mayor fuerza: su relación con modelos de personalidad basados en rasgos. En esta línea de investigación Parker, Bagby y Taylor (1989) establecieron relaciones entre alexitimia y el modelo de tres factores de Eysenck, constatando que correlaciona positivamente con neuroticismo $(\mathrm{r}=0.29, \mathrm{p}<0.01)$, lo cual es congruente con las evidencias empíricas que plantean que tanto los individuos neuróticos como los alexitímicos, presentan altos niveles de somatización y disforia.

La alexitimia se correlaciona negativamente con el factor extraversión ( $r=0.37$, $p<0.01 ; r=0.35)$, mientras que para el psicoticismo la correlación fue positiva $y$ sensiblemente más baja $(r=0.17, p<0.05 ; r=0.19)$.

Cabe en este tema reconocer las diferencias entre el constructo alexitimia y los constructos Neuroticismo y Extraversión. Los neuróticos son típicamente muy estimulados fisiológicamente por toda clase de agentes y fácilmente expresan sus emociones. Los alexitímicos pueden también ser muy excitados fisiológicamente por una cantidad de estímulos, pero son menos capaces de identificar los propios sentimientos (el componente subjetivo de las emociones) y, por lo tanto, tienen más dificultades para expresar verbalmente sus estados emocionales. También, los introvertidos son típicamente muy pensativos e introspectivos con sus emociones, mientras que los alexitímicos tienden a estar preocupados con los eventos externos, y raramente sobre su vida interna subjetiva.

Debemos luego concluir que, si bien la alexitimia muestra alguna relación con $\mathrm{N}$ y E, esas dimensiones más amplias de la personalidad no captan algunos de los aspectos más específicos y cruciales del constructo alexitmia.

Usando el procedimiento de indicadores de adecuado ajuste (goodness of fit indicators) recomendados por Cole, dicen los autores que venimos citando (Parker y Taylor, 1997: 75) que el análisis factorial confirmatorio indicó que la alexitimia se 
relaciona moderadamente con $\mathrm{N}$, inversamente con $\mathrm{E}$ y levemente con P. Esto da sostén adicional para afirmar que el constructo alexitimia es relativamente distinto de N, E y P.

Una información complementaria que correlaciona la Escala Toronto de Alexitimia (TAS-20) y la Escala de sentimientos positivos (PFS), dice que mientras los alexitímicos muestran tendencia a experimentar afectos negativos y sólo mínimamente los positivos, de modo consistente con el constructo teórico, tienden a no comunicar sus sentimientos a otras personas. En consecuencia, quedan privados de la regulación afectiva que pueden proveer las relaciones interpersonales significativas.

Prosiguiendo con el tema citamos a Carmen Velasco (Páez, Casullo, 2000), quien examina la relación entre alexitimia y personalidad. Revisará distintas teorías en función de los rasgos y abordará la relación entre el modelo de los cinco factores de la personalidad (Big Five), en particular el neuroticismo y la extraversión, con la alexitimia. Además, aludirá a la relación entre alexitimia y otras variables de personalidad vinculadas a la inhibición emocional y la represión.

El concepto de personalidad, dice, es evasivo y con múltiples definiciones. Actualmente la psicología de la personalidad aporta una visión complementaria a la de la psicología social. Los autores explican la personalidad en función de una o varias cualidades, haciendo abstracción del individuo que las posee y de los factores que la determinan, estas cualidades se llaman rasgos. Un rasgo es toda cualidad o factor de la personalidad que tiene la propiedad de ser relevante, principal, característico, estable y diferenciador (Quintana, 1996, citado por Páez y Casullo, 2002). La clasificación se hace sobre los rasgos, no sobre los individuos.

Los análisis de rasgos suponen que los individuos difieren en variables o dimensiones continuas. Dado que los rasgos son cualidades de los seres, cada uno tiene su opuesto.

Si vamos a hacer una aproximación a la personalidad según sus rasgos, ¿cuáles son los más importantes? Distintos autores, de los cuales veremos los principales, han hecho sus propuestas. 
Se pueden observar dos corrientes distintas: teorías derivadas del criterio léxico las que se basan en el análisis del conjunto de adjetivos de un idioma determinado que permiten describir a los sujetos y otras teorías que se interesan especialmente en la conducta manifiesta, en el comportamiento de los individuos. Por ejemplo, el modelo de Catell, uno de los primeros, tuvo como objetivo esencial, desde el enfoque léxico, la determinación del número y la naturaleza de las dimensiones fundamentales que subyacen a la personalidad y se expresan en el lenguaje.

Las teorías basadas en el léxico se iniciaron con los trabajos de Allport y Odbert (1936) y, posteriormente, con Catell (1943, 1945, 1947, 1975). El lenguaje es una fuente fructífera de información sobre la existencia de rasgos. La importancia de un rasgo se evidencia a través de un número de palabras que lo describen. Catell, luego de someter datos de miles de sujetos a análisis factoriales, afirmó que la esencia de la personalidad puede ser determinada a través de un conjunto de 16 factores básicos. Estos factores fueron plasmados en un inventario o instrumento conocido con el nombre de 16PF (Catell, Eber y Tatsuoka, 1980).

Eysenck (1967, 1975, 1985), como Catell, intentó diseñar un modelo de personalidad, pero se alejó del criterio léxico. Se basó en las tipologías de Hipócrates y Galeno, en teorías de Jung y Wundt, y se apoyó en constructos biológicos (combinación de distintos niveles de rasgos). Cada tipo está relacionado con diferentes aspectos del sistema nervioso y está integrado por rasgos. Presupone que las tipologías podrían ser el resultado de la combinación de distintos niveles de dos rasgos de orden superior, denominados introversión-extraversión (E) y emocionalidad-estabilidad $(\mathrm{N})$, situados en la cima de una jerarquía de cualidades.

Describió también una tercera dimensión de personalidad denominada psicoticismo $(\mathrm{P})$, que ha recibido menor atención por parte de los investigadores. Se lo conoce como el modelo de los tres factores. Respecto de la asociación de la alexitimia y el cuestionario de personalidad $\mathrm{EPQ}^{2}$, se encontró una asociación positiva entre alexitimia y $\mathrm{N}$, lo cual sostienen J. Parker y G. Taylor (1997: 73): «es consistente con la evidencia clínica y

\footnotetext{
${ }^{2}$ Evalúa las dimensiones N: Neuroticismo; E: Extraversión y P: Psicoticismo.
} 
empírica de que tanto las personas neuróticas como las alexitímicas tienden a la somatización y a la disforia (humor negativo). También los hallazgos de asociación negativa entre alexitimia y E no es sorprendente, ya que los alexitímicos y las personas introversivas tienen dificultad en comunicar los sentimientos a las otras personas y son habitualmente vistos por los demás como distantes»». Si bien la alexitimia está asociada positivamente con neuroticismo, convendría distinguir este factor de la personalidad del trastorno psicopatológico.

A finales de los años sesenta, el desarrollo de la psicología de la personalidad se detuvo en forma abrupta debido a la falta de consenso en las dimensiones básicas subyacentes, e incluso se cuestionó hasta la validez del concepto de rasgo.

Esta crisis terminó, en los países anglosajones, hacia finales de los años setenta. En los ochenta emergió un consenso cada vez más fuerte, que propone la existencia de cinco factores, llamado Big Five.

Los estudios interculturales han podido comprobar la generalidad del modelo a partir de la administración del cuestionario que los evalúa, en seis muestras de diferentes idiomas (alemán, portugués, hebreo, chino, coreano y japonés). La obtención de factores idénticos en diferentes muestras, es un sólido apoyo empírico a la idea de una estructura universal de la personalidad.

\subsubsection{Alexitimia y mecanismos de defensa.}

En psicoanálisis, el concepto de mecanismo de defensa fue originalmente desarrollado por Freud (1926), y refinado por su hija Ana Freud. Posteriormente H. Hartmann (1939), representante de la Psicología del Yo, destacó los aspectos adaptativos de las defensas. Los mecanismos de defensa consisten en operaciones psíquicas inconcientes movilizadas para manejar afectos y evitar la experiencia de angustia provocada por el conflicto psíquico, traumas, etcétera.

Según Vaillant ( Vaillant 1994: (1994: pág. 44). 
las defensas se contraponen a los efectos negativos de los estados afectivos, permitiendo al sujeto «reducir la disonancia cognitiva y minimizar cambios súbitos en la realidad psíquica (medio interno) y en el medio externo, alterando cómo se los percibe»

Como representante de la Teoría de Relaciones Objetales, O. Kernberg (1977, 1979, 1989) propone el funcionamiento defensivo como uno de los ítems a tener en cuenta en los llamados Criterios de diferenciación Clínica para el Diagnóstico Estructural de la Personalidad. El nivel defensivo evolucionado refiere a un aparato psíquico que se ha organizado con el funcionamiento de la represión y defensas auxiliares como racionalización, intelectualización, formación reactiva, aislamiento, etcétera, diferenciando el campo de las neurosis. Las llamadas defensas primitivas, en cambio, reguladas por la escisión: idealización, devaluación, proyección, identificación proyectiva, acting-out y negación de bajo nivel, revelan el territorio de organizaciones estructurales de la personalidad con la identidad menos integrada, como las estructuras Borderline y Psicóticas.

Las defensas maduras o evolucionadas están relacionadas con una representación más diferenciada de sí mismo (self) y del mundo, en la cual la organización cognitiva puede formar transformaciones simbólicas de los propios deseos, emociones y pensamientos, y simultáneamente, también de representaciones complejas y diferenciadas de los otros significativos. Las personas con defensas evolucionadas pueden gozar de relaciones interpersonales estables, satisfactorias y de mejor salud que las que tienen organización defensiva primitiva o inmadura.

En nuestra revisión sobre cuadros psicosomáticos hemos citado a varios autores, entre ellos Winnicott ${ }^{3}$, que señalaban la presencia de la defensa primitiva de escisión (disociación) entre la mente y el cuerpo. Tal comprensión de los cuadros los situaría claramente dentro de las personas con estilos de defensa inmaduras. Es Kuchenoff (1993, citado por J. Parker y G. Taylor (Taylor et al., 1997: 89) quien relaciona específicamente la alexitimia con la defensa de «negación primitiva», similar al concepto de escisión (foreclosure) de Freud (1918), definida por Kuchenoff como «la exclusión radical de la experiencia intrapsíquica, de insoportables afectos y pensamientos». Explica: «tal

\footnotetext{
${ }^{3}$ Capítulo 1.
} 
exclusión de la representación psíquica origina una sobrecarga psíquica que no puede ser simbolizada».

Incorporando las contribuciones de Dorpat (1985: 104, citado por J. Parker y G. Taylor (Taylor et al., 1997: 89)): «Esta defensa primitiva impide la formación de las representaciones verbales de las experiencias y podía muy bien dar cuenta del déficit psíquico estructural y de muchos de los rasgos clínicos asociados con el constructo alexitimia. Éstos incluyen la ausencia de los afectos normales y de las representaciones objetales, ausencia de sueños diurnos de realización de deseos y tendencia a actuar o repetir, más que a recordar, experiencias afectivas tempranas que quedan codificadas como esquemas sensoriomotrices, organizadas en un nivel preconceptual».

Estas teorizaciones muy consistentes han sido sometidas a validación experimental, tropezando con la dificultad de instrumentos evaluativos suficientemente válidos para evaluar el funcionamiento defensivo y su nivel. Dentro de los estudios de correlación más confiables, como síntesis de las investigaciones realizadas por numerosos investigadores, se halló que la alexitimia está positivamente asociada con defensas inmaduras o maladaptativas, y negativamente asociada con defensas adaptativas o maduras (Wise, Mann, Epsten, 1991). Resultados similares fueron informados por Schaffer (1993). J. Parker y G. Taylor informan que sus resultados, que correlacionan la TAS-20 con el DSQ (Cuestionario de Defensas de Andrews), demuestran que la alexitimia se correlaciona fuertemente con defensas inmaduras $(\mathrm{r}=0.55 \mathrm{p}<0.01)$; débilmente con el factor de defensa neurótico $(\mathrm{r}=0.23 \mathrm{p}<0.01)$ y negativamente con el de defensas maduras $(\mathrm{r}=-0.25<0.01)$.

Los individuos alexitímicos tienden a utilizar estilos de defensa inmaduros como la negación, la evitación y la externalización y Kuchenhoff (1993) ha vinculado la alexitimia con el concepto de «negación primitiva», definida en términos de la exclusión radical de la experiencia subjetiva de pensamientos y afectos altamente estresantes.

Existen dos vías de acceso para la comprobación empírica de la relación entre alexitimia y mecanismos de defensa. La primera, representada por Bond (1983), quien elaboró un instrumento denominado Defense Style Questionnaire (DSQ), en el que aparecen operacionalizadas cuatro dimensiones:

a) Patrones de acción inadaptada (abandono, regresión, acting out, inhibición, agresión pasiva y proyección). 
b) Estilos de defensa basados en la distorsión de la imagen (omnipotencia, escisión e idealización primitiva).

c) Estilos de defensa basados en el autosacrificio (formación reactiva y seudoaltruismo).

d) Estilos de defensa adaptativos (supresión, sublimación y sentido del humor).

Andrews y col. (1989) recategorizaron dichas dimensiones, y los datos obtenidos permitieron comprobar la existencia de tres estilos de defensa: maduro, inmaduro y neurótico. Utilizaron el instrumento descrito junto con la Escala TAS y encontraron que la alexitimia se correlaciona positivamente con el estilo de defensa inmaduro.

La segunda vía de acceso a la comprobación empírica del nivel defensivo se basa en la operacionalización del concepto de represión planteada por Bonano y Singer (1990). Según estos autores, la represión es fundamentalmente un estilo de funcionamiento que se evalúa a través de dos instrumentos (el Inventario de Deseabilidad Social y la Escala de Ansiedad Manifiesta de Taylor). Sobre la base de este marco teórico se ha encontrado que alexitimia y represión son dos conceptos diferenciados aun cuando compartan la pobreza de la vida imaginaria y el pensamiento concreto, lo que limita el trabajo afectivo y es factor de riesgo de enfermedades psicosomáticas.

Prosiguiendo con el estudio de las defensas y la alexitimia, y en relación con la posibilidad de que el modelo del conflicto neurótico (Freud, 1898) pueda explicar la alexitimia, es necesario señalar que en las sesiones psicoterapéuticas de los pacientes alexitímicos es observable clínicamente la carencia de vivencia de conflicto asociada a sus síntomas generalmente somáticos. Se ha informado, y es observable en las entrevistas, una asociación entre alexitimia y el uso de defensas «inmaduras» o primitivas. Cabe mencionar que más que constituir una crítica al constructo alexitimia, justamente, los mecanismos defensivos primitivos emergen cuando: $a$ ) hay una ausencia o fracaso de niveles más elevados de operaciones defensivas, y $b$ ) con el propósito de regular emociones intensas y disruptivas que no se hallan completamente representadas en la mente y permanecen organizadas en un nivel preconceptual.

Focalizándonos sobre las relaciones entre represión, inhibición y alexitimia, se concibe la represión como un estilo de evitación o de no-confrontación con hechos 
estresantes, y como una inhibición de la reacción afectiva. En este sentido, la emoción define el campo de estudio de la represión, ya que permite observar si se expresa y cómo lo hace. Así, los procesos expresivos se inhiben o alteran. Un individuo puede experimentar una emoción y no expresarla.

El concepto de represión es muy cercano a uno de los componentes de la alexitimia, dada su incapacidad para describir emociones, los alexitímicos tienden a hablar menos sobre sus emociones, en particular, las negativas.

El déficit del procesamiento cognitivo de los sucesos emocionales está asociado con conductas de evitación, imágenes intrusivas, pensamientos repetitivos, revivir las emociones negativas y trastornos en la salud. A menudo, estos rasgos hacen que se describa a los alexitímicos como «personas inhibidas».

Junto con el estudio de las defensas en tanto procesos intrapsíquicos nos interesan particularmente la intervención de otras variables, del macrocontexto, por ejemplo, la relación entre alexitimia, nivel socioeconómico y educación.

Nos vamos a ocupar a continuación de estas relaciones, así como de estudiar de qué manera la cultura interviene en el desarrollo de alexitimia. Dicen los autores consultados que: «Considerando o dando por aceptado que la inteligencia del niño y su medio social y familiar influencian el desarrollo de las habilidades léxicas y la expresividad emocional verbal, se podría esperar que la alexitimia muestre alguna asociación con la inteligencia, el nivel educacional y el status socioeconómico. Investigaciones preliminares sobre la relación de la alexitimia y esas variables han mostrado escasa o baja asociación con el nivel socioeconómico bajo, bajo nivel educativo y baja inteligencia (Kauhanen y col., 1993; Kirmyer y Robbins, 1993; Parker, Taylor y Bagby, 1989b).

No hay duda de que la expresión verbal de las emociones está también influenciada por las actitudes culturales prevalecientes y por las limitaciones impuestas por ciertos lenguajes (Leff, 1977; Mesquita y Frijda, 1992). Parecería, sin embargo, que los procesos imaginarios constreñidos característicos de la alexitimia no podrían explicarse meramente por influencias culturales. Existe evidencia preliminar sobre que la alexitimia no es un constructo surgido culturalmente. Tal conclusión se basa en los informes de alexitimia en poblaciones clínicas y no clínicas en diversas culturas y por la exitosa validación intercultural de la evaluación del constructo mediante cuestionario autoadministrado, en países como Italia, India, Japón y Corea. (Bagby y Taylor, 1997:36). 


\subsubsection{Alexitimia y Cultura.}

Si bien incorporaremos la información que han aportado otros investigadores sobre este interesante tema, vamos a presentar en los tópicos de nuestro interés lo desarrollado en el texto más exhaustivo y actualizado disponible: Paéz y Casullo (2000).

Los autores plantean que la mayor parte de las características más salientes de la experiencia emocional son externas e interactivas.

Cuando las culturas se convierten en individualistas, la expresión emocional evoluciona, mediante la combinación de experiencias corporales y psicológicas, hacia un lenguaje afectivo en el que las personas expresan síntomas psicológicos altamente diferenciados.

Se puede considerar que las culturas individualistas poseen un léxico emocional muy elaborado cognitivamente, o altamente diferenciado.

Las clases populares se caracterizan por una subcultura más colectivista, un lenguaje más contextual, menos psicologista y una expresión somatizada de las emociones.

Las investigaciones han encontrado una relación negativa entre el status social de clase baja y la alexitimia. Por lo tanto, la orientación hacia los hechos externos, un estilo de pensamiento concreto, poco mentalista de las clases populares y menos educadas, parece reforzar la expresión somatizada de las emociones.

El colectivismo cultural se asocia a una menor frecuencia de los aspectos subjetivos o mentales de las emociones básicas.

Acerca de cómo la cultura influye en la expresión verbal de las emociones, dicen que la tradición confuciana y taoísta asiática valora la comunicación indirecta, contextual y alerta en cambio, contra la verborrea. Mencionan en el texto que citamos, el dicho confuciano: «El hombre superior actúa antes de hablar y habla luego de acuerdo con sus acciones». El colectivismo y la expresión verbal poco elaborada de las emociones no son sólo específicos de las culturas asiáticas, sino que caracterizan también a las clases populares de las sociedades occidentales.

Darío Páez, Itziar Fernández y Sonia Mayordomo (Páez y Casullo, 2000), se preguntan: si existen culturas alexitímicas? y para tal indagación, examinan cómo las diferencias culturales respecto de distintos valores se asocian a los rasgos de personalidad vinculados a la alexitimia. Investigan valores tales como la distancia al poder, el desarrollo lingüístico, el carácter colectivista de la sociedad, la expresión somática o mental y 
psicológica de las emociones, etc. y rasgos de la personalidad como la extraversión, el neuroticismo y la apertura a la experiencia.

Habíamos ya por nuestra parte visto en el Capítulo 1, que la alexitimia se asocia negativamente con la extraversión y la apertura a la experiencia, y positivamente, con el neuroticismo. Las relaciones del neuroticismo y la extraversión con las dimensiones de la alexitimia son, sin embargo, complejas. Los sujetos extravertidos tenderán más a socializar y a hablar sobre sus emociones, al menos las positivas. Los sujetos introvertidos reflexionarán más sobre sus emociones, en particular sobre los aspectos internos, mientras que ocurre lo inverso con los alexitímicos.

El neuroticismo se define como una dimensión de personalidad caracterizada por la tendencia a experimentar emociones negativas. Los sujetos neuróticos tienden más a hablar sobre sí mismos, en particular, sobre sus emociones negativas, mientras que los alexitímicos tienden a hablar menos sobre sus emociones, en particular las negativas.

Así, la alexitimia se asocia con una mayor tendencia a experimentar ansiedad, depresión y vergüenza. Entonces, la relación de la alexitimia con el neuroticismo y la extraversión se daría en el área de la vivencia afectiva.

Luego de comparar las naciones mediante tests de personalidad, como la Escala de Alexitimia Toronto (TAS-20) y el Cuestionario de Personalidad de Eysenck (EPG), y sin olvidar que las investigaciones de personalidad tienen la limitación intrínseca de haber sido escalas elaboradas por Occidente, concluyen que: $a$ ) hay diferencias entre naciones en la expresión somática o psicológica de las emociones, y b) hay covariación entre el escaso desarrollo lingüístico y la vivencia somática de las emociones.

Analizando ahora la relación entre cultura y diferenciación entre síntomas físicos y emociones, exponen que existe relación entre la riqueza del lenguaje y el desarrollo cognitivo de la vivencia emocional.

Veamos unos ejemplos: los tahitianos disponen de pocas palabras y escasas frases para la emoción de tristeza. En algunas culturas, algunas emociones están 
hipocognitivizadas o subdesarrolladas. Así sucede también en los inuit. Las personas de esas culturas son incapaces de articular claramente sus sentimientos y de asociar sus reacciones físicas con la pérdida o el fracaso. La falta de «léxico emocional» en algunas culturas y el evitar hablar sobre ciertas emociones, lleva a que éstas se expresen somáticamente y de forma poco articulada.

Concluyen, diciendo, que la falta de expresión verbal provocaría no sólo una expresión somática sino también una baja intensidad emocional.

Proceden luego a analizar la relación entre tipos de culturas - por ejemplo las colectivistas- y la expresión somática o verbal de las emociones. Informan que la diferenciación entre síntomas físicos y sentimientos generalmente no está presente en las culturas no-occidentales. La expresión somática de las emociones es mayoritaria en todas las culturas no-occidentales. Por ejemplo, dicen, las culturas asiáticas de tipo colectivista, en las que habita casi la mitad de la población mundial, enfatizan o subrayan la existencia de un lenguaje somático para el dolor o malestar emocional o, dicho de otro modo, se desarrollan cognitivamente de forma deficitaria los atributos internos de la emoción.

Según su revisión, la cultura china tradicional de tipo colectivista se caracterizaría por presentar la primera «faceta» de la alexitimia, es decir, la expresión somática de las emociones y la baja elaboración intrapsíquica de ellas.

El carácter colectivista de la cultura china desvía la atención y desvaloriza la vida interna del sujeto, orientándolo hacia los aspectos interpersonales, lo cual explica la baja elaboración psicológica de las emociones.

Las culturas colectivistas subrayan la importancia de las relaciones interpersonales. Los roles sociales y la pertenencia grupal constituyen la base de la identidad personal. Así la mayor parte de las características más salientes de la experiencia emocional son externas e interactivas.

La expresión verbal poco elaborada de las emociones no es sólo específica de las culturas asiáticas, sino que caracteriza también a las clases populares de las sociedades occidentales. 
Prosiguiendo con el estudio de la clase social, relatan que las clases altas de las sociedades occidentales presentan un lenguaje psicologista y se caracterizan por presentar un mayor individualismo. En las clases altas predomina un lenguaje inferencial e internalizado. Los años educativos proveen a las personas del vocabulario necesario para hablar mejor sobre las emociones.

Algunos autores señalan, sin embargo, que la somatización y la baja verbalización no implican automáticamente un déficit de razonamiento psicológico.

Los autores citados continúan, analizando otra dimensión cultural que puede afectar la expresión verbal de las emociones: la distancia jerárquica. En las culturas en las que ésta es mayor, se verifica una distancia emocional importante que separa a los subordinados de las autoridades.

La prohibición de hablar sobre temas afectivos personales se extiende hasta la propia familia, en las culturas de gran distancia con el poder y en las culturas colectivistas asiáticas, en las que el silencio es una forma de expresión de la armonía familiar y social (Kirmayer, 1987).

Dos culturas asociadas a una gran distancia jerárquica, en mayor medida que en el colectivismo, son la china y la india. La china se caracteriza por la supresión y la inhibición de emociones fuertes que amenacen al orden social. Al respecto indican que los niños y adolescentes presentan menos síntomas agresivos y conductas antisociales que en Occidente. En la cultura india, el control social de la sexualidad y de la conducta social es fuerte; las reglas de conducta india no sólo implican no mezclarse con castas inferiores, sino que también proscriben las faltas de respeto ante los mayores y los excesos emocionales, ya sean eróticos, agresivos, de miedo o de ansiedad. Los padres se manifiestan distantes respecto a sus hijos y se prohíben las manifestaciones afectivas fuertes. Los niños presentan una gran fijación en la figura materna, que es la fuente de afectividad. Concluyen que se basan en la supresión y no en el afrontamiento de los conflictos emocionales. Las sociedades caracterizadas por una gran distancia jerárquica presentan menor expresión emocional y menores reacciones mentales relacionadas con la 
tristeza y el enojo. Lo mismo ocurre con los países de cultura masculina, colectivista y de bajo nivel de incertidumbre.

La alexitimia secundaria es mayor en culturas colectivistas y con una gran distancia al poder; en ellas se comprueba una menor expresión verbal.

Finalmente, Darío Páez, Itziar Fernández y Sonia Mayordomo proponen que la distancia al poder se asocia con el rechazo a la vivencia emocional intensa y al malestar afectivo, por lo que se puede decir que las culturas de mayor distancia se caracterizan por un «ethos alexitímico».

Respecto del examen de diferencias según género, cultura y alexitimia, plantean que la dimensión masculinidad-feminidad cultural hace referencia al énfasis relativo a la armonía y a la comunión interpersonal que caracteriza al género femenino. Una consecuencia de los valores culturales femeninos es la obligación de proveer soporte emocional. La llamada feminidad cultural se vincula a una mayor expresión verbal de las emociones.

Contrapuestamente, en lo referente a la dificultad para distinguir entre sentimientos y sensaciones corporales, las mujeres presentan un déficit importante, mientras que los hombres detectan los cambios fisiológicos de forma más acertada y utilizan los síntomas fisiológicos internos para determinar cómo se sienten. Confirmando esta idea, refieren que una investigación transcultural que utilizó la TAS-20 con muestras de ocho países confirmó que las mujeres muestran mayor dificultad para diferenciar las sensaciones físicas de los sentimientos que los hombres. Sin embargo esta «superioridad» de los hombres varía de forma importante entre los países.

Con respecto a la dificultad para hablar y describir los sentimientos, la literatura sobre el tema plantea que los hombres presentan un mayor déficit.

Utilizando las puntuaciones de la TAS-20 en los ocho países, se encontró que, en general, las mujeres mostraban menor déficit en lenguaje emocional. Sin embargo, esta diferencia era heterogénea culturalmente y no significativa. 
Los hombres hablan más sobre los hechos y las mujeres sobre las relaciones. Los hombres expresan más actitudes orientadas hacia la tarea (por ejemplo, ensayar o intentar resolver la tarea), mientras que las mujeres presentan actitudes más emocionales (por ejemplo, ofrecer soporte social).

Comparando las medias de hombres y mujeres en ocho países en la dimensión de pensamiento operatorio de la TAS-20, se confirmó de forma homogénea que los hombres presentan niveles superiores de pensamiento orientado hacia lo externo y concreto (media=18.6) con respecto a las mujeres (media=16.65). Este resultado, afirman, es homogéneo y estable culturalmente (Páez, Martínez-Sánchez y col., 1999).

Síntesis de la evidencia empírica, según los autores mencionados:

a) Estudios etnográficos y de psiquiatría transcultural sugieren que el subdesarrollo lingüístico de una emoción se asocia a su expresión somática. También, un hiperdesarrollo lingüístico se puede asociar a la inhibición de la intensidad emocional.

b) Existen elementos que apoyan la idea de una asociación entre colectivismo, y una menor capacidad para identificar y diferenciar los sentimientos internos y un déficit de elaboración cognitiva sobre ellos.

c) La somatización y la baja verbalización no implican automáticamente un déficit de razonamiento psicológico. En la mayoría de las culturas del mundo no occidental, predomina un lenguaje somático, y ello no implica automáticamente una menor elaboración cognitiva de las emociones.

d) Hay datos que confirman que las personas pertenecientes a culturas con gran distancia al poder hablan menos sobre sus emociones, lo cual se explicaría debido a la existencia de normas de rechazo de las emociones tanto negativas, como positivas. 
e) La masculinidad se asocia con algunos rasgos de la alexitimia, tales como la menor expresión verbal, las reacciones psicológicas menos marcadas y el malestar afectivo. Los hombres presentan una mayor puntuación en «pensamiento operatorio» y ello es estable en las diferentes culturas. La diferencia entre hombres y mujeres no es sistemática en la expresión verbal de las emociones y la «superioridad» femenina en la comunicación verbal de las emociones se invierte en las culturas de gran distancia al poder y más colectivistas, como la cultura india.

\subsubsection{Perfil Alexitímico.}

Trazamos este perfil con el ánimo de diseñar las características sobresalientes de los alexitímicos y facilitar su registro. Como todo perfil solamente denota, pero no comprende la inmensa variedad de las formas de presentación propias de las subjetividades. Esto implica que las características que a continuación enunciaremos no sólo pueden expresarse en intensidades variables, sino que pueden ofrecer, según los casos, distintas formas.

Globalmente, el perfil de los sujetos que presentan altos niveles de alexitimia se caracteriza por:

a) Actividad imaginaria y de fantasía empobrecida. Fracaso en el recuerdo de sueños.

b) Dificultad para distinguir entre emociones, sensaciones y sentimientos, es decir, de diferenciar entre fenómenos fisiológicos y psicológicos.

c) Escasa comunicación de sus estados afectivos.

d) Altos niveles de ansiedad cognitiva, fisiológica, motora y depresión, que se expresa clínica e interpersonalmente, pero escasamente reconocida por el sujeto, dada su poca autoconciencia. 
e) Tendencia a excluir la comunicación de sentimientos negativos relacionados con su reactividad emocional.

f) Limitada capacidad para la introspección, particularmente en interrogarse a sí mismos sobre qué sienten y piensan.

g) Dificultad marcada y resistencia a técnicas psicoterapéuticas derivadas de la práctica psicoanalítica que promueven la introspección.

h) Presencia de síntomas físicos.

i) Pobre capacidad para la empatía en las relaciones interpersonales.

j) Relaciones sociales poco espontáneas, rutinarias y rígidamente orientadas por los roles sociales prescriptos.

k) Alto grado de conformismo social. Sumisión a los estereotipos culturales.

1) Patrón de actividad y expectativas orientado hacia tareas concretas y el locus de control externo.

m) Utilización de formas evitativas de afrontamiento. 
n) Carencia de la vivencia de conflicto personal asociada a sus síntomas generalmente somáticos: es el órgano o su funcionamiento los que tienen los problemas.

\subsubsection{Resumen.}

La alexitimia no es una respuesta secundaria simple que acompaña estados ansiosos o depresivos.

A pesar de que los alexitímicos son capaces de informar su malestar emocional cuando contestan preguntas muy específicas, ellos saben muy poco sobre sus propios sentimientos y en la mayoría de las instancias son incapaces de vincularlos con memorias, fantasías o situaciones específicas de sus vidas.

Usando el procedimiento de indicadores de adecuado ajuste, el análisis factorial confirmatorio indicó que la alexitimia se relaciona moderadamente con $\mathrm{N}$, inversamente con E y levemente con P. Esto da sostén adicional para afirmar que el constructo alexitimia es relativamente distinto de Neuroticismo, Extraversión y Psicotismo. Debemos luego concluir que si bien la alexitimia muestra alguna relación con $\mathrm{N}$ y E, estas dimensiones no captan algunos de los más específicos y cruciales aspectos del constructo alexitmia.

Si bien la alexitimia está asociada positivamente con neuroticismo, convendría distinguir esa dimensión de la personalidad del trastorno psicopatológico.

Los sujetos neuróticos tienden más a hablar sobre sí mismos, en particular, sobre sus emociones negativas, mientras que los alexitímicos tienden a hablar menos sobre sus emociones, en particular las negativas. Los sujetos introvertidos reflexionarán más sobre sus emociones, en particular sobre los aspectos internos, mientras que ocurre lo inverso con los alexitímicos.

Ha sido posible verificar la vinculación entre la presencia de características alexitímicas y algunos mecanismos de defensa yoicos primitivos, como la negación, la disociación y el acting-out. Se halló a la alexitimia relacionada con mecanismos defensivos 
inmaduros o primitivos. Alexitimia y represión son dos conceptos diferenciados aun cuando compartan la pobreza de la vida imaginaria y el pensamiento concreto.

La alexitimia aparece asociada con estrategias de afrontamiento (coping) relacionadas con la evitación cognitiva, emocional y conductual.

Se puede considerar que las culturas individualistas poseen un léxico emocional muy elaborado cognitivamente o altamente diferenciado. Las investigaciones han encontrado una relación negativa entre el status social de clase baja y la alexitimia. La orientación hacia los hechos externos, un estilo de pensamiento concreto, poco mentalista de las clases populares y menos educadas, parece reforzar la expresión somatizada de las emociones.

Los años educativos proveen a las personas el vocabulario necesario para hablar mejor sobre las emociones. Existe relación entre la riqueza del lenguaje y el desarrollo cognitivo de la vivencia emocional. Sin embargo, las investigaciones preliminares, realizadas con las Escalas Toronto de Alexitimia, sobre la relación de la alexitimia y esas variables han mostrado escasa o baja asociación con el nivel socioeconómico bajo, bajo nivel educativo y baja inteligencia.

Se señala que la somatización y la baja verbalización no implican automáticamente un déficit de razonamiento psicológico de las emociones, éste último sí propio de la alexitimia.

Con respecto a la dificultad para hablar y describir los sentimientos, la literatura sobre el tema plantea que los hombres presentan un mayor déficit. En la dimensión «pensamiento operatorio» de la alexitimia, los hombres obtienen puntajes significativamente más altos. La alexitimia no es resultante sólo de las diferencias culturales en la expresividad emocional: este resultado es homogéneo y estable culturalmente.

El colectivismo y la expresión verbal poco elaborada de las emociones no son sólo específicos de las culturas asiáticas, sino que caracterizan también a las clases populares de las sociedades occidentales.

La alexitimia, entonces, es un rasgo de personalidad que refleja un déficit en la regulación de los afectos, los cuales no se diferencian adecuadamente y, por ende, no se 
comunican. Se asocia a una menor capacidad para vivenciar emociones positivas, menor extraversión y mayor presencia de malestares con características neuróticas. Un alexitímico no es una persona completamente introvertida, tampoco es un sujeto definidamente neurótico, ya que este rasgo de personalidad supone poder verbalizar los sentimientos negativos.

Las personas alexitímicas muestran una frecuencia alta de activación displacentera indiferenciada que no pueden simbolizar en palabras.

\section{PARTE II 2. 2 La Evaluación de la Alexitimia}

\subsubsection{Instrumentos de evaluación de la alexitimia. Desarrollo de la Escala}

\section{Toronto de Alexitimia TAS (TAS26) y de la TAS-20.}

Como es esperable, formando parte de los requerimientos propios de las metodologías científicas, se volvió necesario demostrar la validez del constructo hipotético alexitimia. Mencionaremos algunos de los principales instrumentos elaborados para facilitar una evaluación sistemática y estandarizada del constructo, en diversas muestras empíricas, son: el Cuestionario Psicosomático del Hospital Beth Israel (BIQ), desarrollado por Sifneos en 1973; el Cuestionario de Respuesta Alexitímica provocada (APRQ), de Krystal, Giller y Cichetti; la escala de Alexitimia del MMPI (Minnesota Multiphasic Personality Inventory) y la Escala de personalidad Schalling-Sifneos (SSPS). Dentro de las clásicamente llamadas «técnicas proyectivas» ${ }^{4}$ se estudiaron principalmente respuestas a ciertas láminas del TAT (Thematic Aperception Test), al SAT (Scored Archetypal Test) y al test conocido como «de las manchas de tinta»: el Rorschach. Nos referiremos específicamente a este último más adelante.

\footnotetext{
${ }^{4}$ Las técnicas proyectivas consisten en pruebas que facilitan el despliegue de los múltiples aspectos de la personalidad, permitiendo ponderar la interacción de tanto los aspectos conflictivos y patológicos como de los adaptativos. Son tanto cuantitativas como cualitativas. Las técnicas objetivas usualmente restringen su evaluación a alguna dimensión y aptitud del individuo y sus resultados son cuantitativos.
} 
A continuación haremos una revisión de los diversos instrumentos de evaluación del constructo desarrollados a partir de los años setenta:

a) Dentro de los instrumentos de exploración, podemos mencionar:

\section{- $\quad$ Beth Israel Hospital Psychosomatic Questionnaire (BIQ)}

El BIQ fue desarrollado por Sifneos (1972), basándose en observaciones clínicas sobre las diferencias en el estilo afectivo de los pacientes con trastornos afectivos y psicosomáticos, con el objeto de proporcionar una medida estandarizada de alexitimia. Es un cuestionario de 17 ítems completados por un entrevistador en el curso de una sesión. Obtuvo escasa validez en un comienzo, pero los estudios recientes que examinan la validez concurrente del BIQ y el TAS son más positivos.

- Alexithymia Provoked Response Questionnaire (APRQ)

El APRQ fue desarrollado por Krystal, Giller y Cicchetti (1986), apremiados por la necesidad de elaborar una entrevista estandarizada que permitiera minimizar los efectos de los sesgos introducidos por el entrevistador. Consiste en 17 ítems derivados de la versión de autoinforme del BIQ, a fin de evaluar la capacidad del sujeto para usar el lenguaje afectivo mientras se imagina diversas situaciones potencialmente estresantes. Tiene correlación significativa con el BIQ, pero su vinculación con la TAS es escasa, dato que cuestiona su utilidad clínica.

\section{- California Q-Set Alexithymia Prototype}

Desarrollada por Haviland y Reise (1996). Basada en rasgos prototípicamente alexitímicos, de aquí se derivan 100 descriptores de personalidad relacionados, con dicho constructo. 
- $\quad$ Subescala de Alexitimia del Perfil Psicodinámico de Karolinska (KAPP)

Desarrollado por Weinryb, Rossel y Asberg (1991), basado en la teoría psicoanalítica, que pretende medir modos relativamente estables de funcionamiento mental referidos a la autopercepción y a las relaciones interpersonales. Está compuesto por 18 subescalas ordinales. La información necesaria para evaluar las subescalas del KAPP se obtiene mediante una entrevista basada en el procedimiento estructurado de Kernberg (1984).

\section{- Técnicas Proyectivas}

El uso de técnicas proyectivas para evaluar características alexitímicas se remonta a Ruesch (1948), quien describe que los pacientes con «personalidades infantiles» producen sólo fantasías imaginativas y estereotipadas en respuesta al Rorschach y al TAT. Algunos autores desaconsejan su empleo en investigación, circunscribiéndolo exclusivamente al ámbito clínico.

- Índices de Alexitimia del Rorschach, Sistema Comprehensivo

El estudio más riguroso utilizando una técnica proyectiva ha sido el de Acklin y Bernat (1987), quienes emplean el Rorschach para investigar las relaciones entre depresión, alexitimia y dolor lumbar crónico.

A partir de los características descriptivas del constructo, postulan un conjunto de índices Rorschach propios del Sistema Comprehensivo (Exner, 1974). Nos ocuparemos especialmente de su propuesta más adelante.

Además de los trabajos de Acklin y Alexander (1988) y Clerici y col. (1992) no se han publicado estudios que examinen rigurosamente la validez y fiabilidad de estos índices. Lunazzi y col. $(1999,2002)$ no hallaron confirmado el índice Lambda alto y sí, en cambio, el resto.

P. Porcelli (2004) propone una lista de indicadores Rorschach (SC) más amplia que la previa de Acklin y Bernat, e introduce algunos índices nuevos que no pertenecen al Sistema Comprehensivo. 
- $\quad$ El Test Arquetípico de los nueve elementos (SAT-9)

Se trata de un texto adaptado por Demers-Desrosiers (1982), basado en la teoría de Durand sobre la estructura de la imaginación. Es una técnica proyectiva de dibujo para evaluar la función simbólica y la capacidad para crear fantasías. Se presentan al sujeto nueve símbolos. A medida de que aumenta el nivel de alexitimia, los dibujos e historias pierden cohesión y originalidad. Los dibujos más creativos se encuentran en sujetos no alexitímicos. No hay demasiado sustento empírico que recomiende el uso del SAT-9, ya que se desconocen sus propiedades psicométricas.

- $\quad$ Test de Apercepción Temática de Murray (TAT)

Los índices hallados en el TAT comparados con otras medidas de alexitimia resultan, en general, inconsistentes, por lo que se ha cuestionado su uso. Sin embargo, también se menciona el interés clínico de su empleo.

- $\quad$ Análisis del contenido verbal de Lolas

Dado que la alexitimia es también un trastorno comunicativo, puede ser estudiada mediante el análisis del contenido del lenguaje. No obstante, como subraya Lolas (1997): «cuando el lenguaje se emplea con fines diagnósticos es necesario alcanzar la máxima precisión». En su trabajo se desarrolla un sistema de categorías del contenido verbal que permiten reconstruir sus significados emocionales.

Desde esta perspectiva se reformula el concepto de alexitimia como una ausencia de significados emocionales compartidos en situaciones reales, más que como una simple disminución de expresiones afectivas. Lolas enfatiza que un único método de evaluación no puede dar una respuesta completamente adecuada.

b) Dentro de los Intrumentos de autoinforme, encontramos:

- La Escala de Alexitimia del MMPI 
Los 22 ítems fueron desarrollados por Kleiger y Kinsmen (1980). Esta escala ha sido ampliamente criticada por presentar una pobre consistencia interna y sesgos de respuesta por deseabilidad social, así como una estructura de tres factores escasamente representativa del dominio teórico del constructo, problemas derivados del proceso inadecuado de selección de los ítems. Es desaconsejable su empleo para evaluar la alexitimia.

- Schalling-Sifneos Personality Scale (SSPS)

Es un autoinforme de 20 ítems de cuatro niveles, cuyo contenido corresponde en gran parte con los ítems clave del BIQ.

Su estructura factorial no resulta sustancialmente congruente con los dominios teóricos del constructo, además, carece de homogeneidad y consistencia interna.

- $\quad \underline{\text { La Escala de Alexitimia de Toronto (TAS) }}$

En un panorama dominado por las limitaciones para evaluar la alexitimia, Taylor, Ryan y Bagby (1985) desarrollaron este autoinforme para disponer de un instrumento psicométrico válido y fiable; los autores emplearon en su elaboración una aproximación combinada, racional y empírica, definiendo previamente cinco áreas de contenido, que pretenden reflejar el dominio del constructo:

- Dificultad para describir sentimientos.

- Dificultad para distinguir entre los sentimientos y las sensaciones corporales que acompañan a los estados de activación emocional.

- Ausencia de introspección.

- Conformismo social.

- Vida fantasiosa empobrecida y fracaso en el recuerdo de los sueños.

La escala muestra una adecuada consistencia interna $(\mathrm{a}=0.79)$, así como una buena fiabilidad test-retest.

Aunque la alexitimia ha sido considerada un constructo dimensional, se establecen inicialmente puntuaciones de corte, con el objeto de facilitar los estudios 
comparativos entre diversas poblaciones. De este modo, los sujetos que puntúan 74 o más se consideran alexitímicos.

La TAS: tiene validez convergente y discriminante. Las investigaciones realizadas con este instrumento informan que la alexitimia no es resultante sólo de las diferencias culturales en la expresividad emocional, sino que se presenta consistentemente en las diferentes culturas, independientemente del nivel socioeconómico.

- Escala revisada: TAS-R

Presenta como novedad la ausencia de ítems que reflejan ensoñación diaria o cualquier otro tipo de actividad imaginativa y, por el contrario, la inclusión de un mayor número de ítems que miden el pensamiento orientado a lo externo.

- $\underline{\text { TAS-20 }}$

Es una nueva versión que conserva 13 ítems de la TAS inicial. La puntuación puede oscilar entre 20 y 100 puntos, considerándose como alexitímico a aquel sujeto que obtenga una puntuación igual o superior a 61 .

Hay tres factores coherentes con el constructo que se evalúa:

- Dificultad para identificar sentimientos y diferenciarlos de las sensaciones corporales o fisiológicas que acompañan a la activación emocional.

- Dificultad para describir los sentimientos de los demás.

- Estilo de pensamiento orientado hacia lo externo.

La TAS-20 presenta una buena consistencia interna $(\mathrm{a}=0.81)$ y una buena fiabilidad test-retest. Refleja una buena dimensión general de alexitimia. La validez de esta escala es avalada en diferentes culturas. A diferencia de la TAS26 la TAS-20 excluye la exploración de manifestaciones de la vida imaginativa. 
Resumiendo, veamos el panorama de las técnicas desarrolladas:

Principales medidas de evaluación de la alexitimia

Cuestionarios:

- Beth Israel Questionnaire (BIQ) (Sifneos, 1973).

- Cuestionario provocador de respuestas para la alexitimia (APQR) (Krystal et al., 1986).

- Escala de observación de la alexitimia (OAS) (Haviland et al., 2000).

- Escala Toronto de alexitimia de 26 ítems (TAS) (Taylor et al., 1985).

- Escala Toronto de alexitimia revisada (TAS-R) (Taylor et al., 1992).

- Escala Toronto de alexitimia de 20 ítems (TAS-20) (Bagby et al., 1994a; 1994b; Parker et al., 2003; Taylor et al., 2003).

- Schalling-Sifneos Personality Scale (SSPS) (Apfel \& Sifneos, 1979).

- Schalling-Sifneos Personality Scale Revised (SSPS-R) (Sifneos, 1986).

- MMPI Alexithymia Scale (MMPI-A) (Kleiger y Kinsman, 1980).

- Shipko y Noviello (1984) MMPI Alexithymia Scale.

- Analog Alexithymia Scale (AAS) (Faryna et al., 1986).

- California Q-Set (CAQ) for alexithymia (Haviland y Reise, 1996).

- Amsterdam Alexithymia Scale (AAS) (Bermond et al., 1999).

- Bermond-Vorst Alexithymia Questionnaire (BVAQ) (Vorst y Bermond, 2001).

Técnicas proyectivas:

- Scored Archetypal Test with Nine Elements (SAT9) (Cohen et al., 1985).

- Rorschach Scale (Acklin y Bernat, 1997) (Porcelli, 2004). 


\section{Desarrollo de la Escala Toronto de Alexitimia (TAS)}

Como vimos, la evaluación de la alexitimia se ha encarado tanto por medio de procedimientos clínicos -entrevistas- como mediante técnicas de evaluación objetivas y proyectivas. Estas últimas en forma bastante escasa, ya que sólo en la técnica Rorschach, Sistema Comprehensivo de Exner, se ha comunicado un agrupamiento de indicadores apropiado para evaluarla (Acklin y Bernat, 1987; Porcelli, 2004).

Vamos a asistir a continuación al significativo esfuerzo desarrollado para operacionalizar el constructo alexitimia y demostrar su confiabilidad y validez. Desde su formulación, y posiblemente llevando a la práctica el criterio enunciado por G. Taylor: «En cualquier campo de investigación científica se hace necesario demostrar la validez de un nuevo constructo hipotético y mostrar que no se trata de una nueva denominación para describir un constructo ya establecido» (Taylor, Bagby y Parker, 1997), mediante el desarrollo o aplicación de diferentes técnicas en distintos grupos humanos -a su vez atravesados por variables-, se ha llevado a cabo un activo campo de investigación. Se hicieron numerosos intentos para conseguir la precisión teórica del constructo y el logro de las medidas de alexitimia que deben cumplir los requerimientos generales exigibles a las medidas estandarizadas de personalidad. En este sentido, el desarrollo de la Escala de Alexitimia de Toronto (Taylor, Ryan y Bagby, 1985), y más recientemente de la versión revisada TAS-20 (Bagby, Taylor y Parker, 1994) proporcionan un instrumento que posee notables propiedades psicométricas. En la revisión que hicimos anteriormente de este capítulo, se puso en evidencia, en su extensa utilización, que la Escala Toronto de Alexitimia de 26 ítems (TAS) y la TAS-20 tienen validez convergente y discriminante. Sin embargo, llegar a disponer hoy de esos instrumentos exigió un largo derrotero, que vamos a describir.

Tal como mencionamos antes, desde 1970 se desarrollaron y aplicaron distintas medidas de evaluación de la alexitimia. P. Sifneos, señala, sin embargo, dos tipos de limitaciones en la evaluación de la Alexitimia: en la viabilidad de técnicas que diferencien alexitimia primaria de secundaria, y otro, referido a las técnicas de evaluación mediante autoinforme. Las tomografías por emisión de positrones, que constituyen el mejor recurso de ingeniería biomédica para el fin del diagnóstico entre alexitimia primaria y secundaria, 
no son de fácil acceso. En cuanto a los cuestionarios de autoinforme, dice no considerarlos decisivos. Así expresa: «Finalmente, una de las dificultades concernientes a los déficit afectivos reside en nuestra incapacidad para diagnosticar con precisión la alexitimia primaria y de distinguirla de la secundaria. Los únicos instrumentos de que disponemos son las entrevistas clínicas y los cuestionarios de autoinforme. Las primeras han sido utilizadas en el desarrollo del BIQ, que propone examinar ocho características cruciales de la alexitimia en el curso de la entrevista. Ciertos instrumentos de autoevaluación, tales como versiones modificadas del MMPI, el SAT9, el SSPS-R y la escala validada de alexitimia de Toronto, el PVIPT, desarrollado por Montreuil en París, son igualmente muy promisorios. Todos esos test son de una gran ayuda, pero no son decisivos. En mi criterio, la utilización de tomografía de emisión de positrones (PET), que permite observar las desconexiones entre las esferas límbica y cortical en la actividad cerebral individual, durante sesiones en las que se les muestra a pacientes potencialmente alexitímicos y a sujetos de control videos con escenas violentas de cólera o de tristeza que suscitan emociones fuertes podrían ofrecer un gran interés. Entonces, y solamente entonces, podríamos comprender plenamente el campo fascinante de los aspectos psiconeurobiológicos del comportamiento humano y volver ese conocimiento propicio para aportar una contribución al tratamiento de los pacientes psicosomáticos sufrientes» (Sifneos 1995: 28).

Comprendemos la salvedad que establece Sifneos entre los métodos de diagnóstico concluyente para diagnosticar la lesión de las conexiones corticales, como las tomografías computadas, aún más las tomografías por emisión de positrones, cuya accesibilidad en la investigación clínica está aún, por cierto, reducida, y los métodos exploratorios de diagnóstico, como las técnicas de evaluación psicológica. Si bien compartimos la opinión de P. Sifneos respecto de las limitaciones de los autoinformes, ya que se basan en las respuestas voluntarias de los sujetos sobre sí mismos, en particular las escalas Toronto de Alexitimia (TAS) y TAS-20, han sido exhaustivamente investigadas y son mundialmente reconocidas por su elevada confiabilidad y validez. Veamos sus características y propiedades.

En la década del ochenta, G. Taylor y M. Bagby, como vimos, comenzaron a trabajar para obtener una técnica de evaluación de la alexitimia válida y confiable. 
Obtuvieron así el diseño de la llamada Escala de Alexitimia Toronto (TAS), revisando intentos realizados anteriormente, a los que sometieron a un mayor rigor psicométrico. Sobre cinco dimensiones, elaboraron la escala compuesta por 26 ítems en un cuestionario autoadministrable. Sometieron la escala TAS a numerosos estudios de correlación ${ }^{5}$, obteniendo que se correlaciona de manera altamente positiva con indicadores de depresión, ansiedad estado y rasgo, hipocondría y baja capacidad para el análisis de conflictos.

La Escala de Alexitimia Toronto (TAS), luego de los sucesivos intentos para afinarla psicométricamente, resulta en un instrumento sencillo, rápido y sensible, que ha obtenido, por su confiabilidad y validez, reconocimiento y uso internacional. Consiste en un cuestionario autoadministrable que formula veintiséis preguntas que permiten calcular un puntaje total en alexitimia. Estas preguntas investigan, a su vez, la presencia de los cuatro factores que constituyen el constructo, los que pueden examinarse por separado. Estos factores son: $a$ ) dificultad para diferenciar sentimientos de sensaciones corporales, $b$ ) dificultad para comunicar los sentimientos, $c$ ) escasa capacidad para imaginar o fantasear, d) pensamiento operatorio. Luego de numerosos investigaciones, los autores informan que la TAS (TAS26) tiene una buena confiabilidad y una apropiada consistencia interna $(a=0,79)$. Prosiguen sin embargo sus estudios hasta confeccionar un cuestionario de sólo 20 ítems, que explora tres de los factores que integraban la TAS. Se excluye el examen del factor vida de fantasía. La TAS-20 presenta una buena consistencia interna ( $\mathrm{a}=0.81)$, y una buena fiabilidad test-retest; es también muy empleada actualmente en el marco internacional. Consistentemente con los resultados de otros estudios de investigación sobre alexitimia y manejo emocional o manejo del estrés (Fukunishi y Rahe, 1995, Páez et al., 1995), encontraron que los puntajes en la TAS estuvieron asociados fuertemente con afectividad negativa. Se ha verificado también el más alto nivel de distress en pacientes con elevada alexitimia, pacientes que a su vez habían fracasado en usar estrategias de manejo activas y directivas, tales como ignorar o reinterpretar el dolor, emplear aseveraciones auto afirmativas o incrementar la actividad ocupacional.

\footnotetext{
${ }^{5}$ El Inventario de Depresión de Beck, la Escala de Ansiedad IDARE, la Escala de Necesidad de Cognición de Cacciopo, el Inventario de Personalidad California, el Inventario de Personalidad Básica de Jackson, la Escala Shipey-Hartford para estimar Inteligencia Verbal y No Verbal.
} 
En 1990 se publicó en la Argentina una adaptación al castellano de la escala TAS realizada por M. M. Casullo, M. Maristany y A. Wiater, se la propuso como esencialmente fiel a la original. Realizaron trabajos de adaptación lingüística y redujeron la escala de cinco alternativas tipo. Facilitaron también las medias poblacionales en una muestra argentina. Disponer de esta escala prometía un instrumento rápido y de fácil aplicación para reconocer a los sujetos alexitímicos en la población, capacidades que nos llevaron a investigar en sucesivos pasos: $a$ ) la validez y confiabilidad de la adaptación argentina; $b$ ) la capacidad de discriminación diagnóstica, tanto del puntaje total como de sus factores y c) las variables que afectan la validez del constructo (Lunazzi y col., 1997, 1999, 2000a, d) para diferenciar si, efectivamente, la alexitimia puede considerarse y mediante qué indicadores psicodiagnósticos, también como factor de riesgo psicosomático (Lunazzi 2000b).

En una investigación que realizamos en la ciudad de La Plata (Lunazzi, Lazzarino, Lojo, 1999) en 30 pacientes de Artritis Reumatoidea (AR) con el objetivo de comprender las reacciones al dolor no vinculadas con la severidad del cuadro clínico, el $87 \%$ de los pacientes puntuaron en el rango alexitímico y apareció en el $27 \%$ de ellos alexitimia muy elevada (>74) o definitiva.

Otra investigación que realizamos tuvo por objeto el estudio de las variables que intervienen en la validez de la TAS (Lunazzi, 2000). Las variables que estudiamos en 550 casos fueron nivel socioeconómico, orientación ocupacional, edad y presencia de cuadro psicosomático. Las diferencias entre el puntaje total de las muestras de los sujetos normales y los psicosomáticos fueron altamente significativas. También se verificaron diferencias en los puntajes de ciertos factores, según la intervención de las diferentes variables. El factor I (capacidad para identificar y describir sentimientos) de la TAS mostró limitación muy significativa $(\mathrm{p}<0,01)$ entre los psicosomáticos respecto de la muestra de no-pacientes de la misma ciudad. También el puntaje total de los psicosomáticos fue muy significativamente superior al de los no-pacientes. El factor III (uso de la vida de fantasía o imaginaria) también mostró limitación muy significativa $(\mathrm{p}<0,01)$ entre los no pacientes de nivel socio económico medio bajo y los no pacientes. Sin embargo el puntaje total se mantuvo en la media no alexitímica. 
Hemos comprobado la validez de la adaptación argentina de la TAS (Casullo y 1990). Conservado los puntos de corte $(=>74)$ que se utilizan internacionalmente para evaluar alexitimia definitiva y homologar las observaciones.

Queremos señalar, de acuerdo con nuestra experiencia con la TAS, que las condiciones de la administración merecen especial atención. Algunos resultados confusos y aún inciertos de la TAS, que algunos autores informan, podrían explicarse por esa variable. A veces, algunos administradores no especialmente adiestrados en evaluación psicológica, confiando en que se trata de un cuestionario autoadministrable, los entregan a los pacientes sin mediar las necesarias intervenciones destinadas a crear motivación de respuesta, y sin la participación personal para que pacientes con limitaciones variadas y serias puedan comprender y contestar adecuadamente las preguntas del cuestionario.

Nos encontramos, como conclusión de nuestros trabajos, con un instrumento eficaz, confiable y sensible, con las características de un cuestionario autoadministrable, aunque cuando el nivel educativo de los sujetos era bajo, se volvió recomendable que el entrevistador acompañara y explicara ciertas preguntas.

Si bien pensamos que poder contar con la TAS es muy satisfactorio, ésta comparte las limitaciones de los cuestionarios autoinforme. Fundamentalmente, explora el nivel de información sobre sí mismo que el sujeto conoce y está dispuesto a revelar. Examinar o complementar con otro nivel de información sobre el sujeto que él desconozca, prometería, sin duda, una evaluación más completa y amplia de las dimensiones de su personalidad. En el siguiente cuadro podemos examinar las características de los instrumentos de autoinforme, por un lado, y de los instrumentos llamados proyectivos, en especial el Rorschach, por otro. 
Ventajas y limitaciones del autoinforme ${ }^{6}$. Comparación entre cuestionarios y el Rorschach:

\begin{tabular}{|c|c|}
\hline $\begin{array}{l}\text { ESCALAS, CUESTIONARIOS } \\
\text { AUTOADMINISTRADOS }\end{array}$ & $\begin{array}{l}\text { TÉCNICAS PROYECTIVAS, } \\
\text { RORSCHACH SISTEMA } \\
\text { COMPREHENSIVO }\end{array}$ \\
\hline $\begin{array}{l}\text { CIENCIAS NOMOTÉTICAS } \\
\text { ESTÍMULO: } \\
\text { MATERIAL ESTRUCTURADO } \\
\text { CUESTIONARIOS CON PREGUNTAS }\end{array}$ & $\begin{array}{l}\text { CIENCIAS IDIOGRÁFICAS } \\
\text { ESTÍMULO: } \\
\text { MATERIAL AMBIGUO } \\
\text { MANCHAS DE TINTA }\end{array}$ \\
\hline PARADIGMA CUANTITATIVO & PARADIGMA CUALITATIVO \\
\hline $\begin{array}{l}\text { SON CONTESTADOS CON CONTROL } \\
\text { VOLUNTARIO, DE ACUERDO A LA } \\
\text { DESEABILIDAD SOCIAL. }\end{array}$ & $\begin{array}{l}\text { EL SUJETO ES INCAPAZ DE } \\
\text { CONTROLAR SUS RESPUESTAS }\end{array}$ \\
\hline $\begin{array}{l}\text { DEPENDEN DE LA COMPRENSIÓN } \\
\text { CONCIENTE DE LAS PREGUNTAS. }\end{array}$ & $\begin{array}{l}\text { FUNDAMENTOS EXPERIMENTALES Y } \\
\text { BASE EMPÍRICA MUY AMPLIA ( } 70.000 \text { CASOS) }\end{array}$ \\
\hline DEPENDEN DEL SABER Y EL & AMPLIA BASE DE DATOS \\
\hline AUTOCONOCIMIENTO QUE TENGA EL SUJETO. & $\begin{array}{l}\text { INTERNACIONAL CON MUESTRAS } \\
\text { NORMATIVAS PSICOPATOLÓGICAS Y }\end{array}$ \\
\hline $\begin{array}{l}\text { DESCUIDAN CONDICIONES CLÍNICAS } \\
\text { DE ADMINISTRACIÓN. }\end{array}$ & $\begin{array}{l}\text { EVOLUTIVAS } \\
\text { AMPLIA CONTRASTACIÓN }\end{array}$ \\
\hline PUEDEN NO RECONOCERSE LOS & LOS RASGOS DE PERSONALIDAD SE \\
\hline PROPIOS RASGOS DE PERSONALIDAD. & $\begin{array}{l}\text { PONEN DE MANIFIESTO SEAN RECONOCIDOS } \\
\text { O NO }\end{array}$ \\
\hline $\begin{array}{l}\text { NEGLIGENCIA DE REQUISITOS } \\
\text { CLÍNICOS PARA LA EVALUACIÓN } \\
\text { (ADMINISTRACIÓN) }\end{array}$ & $\begin{array}{c}\text { ALTO COEFICIENTE DE } \\
\text { CONFIABILIDAD INTER. CODIFICADORES }\end{array}$ \\
\hline INFORMA RESULTADO, NO PROCESO & INFORMA RESULTADO Y PROCESO \\
\hline
\end{tabular}

\footnotetext{
${ }^{6}$ Presentado y adaptado por la autora, en la clase Rorschach y Alexitimia del Curso de Especialización en Psiconeuroinmunoendocrinología. Laboratorio Novartis, 13 de octubre de 2004.
} 
Podemos considerar que los las técnicas mediante cuestionarios, generalmente autoadministrables, proceden de las llamadas ciencias nomotéticas, las que se interesan por las leyes generales y obtienen la información pertinente, de grandes grupos poblacionales evolutivos, normales o patológicos. Las ciencias idiosincrásicas, en cambio, se ocupan del caso particular, considerado único, aunque se reconoce que participa de leyes más generales. Los cuestionarios proceden del paradigma cuantitativo, se expresan numéricamente, utilizan un material estructurado (preguntas definidas que deben responderse con alternativas: sí, no, o a veces). Como vemos, dependen de que el examinado comprenda conscientemente la pregunta, de cuánto conoce sobre sí mismo, de que las conteste honestamente y, sin acomodarlas a la deseabilidad social. A menudo, lamentablemente, tomando por sentado que son aptos para las administraciones autoadministradas y grupales, las condiciones de administración se descuidan, sin contemplar las limitaciones de comprensión de los casos singulares. Habitualmente, se obtiene un resultado, o puntaje, pero se desconoce cómo el sujeto llegó a ese valor. Respecto del otro grupo de técnicas que estamos comparando, las idiosincrásicas, donde se incluyen variados instrumentos de exploración psicológica, éstas se interesan cualitativamente por el caso, presentan consignas o estímulos ambiguos, es decir susceptibles de provocar muchas interpretaciones, y el examinado debe dar su propia respuesta. El sujeto desconoce, por lo tanto, cómo van a ser evaluadas sus preguntas, y podemos reconocer los múltiples procesos que dieron sustento a las respuestas. En el caso especial del Rorschach, Sistema Comprehensivo, al enfoque cualitativo se le suma una importante base empírica y requisitos psicométricos, que permiten también expresar cuantitativamente sus agrupaciones de funcionamientos psicológicos. Facilita además amplias muestras de referencia para contrastar los resultados obtenidos.

Por lo tanto, y según explicamos, los resultados del autoinforme TAS se verían enriquecidos y profundizados por la articulación complementaria de otra técnica de evaluación indirecta, de foco exploratorio más amplio: la técnica Rorschach, para la evaluación concurrente del constructo alexitimia. Utilizar más de un método de evaluación permitiría estimar más completamente los casos y facilitaría examinar su validez convergente para la evaluación del constructo. 
En correspondencia con lo dicho, según expresa Ma Tous (Cordero, 2000), al referirse a validez convergente frente a validez de constructo: «Otros trabajos de integración se realizan en un intento de relacionar diferentes métodos de medida que evalúan los mismos factores de personalidad. En este planteo la validez convergente tiene gran importancia, ya que se trata de conseguir una corroboración de los datos obtenidos de un mismo rasgo mediante procedimientos de medida independientes. En la práctica, esto se consigue relacionando los datos obtenidos por dos instrumentos de medida diferentes, por ejemplo: el MMPI y el Rorschach, cada uno por separado mide el mismo factor. La integración entre MMPI y otros test como Rorschach y TAT despierta gran interés. Ambos (MMPI por un lado, Rorschach y TAT por otro) miden conducta verbal (mismo factor), pero de distinta forma: mientras que el MMPI permite obtener un conocimiento de sí mismo, el Rorschach y el TAT, en cambio, miden procesos de pensamiento y fantasía».

\subsubsection{La Técnica Rorschach y el Sistema Comprehensivo de J. Exner.}

Las 10 manchas de tinta que constituyen los estímulos de la técnica de Rorschach se dieron a conocer en 1921 con la publicación de la célebre monografía de Hermann Rorschach Psicodiagnóstico. Ese material estímulo permanece intacto, ya que las matrices originales han sido preservadas por Hans Huber en Suiza, y ha sido ampliamente empleado desde su creación. En la actualidad sigue ocupando el primer lugar entre las técnicas de evaluación empleadas por el psicólogo, según informa la Sociedad de Evaluación de la Personalidad de los Estados Unidos, en su relevamiento de 1996.

Muchos de los datos que se obtienen con el Rorschach no pueden obtenerse por medio de otros instrumentos, ya que al presentar un material ambiguo y poco estructurado (manchas de tinta) propone al sujeto que construya respuestas congruentes. El sujeto, al dar sus respuestas, pone de manifiesto su modo de explorar la situación estímulo, qué áreas y aspectos percibe, las relaciones y razonamientos con que fundamenta sus respuestas, la capacidad o no de regular emociones de distinto tipo que emergen en el contacto con la tarea y los estímulos que presenta.

El logro mayor del Rorschach es obtener una evaluación de la interrelación entre funcionamiento cognitivo y personalidad, ya que lo que se conoce y elige se vincula con una larga historia personal en la que se organizan tales patrones. Sus datos permiten acceder al funcionamiento de la personalidad, al enfoque del sujeto respecto del medio ambiente, a sus recursos para la resolución de problemas, la cualidad y regulación afectiva, 
la tolerancia al estrés, las habilidades y competencias, la relación entre capacidades y aspiraciones, sublimación, habilidad para procesar y organizar estímulos ambientales independientemente de factores intelectuales, la precisión perceptiva, la prueba de realidad y las variables que limitan su funcionamiento, lo afectan o impactan sobre él.

Desde su aparición el Sistema Comprehensivo para el Rorschach de Exner (1974) ha sido progresivamente adoptado en el marco internacional, dando lugar a una importantísima posibilidad de contrastación. Los principales méritos del Sistema Comprehensivo del Rorschach consisten en: $a$ ) rigurosa explicitación de criterios sobre el examinador, consigna, registro, interrogatorio y codificación de variables, capacidad que ha probado una confiabilidad de .85 entre 10 o 15 codificadores; $b$ ) haber determinado sus propiedades psicométricas sobre una base de datos y muestreo que aseguran su validación empírica (7500 adultos para P, 3000 sujetos para D, Normas sobre 700 adultos no pacientes) y c) Contar con una difusión internacional sin precedentes que permite estudios interculturales.

La técnica Rorschach ha sido enriquecida con el desarrollo de un nuevo método de administración, codificación e interpretación: el Sistema Comprehensivo de J. E. Exner (Exner, 1995). Este nuevo método ha dotado a la técnica de rigor psicométrico y originó la unificación metodológica de la mayoría de los rorscharchistas en el mundo. Dicha circunstancia ha privilegiado al Rorschach como instrumento de uso y comparación internacional.

Es oportuno, al tratar esta cuestión, tener en cuenta que no haber cumplido previamente con esos requisitos le valió al Rorschach severas críticas. Corresponde a J. Exner el enorme mérito de haber conquistado para la técnica actualmente su status científico. Mérito gigante, el Rorschach de Exner satisface completamente los criterios normalizados para ser considerado un test, incluyendo la siguiente descripción de 'test' de los Standards for Educational \& Psychological Test promulgados por la American Psychological Association en 1974. En relación con esto, I. Weiner dice: «El status científico de un instrumento de medición es una función de sus propiedades psicométricas. Un instrumento es considerado psicométricamente confiable cuando: $a$ ) los examinadores entrenados pueden llegar a un acuerdo razonable en la codificación de las variables; $b$ ) las estimaciones de su confiabilidad indican que provee información razonablemente exacta, 
esto es, que los resultados que el $\mathrm{RIM}^{7}$ genera están muy próximos a los resultados verdaderos; c) sus corolarios demostrados identifican los propósitos para los que es razonablemente válido y $d$ ) los datos normativos concernientes a su estadística descriptiva entre varias poblaciones son adecuados, como para permitir comparaciones individuales con grupos de referencia adecuados» (Anastasi, 1988); y agrega: «Cuando se administra y se codifica el RIM de acuerdo al Sistema Comprehensivo (Exner, 1993), se satisfacen cada uno de estos cuatro requisitos psicométricos» (Weiner, 1997, 68 a: 5-19; Weiner, 2004: 137) (Meyer, Hilsenroth, Baxter, Exner, Fowler, Piers, Resnick, 2002: 219-274).

Una información relevante para nuestro objetivo presente es que el Rorschach permite codificar la regulación de los afectos de un sujeto e informa exhaustivamente acerca de éstos y sus relaciones con otras dimensiones de la personalidad. Estos datos pueden valorarse en diversos dispositivos, contextos y poblaciones. Adoptamos el Sistema Comprehensivo de J. Exner por su gran confiabilidad y su capacidad de desarrollo de un sistema unificado. Como señala Constantino (1996): «el Rorschach no hubiera permanecido en su lugar principal dentro de la práctica profesional de la psicología».Más adelante dice: «Exner merece ser reconocido por presentar la investigación, las proporciones utilizadas, las hipótesis generadas, las limitaciones, las fortalezas, y por su incansable esfuerzo en desarrollar un instrumento cada vez mejor. El resultado es un Rorschach (Atkinson, 1986; Parker, Hanson y Hunsley, 1988) psicométricamente comparable al MMPI (Hathaway y McKinley, 1943). Además, la estandarización de la administración, clasificación e interpretación de las normas para adultos, niños y adolescentes reducen en gran medida el sesgo presente en la evaluación proyectiva, haciendo del Rorschach una técnica psicométrica altamente respetada en la práctica clínica y aceptado en marcos forenses» (Constantino y Malgady, 1996: 559).

En cuanto a la validez de la técnica Rorschach, el enfoque empírico y experimental de J. Exner y su Sistema Comprehensivo ha favorecido enormemente la investigación. Junto con las escalas de puntajes normativos en las distintas edades, son muy abundantes y significativos los resultados de su aplicación en distintos tipos de muestras, tanto de culturas especiales como psicopatológicas ${ }^{8}$.

\footnotetext{
${ }^{7}$ RIM: Rorschach Inkblot Method (Método de las manchas de tinta Rorschach).

${ }^{8}$ Exner y sus colaboradores han establecido desde 1980, en Asheville, los Rorschach Workshops, una institución que está dedicada a la enseñanza, entrenamiento y la investigación de la validez del S.C. Los Rorschach Workshops, mediante el Alumni Newsletter, que informa de modo continuo a sus alumnos en todo el mundo los resultados de investigación en las 112 variables que se evalúan en cada protocolo de Rorschach,
} 
En un artículo publicado en The Clinical Psychologist de noviembre de 2002, Irving Weiner, Charles D. Spielberger y Norman Abeles ${ }^{9}$ informan que, en 1996 el Board of Professional Affairs de la Asociación de Psicólogos norteamericana (APA) nombró al Grupo de Trabajo de Evaluación Psicológica (PAWG) encargado de reunir evidencias de las evaluaciones en la práctica clínica, particularmente con referencia a la validez y utilidad de los test psicológicos dirigidos a los cuidados de la salud. El informe final de la PAWG, publicado en la American Psychologist, mediante una revisión de las predicciones y el estudio meta-analítico concluyó que «la validez de los test psicológicos es fuerte e irresistible» y «comparable con la validez de los métodos médicos» (Meyer et al., 2001: $128)^{10}$. En cuanto a la validez del constructo, en el artículo que citamos también se mencionan dos ejemplos inferidos de los datos de referencia del Sistema Comprehensivo. Primero, los cambios relacionados con la edad en 1390 niños y adolescentes no-pacientes de 5 a 16 años confirman la conceptualización del Índice de Egocentrismo como medida del autocentramiento (concepto de Piaget e Inhelder). El segundo ejemplo alude al índice $\mathrm{X}-\%$ (deterioro de la realidad) y al Wsum6 (índice de trastorno del pensamiento), los que mostraron las desviaciones esperadas al analizar los datos de referencia del Sistema Comprehensivo de 600 adultos no-pacientes y muestras de 535 adultos pacientes psiquiátricos ambulatorios, 279 pacientes hospitalizados con desórdenes de depresión mayor y 328 pacientes hospitalizados con la primera admisión por esquizofrenia (Exner, 2001).

\footnotetext{
las correcciones e inclusiones de nuevas variables.

${ }^{9}$ Artículo traducido y publicado en el Boletín Informativo de ADEIP, 2002, n. ${ }^{\circ} 45$ (34-39): Psicología Cientifica y Método Rorschach.

${ }^{10}$ Las correlaciones específicas fueron volcadas en una lista a fin de comparación, incluyendo las siguientes: Peso y altura para adultos estadounidenses (.44); Escala de validez y detección de simulación de patología del MMPI (.44); Cociente Intelectual del Wais y nivel de educación obtenido (.44); El puntaje Rorschach PRS (Prognostic Rating Scale) y el consiguiente resultado de la psicoterapia (.44); Viagra y mejoramiento del funcionamiento sexual masculino (.38); Puntaje del Test de Dependencia Aperceptiva Rorschach y la conducta dependiente (.37); Puntaje de la Escala del MMP y la habilidad promedio para detectar desórdenes depresivos o psicóticos (.37); Puntaje del Hare Psychopathy Checklist y la consiguiente conducta violenta (.33); Resultados del screening mamográfico y la detección de cáncer de pecho dentro del año (.32); Pastillas para dormir y mejoramiento a corto plazo de insomnio crónico (.30).
} 
Muestra argentina de 506 no-pacientes, proyecto de investigación acreditado por

\section{la Universidad Nacional de La Plata.}

Creemos necesario expresar que seleccionamos la técnica Rorschach, pues nos proponemos tratar de compensar las limitaciones de los autoinformes (TAS), mediante el uso conjunto de distintos instrumentos de evaluación. Sin embargo, nuestra investigación adolecería de una considerable falencia si no hubiéramos dispuesto de una muestra control demográficamente homologada y de igual cultura para comparar con los pacientes artríticos que nos proponíamos estudiar. Realizar comparaciones entre muestras de distintos países introduce un sesgo cultural que limita seriamente su validez. Durante los años 1999-2003 nos dedicamos a obtener los estadísticos descriptivos normativos para nuestra población en la técnica Rorschach, previamente inexistentes en nuestro país. Así (Lunazzi, Urrutia, García de la Fuente, Elías, Fernández y De la Fuente, 2006) desarrollamos las normas en 506 no-pacientes, de entre 18 y 65 años de edad, demográficamente representativas de la región Gran La Plata, Provincia de Buenos Aires ${ }^{11}$. Utilizaremos dichas normas para comparar la muestra de pacientes artríticos y para facilitar muestras de no pacientes, que nos permitan investigar la controvertida asociación entre la alexitimia y las variables socioeconómica y años educativos.

\subsubsection{Contribución de la Técnica Rorschach en el campo hospitalario.}

Sumamos al interés del empleo conjunto del Rorschach con la TAS para la evaluación del constructo alexitimia, la contribución -que creemos muy útil-del Rorschach en el campo hospitalario y en la problemática de la Medicina Psicosomática.

Piero Porcelli (Porcelli, 2004: 66) ha enumerado los objetivos por los cuales emplear el Rorschach en los equipos médicos.

\footnotetext{
${ }^{11}$ En este apartado, presentamos párrafos del prefacio del libro en el que se publicarán las normas (en prensa, Psimática, 2006) en los que el autor del Sistema Comprehensivo, John Exner, describe nuestro trabajo: «Siempre resulta estimulante la publicación de investigaciones... sobre normas locales, como este estudio sobre no-pacientes de Argentina. [...] He seguido el desarrollo de este trabajo desde su comienzo hasta su culminación y me ha resultado una experiencia gratificante [...] el diseño se ha planteado con gran cuidado, ha sido dirigido de manera adecuada y se ha llevado a cabo con gran profesionalidad. Hay que felicitar a las investigadoras que han realizado este trabajo [...] El resultado es un primoroso estudio que servirá bien como piedra angular del trabajo con el test a quienes lo emplean en diferentes países y culturas, y sin duda será un trampolín para posteriores investigaciones, tanto sobre sujetos no-pacientes como pacientes».
} 
Plantea que la esencia de evaluar con el Rorschach a los pacientes de medicina es la misma que la de su uso en la evaluación psicológica en general, tal como fue delineado por G. Meyer y cita que esos autores incluyeron:

a) Describir el funcionamiento psicológico habitual (en el caso de los pacientes médicos, su capacidad de procesar cognitivamente sus sentimientos y tratar con sus emociones).

b) Confirmar o modificar las impresiones que los clínicos se formaron a través de entrevistas menos estructuradas con los pacientes (chequear las impresiones intuitivas o no refinadas de los médicos sobre los rasgos psicológicos de un paciente dado).

c) Planear el tratamiento (por ejemplo si un tratamiento psicológico debe incorporarse al de psicofármacos).

d) Ayudar en el diagnóstico diferencial de los desórdenes emocionales, conductuales y cognitivos.

e) Monitorear el tratamiento a lo largo del tiempo.

f) Manejar los riesgos incluidos las indeseadas reacciones a los psicofármacos.

g) Proveer orientación (feedback) especializada y empática, obtenida en la evaluación.

Y más adelante Porcelli agrega tres puntos posteriores para incorporar en la lista de Meyer (Meyer et al.2001):

a) Realizar el diagnóstico diferencial entre síndromes psicológicos o psiquiátricos que puedan estar asociados en las enfermedades médicas.

b) Manejar los casos difíciles dentro de la práctica médica.

c) Facilitar la comunicación entre los clínicos y mejorar la alianza de trabajo entre el paciente y el equipo terapéutico.

El Rorschach ofrece entonces: $a$ ) una evaluación del proceso cognitivo de construcción de sentido, proceso que incluye atención, percepción, memoria, toma de decisión y análisis lógico; $b$ ) una evaluación de la imaginería temática que incluye procesos de asociación, atribución y simbolización y c) una evaluación de la vida emocional, que implica tanto aspectos expresivos como el reconocimiento de información 
interpersonal imprescindible para la vinculación humana. A través de la exploración de todas esos funcionamientos, la presencia de alexitimia se volvería reconocible en sus efectos sobre la cognición y en la regulación de los afectos. Facilitaría, junto con la técnica TAS, la validación concurrente del constructo alexitimia. Los resultados de su empleo podrían ofrecer contribuciones valiosas para el equipo de trabajadores de salud (médicos, psicólogos, psiquiatras, asistentes, trabajadores sociales, pacientes, etcétera).

\subsubsection{Resumen de los hallazgos Rorschach en Medicina Psicosomática.}

La problemática de los pacientes psicosomáticos, sin embargo, interesó a los rorschachistas y precedió en casi treinta años a la creación del Sistema Comprehensivo.

Los primeros trabajos conocidos corresponden a una revisión que encaró Bash (Bash, 1986) cubriendo lo producido en el área durante dos décadas. Una dificultad mayor provino de la existencia de numerosos sistemas de codificación del Rorschach, lo que impedía la comparación de los resultados de las investigaciones. A menudo, además, las Escalas usadas para la evaluación temática de las respuestas no cumplían los requisitos de confiabilidad y validez. Fueron reconocibles, a pesar de todo ello, las características comunes de las respuestas al Rorschach de los enfermos psicosomáticos: el escaso número de respuestas (bajo R); la ausencia o pobreza del movimiento humano (M) y del contenido humano $(\mathrm{H})$; la columna de movimiento animal (FM) también baja, pero tendiendo a superar a M; la escasa modulación de la afectividad (Sum C); la tendencia a la impulsividad $(\mathrm{CF}+\mathrm{C}>\mathrm{FC})$; la falta de originalidad y el control racional rígido ( $\mathrm{F}+\%$ alto); un tipo vivencial coartado y alto conformismo social (P elevado) (Bash, 1986).

Exner, posteriormente $(1991,2000)$ investigó la sumatoria de respuestas con contenido de anatomía y radiografía $(\mathrm{An}+\mathrm{Yx} \%)$, y sugirió que indica problemas físicos, rumiaciones con el cuerpo o la propia imagen y manifiestan un sentimiento de gran vulnerabilidad.

Porcelli (2004: 65), basado en su experiencia clínica en ambiente hospitalario, apunta que deberían también tenerse en cuenta en el aumento de An+Xy\% las influencias situacionales (administración en hospital) en la producción de ese tipo de respuestas y que, como en otros índices Rorschach, «la ausencia de evidencia no es evidencia de ausencia». 


\subsubsection{Estudios Rorschach en alexitimia.}

Podemos contar como fuente de consulta, afortunadamente, con el texto más riguroso y comprehensivo publicado hasta la actualidad sobre Medicina Psicosomática y Rorschach (Porcelli, 2004). P. Porcelli llama estudios misceláneos a las investigaciones iniciadas en 1977, dado que usaban sistemas Rorschach diversos, a veces ni siquiera explicitados, lo que limita la seriedad de los resultados. Cita a Vogt (Vogt et al., 1977) como el antecedente más abarcativo de aplicaciones del Rorschach en psicosomática, quien formuló el Síndrome de Fantasía Rorschach (RFS) ${ }^{12}$. Utilizando los sistemas de Bohm y Klopfer, todas las variables seleccionadas representan la capacidad individual para fantasear. A pesar de las muchas falencias que pueden señalarse, dice Porcelli (2004: 98): «este estudio pionero tuvo el mérito de investigar la alexitimia, planteando a priori una cantidad de variables Rorschach vinculadas con un marco teóricamente consistente. Eso permite interpretar los resultados a la luz del modelo conceptual psicoanalítico, como la evidencia de la dificultad para fantasear de los pacientes alexitímicos, lo cual los diferencia de las psiconeurosis. De este modo proveyó soporte a las observaciones clínicas sobre los pacientes psicosomáticos, que constituían la única descripción de la alexitimia en esa época».

Recién en 1987 Acklin y Bernat formularon los Índices Rorschach específicos de alexitimia. Tomando en cuenta que sus pacientes psicosomáticos presentaban como síntoma dolor lumbar, síntoma que es considerado también como «una depresión enmascarada», y que varios autores proponían la idea de que algunas características de la alexitimia eran próximas a la depresión, estos autores llevaron a cabo un interesante estudio, destinado a establecer la existencia de asociación con la depresión, tal como la evalúa la variable DEPI del Sistema Comprehensivo. En una muestra seleccionada de 33 casos (extraídos de una mayor de 136) con dolor lumbar crónico a los que les administraron el inventario de Depresión de Beck, establecieron, como era esperable, «depresión leve». Los compararon con 200 pacientes con diagnóstico de Trastorno de Personalidad (DSM III), con 210 pacientes internos con diagnóstico de Depresión Mayor y con 600 no-pacientes provenientes de la base de datos de la Rorschach Foundation. Sus hipótesis planteaban: a) que los pacientes con dolor lumbar crónico puntuarían más bajo

${ }^{12}$ Vogt et al.: $\mathrm{M}>3 ; \mathrm{FC}: \mathrm{CF}+\mathrm{C}>0.5 ; 0 \%>25 ; \mathrm{R}>20 ; \mathrm{Con} \%>25$. 
que los pacientes depresivos con DEPI; $b$ ) puntuarían más alto en los índices Rorschach de alexitimia que los otros tres grupos y c) mostrarían datos Rorschach más parecidos a los trastornos de personalidad que a los otros dos grupos de control. Se comprobaron a través de los resultados las tres hipótesis y lo más importante, a nuestro entender, la falta de asociación entre depresión y alexitimia.

Si bien P. Porcelli enumera los muchos logros de la investigación, critica la falta de uso de una medida externa que evalúe la alexitimia y sus distintos niveles. A pesar de que llaman a sus índices «de Alexitimia», señala que «adoptaron lo que llamamos "falsa ecuación semántica", según la cual ciertas enfermedades médicas son psicosomáticas (subyaciendo la idea de homogeneidad en la enfermedad) y, por lo tanto, que los pacientes psicosomáticos son también alexitímicos. Brevemente, usaron un índice Rorschach de Alexitimia sin una validación a priori del constructo» (2004: 107).

Recientemente P. Porcelli ha revisado las investigaciones Rorschach sobre alexitimia. Si bien es destacable que sólo en una de las investigaciones se tomó por objeto a la AR juvenil, su revisión permite constatar que, desde 1977 hasta 2002 se han realizado con la técnica Rorschach 14 estudios sobre alexitimia: 6 con el Sistema Comprehensivo, 4 con el sistema Klopfer, uno con el de Rapaport y 3 sin especificar. Respecto de indicadores comprobados de alexitimia, los resultados son variados, y pueden señalarse observaciones metodológicas en algunos casos, por ejemplo ausencia de muestra control, que limitan la validez de éstos (Porcelli, 2004: 94-95, Cuadro 8).

Seleccionaremos dos estudios Rorschach que presentan interés para nuestro trabajo. En 1996 en la Rorschachiana se publicó una investigación realizada por D. Petot que usó algunas variables del SC en una muestra de 52 estudiantes universitarios de literatura, que fueron subdivididos mediante el puntaje de la TAS en alexitímicos $(\mathrm{N}=25,2$ hombres y 23 mujeres) y no alexitímicos (27, 6 hombres y 21 mujeres). Los resultados obtenidos comunican falta de soporte al constructo alexitimia, porque no halló diferencias significativas entre alexitímicos y no alexitímicos. El constructo alexitimia puede aparecer efectivamente representado en la población no-paciente, al administrar por ejemplo la TAS, como en este caso, donde tenemos casi un 50\% de alexitimia definida (TAS $\geq 74$ ). No obstante, si el Rorschach no confirmó lo que los teóricos de la alexitimia (Sifneos, Taylor, Marty, De M’Uzan) sostienen como propio del rasgo de personalidad alexitimia, 
planteamos que, efectivamente, esos sujetos no eran estructuralmente alexitímicos, aunque en la TAS puntuaron positivamente. Si se trata de sujetos con recursos mentales muy ricos, como los esperables en los estudiantes universitarios de literatura francesa, ello desmiente la característica restricción de la vida de fantasía y aún la dificultad para reconocer y describir sentimientos. Parecería apropiado suponer que los universitarios alexitímicos estarían haciendo uso de defensas evolucionadas como el aislamiento, la racionalización y la intelectualización para lidiar de modo controlado con su vida afectiva y que no bastaría puntuar alto o bajo en la TAS para que quede establecida fehacientemente la presencia o ausencia de alexitimia.

En relación a esta investigación que parecería cuestionar la validez misma de los indicadores Rorschach para evaluar la alexitimia, Porcelli expresa (2004: pág. 109-110):

"La autora no evaluó la confiabilidad entre codificadores, no menciona si excluyó los protocolos inválidos (bajo R, alto Lambda), usó las variables del Rorschach como categorías dicotómicas y no puntajes continuos, no controló variables confundientes como la presencia de distrés psicológico o tendencia a la somatización. Mas aún, la muestra es posible que no sea representativa de las características alexitímicas, los sujetos fueron voluntarios, reclutados de los cursos universitarios, lo que puede hacer que estén dispuestos a mostrarse a sí mismos, revelar sus problemas existenciales y de gozar de profundidad intelectual, como por otra parte reconoce la propia autora. También la muestra no es representativa de lo que uno puede esperar de las personas alexitímicas, pues en la población general se encontró que la alexitimia esta asociada positivamente con el género masculino, baja educación y edad mayor (Kauhanen et al., 1993; Joukamaa et al, 1995; Salminen et al., 1999; Honkalami et al, 2001), lo que es exactamente lo opuesto a los rasgos sociodemográficos de la muestra utilizada, compuesta predominantemente por jóvenes mujeres muy educadas."

Por último, el otro estudio Rorschach que consideraremos, de M. Prazeres (Prazeres, 1996), cuyos resultados según Porcelli son «muy prometedores y merecen atención y replicación», halló que Col-Shd Blends $>0$ y T $>0$ se correlacionan negativamente con los puntajes de alexitimia, tal como es esperable. 
Porcelli concluye su capítulo dedicado a Rorschach y Alexitimia (Porcelli, 2004) con las siguientes aportaciones: «No se puede tener una conclusión firme de los estudios Rorschach sobre alexitimia. Contrastando con el alto nivel de la cualidad del debate teórico, clínico y empírico, los estudios Rorschach están lejos de alcanzar tal nivel de calidad. A pesar de que la alexitimia es el campo de la psicosomática en el que los rorschachistas han mostrado mucho interés no alcanza el nivel de los estudios realizados en otras áreas de aplicación, como por ejemplo Psicopatología». Y más adelante plantea que, consistentemente con la literatura, los indicadores Rorschach esperadas en alexitímicos son:

a) El rasgo proceso imaginativo constreñido, que describe a los sujetos que carecen de capacidad para la introspección, no se aperciben de sus sentimientos y muestran una vida de fantasía pobre. Esos rasgos se identifican por las variables Rorschach relacionadas con la fantasía, por ejemplo, baja capacidad para usar las funciones ideacionales más elevadas; para volverse sobre sí mismo, tales como baja respuesta de movimiento humano (M), M particularmente adecuadamente percibido (bajo M con F de cualidad ordinaria e inusual, MA\%) y baja producción del conjunto de las respuestas de movimiento $(\mathrm{M}+\mathrm{FM}+\mathrm{m})$, baja capacidad para preservar el espacio transicional (puntajes de la Escala de Realidad Fantasía, RFS con puntajes positivos en el rango alto).

b) La característica de escasa expresión emocional, por su parte, describe a sujetos que son incapaces de procesar cognitivamente sus estados emocionales. Esta característica se capta por los indicadores Rorschach que registran la capacidad escasa para expresar (bajo WsumC) estados emocionales.

c) La dimensión pensamiento orientado al exterior describe a sujetos cuyo pensamiento es sobresimplificado, referidos a hechos, dirigidos a evitar la ambigüedad emocional y el involucramiento afectivo. El indicador Rorschach Lambda alto indica estilo de pensamiento simplista y evitativo. 
d) La característica relaciones interpersonales perturbadas describe a sujetos que tienen relaciones interpersonales superficiales y encuentran dificultoso establecer vínculos seguros e íntimos. Dicha dimensión se identifica a través de las variables Rorschach que muestran conformismo social (alto P), dificultad para establecer relaciones estables (bajo H puro y elevado CDI) y expresión dificultosa de las necesidades de relaciones íntimas con los otros significativos (protocolos sin $\mathrm{T}$, respuesta de Textura).

Otras características de los protocolos Rorschach de alexitímicos pueden encontrarse en variables que no predice el puntaje de la TAS-20, pero que sin embargo significativamente diferencian a los sujetos en los rangos de alexitimia elevada y baja.

Esas variables están relacionadas con:

- Escasa capacidad para controlar adaptativamente las descargas emocionales (bajo FC).

- Recursos internos limitados (bajo EA), escasa introspectividad (bajo FD) y estilo de afrontamiento inconsistente (EB ambigual).

- Pensamiento simple como evidencia de escasa complejidad psicológica (Bajo Blends, alto R-Eng, Códigos Especiales bajos), baja capacidad para la integración cognitiva de los estímulos externos (Zf bajo y bajo $\mathrm{DQ}+$ ), estereotipia ideacional (A elevado como la categoría de contenido predominante y al menos una PSV).

\subsubsection{Obstáculos metodológicos que pueden limitar la validez de los estudios} Rorschach en Alexitmia.

En la página 125 Porcelli informa sobre los problemas que pueden limitar la validez de los estudios Rorschach sobre alexitimia. Un problema es el uso de diferentes sistemas Rorschach, lo que dificulta las comparaciones entre los estudios. Otro problema es la demostración de falencias metodológicas básicas tales como el hecho de que los 
investigadores no ofrezcan datos sobre la confiabilidad de la codificación entre codificadores y la inclusión de protocolos no válidos, lo que cuestiona la confiabilidad del instrumento. Algunas veces la muestra es pequeña y no se aporta información acerca de cómo fue recolectada, introduciendo de ese modo muchas variables confusas que el investigador no controla. Las muestras de control a menudo se integraron por psiconeuróticos, sin informar cómo se los obtuvo ni con que medida se evaluó su diagnóstico. Dice: «Según nuestro punto de vista, entre los más importantes límites conceptuales, se encuentra la asunción subyacente de la falsa ecuación semántica: los estudios utilizaron pacientes con trastornos médicos que fueron, sin embargo, considerados psicosomáticos, a causa de la creencia no probada de que todos los pacientes psicosomáticos fueron considerados alexitímicos sin usar medidas apropiadas de evaluación de la alexitimia o usando medidas poco válidas. A menudo, algunos autores llamaron alexitimia a lo que, en cambio, era una enfermedad médica. Afortunadamente la adopción de la TAS-20 como medida de la alexitimia y del Rorschach Sistema Comprehensivo como el sistema standard promete mejorar la calidad de las futuras investigaciones».

\subsubsection{Propuesta de evaluación Rorschach de la alexitimia.}

P. Porcelli (2004) ofrece una propuesta de variables de alexitimia Rorschach que constituye, a nuestro entender, un avance respecto de la disponible de siete variables asociadas a la alexitimia de Acklin y Bernat (1987). Si bien Porcelli incorpora nuevas variables se basa en el cotejo teórico empírico del constructo (cognición, afecto y fantasía) que propusieron aquellos autores. Porcelli desarrolló una investigación con G. Meyer (2002) sobre 24 variables Rorschach, utilizando de modo concurrente la Escala Toronto de Alexitimia (TAS-20) para discriminar alexitimia definitiva, indeterminada o ausente. Su objetivo se dirigió a la predicción del criterio, empleando el Modelo de Regresión Jerárquica para predecir el promedio del puntaje TAS. Mediante la realización de un diseño de investigación destacable lograron demostrar la validez de 21 variables Rorschach asociadas al funcionamiento alexitímico. Entre ellas, dos no corresponden al Sistema Comprehensivo, el involucramiento con la tarea de dar respuestas R-engagement (R-eng, Meyer, 1996, 1997, 1999, 2000, 2001a, 2001b, 2003, 2004) y la Escala de Realidad y 
Fantasía (RFS) ${ }^{13}$. Porcelli, a partir de un trabajo sumamente crítico y cuidadoso, con una base de datos de muestras psicosomáticas de sus investigaciones previas en las que eliminó los protocolos Rorschach no válidos $(\mathrm{R}<14)$, informó los coeficientes de confiabilidad intercodificadores, trabajó para analizar variables «confundientes» como presencia de depresión (DEPI) y variables independientes como la duración de la enfermedad, nos ofrece así una propuesta muy refinada y actualizada para seguir investigando.

En un esfuerzo apreciable por colocar el Rorschach como instrumento poderoso en la investigación y definición de los diagnósticos diferenciales en el campo de la Psicosomática, P. Porcelli propone una lista de variables relacionadas con diferentes características descriptas en los sujetos alexitímicos, que podemos ver en el siguiente cuadro:

\begin{tabular}{|c|c|c|}
\hline Dimensión & Descripción & Variables \\
\hline Fantasía & $\begin{array}{l}\text { Constricción de los } \\
\text { procesos imaginativos }\end{array}$ & $\begin{array}{l}\text { Bajo M } \\
\text { Bajo MA\% } \\
\text { Bajo M+FM+m } \\
\text { RFS Positivo }\end{array}$ \\
\hline Afecto & $\begin{array}{l}\text { Expresión emocional } \\
\text { restringida }\end{array}$ & Bajo WSumC \\
\hline Cognición & $\begin{array}{l}\text { Estilo de pensamiento } \\
\text { simplístico, evitativo }\end{array}$ & Lambda elevado \\
\hline $\begin{array}{l}\text { Relaciones } \\
\text { Interpersonales }\end{array}$ & $\begin{array}{l}\text { Conformismo social y } \\
\text { dificultad en relaciones } \\
\text { cercanas }\end{array}$ & $\begin{array}{l}\text { Popular elevado } \\
\text { Bajo H puro } \\
\text { CDI elevado } \\
\mathrm{T}=0\end{array}$ \\
\hline Otras características & Afecto & Bajo FC \\
\hline
\end{tabular}

\footnotetext{
${ }^{13}$ En el Anexo informaremos sobre estos nuevos dispositivos, así como de los resultados hallados en nuestras muestras.
} 


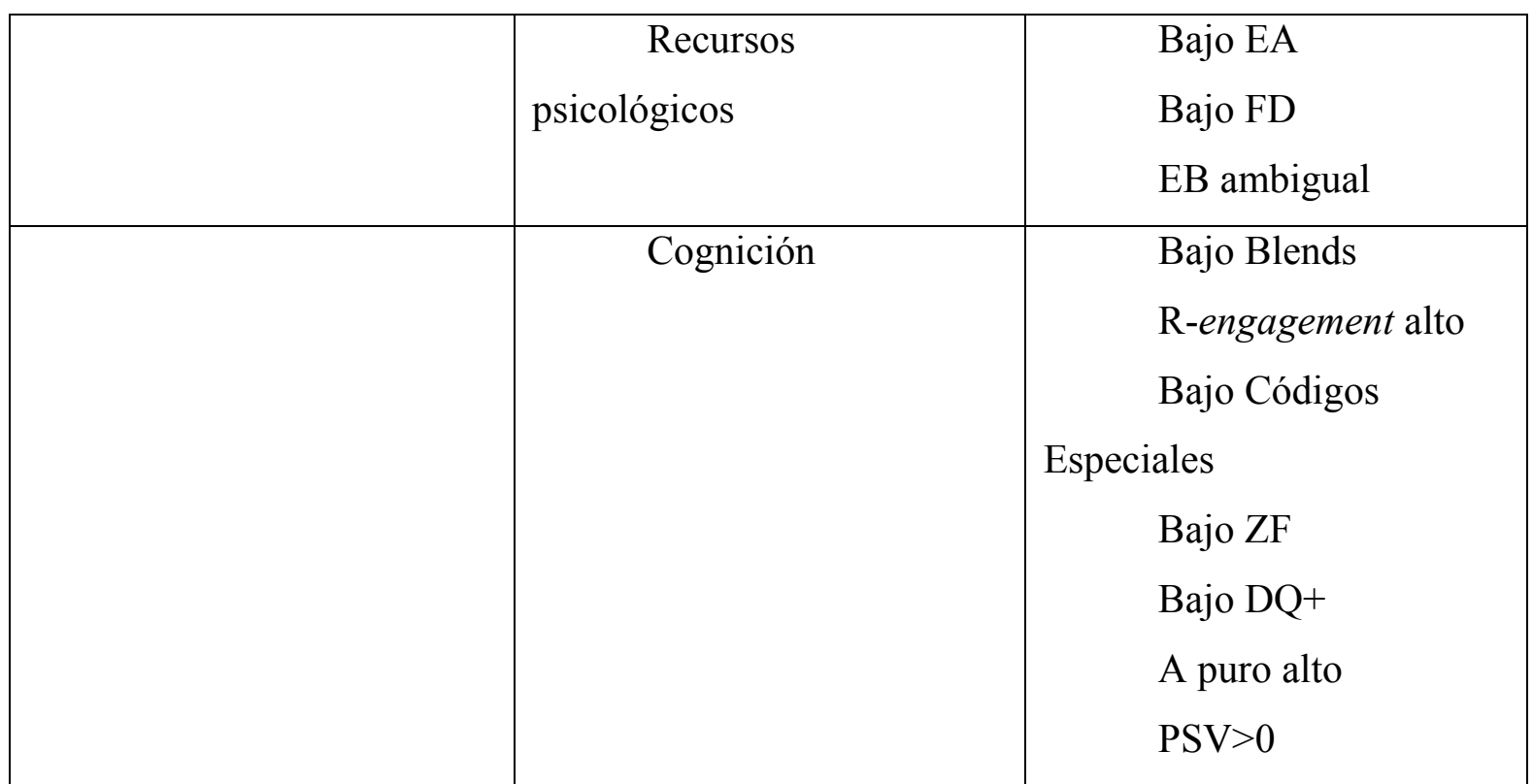

a) El rasgo de Constricción de los Procesos imaginativos describe a sujetos que carecen de la capacidad de introspección, que desconocen sus sentimientos y que muestran una marcada pobreza en la fantasía. Estos rasgos se identifican mediante las variables Rorschach relacionadas con fantasía, principalmente la poca capacidad para usar funciones ideacionales superiores, para dirigirse al propio sí mismo (self) por ejemplo.

b) Bajo movimiento humano (M), especialmente el percibido adecuadamente (Bajo M con Cualidad Formal ordinaria e inusual MA\%), baja producción del conjunto de las respuestas de movimiento $(\mathrm{M}+\mathrm{FM}+\mathrm{m}) \mathrm{y}$ escasa capacidad para usar y preservar el espacio transicional (puntaje de RFS en el rango positivo alto).

c) El Rasgo de Expresión emocional Restringida describe a sujetos que son incapaces para procesar cognitivamente los estados emocionales. Este rasgo se capta por las variables Rorschach que indican escasa habilidad para expresar estados emocionales (Bajo WsumC).

d) El Rasgo de pensamiento orientado hacia el exterior describe a sujetos cuyos pensamientos son sobresimplificados, referidos a actos, dirigidos a evitar ambigüedades emocionales y el involucramiento afectivo (Lambda elevado). 
e) El Rasgo de Relaciones Interpersonales perturbadas describe a sujetos que tienen relaciones interpersonales superficiales y que encuentran dificultad en formar vínculos seguros e íntimos. Este rasgo se identifica mediante las variables Rorschach que indican conformidad social (P elevado), dificultad para establecer relaciones estables (bajo $\mathrm{H}$ puro y alto CDI) y dificultad para expresar necesidades de relaciones íntimas con los otros significativos (protocolos sin $\mathrm{T}$, respuestas de textura).

También es valioso tomar en cuenta lo que P.Porcelli destaca cuando expone: «Otras características de los protocolos Rorschach de los alexitímicos pueden demostrarse en variables que no predicen los puntajes de la TAS-20, pero que, sin embargo, diferenciaron significativamente los sujetos en los rangos de puntaje de alexitimia elevada y baja. Estas variables están relacionadas con: escasa capacidad para controlar adaptativamente las expresiones emocionales (bajo FC); recursos internos escasos (Bajo EA), escasa introspectividad (bajo FD) y estilo de afrontamiento inconsistente (EB ambigual); pensamiento simplístico, tal como el evidenciado en escasa complejidad psicológica (bajo Blends, R-Engagement alto y bajos Códigos Especiales); escasa capacidad para la integración cognitiva de los estímulos externos (bajo Zf y DQ+); estereotipia ideacional (elevado A como la única categoría de contenido y al menos una PSV)» (Porcelli, 2004: 124).

Las características de la alexitimia en los protocolos Rorschach pueden evaluarse, entonces, por la presencia de los indicadores específicos sugeridos por P. Porcelli. Por nuestra parte, para el cometido de nuestra investigación, vamos a incorporar algunos otros indicadores, surgidos de nuestros propios trabajos. 


\subsection{Investigaciones y evaluaciones en la Artritis Reumatoidea (AR).}

A los fines de focalizarnos en la enfermedad psicosomática, que nos proponemos investigar, la Artritis Reumatoidea (AR) vamos a revisar específicamente los estudios y evaluaciones que se han desarrollado sobre ella. Dichos estudios podrán orientar o responder a las numerosas preguntas que el abordaje de la $\mathrm{AR}$, nos suscita, por ejemplo, su desencadenamiento, la respuesta al dolor e incapacidad, si se presenta heterogeneidad psicológica, etc.

Cabe necesariamente que nos planteemos si las características psicológicas que vamos a estudiar en los pacientes con AR han sobrevenido como consecuencia del desencadenamiento y desarrollo de la enfermedad, o si las precedían. Las alternativas que se abren entonces son: si las características psicológicas precedían a la enfermedad, no son directa consecuencia de ella y pueden considerarse rasgos, es decir, dimensiones estables de la personalidad. Si, por el contrario, las características psicológicas están asociadas con la aparición de la enfermedad, deberemos considerarlas un estado, o provocadas por la grave circunstancia. Estamos advertidos de que contestar a dicho planteo, si bien necesario, puede ser de difícil esclarecimiento. Es imprescindible reconocer constantemente, la interrelación y ponderación relativa de las dimensiones vinculares, culturales, biológicas, traumáticas, psicológicas y genéticas en las múltiples manifestaciones del enfermar humano, dimensiones, por cierto, sólo erróneamente aislables del todo. Recordamos que la artritis reumatoidea (AR) es una enfermedad discapacitante que afecta al $1 \%$ de la población mundial, chicos y adultos, en su mayoría afecta a mujeres entre los 25 y 50 años de edad, en una relación de 3 mujeres por cada hombre afectado. En la Argentina, según datos de la Secretaría de Salud del Gobierno de la Ciudad de Buenos Aires, 500.000 personas sufren de AR. Se trata de una enfermedad crónica, que los médicos no pueden curar, pero sí controlar. En virtud de la inflamación de la membrana sinovial de las articulaciones que puede devenir deformante, las personas se ven impedidas de llevar una vida productiva y de realizar acciones básicas tales como vestirse o bañarse solos. En los casos más avanzados pierden movilidad, la AR les impide interactuar con otras personas; la pérdida del status corporal a menudo deviene en aislamiento social. 
Los siguientes relevamientos permiten adquirir una noción más cercana de los efectos que el diagnóstico o la evolución de la enfermedad pueden acarrear a los pacientes: a) el $63 \%$ de aquellos que tenían un empleo al momento de ser diagnosticados se vieron obligados a dejar su trabajo, $b$ ) el 70\% de los pacientes dejan de hacer ejercicio y las tareas del hogar, mientras que los demás abandonan su vida social, c) el $81 \%$ de los pacientes dijo que la $\mathrm{AR}$ les crea frustración porque les limita la posibilidad de controlarse y desempeñarse en su vida cotidiana, $d$ ) la mayoría de los pacientes consultados afirman que la AR les impide cuidarse a sí mismos y e) el 52\% se encuentra severamente restringido para cuidar a su familia ${ }^{14}$.

Como puede desprenderse de la descripción de los efectos que la evolución de la AR produce en los pacientes, su sufrimiento y paulatina disminución, serían esperables también considerables consecuencias psicológicas resultantes. Tomando en cuenta, entonces, que nuestra pretensión es estudiar las características psicológicas (alexitimia) de los pacientes de AR, adquieren relevancia las investigaciones destinadas a probar si estas características preceden y acompañan a la enfermedad, o si son consecuencia de la enfermedad en sí misma.

Respecto de esta pregunta se encuentra abundante investigación con conclusiones similares. Citaremos en particular las investigaciones desarrolladas por Vollhardt y colaboradores, dado que reúnen los mejores requisitos metodológicos. B. Vollhardt (1982) identificó subgrupos apareados dentro de la $A R$, según presencia o ausencia de factor $A R$ seropositivo $^{15}$. Encontró que los pacientes con el factor AR seropositivo y cambios en las articulaciones evidentes mediante Rayos X eran los más homogéneos con respecto a las medidas psicométricas de síntomas de distress y trastornos del humor. Estos pacientes, sin embargo, mostraban menos psicopatología estadísticamente significativa que los AR a quienes les faltaba la combinación del factor sero de la AR y cambios articulares erosivos. Según este autor, el perfil psicológico de los pacientes seropositivos no puede ser considerado un fenómeno de adaptación a la inflamación articular crónica. Basa su

\footnotetext{
${ }^{14}$ Información de la Arthritis Foundation publicada en una nota en la Revista La Nación del 23 de octubre de 2000, p. 83.

${ }^{15}$ Se denomina seropositivo al paciente en cuyo suero sanguíneo se encuentra el gen o factor de la enfermedad.
} 
afirmación en que los pacientes no diferían psicológicamente entre sí, según indicaron los test psicológicos que los evaluaron, en dimensiones psicológicas consideradas previas a la enfermedad. Cuando nosotros analizamos sus resultados, obtenemos las siguientes enseñanzas: $a$ ) dentro de la AR hay subgrupos; dos subgrupos principales se establecen según la seropositividad o la seronegatividad; $b$ ) los pacientes seropositivos y con mayor erosión articular mostraron, sin embargo, menos psicopatología que el otro grupo; c) las características psicológicas de los seropositivos estaban presentes antes de la enfermedad y no pueden, por lo tanto, considerarse una adaptación a ella.

Vollhardt y su equipo investigaron también subgrupos de pacientes con AR equiparados según duración de la enfermedad y limitación funcional, y mostraron que la mayor psicopatología significativa estadísticamente se encontraba asociada a mayores antecedentes psicopatológicos en sus vidas. No fue la duración de la enfermedad en sí misma la asociada con la limitación funcional, sino las características psicopatológicas previas que continuaban. Además, un estudio de seguimiento que usó muchos indicadores del TAT (Test de Apercepción Temática de Murray) para evaluar las características alexítimicas encontradas en los pacientes seropositivos concluyó en que éstos no eran ni más ni menos alexitímicos que los otros grupos (Vollhardt, Ackerman y Shindledecker, 1986). Es decir, que la seropositividad o seronegatividad en sí misma no mostró asociación con la alexitimia.

Al menos de modo provisorio, tomemos nota de lo que sugieren sus conclusiones: a) Ser artrítico, tanto seropositivo como no seropositivo, no implica a la vez ser también necesariamente alexitímico, $b$ ) En la experiencia de dolor y de la limitación funcional, son significativos los mayores antecedentes psicopatológicos (más que los daños y la duración de la enfermedad en sí misma).

El problema que nos interesa, la discriminación entre características previas a la AR o resultantes de ella, ha sido pormenorizadamente también estudiado por G. Taylor, como vimos en la sección referida a alexitimia y personalidad: estado o rasgo. Su artículo $E l$ constructo alexitimia: conceptualización, validación y relación con dimensiones básicas de la personalidad (Taylor, 1994: 127) vincula a la alexitimia con las dimensiones básicas de la personalidad, y demuestra la estabilidad de la característica. La postula como un 
rasgo y no un estado, aunque no deberemos excluir, en lo posible, el estudio de cómo un estado crónico de enfermedad paulatinamente discapacitante aparece asociado a la presencia de alexitimia y al empleo o no de estrategias de afrontamiento por parte de los pacientes.

Los estudios parecen indicar, entonces, que las características psicológicas preceden a la enfermedad y la acompañan. Es decir, que la alexitimia se encuentra (o no) tanto en los seropositivos como en los seronegativos, que las características psicológicas eran previas al desencadenamiento de la enfermedad y que estas características evolucionaban de modo consecuente durante la evolución de la enfermedad. Es decir, a mayor psicopatología previa, mayor probabilidad de incremento de ésta en la evolución de la enfermedad. (Rice y col., 1999) (Fifield, 1998). Precisando, parece adecuado considerar a la experiencia del dolor o la limitación funcional como relacionadas con las características psicopatológicas previas del paciente y no como efectos exclusivamente resultantes de la magnitud del daño objetivamente presente.

Otra cuestión de gran interés para nosotros es conocer si los pacientes de AR presentarán rasgos comunes, como por ejemplo los descriptos en los cardíacos, como personalidad de tipo A, o si serán heterogéneos psicológicamente.

En la revisión de investigaciones que desarrollamos a continuación, procuraremos establecer si podrían reconocerse diferencias psicológicas significativas entre los pacientes con AR en función de: $a$ ) el desencadenamiento de la enfermedad; $b$ ) la respuesta al dolor, fatiga e incapacidad y $c$ ) la respuesta a la medicación.

\section{El desencadenamiento}

Sabemos que la AR fue clasificada en un tiempo entre las siete enfermedades psicosomáticas clásicas, dados sus componentes genéticos, orgánicos y psicológicos. Actualmente es conocida en su calidad de enfermedad autoinmune. Se considera que la enfermedad se inicia con una respuesta inmune anormal contra un virus común o bacteria, la cual entonces se vuelve auto-perpetrada (Baker, 1987). Las reacciones inflamatorias se instalan en el cuerpo, especialmente en las articulaciones, produciendo su deformación y 
rigidez. Se realizan múltiples estudios para acceder al conocimiento de las causalidades asociadas a las enfermedades autoinmunes. Como señala una fuente consultada, poco se ha avanzado desde los comienzos en ese sentido y «a pesar de que la AR debe incluir algún desequilibrio en la regulación inmunológica, exactamente porqué el sistema inmunitario de una persona pierde la capacidad para diferenciar entre las macromoléculas propias y las ajenas se desconoce (Schoenfeld y Schwartz, 1984)» (citado por Taylor y col., 1997).

Del mismo modo que en otras enfermedades autoinmunes, como la colitis ulcerosa de aparición juvenil, o el Tipo I de diabetes mellitus, un alto porcentaje de pacientes con AR informan haber experimentado experiencias emocionalmente muy estresantes previas al desencadenamiento o manifestación de la enfermedad. En otro grupo de casos, no se informan o el paciente desconoce la presencia de experiencias estresantes. Tal desconocimiento no es sorprendente, ya que hemos mencionado anteriormente el característico escaso reconocimiento de los pacientes psicosomáticos respecto de sus propios sentimientos y procesos psicológicos.

Como sucede con otras enfermedades tradicionalmente consideradas psicosomáticas, se han ahora identificado subtipos en la artritis reumatoidea, los que difieren tanto en los rasgos clínicos e inmunológicos como en las características de su evolución. Algunos estudios ${ }^{16}$ han también sugerido que hay heterogeneidad psicológica entre los pacientes de AR (Rimon, 1969; Rimon y Laakso, 1985) por ejemplo, identificaron un subtipo que estaba menos relacionado con factores genéticos y más influido por acontecimientos vitales emocionalmente estresantes y un segundo subtipo que se hallaba más asociado con factores hereditarios y menos con factores estresantes. Otros subtipos de esta enfermedad fueron identificados también por Crown, Crown y Fleming (1975), quienes encontraron que en los pacientes seropositivos al factor de la AR obtenían puntaje negativo en una escala de psicopatología neurótica, y que en cambio, los pacientes seronegativos puntuaban significativamente más alto. Estas investigaciones nos aportan entonces lo siguiente: $a$ ) habría heterogeneidad, pues en los desencadenamientos se encontraron diferentes factores, a veces estresantes, otras veces genéticos; $b$ ) los niveles de psicopatología son heterogéneos dentro de los pacientes.

\footnotetext{
${ }^{16}$ Los resultados de las investigaciones se obtuvieron del texto de Taylor y col. (1997).
} 


\section{La respuesta al dolor, fatiga e incapacidad}

Retomando las investigaciones que toman por objeto el riesgo a largo plazo de dolor, fatiga e incapacidad en los AR, si bien señalan que el dolor es una experiencia subjetiva única y que no hay una definición clara sobre cuál sería una conducta «normal» relacionada con el dolor (Rice y col., 1999), han puesto de manifiesto que la situación de perturbación emocional en la personalidad influye en la experiencia de dolor. La relación entre los síntomas de la AR y la presencia tanto previa como actual de perturbación emocional, atrae la atención de clínicos e investigadores. Podemos, por ejemplo, notar que en los informes Reuters Health Information 2002 (Journal of Arthritis, n. ${ }^{\circ}$ 29:78-86) se citan numerosos estudios sobre neuroticismo asociado al desarrollo de depresión en los pacientes con AR. Estimaremos entonces como establecida la siguiente conclusión: «un episodio de depresión mayor, si ocurre previamente al desencadenamiento de la AR, deja a los pacientes en riesgo de mayores niveles de dolor, aún años después del episodio depresivo mayor» (Fifield, 1998).

También J. Rice (1999) advierte que «El diagnóstico y tratamiento de este síntoma (dolor) es a menudo problemático a causa de las muchas condiciones que pueden causar dolor, la naturaleza subjetiva de la queja y la variedad de factores psicosociales que pueden modificar la experiencia de dolor». Es frecuente, en los consultorios, constatar que enfermos con grado leve de inflamación articular manifiestan en cambio alta queja de dolor, y también verificar la situación opuesta (Lunazzi, Lazzarino, Lojo, 1999). Es importante entonces enfatizar que no son los daños objetivos o las limitaciones causadas por la enfermedad los que determinan la experiencia de dolor, fatiga o incapacidad. Esta es una respuesta subjetiva heterogénea, mucho más asociada a la presencia de antecedentes psicopatológicos que a la enfermedad en sí misma.

\section{Respuesta a la Medicación}

En los artríticos reumatoides cabe señalar, como describimos antes, que se verifica un subgrupo con demostrada etiología genética asociada con menor perturbación emocional, y otro subgrupo en el cual la vulnerabilidad emocional aparece como lo más 
relevante y en clara relación con el dolor y la incapacidad que la AR puede traer aparejada. Sin embargo, es importante señalar que a pesar de las diferencias que acentúan más los antecedentes genéticos o las perturbaciones psicológicas, todos los pacientes responden en forma homogénea a los tratamientos médicos. Es decir, que la respuesta a los cambios erosivos articulares se ve modificada por la medicación, tanto pueda demostrarse o no la etiología.

En suma, las características psicológicas no son consecuencia de la enfermedad, sino que la preceden. Sería errónea la expectativa de homogeneidad entre los enfermos de AR. Como en todas las situaciones, los que se enferman son sujetos portadores de cualidades subjetivas únicas aunque puedan, sin embargo, también compartir otras de orden más general. Como vimos, por otra parte, los resultados de las investigaciones empíricas informan falencias, y por ello, no son concluyentes en cuanto a demostrar una asociación fuerte entre la alexitimia y esta enfermedad; excepto la posible influencia de rasgos psicopatológicos de personalidad previos sobre la experiencia del dolor, de la limitación y el estilo de afrontar la enfermedad de estos pacientes.

\subsubsection{Evaluación de la AR, mediante la TAS26 y TAS-20.}

A continuación veremos algunas de las investigaciones en las que se ha empleado la escala TAS específicamente en la artritis reumatoidea (AR). En un estudio realizado en la India, Fernández et al. (1989) usaron tanto el BIQ (Beth Israel Questionnaire) y la TAS (Toronto Alexithymia Scale) para evaluar la alexitimia en un grupo de pacientes con AR, comparados con un grupo de adultos saludables sociodemográficamente equivalentes. Los pacientes de AR calificaron significativamente más alto que los sujetos sanos tanto en el BIQ como en la TAS, y se encontró una correlación significativamente positiva entre las dos medidas. Basándose en el puntaje de corte establecido de la TAS, el 27.5\% de los pacientes con AR eran alexitímicos, comparados con sólo el 7.5\% de los sujetos sanos. Aunque la alexitimia no se halló relacionada con la duración de la enfermedad, los pacientes con AR y mayor impedimento funcional mostraron significativamente puntajes más altos en alexitimia. Se mencionan otros dos estudios más de estos autores, que han explorado la asociación posible entre alexitimia y AR, pero los pacientes no fueron categorizados en subgrupos fisiológicamente distinguibles (alexitimia primaria o secundaria), por lo que no los describiremos. 
En un estudio más reciente, pero de resultados menos concluyentes que el anteriormente mencionado, Jordan y Lumley (1993) administraron la TAS a un grupo de pacientes que estaban recibiendo tratamiento para su AR como pacientes externos de un gran hospital metropolitano de los Estados Unidos. Los pacientes también completaron evaluaciones de afectividad negativa, severidad de la percepción del dolor, control de la percepción de dolor, estrategias para manejar el dolor, funcionamiento psicosocial y nivel de actividad de la enfermedad. A pesar de que no hubo muestra de control con relación a este grupo, el puntaje medio de la TAS en los pacientes, según informaron, no fue significativamente diferente al poblacional normal.

Por nuestra parte, contrapuestamente, se hizo visible que, cuando evaluamos con la escala TAS a 30 pacientes concurrentes al Hospital Rossi de La Plata diagnosticados con artritis reumatoidea, el 87\% se incluyo dentro del rango alexitímico, y el 27\% de los casos presento alexitimia muy severa ( $\geq 74)$ (Lunazzi, Lazzarino, Lojo, 1999).

Notemos que en las investigaciones TAS en la AR los resultados que revisamos no son concluyentes y merecen al menos replicación con mejores recaudos metodológicos.

\subsubsection{Evaluación de la alexitimia en la AR mediante la Técnica Rorschach y el}

\section{Sistema Comprehensivo.}

Tal como informamos anteriormente la técnica Rorschach fue abundantemente empleada para la investigación de las características de personalidad de los psicosomáticos. Son sumamente escasas, sin embargo, las investigaciones mediante el Rorschach que tuvieron por objeto específicamente a la AR. Respecto de la AR, encontramos citado (Masling, 2002) un aporte de S. Fisher, quien en 1970 informó que las respuestas de los artríticos eran diferentes de las de otros pacientes, pues tendían a manifestar imágenes con límites duros y definidos, llamados por él de «barrera». En 1958 E. Cleveland y S. Fisher dieron a conocer su lista de contenidos Barrera/Penetración en las respuestas al Rorschach. Los contenidos «Penetración» aluden a objetos con límites frágiles o difusos, por ejemplo «nubes», «algas», «agua». Los contenidos «Barrera», en cambio, denotan fronteras bien definidas, por ejemplo «cráneo», «escarabajo» «castillo». 
En 1987, Acklin y Bernat propusieron un Índice de Alexitimia usando el Sistema Comprehensivo. El índice fue aplicado a pacientes con dolor crónico de columna sacra (Acklin, 1987). En un estudio subsecuente, Acklin y Alexander (1988) examinaron la validez del índice de alexitimia en cuatro grupos de pacientes psicosomáticos que presentaban: dolor sacro crónico, problemas gastrointestinales, trastornos dermatológicos y migraña. Según expresa el autor: «Las aplicaciones preliminares del índice de alexitimia fueron estimulantes para la discriminación de pacientes psicosomáticos de no-pacientes, y promisorios para futuras investigaciones empíricas. No obstante, ya que se trataba de resultados grupales, tienden a oscurecer una comprensión detallada de la naturaleza idiográfica de la alexitimia» (Acklin, 1990).

El cluster de indicadores de alexitimia propone agrupamientos de variables del Rorschach que evalúan funcionamientos: $a$ ) cognitivos: esterotipia (Lambda alto)y cognición concreta (Bajo Blend); $b$ ) afectivos: restricción afectiva (Suma C) y escaso afecto adaptativamente regulado $(\mathrm{FC}) ; c$ ) ideacionales: limitación de la vida imaginaria (bajo R y M) y $d$ ) adaptativos: deficiencias ideacionales y afectivas objetivables en el Tipo Vivencial restringido $(\mathrm{EA}<6)$ (Acklin, 1990: 181). Como se observa, la evaluación de estos funcionamientos guarda correspondencia con los cuatro factores investigados por la TAS.

El agrupamiento (cluster) de variables Rorschach indicadoras de alexitimia de Acklin y Bernat ha sido probado en diversas muestras de pacientes, pero sólo específicamente en la AR con sujetos jóvenes (Díaz Curiel, 1994), y se ha comprobado la mayoría.

Hemos, por nuestra parte (Lunazzi, 1999a, 1999b), hallado confirmación preliminar sobre la validez del agrupamiento de Acklin, excepto el Lambda Alto (Lunazzi, 2005).

Dentro de los hallazgos provenientes de nuestras investigaciones, como anticipamos al comienzo de este capítulo, en las que aplicamos, en forma conjunta o independiente, técnicas de evaluación objetivas (Escala TAS) y proyectivas (Rorschach Sistema Comprehensivo) en administraciones individuales, nos llamaron la atención los resultados de las muestras psicosomáticas donde incluimos pacientes con Artritis Reumatoidea. Los AR manifestaron en el Rorschach los mayores puntajes en el Índice de desvalimiento (C.D.I.), Índice de Estrés Crónico e Índice de Estrés Situacional (puntaje D y D ajustado), 
así como de Índice de Depresión (DEPI) (Lunazzi, 1999a). También, los pacientes con AR obtuvieron puntuaciones en Alto Lambda, puntuaciones no halladas en los demás pacientes psicosomáticos, pero cabe señalar, que la diferencia no fue estadísticamente significativa.

Nuestras investigaciones, mediante el uso de la Escala TAS y el Rorschach, Sistema Comprehensivo (Lunazzi, García de la Fuente, Elías y Kosak, 1997; Lunazzi, 1999a; Lunazzi, 2001a; Lunazzi, 2001b; Lunazzi, 2005a) en administraciones individuales a las distintas muestras de pacientes y no pacientes estudiadas, tanto la escala TAS como la técnica Rorschach (Sistema Comprehensivo de Exner) mostraron su eficacia para poner de relieve las características manifiestas del estilo cognitivo y afectivo del alexitímico, así como la dinámica y organización subyacente. La TAS permitió diferenciar muestras con elevada alexitimia y sin alexitimia asociadas con la presencia o ausencia de cuadro psicosomático. La técnica Rorschach informó sobre la estereotipia cognitiva, las limitaciones de los procesos de mentalización y el déficit en la regulación de los afectos, así como acerca de indicadores esperables en presencia de riesgo psicosomático ${ }^{17}$.

Díaz Curiel, en 1994, empleó 16 variables del SC en 39 niños (18 varones y 21 mujeres) que padecían Artritis Reumatoidea. Separó 5 subgrupos de la enfermedad, y 4 subgrupos según limitación funcional. Los resultados informaron que sólo FC fue significativo entre los 5 grupos. Se comprobó que el bajo Lambda (menor capacidad para desligarse de situaciones dolorosas o penosas) estuvo positivamente correlacionado con mayor daño funcional. El FC fue más alto en el grupo poliarticular seropositivo y más bajo en el grupo de AR sistémica. Esto es consistente con el perfil psicológico de estos jóvenes pacientes, los que se describieron como más controlados emocionalmente en el caso de ser seropositivos poliarticulares y emocionalmente más inmaduros si tenían AR sistémica. Además Lambda mostró una correlación inversa con la limitación funcional y la vulnerabilidad psicológica. La limitación funcional obtuvo correlación directa con An+Xy y SumC. A modo de conclusión general, los autores proponen que los protocolos Rorschach de los alexitímicos tendrían Bajo FC; Bajo CF, Bajo Afro, Alto S, Bajo Blends, Bajo M, Bajo EA y Alto Lambda.

\footnotetext{
${ }^{17}$ Proyecto de investigación H11/122 (1997-1999) La alexitimia como factor de riesgo psicosomático, Programa de Incentivos U.N.L.P. C.I.N.
} 
Dice al respecto Porcelli (2004: 108): «A pesar de que el estudio tiene limitaciones tales como no comunicar si se incluyeron protocolos inválidos, falta de índices de confiabilidad entre codificadores, comparaciones entre grupos de muy pequeño tamaño, falta de criterio externo para evaluar la alexitimia y la asunción semántica falsa, comunica importantes resultados: las formas mas graves de AR juvenil y alto impedimento funcional están asociadas con mucho sufrimiento psicológico y pobreza de los recursos de afrontamiento. Sin embargo sus hallazgos no podrían considerarse como representativos de un estudio Rorschach válido del constructo alexitimia».

El mencionado P. Porcelli ha realizado, como describimos antes, una agrupación de indicadores de alexitimia en el Rorschach más abarcativa que la precedente de Acklin y Bernat, incorporando otras características en afecto, cognición y recursos adaptativos. Incluye también la evaluación de las relaciones interpersonales (Porcelli, 2004: 125). Tomando en consideración que no se cuenta con referencias respecto de estudios Rorschach completos centrados en la AR y la alexitimia, poder aplicar los desarrollos de Porcelli promete, disponer de la propuesta más actualizada para encarar nuestro cometido.

Dado que M. Acklin y Bernat (Acklin, Bernat, 1989) habían elaborado un agrupamiento de indicadores Rorschach que evalúan la alexitimia con soporte teórico y empírico, evaluaremos su cumplimiento en nuestra investigación. Examinaremos también los resultados de los otros indicadores de alexitimia propuestos más recientemente (Porcelli, 2004), junto con otros surgidos de nuestro propio trabajo.

Como corolario de lo expuesto precedentemente, nos preguntamos en este trabajo, si la introducción de la categoría de análisis alexitimia permitirá describir las características psicológicas de los pacientes con Artritis Reumatoidea. Pensamos que el uso concurrente de multimétodos facilitará una descripción más completa de las características psicológicas, tornándolas mejor comunicables y tratables. 


\section{PARTE IV 2.4. Síntesis de la Revisión del Estado de la Cuestión.}

Las principales puntuaciones de la revisión del estado de la cuestión nos permiten reconocer que:

- La alexitimia se postula como un rasgo y no un estado.

Investigaciones longitudinales han permitido comparar la estabilidad de esta dimensión de la personalidad.

- Los puntajes altos en las TAS estuvieron asociados fuertemente con afectividad negativa. Se ha encontrado el más alto nivel de distress en pacientes con elevada alexitimia, pacientes que a su vez habían fracasado en usar estrategias de manejo activas y directivas, tales como ignorar o reinterpretar el dolor, emplear aseveraciones autoafirmativas e incrementar la actividad ocupacional.

- La falta de asociación entre depresión y alexitimia establece una diferencia entre los psicosomáticos y los psiconeuróticos, en los cuales se halla.

Si bien es indudable que la expresión verbal de las emociones está influenciada por las actitudes culturales y por las limitaciones impuestas por ciertos lenguajes, la restricción de los procesos imaginarios característica de la alexitimia no puede explicarse simplemente por influencias culturales. La alexitimia no es efecto de la cultura, como lo demuestran investigaciones con pacientes y no-pacientes de diversas culturas, y por la validación cruzada de las TAS y TAS-20 en muchos países diferentes, incluidos Italia, India, Japón y Corea.

Considerando que la inteligencia del niño y su medio social y familiar influencian el desarrollo de las habilidades léxicas y la expresividad emocional verbal, se podría esperar que la alexitimia muestre alguna asociación con la inteligencia, el nivel educacional y el status socioeconómico. Investigaciones preliminares, sin embargo, sobre la relación de la alexitimia y esas variables, han mostrado escasa o baja asociación con el nivel socioeconómico bajo, bajo nivel educativo y baja inteligencia. 
En la población general, sin embargo, como informan otras investigaciones, se encontró que la alexitimia está asociada positivamente con el género masculino, baja educación y edad mayor (Kauhanen et al., 1993; Joukamaa et al, 1995; Salminen et al., 1999; Honkalami et al., 2001). Otros investigadores, por su parte, sostienen que las clases populares se caracterizan por la orientación hacia los hechos externos, un estilo de pensamiento concreto, menor educación, una subcultura colectivista, un lenguaje menos psicologista y la expresión somatizada de las emociones. Aportando prueba empírica, citan que las investigaciones han encontrado una relación negativa entre el status social de clase baja y la alexitimia (Páez, Fernández y Mayordomo en Páez y Casullo, 2000).

Hallamos en los párrafos previos afirmaciones contrapuestas que promueven nuestro propio intento de verificación en la artritis reumatoidea (AR).

Tanto las características de personalidad como la presencia de psicopatología son heterogéneas dentro de los pacientes de AR.

Las investigaciones en la AR plantean que las características psicológicas de los pacientes con AR preceden al diagnóstico y no pueden considerarse una mera adaptación a la enfermedad. Se manifiestan tanto en el desencadenamiento de la enfermedad como en los modos de sobrellevarla. La alexitimia se encuentra - o no- tanto en los seropositivos como en los seronegativos, las características psicológicas eran previas al desencadenamiento de la enfermedad y estas características evolucionaban de modo consecuente durante la evolución de la enfermedad. Es decir, a mayor psicopatología previa, mayor probabilidad de incremento de ésta en la evolución de la enfermedad. La experiencia del dolor, la fatiga o la incapacidad es una respuesta subjetiva heterogénea, mucho más asociada a la presencia de antecedentes psicopatológicos que a la enfermedad en sí. A pesar de las diferencias que acentúen más los antecedentes genéticos o las perturbaciones psicológicas, todos los pacientes responden en forma homogénea a la medicación.

Las evaluaciones de la alexitimia en la AR mediante la TAS no son concluyentes: algunas investigaciones informan que los pacientes de AR calificaron significativamente más alto que los sujetos sanos tanto en el BIQ como en la TAS, encontrándose una correlación significativamente positiva entre las dos medidas. Basándose en el puntaje de corte establecido de la TAS, el 27,5\% de los pacientes con AR eran alexitímicos comparados sólo con el 7,5\% de los sujetos sanos. Otra investigación también informó que el $87 \%$ de los pacientes de AR puntuaron en el rango alexitímico y en el $27 \%$ de ellos 
apareció alexitimia muy elevada (>74). El factor I (capacidad para identificar y describir sentimientos) de la TAS mostró una limitación muy significativa $(\mathrm{p}<0,01)$ respecto de la muestra de no-pacientes de la misma ciudad.

Contrapuestamente, otra investigación con una muestra muy numerosa concluyó que, a pesar de que no hubo muestra de control con relación a este grupo, el puntaje medio de la TAS, para los pacientes de AR no fue significativamente diferente, si se lo compara con el de la población general.

Se puede cometer una «falsa ecuación semántica» si se supone que todos los psicosomáticos son alexitímicos o que todos los artríticos son sujetos homogéneos. Es indicado evaluar con un criterio externo la presencia de alexitimia, por ejemplo con la TAS. No obstante, la TAS ha resultado alto en sujetos no alexitímicos según el Rorschach. Es imprescindible el uso conjunto de multimétodos para su completa evaluación. La TAS, del mismo modo que otros autoinformes, no permite acceder al conocimiento del sujeto sino a cómo el sujeto supone que es y desea ser visto. El Rorschach evalúa en uno de sus ejes de análisis (procesos mentales relacionados con la elaboración ideacional y contenidos temáticos) la actividad imaginaria, pero ligada a los recursos cognitivos y la regulación afectiva del caso. Otras características de los protocolos Rorschach de los alexitímicos pueden mostrarse en variables que no predicen los puntajes de la TAS-20, pero que sin embargo diferenciaron significativamente a los sujetos en los rangos de puntaje en alexitimia elevada y baja. Un único método no puede dar una respuesta adecuada en el estudio de un constructo.

Las relaciones entre alexitimia, inteligencia y nivel social o educativo son controvertidas y no se han investigado en la AR.

No se han realizado aún investigaciones suficientemente confiables o específicas acerca de la presencia de alexitimia en la AR. Las investigaciones realizadas presentan objeciones y no se informa una respuesta fundada acerca de si se hallará o no alexitimia evaluada con la TAS.

Es destacada la utilidad del empleo del Rorschach en Medicina Psicosomática y en los Equipos de Salud. Sin embargo, se señalan limitaciones metodológicas en estudios Rorschach sobre alexitimia. Éstas consisten en falta de muestra control, falta de especificación en la selección de muestras, ausencia de una medida externa para ponderar su presencia o resultados no concluyentes. 
Emplear una medida externa, la TAS, para establecer la presencia o no de alexitimia, y el uso conjunto con otra técnica como el Rorschach, permitirá reconocer cuando se trata o no de alexitimia, aunque la TAS haya puntuado muy elevada. De este modo será especialmente interesante analizar como estos métodos diferentes se relacionan entre sí y cómo pueden usarse métodos distintos para comprender más ampliamente al constructo y al grupo o sujeto en evaluación. Es imprescindible el uso conjunto de multimétodos para la completa evaluación del constructo alexitimia.

No se encuentran investigaciones con la técnica Rorschach en adultos sobre la AR, ni tampoco estudios que investiguen la AR con el uso conjunto de la TAS y el Rorschach.

Si bien la alexitimia no es un estado, y no se la halló relacionada con la duración de la enfermedad, se informó que los pacientes con AR y mayor impedimento funcional mostraron puntajes significativamente más altos en alexitimia. No deberemos excluir el estudio de cómo un estado crónico de enfermedad paulatinamente discapacitante, con limitación funcional, aparece asociado a la presencia de alexitimia y al empleo-o no- de estrategias de afrontamiento por parte de los pacientes. 


\title{
Capitulo 3
}

\section{LA INVESTIGACIÓN}

\author{
Consideramos que aunque el constructo \\ alexitimia se refiere a problemáticas de varias \\ décadas, su valor nos sugiere el de los vinos \\ añejos, que requieren tiempo y conocimiento \\ para saborearlos. \\ R. SIVAK Y A. WIATER \\ (Alexitimia: la dificultad para verbalizar los \\ afectos)
}

Presentaremos en este Capítulo nuestra investigación, según el siguiente ordenamiento:

3.1 Problemas, Objetivos e Hipótesis

3.2 Metodología y Muestras

3.2.1 Procedimiento

3.2.2 Composición y obtención de las Muestras

3.2.3 Características de la Muestra I, Artríticos Reumatoideos (AR)

3.2.4 Selección, Codificación y Observaciones sobre las muestras.

\subsection{Problemas, Objetivos e Hipótesis}

Como corolario del recorte del cuadro psicosomático específico denominado artritis reumatoidea, (AR) notamos que:

- La asociación entre la alexitimia y la AR no está demostrada.

- No se encuentran investigaciones con la técnica Rorschach en adultos sobre la $\mathrm{AR}$, ni tampoco estudios que investiguen la AR con el uso conjunto de la TAS y el Rorschach.

- Las relaciones entre la alexitimia y el nivel socioeconómico o el nivel educativo son controvertidas y no se han investigado en la AR.

Son, entonces, nuestros objetivos:

1. Contribuir a la precisión del diagnóstico de la alexitimia en la AR. 
2. Validar el uso de dos técnicas destinadas para el diagnóstico de la alexitimia: la TAS26 y el Rorschach (Sistema Comprehensivo) y evaluar su funcionamiento (convergente o no) en el diagnóstico de la alexitimia.

Nos preguntamos, entonces:

¿Los pacientes con artritis reumatoidea manifestarán algún déficit en la regulación de los afectos, evaluable empíricamente?

¿Será tal déficit objetivable mediante el uso conjunto de técnicas que evalúan la alexitimia?

¿Podrá establecerse una asociación estadísticamente significativa, desde el punto de vista probabilístico, entre la alexitimia y la AR?

¿Se encontrarán asociaciones estadísticamente significativas, entre la alexitimia y el nivel socioeconómico y los años educativos?

Con los objetivos de investigar la posible asociación entre la alexitmia y la AR y aportar respuestas a la problemática enunciada, planteamos las siguientes hipótesis:

\section{Hipótesis:}

\section{Hipótesis 1:}

Los pacientes diagnosticados con artritis reumatoidea presentarán un déficit reconocible en la regulación de los afectos llamado alexitimia, evaluada mediante el empleo de multimétodos, tales como la Escala Toronto de Alexitimia (TAS26) y la técnica Rorschach (Sistema Comprehensivo).

\section{Hipótesis 2:}

De acuerdo al constructo teórico alexitimia, entendido como déficit de la regulación de los afectos, y por la naturaleza de los instrumentos de evaluación utilizados, (TAS26) y 
Rorschach (SC) a través de su uso conjunto o independiente, se podrán observar distintas asociaciones entre la alexitimia y el nivel socioeconómico o entre la alexitimia y los años educativos.

Son, entonces, nuestros objetivos:

1.-Contribuir a la precisión del diagnóstico de la alexitimia en la AR.

2.-Validar el uso de dos técnicas destinadas para el diagnóstico de la alexitimia: la TAS26 y el Rorschach (Sistema Comprehensivo) y evaluar su funcionamiento (convergente o no) en el diagnóstico de la alexitimia.

3.- Investigar si la alexitimia en la AR presenta asociaciones con el nivel socioeconómico y/o con los años educativos.

Poder demostrar la presencia de alexitimia no se orienta al sostenimiento de causalidades, más bien a constatar un hallazgo que, al ser ponderado, permitiría caracterizar y reconocer mejor a sus portadores. Consideramos que esta comprobación revestiría de utilidad tanto en la asistencia al paciente como en la asistencia del vínculo médico-paciente.

Se pretende que si se constata efectivamente la presencia de alexitimia, las conclusiones enriquecerán la comprensión del funcionamiento psicológico de los artríticos reumatoides y darán base a mejores estrategias terapéuticas. 


\subsection{Metodología y muestras}

\subsubsection{Procedimiento}

Nos propusimos, entonces, realizar un estudio enmarcado en el método hipotético deductivo, por el cual se tratará de justificar la hipótesis por medio de los resultados empíricos obtenidos mediante las técnicas aplicadas. Consiste en una investigación correlacional a los fines de medir el grado de relación que exista entre la categoría alexitimia y los pacientes en tratamiento por el diagnóstico de Artritis Reumatoidea (AR). Proponemos la categoría alexitimia como una variable que afecta la normal regulación de los afectos.

Las técnicas que aplicamos son los dos instrumentos más reconocidos en la actualidad para la evaluación de la alexitimia. La Escala Toronto de Alexitimia (TAS) consiste en un cuestionario con 26 preguntas que examinan los cuatro factores característicos de la alexitimia: Factor I: Dificultad para diferenciar sentimientos de sensaciones corporales; Factor II: Dificultad para comunicar los sentimientos; Factor III: Actividad imaginaria restringida; Factor IV: Pensamiento operatorio (el interés se halla dirigido a hechos o actividades externas, con escasa introspección). La TAS ha logrado 0.79 en los estudios que miden su validez y confiabilidad y permite, según los puntos de corte respectivos, establecer: la presencia definitiva de alexitimia, la alexitimia indeterminada y la ausencia de alexitimia.

La técnica Rorschach, conocida como «la de las manchas de tinta», propone que el sujeto dé respuestas sobre los parecidos que encuentra. La consigna «¿Qué podría ser esto?», al presentar las manchas, demanda a la vez procesos imaginarios, de regulación de emociones y racionales de ajuste perceptual al estímulo presentado. Al facilitar estímulos ambiguos, la técnica, a la vez que pone de manifiesto las dimensiones conocidas y desconocidas de la personalidad, impide que el sujeto pueda controlar voluntariamente sus respuestas. En las últimas décadas se ha desarrollado un nuevo sistema de administración, codificación e interpretación, el Sistema Comprehensivo, que ofrece una importante base empírica y rigor psicométrico. En el Sistema Comprehensivo se han investigado numerosos índices Rorschach que evalúan la alexitimia. Dichos indicadores agrupados, evalúan: $a$ ) los procesos imaginarios a través de la productividad y el uso de la capacidad 
de fantasía; $b$ ) la regulación de los afectos, según modulación o déficit de la modulación, de la excitabilidad emocional y disfórica; $c$ ) la cognición y su estilo de pensamiento concreto y preocupación por el cuerpo; $d$ ) las características de las relaciones interpersonales, a la vez orientadas por el conformismo cognitivo y social, la escasa introspección y la sobrecarga emocional.

Los instrumentos con los cuales recogimos los datos que nos indican alexitimia, son, como hemos descripto, de diferente índole. La TAS26 (Toronto Alexithymia Scale) consiste, como todo cuestionario autoadministrado, en una medida directa de lo que el paciente comprende que se le está preguntando, de lo que sabe de sí y de lo que está dispuesto a manifestar. El Rorschach investiga de modo indirecto la alexitimia, y el paciente desconoce a través de qué procedimientos se lo evalúa. Además, el Rorschach describe tanto aspectos de funcionamiento como de la estructura de la personalidad subyacente.

Hemos elegido emplear conjuntamente ambas técnicas, es decir, una metodología múltiple y complementaria, para investigar la asociación entre alexitimia y AR, por considerarla la más adecuada para el tipo de fenómeno que estudiamos. De este modo, tanto los métodos de evaluación objetivos y directos (TAS26) como los proyectivos (Rorschach, Sistema Comprehensivo), facilitarán la validación concurrente de la categoría alexitimia.

El procedimiento se desarrolló mediante el cotejo de una muestra I, integrada por pacientes diagnosticados como artríticos reumatoideos $(\mathrm{N}=60)$ y dos muestras II $(\mathrm{N}=60)$ y III, ( $\mathrm{N}=60)$ integradas por no-pacientes, es decir, sujetos normales que no se hallen ni hayan estado en tratamientos médicos, psiquiátricos o psicológicos. Las muestras I y II estuvieron compuestas por sujetos voluntarios, equiparados demográficamente en sexo, edad y nivel socioeconómico. Con el objetivo de delimitar la influencia de la variable años educativos en asociación con la alexitimia, cotejamos la muestra de artríticos reumatoides con una muestra III de no-pacientes de igual edad, pero con una diferencia altamente significativa en mayores de años educativos. En suma la muestra I de artríticos (AR), se comparó con la muestra II no-pacientes de igual nivel socioeconómico medio bajo. La muestra I de artríticos (AR), se comparó con la muestra III, no pacientes con muchos más 
años educativos. Para precisar las investigaciones de la asociación con años educativos y responder a nuevas preguntas que el estudio produjo, se establecieron dentro de las muestras, submuestras que permitieron realizar comparaciones más pormenorizadas.

Tomando en consideración que «Tanto los evaluadores como los evaluados viven inmersos en un tipo particular de sociedad, en un momento histórico concreto, en el que se ha llegado a un nivel de conocimientos específico, con una adscripción o pertenencia a un determinado estrato sociocultural y donde existe una serie de coordenadas que aportan marcos de referencia o modelos de relación entre sus miembros» (Sendín, Esbert, 2000), hemos considerado imprescindible controlar las variables derivadas del contexto social, que vuelven desaconsejable y sesgada la comparación con grupos propios de otras culturas. Por ello, las tres muestras que estudiamos se hallan homologadas según el contexto cultural. Todas ellas fueron obtenidas en el área del Gran La Plata, Argentina, y están compuestas por adultos de entre 18 y 65 años de edad, demográficamente representativos de la población. Como se señaló en el Capítulo 2, los resultados de la técnica Rorschach de los pacientes (AR), se compararon con los estadísticos descriptivos normativos de nopacientes de la misma población.

La comparación entre las muestras, en un total de 180 casos (cada una de ellas se compone de 60 casos) permitió evaluar la categoría estudiada, la alexitimia, y la presencia de variables asociadas con su desarrollo.

En síntesis, implementamos la realización de los siguientes procedimientos:

La aplicación de una entrevista semi-dirigida en forma individual, con enfoque clínico. Sus objetivos consisten en: $a$ ) el relevamiento de datos personales del paciente y de la historia de la enfermedad, necesarios para la elaboración de los resultados, y b) el desarrollo de un vínculo de trabajo propicio para la administración de las técnicas.

1. La administración de los instrumentos seleccionados de exploración psicológica, con el objetivo es evaluar la presencia (o no) de alexitimia. 
2. Los instrumentos de exploración psicológica seleccionados fueron: la Escala Toronto de Alexitimia (TAS26) y la Técnica Rorschach (Sistema Comprehensivo de Exner).

La selección de las mencionadas técnicas se fundó en los siguientes criterios:

a. La Escala TAS: consiste en un cuestionario sencillo y válido para evaluar la presencia de alexitimia, a la vez que introduce la secuencia de administración de técnicas en una relación de examen psicológico continente y poco demandante. Se dispone de una adaptación argentina, que ha demostrado adecuada confiabilidad y validez.

b. La Técnica de Rorschach, Sistema Comprehensivo': Aporta indicadores cuantitativos y cualitativos acerca de la estructura y funcionamiento de la personalidad y, en particular, sobre el déficit alexitímico. Su confiabilidad y validez presenta rigor psicométrico. Disponemos de los estadísticos descriptivos normativos de igual edad, de la población que estudiamos.

3. Estudio de la Elaboración Estadística de los datos cuantitativos: una vez que se implementó la metodología de la muestra testigo y las muestras de control, se sometieron los resultados obtenidos mediante los instrumentos de exploración psicológica a la elaboración estadística. Para reconocer el grado de significación de las diferencias de las medias de las muestras respecto de la variable alexitimia, se aplicó la prueba estadística «t» («t» de Student) para comparar dos grupos, y el ANOVA «F» de Fisher para establecer la comprobación o refutación de la hipótesis y la validación de los resultados diagnósticos, cuando se entrecruzan los resultados de varias muestras. Cuando las comparaciones lo requirieron se implementó la introducción de otras medidas estadísticas, tales como el Test de Diferencias de Proporciones, $\mathrm{CHI} 2$ y el Test de Tukey.

\footnotetext{
${ }^{1}$ El empleo del Sistema Comprehensivo, ampliamente utilizado en forma internacional, anticipa la contrastación con resultados de otras investigaciones relacionadas.
} 
4. Análisis cuanti-cualitativo de los funcionamientos y dimensiones que incluye el constructo alexitimia: este estudio se implementó a los fines de observar y definir las posibles particularidades propias de los sujetos que padecen AR.

5. Entrecruzamiento de los datos cuantitativos y cualitativos: mediante este análisis nos propusimos establecer el tipo de aporte de cada técnica utilizada y su efectividad.

\subsubsection{Composición y Obtención de las Muestras:}

\section{Muestra I: pacientes con artritis reumatoidea}

Se halla compuesta por 60 pacientes voluntarios, entre 18 y 65 años de edad, diagnosticados mediante pruebas de laboratorio como artríticos reumatoides. Presentan nivel socioeconómico medio, en las categoría medio- alto, medio- medio y medio-bajo. El nivel socio económico medio-bajo se halla presente en el 60\% de los casos. Los años educativos se distribuyen de la siguiente manera: 0-7 años educativos, en 33 casos, de 8 14 años educativos en 20 casos y $\geq 15$ en 7 casos. El promedio de años educativos de la muestra es de 7,3 años.

\section{Muestra II: sujetos no-pacientes}

Integrada por 60 no-pacientes normales voluntarios, entre 18 y 65 años de edad, sanos, sin enfermedad psicosomática, física o psicopatología manifiesta, que no se hallen ni hubieran estado en tratamientos psiquiátricos ni psicológicos, equiparados demográficamente con la muestra $\mathrm{A}$. El nivel socio económico medio-bajo, se considera equiparado con muestra I, ya que no presenta diferencias significativas. El promedio de años educativos de la Muestra II es 10, 66 años.

\section{Muestra III: sujetos no-pacientes}

Integrada por 60 no-pacientes normales voluntarios, entre 18 y 65 años de edad, sanos, sin enfermedad psicosomática, física o psicopatología manifiesta, que no se hallen ni hubieran estado en tratamientos psiquiátricos ni psicológicos. Presentan diferencias 
significativas en su mejor nivel de años educativos respecto de las muestras I. y II, ya que su promedio de años educativos es 15, 38 años.

\section{. Obtención de las Muestras:}

La muestra I se obtuvo en un hospital público perteneciente al Ministerio Nacional de Salud, el Hospital Rodolfo Rossi de La Plata, Servicio de Reumatología. Las muestras II y III normativas se seleccionaron de nuestra base de datos para la construcción de los Estadísticos Descriptivos en 506 no-pacientes de entre 18 a 65 años de edad, para la Técnica Rorschach (SC), en la región del Gran La Plata (Lunazzi y Col., 2006). La muestra II se integró con casos de semejante nivel socioeconómico medio-bajo, que la muestra I y se la equiparó demográficamente con ella. La muestra normativa III se seleccionó al azar, de la base de datos, con casos que tuvieran mayores años educativos que las muestras I y II.

Las muestras I, II y III están constituidas por sujetos voluntarios (Sampieri, 1998, pág. 227), ya que se trata de muestras fortuitas, en las que los sujetos llegan de modo casual a componerlas. Se los define como voluntarios, dado que por su propia voluntad acceden a participar en el estudio, cuando se los invita a participar en la investigación.

Presentaremos a continuación las características descriptivas de la muestra I (AR), ilustradas en los cuadros I a y I b:

\subsubsection{Características y Composición de la muestra I}




\section{Cuadro I a}

\section{Muestra I: Artríticos Reumatoideos. ( $\mathrm{N}=60$ pacientes)}

\section{Características de la Muestra}

\begin{tabular}{|c|c|c|c|c|c|c|c|c|}
\hline \begin{tabular}{|l|} 
No de \\
Caso
\end{tabular} & Edad & Sexo & $\begin{array}{l}\text { Años } \\
\text { Educ. }\end{array}$ & $\begin{array}{l}\text { Nivel } \\
\text { socio- } \\
\text { económico }\end{array}$ & Alexitimia & $\begin{array}{l}\text { Años de } \\
\text { Enfermedad }\end{array}$ & $\begin{array}{l}\text { Grado de } \\
\text { impedimento }\end{array}$ & Antecedentes \\
\hline 001 & 54 & fem & 11 & 3 & $\mathrm{D}$ & 10 & Mínimo & No \\
\hline 002 & 65 & fem & 7 & 3 & $\mathrm{I}$ & 8 & Mínimo & No \\
\hline 003 & 50 & fem & 1 & 3 & I & 12 & Mínimo & Sí \\
\hline 004 & 49 & fem & 1 & 3 & I & 34 & Mediano & No \\
\hline 005 & 42 & masc & 5 & 3 & $\mathrm{D}$ & 6 & Mediano & Sí \\
\hline 006 & 64 & fem & 7 & 3 & I & 6 & Mínimo & No \\
\hline 007 & 36 & fem & 15 & 3 & $\mathrm{D}$ & 12 & Severo & No \\
\hline 008 & 62 & fem & 1 & 2 & $\mathrm{I}$ & 12 & Mediano & No \\
\hline 009 & 65 & fem & 1 & 2 & I & 18 & Mínimo & Sí \\
\hline 010 & 58 & fem & 9 & 3 & $\mathrm{D}$ & 20 & Severo & No \\
\hline 011 & 43 & fem & 1 & 3 & $\mathrm{D}$ & 10 & Mediano & No \\
\hline 012 & 51 & fem & 12 & 2 & I & 12 & Mínimo & Sí \\
\hline 013 & \begin{tabular}{|l|l|}
3 & 65
\end{tabular} & fem & 10 & 3 & $\mathrm{D}$ & 44 & Severo & No \\
\hline 014 & 46 & fem & 6 & 3 & I & 3 & Mínimo & No \\
\hline 015 & 37 & fem & 12 & 2 & $A$ & 12 & Mínimo & No \\
\hline 016 & 30 & fem & 14 & 3 & $\mathrm{D}$ & 6 & Mínimo & No \\
\hline 017 & 45 & fem & 7 & 3 & I & 16 & Mínimo & Sí \\
\hline 018 & 56 & fem & 1 & 3 & $\mathrm{D}$ & 7 & Mediano & No \\
\hline 019 & 36 & fem & 14 & 2 & I & 12 & Mínimo & No \\
\hline 020 & 44 & fem & 11 & 3 & $\mathrm{D}$ & 5 & Mediano & No \\
\hline 021 & 45 & fem & 12 & 3 & I & 12 & Mediano & No \\
\hline 022 & 51 & masc & 7 & 2 & $A$ & 3 & Mínimo & No \\
\hline 023 & 40 & fem & 12 & 2 & I & 7 & Mínimo & Sí \\
\hline 024 & 37 & fem & 1 & 3 & $\mathrm{D}$ & 9 & Mínimo & Sí \\
\hline 025 & 44 & fem & 10 & 3 & $\mathrm{D}$ & 8 & Mínimo & No \\
\hline 026 & 28 & masc & 17 & 1 & I & 5 & Mínimo & Sí \\
\hline 027 & 48 & fem & 12 & 3 & $\mathrm{D}$ & 10 & Mediano & No \\
\hline 028 & 30 & fem & 10 & 2 & $\mathrm{D}$ & 6 & Mínimo & Sí \\
\hline 029 & 73 & fem & 4 & 3 & $\mathrm{D}$ & 6 & Mínimo & No \\
\hline 030 & 55 & fem & 12 & 2 & $\mathrm{D}$ & 7 & Mínimo & No \\
\hline 031 & 55 & masc & 12 & 3 & I & 20 & Mínimo & No \\
\hline 032 & 51 & masc & 2 & 2 & $A$ & 3 & Mínimo & No \\
\hline 033 & 53 & fem & 1 & 3 & I & 20 & Mínimo & No \\
\hline 034 & 23 & fem & 1 & 2 & $\mathrm{D}$ & 8 & Mínimo & No \\
\hline 035 & 30 & fem & 15 & 2 & I & 8 & Mínimo & No \\
\hline 036 & 39 & fem & 5 & 2 & $\mathrm{D}$ & 8 & Mínimo & No \\
\hline
\end{tabular}




\begin{tabular}{|c|c|c|c|c|c|c|c|c|}
\hline 037 & 59 & fem & 15 & 2 & $A$ & 4 & Mínimo & No \\
\hline 038 & 52 & fem & 4 & 3 & $D$ & 10 & Mínimo & No \\
\hline 039 & 39 & fem & 15 & 3 & I & 4 & Mínimo & No \\
\hline 040 & 45 & fem & 1 & 3 & $D$ & 36 & Mínimo & No \\
\hline 041 & 61 & fem & 10 & 2 & I & 7 & Mínimo & No \\
\hline 042 & 19 & fem & 1 & 2 & I & 1 & Mínimo & No \\
\hline 043 & 37 & fem & 8 & 2 & I & 12 & Mediano & Sí \\
\hline 044 & 47 & fem & 7 & 3 & $D$ & 2 & Mediano & No \\
\hline 045 & 51 & fem & 1 & 2 & I & 10 & Severo & No \\
\hline 046 & 41 & fem & 7 & 3 & $A$ & 10 & Mediano & Sí \\
\hline 047 & 44 & fem & 17 & 1 & I & 8 & Mínimo & No \\
\hline 048 & 58 & fem & 7 & 3 & $\mathrm{D}$ & 10 & Mediano & No \\
\hline 049 & 45 & fem & 1 & 3 & I & 3 & Mínimo & No \\
\hline 050 & 45 & fem & 7 & 3 & I & 16 & Mínimo & Sí \\
\hline 051 & 65 & fem & 10 & 3 & $D$ & 44 & Severo & Sí \\
\hline 052 & 46 & fem & 6 & 3 & I & 3 & Mínimo & Sí \\
\hline 053 & 65 & fem & 1 & 2 & I & 18 & Mínimo & Sí \\
\hline 054 & 28 & masc & 17 & 1 & I & 5 & Mínimo & Sí \\
\hline 055 & 40 & fem & 12 & 2 & I & 7 & Mínimo & No \\
\hline 056 & 37 & fem & 1 & 3 & $D$ & 9 & Mínimo & Sí \\
\hline 057 & 53 & fem & 1 & 3 & I & 20 & Mínimo & No \\
\hline 058 & 49 & fem & 1 & 3 & I & 34 & Mediano & No \\
\hline 059 & 37 & fem & 12 & 2 & $A$ & 12 & Mínimo & No \\
\hline 060 & 50 & fem & 1 & 3 & I & 12 & Mediano & No \\
\hline
\end{tabular}

\section{Cuadro I b}

\section{Muestra I: Artríticos Reumatoideos. ( $\mathrm{N}=60$ pacientes)}

\section{Características de la Muestra: distribución de la composición}

\section{Sexo:}

Mujeres:

54 casos $\quad 90 \%$

Varones:

6 casos $\quad 10 \%$

\section{Años educativos:}

$$
\begin{aligned}
& 0 a \leq 7 \\
& \geq 8 \leq 14 \\
& \geq 15
\end{aligned}
$$

$\begin{array}{rr}33 \text { casos } & 55 \% \\ 20 \text { casos } & 33,33 \% \\ 7 \text { casos } & 11.66 \%\end{array}$




\section{Nivel socioeconómico:}

1: Medio Alto

2: Medio Medio

3: Medio Bajo

\section{Alexitimia:}

D: Alexitimia definitiva

puntaje TAS $\geq 74$

puntaje TAS $\geq 62<74$

I: Alexitimia indeterminada

A: Alexitimia ausente
23 casos

$\begin{array}{rr}3 \text { casos } & 5 \% \\ 21 \text { casos } & 35 \% \\ 36 \text { casos } & 60 \%\end{array}$

6 casos $\quad 10 \%$

\section{Años de enfermedad:}

$$
\begin{aligned}
& 1-7 \\
& \geq 8 \leq 12 \\
& \geq 16 \leq 20 \\
& >30
\end{aligned}
$$

\section{Impedimento funcional:}

Mínimo

Mediano

Severo

Con antecedentes

Sin antecedentes
22 casos $36,66 \%$
25 casos $41,66 \%$
8 casos $13,33 \%$
5 casos $8,33 \%$

Como se observa, la muestra I se compone por 54 mujeres $(90 \%)$ y 6 varones $(10 \%)$. La distribución de la artritis reumatoidea informada por la Sociedad de Reumatología es de un varón cada tres mujeres. Observamos que en la muestra recolectada en el Hospital Rossi la proporción de presencia femenina es mayor.

Respecto de la edad, la distribución de la muestra de AR según rango de edad es 18$25=2$ casos; 26 a $35=5$ casos; 36 a $45=20$ casos; 46 a $55=21$ casos; 56 a $65=13$ casos, y se incluyó un solo caso que superaba el rango de edad.. Como puede notarse, la distribución de la muestra responde a la poblacional de la enfermedad, ya que es más común a partir de los 40 años, aproximadamente. 
En relación a la Presencia de antecedentes familiares de la Enfermedad: cuarenta y tres pacientes $(71,66 \%)$ informaron no tener antecedentes. Diecisiete $(28,33 \%)$ informó, en cambio, sobre la presencia de la enfermedad en miembros de sus familias. Para obtener esta información sobre componente genético en la muestra I, se solicitó la colaboración del Servicio de Reumatología, que facilitó los casos (Hospital R. Rossi de La Plata), pero se nos explicó que el hospital no disponía de los recursos para investigar esos datos y que sólo en casos muy excepcionales se los solicitaba.

La duración de la enfermedad al momento del estudio: la muestra I presentó la siguiente distribución: entre 2 y 7 años de declarada la enfermedad: 22 casos $=36,66 \%$; entre 8 y 12 años: 25 casos $=41,66 \%$; entre 16 y 20 años: 8 casos $=13,33 \%$ y $>30$ años: 5 casos $=$ $8,33 \%$.

Sobre el Impedimento funcional: la distribución del impedimento en la muestra I se presentó así: impedimento mínimo, 41 casos, lo que representa el 68,33\% de la muestra; impedimento mediano, 14 casos $=23,33 \%$; impedimento severo, 5 pacientes $=8,33 \%$. No se observó una asociación directa entre años de padecimiento de la enfermedad y mayor discapacidad física y dolor (impedimento funcional).

En Años educativos: Se registró la siguiente distribución entre la muestra I (AR): entre 0 a $\leq 7$ años educativos:33 casos (55\%); entre $\geq 8 \mathrm{y} \leq 14: 20$ casos $(33,33 \%)$ y los casos con $\geq 15$ años educativos: 7 casos $(11,66 \%)$.

La información sobre Nivel socioeconómico: puede verse en el cuadro I, según los siguientes códigos: nivel medio-alto $=$ código 1 ; nivel medio-medio $=$ código 2 , y nivel medio-bajo $=$ código 3 , distribuidos de la siguiente manera: nivel medio-alto $=3$ casos (5\%); nivel medio-medio: 21 casos (35\%), nivel medio-bajo: 36 casos (60\%).

Observamos que no hay una asociación directa entre más años educativos y mejor nivel socioeconómico. Hay casos que han logrado un nivel educativo superior (>14-15 años) y no pertenecen al nivel económico medio alto, se encuentran en el medio-medio y 
en el medio-bajo. Los pocos casos (3) de nivel económico medio alto, efectivamente exhiben los mayores años de educación (17 años).

La distribución de Presencia de alexitimia fue: alexitimia definitiva (D) puntaje TAS $\geq 74$ : 23 casos (38,33\%); alexitimia indeterminada (I) puntaje TAS $\geq 62<74: 31$ casos $(51,66 \%)$; alexitimia ausente (A) puntaje TAS $<62$ : 6 casos $(10 \%)$.

\subsubsection{Selección, codificación y observaciones sobre las muestras.}

La muestra original se compuso de 70 casos. Se eliminaron 4 por tratarse de protocolos no válidos $(<14 \mathrm{R})$ y 6 por asociación de la artritis reumatoidea (AR) con otra enfermedad, la más común lupus (LES).

Los casos de la muestra de artríticos (muestra I) fueron administrados y codificados por la autora. Los casos de las muestras de No pacientes (muestra II y III) fueron recolectados y administrados por las integrantes del equipo de investigación que dirigió la autora para obtener los estadísticos descriptivos de la región Gran La Plata (Lunazzi 2006a). El análisis realizado por T. Shaffer (figura en el Anexo5) informó para dicha investigación, un coeficiente de confiabilidad entre codificadores muy elevado. Igualmente, al seleccionarse de la muestra total de 506 no pacientes las muestras II y III fueron totalmente re codificados por la autora.

Conducta durante las entrevistas y la administración de las Técnicas:

Se trató en su gran mayoría de un grupo de pacientes bien dispuestos y colaboradores. También, a menudo propenso a utilizar la entrevista con discurso predominantemente catártico ( $80 \%$ de los casos, estimativamente). El resto de los pacientes tuvo características más controladas o represivas, pero en todos los casos con disposición adaptativa, no resistente. 
Escala Toronto de Alexitimia (TAS26)

A pesar de tratarse de un cuestionario autoadministrable, la muestra de pacientes artríticos presentó dificultades de comprensión y fue necesario para asegurar la confiabilidad de la evaluación que la examinadora acompañara la tarea y explicara cada pregunta. En las muestras de no-pacientes II y III, no se manifestaron dificultades de comprensión que se comunicaran en preguntas al examinador.

Técnica Rorschach, Sistema Comprehensivo de Exner

De una muestra inicial de pacientes artríticos compuesta por 70 casos, se excluyeron 4 por contener Rorschach no válidos $(\mathrm{R}<14)$. En la muestra II, no-pacientes de nivel socioeconómico medio bajo, se eliminaron 2 protocolos por ser inválidos $(\mathrm{R}<14)$.

Las composiciones y distribución de características propias de las muestras II y III se ilustrarán en los respectivos cuadros comparativos que se ilustran en el siguiente capítulo. 


\section{Capitulo 4}

\section{Resultados obTenidos en la Escala Toronto De Alexitimia.}

\begin{abstract}
Uno está todo el tiempo interpretando la propia experiencia, esta capacidad se despliega a partir de la etapa transicional del desarrollo.La separación de los objetos originarios es un proceso gradual. Inicialmente el niño experimenta indiferenciación entre su sí mismo y el otro. Al comienzo experimenta al otro como separado, pero bajo su control omnipotente. A través del uso del objeto transicional (un objeto que es simultáneamente interno y externo) el niño gradualmente renuncia a esa omnipotencia y los objetos son vistos como firmemente enraizados en la realidad externa. El objeto transicional en sí mismo es renunciado y deja atrás -en el desarrollo saludable- un espacio potencial en el cual la realidad externa e interna pueden ser integradas y creadas significativamente.
\end{abstract}

D.W. WINNICOTT (Realidad y Juego)

En este capítulo vamos a presentar y comentar los resultados obtenidos por la Escala Toronto de Alexitimia (TAS26). Analizaremos las comparaciones entre las muestras, tomando en cuenta sus características y datos demográficos, de acuerdo al siguiente plan:

\subsection{Escala Toronto de Alexitimia (TAS26)}

4.2 Composición de las Muestras y Resultados de las Muestras I y II.

4.3 Composición de las Muestras y Resultados de las Muestras I y III

4.4 La TAS26 y la Escala de Realidad/ Fantasía (RFS), (Tibon S, 2003)

\subsection{Estudio Cualitativo de la TAS}

4.6. Discusión de Resultados TAS

4.7. Conclusión 


\subsection{Escala Toronto de Alexitimia (TAS26)}

La escala TAS, recordamos, permite obtener un puntaje total y además, según los puntos de corte establecidos, reconocer los distintos niveles de la presencia de alexitimia. Cuando el puntaje obtenido es $\geq 74$, el nivel de alexitimia es definitivo (D); cuando el puntaje es $<74$ y $\geq 62$ el nivel es indeterminado (I), mientras que un puntaje $<62$ indica ausencia de alexitimia (A). Estamos tomando los puntos de corte, como señalamos previamente, que permiten comparar nuestros resultados con las aplicaciones internacionales (Petot, 1996; Tibon, 2002; Porcelli, 2004). El rango de alexitimia indeterminada, no significa ausencia de alexitimia, indica la pertenencia al rango alexitimia, pero no definitivamente estructurado. Utilizamos los puntajes totales y los niveles de presencia de alexitimia para comparar como influyeron en los resultados de la TAS la presencia o ausencia de enfermedad psicosomática (comparaciones entre pacientes y no pacientes). Comparamos estos resultados, entre pacientes y no pacientes, homologando el nivel socioeconómico (muestras I y II ) y controlando la variable años educativos para evaluar si los mayores años educativos afectaban los resultados de la TAS (muestra I y III). Para pormenorizar la investigación del efecto del nivel socioeconómico y de los años educativos comparamos submuestras dentro de la muestra de pacientes (muestra I ) para evaluar diferencias que fueran significativas.

\subsection{Composición de las muestras y resultados de las Muestras I y II}

\section{Evaluación del nivel socioeconómico}

Evaluamos el nivel socioeconómico mediante un estudio compuesto de los siguientes datos relevados: Empleo actual; Antigüedad en el empleo (meses y años); Tipo de trabajo (1: Estable, 2: Contratado, 3: Inestable); Empleos anteriores; Cobertura social (1: Sí; 2: No); Aportes jubilatorios (1: Sí; 2: No); Vivienda propia (1: Sí; 2: No); Zona (1: Urbana; 2: Suburbana). Este análisis permite la asignación de un código que representa el nivel socioeconómico medio alto (1), el nivel medio-medio (2) y el nivel medio-bajo (3). Obsérvese que en todos los casos se indican niveles medios. La muestra poblacional que estamos utilizando no contiene nivel bajo, reservado a personas indigentes, ni nivel alto, con niveles financieros muy superiores. 
CUADRO II a

Compara artríticos $(n=60)$ con no-pacientes $(n=60)$

homologados según nivel socioeconómico medio-bajo

\begin{tabular}{|c|c|c|c|}
\hline & $\begin{array}{l}\text { Artríticos } \\
N=60\end{array}$ & $\begin{array}{c}\text { No- } \\
\text { pacientes } \\
N=60\end{array}$ & Significación \\
\hline Edad & $\begin{array}{l}\text { Promedio }=46, \\
88 \\
\text { D.S. }=11,55\end{array}$ & $\begin{array}{l}\text { Promedio }=44,4 \\
3 \\
\text { D.S. }=12,05\end{array}$ & $\begin{array}{l}P=0,258 \\
N . / S .\end{array}$ \\
\hline Años educativos & $\begin{array}{l}\text { Promedio }=7,3 \\
6 \\
\text { D.S. }=5,29\end{array}$ & $\begin{array}{l}\text { Promedio }=10,6 \\
6 \\
\text { D.S. }=3,64\end{array}$ & $\begin{array}{l}P=0,000 \\
\text { A./S. }\end{array}$ \\
\hline $\begin{array}{l}\text { Nivel } \\
\text { socioeconómico }\end{array}$ & $\begin{array}{l}\text { Nivel medio- } \\
\text { bajo } \\
60 \%\end{array}$ & $\begin{array}{l}\text { Nivel-medio } \\
\text { bajo } \\
50 \%\end{array}$ & $\begin{array}{l}P=0,359 \\
\text { N./S. }\end{array}$ \\
\hline $\begin{array}{l}\text { Alexitimia definitiva } \\
\text { (TAS } \geq 74 \text { ) }\end{array}$ & $\begin{array}{l}\text { Promedio }=84, \\
04 \\
D . S .=5,62 \\
N=23\end{array}$ & $\mathrm{~N}=0$ & $\begin{array}{l}P=0,000 \\
\text { A./S. }\end{array}$ \\
\hline $\begin{array}{l}\text { Alexitimia } \\
\text { indeterminada } \\
\text { TAS }<74 \text { - TAS } \geq 62\end{array}$ & $\begin{array}{l}\text { Promedio=68, } \\
7 \\
\text { D.S. }=2,9 \\
\mathrm{~N}=31\end{array}$ & $\begin{array}{l}\text { Promedio }=64,3 \\
3 \\
D . S=1,92 \\
N=24\end{array}$ & $\begin{array}{l}P=0,000 \\
A / S .\end{array}$ \\
\hline $\begin{array}{l}\text { Ausencia de } \\
\text { Alexitimia } \\
(\mathrm{TAS}<62) \text {. }\end{array}$ & $\begin{array}{l}\text { Promedio }=57, \\
33 \\
\text { D.S. }=1,03 \\
N=6\end{array}$ & $\begin{array}{l}\text { Promedio }=54,2 \\
2 \\
\text { D.S. }=3,98 \\
N=36\end{array}$ & $\begin{array}{l}P=0,067 \\
N / S\end{array}$ \\
\hline Puntaje Total TAS & $\begin{array}{l}\text { TAS } \\
\text { Promedio }=73, \\
45 \\
\text { D.S. }=9,90\end{array}$ & $\begin{array}{l}\text { TAS } \\
\text { Promedio }=58,2 \\
6 \\
\text { D.S. }=5,99\end{array}$ & $\begin{array}{l}P=0,000 \\
\text { A./S. }\end{array}$ \\
\hline
\end{tabular}

N/S: Diferencias no significativas; S: Diferencias significativas; A/S: Diferencias altamente significativas.

Los resultados en las muestras de artríticos y no-pacientes de igual nivel socioeconómico (medio bajo) muestran que no se hallaron diferencias significativas (N/S) respecto de la edad, nivel socioeconómico y ausencia de alexitimia (TAS<62).

Se registraron, en cambio, diferencias altamente significativas (A/S) entre Alexitimia Definitiva (TAS $\geq 74$ ) presente en los artríticos, y el puntaje total obtenido en la TAS, muy superiores en los pacientes.

La primera observación importante que podemos hacer es que la muestra de artríticos reumatoideos (AR) evaluada por la TAS26, informa:

1. un puntaje total de alexitimia con diferencias altamente significativas (A/S), respecto de los no pacientes de igual edad y nivel socio económico medio bajo. 
2. diferencias altamente significativas $(\mathrm{A} / \mathrm{S})$ en presencia de alexitimia definitiva: en AR el 38\% de los casos, y $0 \%$ en los no-pacientes.

3. diferencias altamente significativas $(\mathrm{A} / \mathrm{S})$ en alexitimia indeterminada, mayor entre los pacientes.

4. También queremos destacar que, si trabajamos con porcentajes, la ausencia de alexitimia fue sólo del 10\% entre los pacientes de la muestra I, mientras que del $60 \%$ en la muestra II (AR 10\% y 60\% de ausencia de alexitimia entre los nopacientes). Al trabajar con promedios, las diferencias no fueron estadísticamente significativas, como puede apreciarse en el Cuadro II. Sin embargo claramente la proporción de ausencia de alexitimia es mucho mayor entre los no-pacientes.

Ya que destacadamente obtuvimos en los pacientes un puntaje total de alexitimia muy alto y la presencia de un 38\% de alexitimia muy elevada, los resultados permiten sostener la capacidad discriminante de la TAS para el diagnóstico de la alexitimia entre los pacientes de AR y los no-pacientes de semejante nivel socioeconómico. Esta validez fue previamente informada en enfermos psicosomáticos, pero no concluyentemente en la AR.

\section{Resultados}

Son observables en los resultados tendencias que corroboran el hallazgo, los pacientes de AR presentan diferencias altamente significativas en el puntaje total y en la presencia de alexitimia definitiva (D). Los no-pacientes con diferencias muy significativas no presentaron alexitimia definitiva, menor alexitimia indeterminada y mucho menor ausencia de alexitimia.

Al haber homologado el mismo nivel socioeconómico y la edad, la variable independiente es la presencia de enfermedad psicosomática (presente en la Muestra I). Aun faltaba investigar si los diferentes niveles socioeconómicos afectan en sí mismos los puntajes y niveles de alexitimia. Para ello hicimos comparaciones de sub muestras de diferente nivel socioeconómico dentro de la muestra I., comparando los niveles medio alto, con medio medio y medio bajo. Los resultados se informan en el siguiente cuadro: 
CUADRO II b Nivel socioeconómico y Alexitimia MUESTRA I

Compara artríticos $(n=60)$, mediante submuestras

según niveles socioeconómicos medio-alto, medio medio y medio-bajo

\begin{tabular}{|c|c|c|}
\hline $\begin{array}{l}\text { Nivel socioeconómico medio alto } \\
3 \text { casos }\end{array}$ & $\begin{array}{l}\text { Nivel socioeconómico medio } \\
\text { medio } \\
21 \text { casos }\end{array}$ & $\begin{array}{l}\text { Nivel socioeconómico medio } \\
\text { bajo } \\
36 \text { casos }\end{array}$ \\
\hline$\%$ & $\begin{array}{l}\text { Alexitimia definitiva } \\
4 \text { casos } \\
19,04 \%\end{array}$ & $\begin{array}{l}\text { Alexitimia definitiva }(\mathrm{TAS} \geq 74 \\
19 \text { casos } \\
52,77 \%\end{array}$ \\
\hline $\begin{array}{l}\text { Alexitimia indeterminada } \\
3 \text { casos } \\
100 \%\end{array}$ & $\begin{array}{l}\text { Alexitimia indeterminada } \\
12 \text { casos } \\
57,14 \%\end{array}$ & $\begin{array}{l}\text { Alexitimia indeterminada } \\
16 \text { casos (TAS }<74-\text { TAS } \geq 62 \text { ) } \\
44,44 \%\end{array}$ \\
\hline$*$ & $\begin{array}{l}\text { Alexitimia ausente } \\
5 \text { casos } \\
23,80 \%\end{array}$ & $*$ ausencia $($ TAS $<62)$ \\
\hline
\end{tabular}

Se compararon entre sí submuestras de nivel socioeconómico medio alto (código 1) con nivel socioeconómico medio medio (código 2); de nivel socioeconómico medio medio con nivel socioeconómico medio bajo (código 3); de nivel socioeconómico medio alto, (código 1) con nivel socioeconómico medio bajo (código 3);

Significación

* Las comparaciones con 0 de presencia no se informan

Submuestras 2 y $3 \quad \mathrm{P}=0.498 \quad \mathrm{~N} / \mathrm{S}$ (alexitimia definitiva)

Submuestras 1 y $2 \quad \mathrm{P}=0.472 \quad \mathrm{~N} / \mathrm{S}$

Submuestras 2 y $3 \quad \mathrm{P}=0.777 \quad \mathrm{~N} / \mathrm{S}$ (alexitimia indeterminada)

Submuestras 1 y $3 \quad \mathrm{P}=0.255 \quad \mathrm{~N} / \mathrm{S}$

Comprobamos que en todas las comparaciones relativas a diferentes niveles socioeconómicos los resultados no mostraron diferencias significativas. 
En consecuencia, y habiendo homologado el nivel socioeconómico entre las muestras I y II, podemos afirmar que la categoría alexitimia, evaluada por la TAS, resultó no asociada al nivel socioeconómico, y sí, en cambio, a la presencia de enfermedad psicosomática, en este caso AR.

Pasemos ahora a estudiar la intervención de la variable educación y su asociación con la alexitimia. Veremos si se modifican - o no- los resultados de la TAS cuando se introducen diferencias muy significativas en los años educativos y se flexibiliza la pertenencia al nivel socio económico medio bajo..

En esta dirección, si comparamos nuevamente las muestras I y II, encontramos que en la muestra I (AR) el promedio de años educativos es de 7,36 (DS 5,29), mientras que el de la muestra II, no pacientes de igual nivel socioeconómico medio bajo, el promedio es 10,66 (DS 3,64), y se determinan diferencias altamente significativas, estadísticamente (A/S). En estas muestras fehacientemente homologadas, las diferencias educativas, sin embargo, necesitan ser profundizadas.

Dado que deseamos discriminar la influencia posible de los años educativos en la presencia de alexitimia evaluada por la TAS, continuaremos con las comparaciones entre los pacientes y otra muestra de no pacientes, con diferencias aún más importantes en años educativos: en todos los casos los 60 voluntarios tendrán más de 8 años de educación y un promedio de 15 años educativos. Introdujimos esta Muestra III, para permitir comparaciones no sesgadas por el nivel socio económico medio bajo (Muestra II), seleccionando al azar de nuestra base normativa de datos, los casos que tuvieran más de 8 años educativos. Utilizar esta nueva muestra prestó utilidad en la evaluación de la Escala de realidad y Fantasía y en otras variables de la Técnica Rorschach.

\section{Evaluación del nivel educativo}

Cuando realizamos la entrevista a los voluntarios para la recolección de datos, realizamos la evaluación de la educación recibida mediante dos preguntas: $a$ ): años completados y $b$ ) grado alcanzado. A menudo las respuestas fueron «tengo secundario» o «hice el primario», pero recién cuando se pregunta «que grado aprobó», como puede advertirse, sólo utilizando las dos preguntas se obtiene suficiente precisión. Los estudios 
entre 0-7 años corresponden a la instrucción primaria; entre 8 y 13 a la secundaria, mientras que 15 ó más años educativos indican educación terciaria y universitaria.

4.3. Composición de las muestras y resultados de las Muestras I y III

$$
\text { CUADRO III }
$$

MUESTRAS I Y III: COMPARA ARTRITICOS $(\mathrm{N}=60)$ CON NO-PACIENTES $(\mathrm{N}=60)$ CON AÑOS EDUCATIVOS $\geq 15$

\begin{tabular}{|c|c|c|c|}
\hline & $\begin{array}{l}\text { Artríticos } \\
\mathrm{N}=60\end{array}$ & $\begin{array}{c}\text { No } \\
\text { pacientes } \\
N=60\end{array}$ & Significación \\
\hline Edad & $\begin{array}{l}\text { Promedio }=46,88 \\
\text { D.S. }=11,55\end{array}$ & $\begin{array}{l}\text { Promedio }=33,18 \\
\text { D.S. }=10,47\end{array}$ & $P=0.000 \mathrm{~A} / \mathrm{S}$ \\
\hline $\begin{array}{l}\text { Años } \\
\text { educativos }\end{array}$ & $\begin{array}{l}\text { Promedio 7,36 } \\
\text { DS = 5, } 29\end{array}$ & $\begin{array}{l}\text { Promedio } \\
15,38 \\
\text { DS }=2,37\end{array}$ & $\begin{array}{l}P=0.000 \mathrm{~A} / \mathrm{S} \\
\mathrm{t}=10,72\end{array}$ \\
\hline $\begin{array}{l}\text { Nivel } \\
\text { socioeconómico }\end{array}$ & $\begin{array}{l}\text { Medio alto } 5 \% \\
\text { Medio medio } \\
35 \% \\
\text { Medio bajo } 60 \%\end{array}$ & $\begin{array}{l}\text { Medio alto } 26 \% \\
\text { Medio medio } \\
66 \% \\
\text { Medio bajo } 8 \%\end{array}$ & $\begin{array}{l}P=0,000 \text { A./S. } \\
P=0,000 \text { A./S. } \\
P=0,000 \text { A./S. }\end{array}$ \\
\hline $\begin{array}{l}\text { Alexitimia } \\
\text { definitiva }\end{array}$ & $\begin{array}{l}\text { Promedio }=84,04 \\
\text { D.S. }=5,62 \\
N=23\end{array}$ & $\begin{array}{l}\text { Promedio }=0 \\
\mathrm{~N}=0\end{array}$ & $P=0,000$ A./S. \\
\hline $\begin{array}{l}\text { Alexitimia } \\
\text { indeterminada }\end{array}$ & $\begin{array}{l}\text { Promedio }=68,7 \\
\text { D.S. }=2,9 \\
N=31\end{array}$ & $\begin{array}{l}\text { Promedio }=62,42 \\
D . S=1,90 \\
N=20\end{array}$ & $P=0,082 \mathrm{~N} / \mathrm{S}$ \\
\hline $\begin{array}{l}\text { Ausencia de } \\
\text { Alexitimia }\end{array}$ & $\begin{array}{l}\text { Promedio }=57,33 \\
\text { D.S. }=1,03 \\
N=6\end{array}$ & $\begin{array}{l}\text { Promedio }=54,40 \\
\text { D.S. }=3,98 \\
N=40\end{array}$ & $P=0,080 \mathrm{~N} / \mathrm{S}$ \\
\hline Puntaje Total TAS & $\begin{array}{l}\text { TAS } \\
\text { Promedio }=73,45 \\
\text { D.S. }=9,90\end{array}$ & $\begin{array}{l}\text { TAS } \\
\text { Promedio }=58,41 \\
\text { D.S. }=4,29\end{array}$ & $P=0,000 \mathrm{~A} / \mathrm{S}$ \\
\hline
\end{tabular}

N/S: Diferencias no significativas; S: Diferencias significativas; A/S: Diferencias altamente significativas.

\section{Resultados}

En el Cuadro III, comparando las muestras de artríticos con un promedio de 7,36 años educativos y de no-pacientes con un promedio de 15,38 años educativos se constatan diferencias no significativas $(\mathrm{N} / \mathrm{S})$, en presencia de alexitimia indeterminada (TAS $\geq 62$ $<74$ ), y en ausencia de alexitimia (TAS $<62$ ), mientras que hay diferencias altamente 
significativas (A/S) en edad (mayores los $\mathrm{AR}$ ), años educativos (inferiores los $\mathrm{AR}$ ), en todos los niveles socioeconómicos (La muestra III, mayoritariamente de nivel mediomedio y los AR, muestra I, mayoritariamente de nivel medio-bajo), alexitimia definitiva $(>74)$ y en puntaje total de alexitimia (superior en los AR). Analizando la diferencia no significativa en la comparación de promedios de alexitimia ausente, encontramos el mismo resultado que en la comparación con la muestra II. Sin embargo considerando los porcentajes se observa que sólo 6 casos $(10 \%)$ entre los pacientes tuvieron ausencia de alexitimia mientras que 40 entre los no- pacientes (66\%).

Se observa, a través de esta comparación entre AR y no-pacientes con mayores años educativos, que se hallan numerosas diferencias A/S. Introducir esta variable permitió comparar más fehacientemente los AR con no-pacientes normales, no limitados por escasos recursos económicos de nivel medio-bajo (Muestra II). La introducción de la muestra III, en las comparaciones con la TAS de los pacientes, corrobora lo hallado en la comparación entre pacientes y la muestra II. Los principales aportes de incorporar esta muestra III, constituída por sujetos de mejores recursos educativos los apreciamos en las comparaciones con el Rorschach.

Los no-pacientes con mejor educación (Muestra III) compartieron con la muestra de no-pacientes de nivel socioeconómico medio-bajo (Muestra II) el puntaje total no significativo de alexitimia y la ausencia de alexitimia definitiva.

Con igual o distinto nivel socioeconómico y con mayor o menor nivel de años educativos, los no-pacientes no obtuvieron un puntaje total significativo de alexitimia ni alexitimia elevada. ). Estos resultados coinciden con los hallados por nosotros (Lunazzi,2000) al investigar las variables que afectan la alexitimia evaluada por la TAS26 . Comparamos distintas muestras representativas de variables en un total de 550 casos. Encontramos que el nivel socioeconómico medio-bajo no estaba asociado con cambios en el puntaje total de alexitimia, el cual permanecía dentro de lo normal para no-pacientes. Solamente en esa muestra, de nivel socioeconómico medio bajo, el Factor 3 de la alexitimia «capacidad para fantasear» apareció significativamente disminuído respecto de las otras muestras de nopacientes.

La TAS discrimina bien entre psicosomáticos (en este caso AR) y no-pacientes en el puntaje total, y en detectar la presencia de alexitimia definitiva, aunque hubiera diferencias 
significativas de educación y niveles socioeconómicos diferentes o iguales. Esto fue así, aunque se encontraron muy significativamente diferencias en edad, (menor en muestra III), y en composición de niveles socioeconómicos.

Nos formulamos, en consecuencia, la siguiente pregunta:

¿Los pacientes de mejor nivel socioeconómico o educativo presentarán alexitimia en la TAS? Vamos a investigar si en los pacientes de artritis reumatoidea hay presencia de alexitimia evaluada por la TAS: $a$ ) cuando tienen mejor nivel socioeconómico que el promedio de la muestra $\mathrm{AR}, \mathrm{y} b$ ) cuando tienen mejor nivel educativo que el promedio de la muestra AR. Como se ilustra realizaremos el análisis comparando submuestras dentro de la muestra I (AR).

\section{Cuadro IV a}

Distribución de presencia de alexitimia, según niveles socioeconómicos y de años educativos entre los pacientes MUESTRA I (AR) $\mathbf{N}=60$

\begin{tabular}{|c|c|c|}
\hline $\begin{array}{l}\text { Alexitimia } \geq 74 \\
\text { DEFINITIVA }\end{array}$ & $\begin{array}{l}\text { Alexitimia } \geq 62<74 \\
\text { INDETERMINADA }\end{array}$ & $\begin{array}{l}\text { Alexitimia }<62 \\
\text { AUSENTE }\end{array}$ \\
\hline Muestra AR: 23 casos & Muestra AR: 31 casos & Muestra AR: 6 casos \\
\hline Años educativos: & Años educativos: & Años educativos: \\
\hline 0 a 7: 12 casos & 0 a 7: 18 casos & 0 a $7: 3$ casos $(50 \%)$ \\
\hline$(52.17 \%)$ & $(58.06 \%)$ & 8 a 14: 2 casos \\
\hline 8 a 14: 10 casos & 8 a 14: 8 casos & $(33.33 \%)$ \\
\hline$(43.47 \%)$ & $(25.80 \%)$ & $\geq 15: 1$ caso $(16.66 \%)$ \\
\hline$\geq 15: 1$ caso $(4.34 \%)$ & $\geq 15: 5$ casos $(16.10 \%)$ & \\
\hline Nivel socioeconómico: & Nivel socioeconómico: & Nivel socioeconómico: \\
\hline Medio Medio: 4 casos & Medio Alto: 3 casos & Medio Medio: 5 casos \\
\hline$(17.39 \%)$ & $(9.67 \%)$ & $(83.33 \%)$ \\
\hline \multirow{4}{*}{$\begin{array}{l}\text { Medio Bajo: } 19 \text { casos } \\
(82.60 \%)\end{array}$} & Medio Medio: 12 casos & Medio Bajo: 1 caso \\
\hline & $(38.70 \%)$ & $(16.66 \%)$ \\
\hline & Medio Bajo: 16 casos & \\
\hline & $(51.61 \%)$ & \\
\hline
\end{tabular}


Observamos que en la muestra de pacientes se registra alexitimia definitiva, tanto entre quienes tienen nivel socioeconómico medio como en los que tienen mejores niveles educativos que el promedio. Esta constatación se verifica igualmente respecto de la alexitimia indeterminada y la alexitimia ausente, tal como fueron evaluadas por la Escala Toronto de Alexitimia (TAS26).

Una observación preliminar sobre el cuadro IVa permitiría suponer que menores años educativos estarían asociados con mayor alexitimia y viceversa ( En alexitimia definitiva educación entre 0 a 7: 12 casos (52.17\%) mientras que educación $\geq 15: 1$ caso (4.34\%);en alexitimia indeterminada educación 0 a 7 años: 18 casos $(58.06 \%) y \geq 15: 5$ casos (16.10\%) y en alexitimia ausente, en 0 a $7: 3 \operatorname{casos}(50 \%) y \geq 15: 1$ caso $(16.66 \%)$. Ya que esta es una observación que no tiene en cuenta los porcentajes de distribución de cada sub grupo en la muestra, hicimos una nueva verificación mediante la prueba estadística de diferencia de proporciones y Chiz para definitivamente analizar la influencia de los años educativos en la alexitimia, según la TAS, mediante la comparación de submuestras de distintos años educativos en la muestra de pacientes de AR.(Cuadro IV b). 


\section{Cuadro IV b}

Comparación de presencia de alexiti mia, se gún sub muestras de años educativos MUESTRA I (pacientes AR) $\mathbf{N}=\mathbf{6 0}$

\begin{tabular}{|l|l|l|}
\hline $\begin{array}{l}\text { Años educativos 0 a 7 } \\
33 \text { casos }\end{array}$ & $\begin{array}{l}\text { Años educativos 8 a 14 } \\
20 \text { casos }\end{array}$ & $\begin{array}{l}\text { Años educativos } \\
7 \text { casos }\end{array}$ \\
\hline $\begin{array}{l}\text { Alexitimia definitiva } \\
12 \text { casos }\end{array}$ & $\begin{array}{l}\text { Alexitimia definitiva } \\
\mathbf{3 6}, \mathbf{3 6} \%\end{array}$ & $*$ \\
\hline $\begin{array}{l}\text { Alexitimia indeterminada } \\
\mathbf{1 8} \text { casos }\end{array}$ & $\begin{array}{l}\text { Alexitimia indeterminada } \\
\mathbf{5 4 , 5 4} \%\end{array}$ & $\begin{array}{l}\text { Alexitimia indeterminada } \\
\mathbf{5} \text { casos }\end{array}$ \\
\hline $\begin{array}{l}\text { Alexitimia ausente } \\
\mathbf{3} \text { casos } \\
9,09 \%\end{array}$ & $\mathbf{4 0 \%}$ & $\mathbf{7 1 , 4 2 \%}$ \\
\hline
\end{tabular}


Se comparó el porcentaje de alexitimia definitiva, indeterminada y ausente de la submuestra 1, de años educativos 0-7 con la submuestra 2 de 8-14 años educativos; Se comparó la submuestra 1, de años educativos 0-7 con la submuestra 3 de años educativos iguales o mayores a 15. Se comparó la submuestra 2 de 8-14 años educativos con la submuestra 3, de años educativos $>=15$. * Las comparaciones respecto de un solo caso no fueron procesadas

\section{Resultados}

Submuestras 1 y $2 \quad \mathrm{P}=0.833 \quad \mathrm{~N} / \mathrm{S}$

Submuestras 1 y $2 \quad \mathrm{P}=0.795 \quad \mathrm{~N} / \mathrm{S}$

Submuestras 2 y $3 \quad \mathrm{P}=0.594 \quad \mathrm{~N} / \mathrm{S}$

Submuestras 1 y $3 \quad \mathrm{P}=0.869 \quad \mathrm{~N} / \mathrm{S}$

Submuestras 1 y $2 \quad \mathrm{P}=0.127 \quad \mathrm{~N} / \mathrm{S}$

En todas las comparaciones las diferencias no fueron significativas.

- Verificamos así que en la AR la alexitimia evaluada por la TAS, no se halla asociada con los años educativos.

\subsection{La TAS26-y la Escala Realidad/Fantasía RFS (Tibon Shira, 2003).}

Presentamos en el cuadro siguiente el estudio que realizamos para establecer la existencia -0 no- de diferencias entre las muestras y la Escala de Realidad y Fantasía(RFS). Recordamos que se trata de una nueva variable, que permite mediante la recodificación de cada respuesta de cada protocolo, conocer la capacidad con que cuenta el sujeto para establecer un espacio de amortiguación, y a la vez, conexión entre los parámetros de Realidad (realidad externa) y Fantasía (realidad interna del propio psiquismo). La combinación equilibrada entre dichas dos dimensiones se manifiesta en un puntaje $=0$; cuando la fantasía colapsa en la realidad, es decir la fantasía se vuelve concreta los puntajes se acercan al polo -5; de modo opuesto, cuando la realidad colapsa la fantasía, volviéndose mínima la actividad de esta última los puntajes se orientan al +5 . 
(Se encontrará información ampliada de este tema en el Anexo 3). Establecimos la presencia de alexitimia definitiva (recordamos puntaje $\mathbf{2 7 4}$

en la TAS26) en el 38\% de los artríticos, e Indeterminada (puntajes entre $\mathbf{2 6 2}<\mathbf{7 4}$ en la TAS26), en un 51\%, de dicha muestra. Es esperable que la restricción del uso del espacio transicional- vida de fantasía entre sí mismo y la realidad externa- se compruebe en la RFS de esta muestra.

Cuadro IV, c: Comparaciones entre Puntaje Total y niveles de Alexitimia y la RFS

\begin{tabular}{|c|c|c|}
\hline $\begin{array}{c}\text { MUESTRA I } \\
\text { N=60 } \\
\text { Artritis } \\
\text { Reumatoidea }\end{array}$ & $\begin{array}{l}\text { MUESTRA II } \\
\text { N=60 } \\
\text { No Pacientes } \\
\text { (Nivel Econ. Medio- } \\
\text { bajo) }\end{array}$ & $\begin{array}{l}\text { MUESTRA III } \\
\mathrm{N}=60 \\
\text { No-pacientes } \\
\text { Años educativos }>8\end{array}$ \\
\hline $\begin{array}{l}\geq 74 \\
\text { (ALEXITIMIA } \\
\text { DEFINITIVA) } \\
\mathrm{N}=23 \\
\text { RFS=Media } 0.26 \\
\text { DS } 1,03\end{array}$ & $\begin{array}{l}\geq 74 \\
\text { (ALEXITIMIA } \\
\text { DEFINITIVA) } \\
\mathrm{N}=0 \\
\text { Media }=0\end{array}$ & $\begin{array}{l}\geq 74 \\
\text { (ALEXITIMIA } \\
\text { DEFINITIVA) } \\
\mathrm{N}=2 \\
\text { Media }=-0,16 \\
\text { DS } 0,38\end{array}$ \\
\hline $\begin{array}{l}\geq 62<74 \\
\text { (ALEXITIMIA } \\
\text { INDETERMINADA) } \\
\text { N=31 } \\
\text { RFS=Media } 0,47 \\
\text { DS } 0,64\end{array}$ & $\begin{array}{l}\geq 62<74 \\
\text { (ALEXITIMIA } \\
\text { INDETERMINADA) } \\
\text { N=24 } \\
\text { RFS=Media } 0,83 \\
\text { DS } 0,50\end{array}$ & $\begin{array}{l}\geq 62<74 \\
\text { (ALEXITIMIA } \\
\text { INDETERMINADA) } \\
\text { N=20 } \\
\text { RFS Media } 0,14 \\
\text { DS } 0,61\end{array}$ \\
\hline $\begin{array}{l}62 \\
\text { (AUSENCIA DE } \\
\text { ALEXITIMIA) } \\
\mathrm{N}=6 \\
\text { RFS=Media } 0,47\end{array}$ & $\begin{array}{l}62 \\
\text { (AUSENCIA DE } \\
\text { ALEXITIMIA) } \\
\mathrm{N}=36 \\
\text { RFS=Media } 0,64\end{array}$ & $\begin{array}{l}<62 \\
\text { (AUSENCIA DE } \\
\text { ALEXITIMIA) } \\
\mathrm{N}=38 \\
\text { RFS=Media }-0,32\end{array}$ \\
\hline
\end{tabular}




\begin{tabular}{|l|l|l|}
\hline DS 0,88 & DS 0,54 & DS 0,82 \\
& & \\
& & \\
\hline RFS & RFS= & RFS $=$ \\
N=60 & N=60 & N=60 \\
RFS=Media 0,39 & RFS=Media 0,73 & RFS $=$ Media $-0,17$ \\
DS 0,83 & DS 0,54 & DS 0,79 \\
& & \\
\hline
\end{tabular}

Comparando las medias de los puntajes totales, de las Muestras I, II y III, en la Escala de realidad y fantasía (RFS) hallamos

Puntaje total RFS:

Muestras I vs II: $\mathrm{P}=0,009 \mathrm{~A} / \mathrm{S}$

Muestras I vs III $\mathrm{P}=0,000 \mathrm{~A} / \mathrm{S}$

Muestras II vs III $\mathrm{P}=0,000 \mathrm{~A} / \mathrm{S}$

Muestras I vs II: ALEXITIMIA DEFINITIVA $t=2,034 ; \mathrm{P}=0,045$ hay diferencias significativas.

Muestras I vs II: ALEXITIMIA INDETERMINADA $t=-2,27 ; \mathrm{P}=0,027$ hay diferencias significativas.

Muestras I vs II AUSENCIA DE ALEXITIMIA $\mathrm{t}=2,054 ; \mathrm{P}=0,036$ hay diferencias significativas.

Como podemos notar en los resultados del Cuadro V, se encuentran diferencias altamente significativas cuando comparamos el puntaje total obtenido en la Escala de Realidad y Fantasía entre las tres muestras. Los no-pacientes de mejor nivel educativo (muestra III) obtuvieron el puntaje más cercano al 0 (equilibrio), su signo negativo muestra el recurso a la fantasía. Los pacientes artríticos (Muestra I) se alejan poco del 0 en dirección hacia el signo positivo (menor uso de la fantasía). Es la muestra de no pacientes de nivel medio bajo (Muestra II) la que se aleja más del 0 , aproximándose al polo de +1 . Exhibe así su tendencia a realizar un uso empobrecido de la vida de fantasía. De todos modos, cabe también expresar que las dispersiones de los puntajes hallados rondan el 0 (equilibrio).

Analizada la RFS según el nivel de alexitimia: definitiva, indeterminada y ausente, hallamos diferencias significativas cuando comparamos las muestras I y II, en todos los casos, y la muestra II se acerca hacia el polo de +1 ( mayor restricción de la fantasía).

Estos resultados demostraron que los no-pacientes de nivel socioeconómico medio bajo (muestra II) tienen una mayor restricción significativamente en el uso de la fantasía que los pacientes artríticos. 
Destacamos el hecho de que los no pacientes no puntuaron en puntaje total de alexitimia ni en alexitimia definitiva, es decir que para la TAS no son alexitímicos. Sin embargo la restricción en el uso de la vida imaginaria apareció evidente, tal como evalúa a través de las codificaciones propias de la RFS.

La elucidación de esta información se realizó con el uso complementario de la técnica Rorschach, como informaremos en el próximo Capítulo.

\subsection{Estudio cualitativo de la TAS}

En todo instrumento cuantitativo de evaluación psicológica, como sabemos, es susceptible proceder igualmente a un estudio cualitativo. Para concretar este último es necesario estudiar cómo se han distribuido las respuestas afirmativas y negativas, cuando se trata de preguntas dicotómicas (verdadero o falso) o las diferentes alternativas, «generalmente sí, moderadamente sí, a veces, moderadamente, no, o no nunca». El análisis de la dispersión de las respuestas se realiza en relación a la pregunta que el cuestionario formula. Por ejemplo, si la pregunta de la TAS es «jes importante tener emociones?»y hay tres alternativas de respuesta, junto con el puntaje total que se obtiene en la técnica se analiza en particular cómo es la actitud del sujeto respecto de las emociones, de acuerdo a cómo haya respondido ese ítem y los otros que exploran el mismo factor.

Intentamos realizar un estudio cualitativo de las respuestas obtenidas en la TAS26 por la muestra I de pacientes de AR. Para ello analizamos si se observaba alguna tendencia reconocible en la distribución de respuestas a las tres alternativas que propone la adaptación argentina de esta técnica: «Generalmente sí», «a veces»y «no, nunca», en relación con las 26 preguntas. La dispersión es muy amplia en las tendencias grupales de respuesta, salvo en una pregunta, la n. ${ }^{\circ}$ 23: «La gente me pide que cuente mejor mis sentimientos».

Hallamos la siguiente distribución de respuestas entre los 60 casos que integran la muestra: 46 casos contestaron «no, nunca» (representan el 76\% de la muestra); 7 casos contestaron positivamente (12\%) y los restantes 7 casos «a veces» (12\%). Es posible, en este resultado, observar que la referencia a los sentimientos emerge en la muestra como problemática: $a$ ) ya sea porque el contexto familiar o cercano no es sensible o no se interesa por la comunicación de sentimientos por parte del sujeto, o $b$ ) ya sea porque la diferenciación y comunicación de los sentimientos no es algo reconocido o practicado por el sujeto. Creemos que no podríamos fundamentar mayores avances, pero queremos 
destacar este dato, pues no se apreciaron ponderaciones claras en las respuestas sobre otras preguntas. Sin embargo, es notable que la ausencia de demanda o de manifestación de comunicación de los sentimientos haya aparecido tan acentuadamente (76\% del grupo), poniendo de manifiesto efectivamente la médula de la problemática del alexitímico tal como la venimos tratando: la relación con los propios sentimientos.

\subsection{Discusión de resultados TAS}

Vamos a analizar nuestros resultados en relación con las investigaciones ya realizadas, en las que se usó la Escala TAS específicamente en la artritis reumatoidea. Retomaremos posteriormente cuestiones más generales referidas al comportamiento de ciertas variables y la evaluación de la alexitimia mediante la TAS y la TAS-20. Respecto a los resultados comunicados sobre Pacientes con AR y mayor impedimento funcional asociado a puntajes más altos en alexitimia, informado en un estudio realizado en la India (Fernández y col.,1989); en nuestra muestra de pacientes ${ }^{1} \mathrm{AR}, \mathrm{N}=60$, el impedimento funcional severo, se halló en 5 casos ( $8,33 \%$ de la muestra), se encontró en 4 casos con alexitimia definitiva (Puntaje TAS $\geq 74$ ), y en el caso restante con alexitimia indeterminada (puntaje $\mathrm{TAS} \geq 62<74$ ); los pacientes con impedimento funcional mediano se distribuyeron entre 7 alexitímicos definitivos, 6 alexitímicos indeterminados y un caso con alexitimia ausente (puntaje TAS $<62$ ); mientras que entre los pacientes hallamos, con impedimento funcional mínimo: 7 con alexitimia definitiva, 29 con alexitimia indeterminada y 5 con alexitmia ausente. Si analizamos por separado el grupo de pacientes con alexitimia ausente, vemos que el $83 \%$ aparecen en los casos con impedimento mínimo, (pero se trata de un grupo muy pequeño, de sólo seis casos) y el caso restante en los pacientes con impedimento mediano. Aunque se observan tendencias que podrían afirmar lo informado por Fernández y col. consideramos que el pequeño número de presencia de impedimento severo en nuestra muestra no nos permite confirmarla.

También en el estudio mencionado, realizado en la India, se informó acerca de la ausencia de relación entre puntaje alto de alexitmia y duración de la enfermedad. Vamos por lo tanto a observar la relación en nuestra muestra. En nuestra muestra, la distribución de años de enfermedad es:
$1-7$ :
22 casos
$(36,66 \%)$

\footnotetext{
${ }^{1}$ Remitimos a los cuadros Ia y Ib, que constan en el Cap.3
} 


$\begin{array}{lll}\geq 8 \leq 12 & 25 \text { casos } & (41,66 \%) \\ \geq 16 \leq 20 & 8 \text { casos } & (13,33 \%) \\ >30 & 5 \text { casos } & (8,33 \%)\end{array}$

Vamos a analizar la composición de presencia de alexitimia según la TAS del grupo de duración menor de la enfermedad (1 a 7 años), por un lado, y el de mayor duración ( $>30$ años), por otro. En el primer grupo, integrado por 22 casos, tenemos con alexitimia definitiva 8 casos (36\%), con alexitimia indeterminada 10 casos (48\%) y sin alexitmia 4 casos $(16 \%)$. Si bien establecer tendencias significativas se muestra difícil por la dispersión de los casos, la presencia de alexitmia definitiva evaluada por la TAS al comienzo de la enfermedad sí permite sostener que la alexitmia no constituye una respuesta adaptativa o desencadenada por la enfermedad, sino que la precede y acompaña.

Analizando el pequeño grupo de 5 casos que hace más de 30 años que padecen la enfermedad, informamos que el padecimiento funcional es mínimo en un caso, mediano en dos y severo en los otros dos pacientes (que hace 44 años que padecen AR), y que la presencia de alexitimia en estos últimos dos casos fue definitiva, los otros tres se distribuyen dos en indeterminada y uno definitiva. Nuevamente aparecen tendencias interesantes, como la de mayor duración de la enfermedad, asociada con mayor alexitimia y con mayor impedimento funcional. No obstante, el pequeño número de la observación que ofrece la muestra no nos permite aseverarlo.

Recordamos que los resultados de las investigaciones que citamos en el Cap. 2, mediante la TAS en la AR no eran concluyentes, algunas afirmaban que los pacientes de AR, según punto de corte de la TAS, presentaban un 27,5\% (Fernández y col, 1989) y 27 \% (Lunazzi, Lazzarino, Lojo, 1999) de presencia definitiva de alexitimia comparadas con no pacientes, un $87 \%$ de alexitmia dentro del rango alexitímico (indeterminada más definitiva) (Lunazzi, Lazzarino, Lojo, 1999), mientras que otras (Jordan y Lumley, 1993) informaban que el promedio de la TAS en los pacientes no había sido significativamente diferente al de la población normal.

Los resultados obtenidos en nuestra investigación también mediante la TAS comparando la muestra I, pacientes de artritis reumatoidea, con la Muestra II, no-pacientes de igual nivel socioeconómico, y con la muestra III, no-pacientes con años educativos 
superiores, son: a) un puntaje total de alexitimia con diferencias altamente significativas (A/S) respecto de los no-pacientes de igual nivel socio económico; b) diferencias altamente significativas (A/S) en presencia de alexitimia definitiva: en AR el 38\% de los casos, y $0 \%$ en los no-pacientes; c) diferencias altamente significativas (A/S) en alexitimia indeterminada, mayor entre los pacientes y d) que el porcentaje de ausencia de alexitimia fue sólo del 10\% entre los pacientes de la muestra I, mientras que fue del 60\% en la muestra II. Sin embargo, estas últimas diferencias evaluadas en promedios no fueron estadísticamente significativas.

Los resultados en las muestras de artríticos y no-pacientes de igual nivel socioeconómico (medio bajo) muestran que no se hallaron diferencias significativas (N/S) respecto de la edad, nivel socioeconómico y ausencia de alexitimia (TAS $<62$ ). $\quad$ Se registraron, en cambio, diferencias entre la muestra I y la Muestra II , altamente significativas $(\mathrm{A} / \mathrm{S})$ entre Alexitimia Definitiva (TAS $\geq 74)$ presente en los artríticos, y el puntaje total obtenido en la TAS, muy superiores en los pacientes. Cuando comparamos a los pacientes artríticos (Muestra I) con la muestra III de no pacientes con mejores niveles educativos y niveles socio económicos mejores, igualmente comprobamos los mismos resultados.

Los pacientes obtuvieron un puntaje total de alexitimia muy alto y la presencia de un $38 \%$ de alexitimia muy elevada. Los resultados enumerados nos permiten sostener la capacidad discriminante de la TAS para el diagnóstico de la alexitimia entre los pacientes de AR y los no-pacientes de semejante nivel socioeconómico o distinto nivel socioeconómico.

También, la alexitimia, tal como fuera evaluada por la Escala Toronto de Alexitimia (TAS26), resultó, en principio, no estar asociada ni al nivel socioeconómico, ni al mayor o menor nivel de años educativos. Decimos en principio, en razón de que la división en sub muestras, en algunas comparaciones fue con pocos casos. Aún en muestras reducidas o ampliadas los resultados se cumplieron en todos los grupos y podrían a partir de nuestra investigación, su número ser incrementado. En todos los cortes y comparaciones, los nopacientes no obtuvieron un puntaje total significativo de alexitimia ni alexitimia elevada. Los estudios con submuestras de pacientes comparando distintos niveles socioeconómicos 
entre sí y distintos niveles de años educativos entre sí, informaron que las diferencias no son significativas. Se confirmó así la falta de asociación en la AR, entre nivel socio económico y años educativos y presencia de alexitimia evaluada por la TAS.

Al investigar el puntaje total y los niveles de presencia de alexitimia definitiva, indeterminada y ausente y los puntajes obtenidos por pacientes y no-pacientes de igual nivel socioeconómico, y no-pacientes con años educativos superiores en la escala de realidad y Fantasía(RFS), se halló una correlación en la dirección esperada. Los nopacientes de mejores recursos educativos presentaron las mejores disposiciones para utilizar la fantasía, la muestra de no-pacientes con nivel socioeconómico medio bajo

(Muestra II) la mayor restricción. Los pacientes artríticos mostraron en menor medida que los no pacientes de la Muestra II la restricción en el uso de la fantasía. Es oportuno comentar que, al referirnos a la Escala de Realidad y Fantasía e informar mejores o peores recursos para el uso de la fantasía, ha de comprenderse que en el término «fantasía», en este caso, hacemos referencia a funcionamientos que incluyen dimensiones cognitivas, afectivas, ideacionales de contacto enriquecido con las realidades internas y externas o con la presencia de pensamiento operatorio, como estrategia de desplazamiento de la introspección y vida afectiva. El estudio que realizamos permite señalar una correlación positiva entre el puntaje total de alexitimia y los niveles de presencia de alexitimia evaluados con la TAS26 y los resultados esperables en la RFS.

Retomando ahora cuestiones más generales, que aún presentan cierta controversia (Cap. 2), referidas al comportamiento de algunas variables y la evaluación de la alexitimia mediante la TAS y la TAS-20, podemos aportar, en resumen, que nuestros resultados informan que no hemos hallado que las variables nivel socioeconómico medio bajo y años educativos superiores estén significativamente asociadas con la presencia de alexitimia, tal como la evalúa la TAS26 en la población no-paciente.

\subsection{Conclusión}

Los resultados obtenidos mediante la TAS en la comparación de la muestra I, pacientes de artritis reumatoidea, con la Muestra II, no-pacientes de igual nivel 
socioeconómico, y de la Muestra I con la muestra III, no-pacientes con años educativos superiores, son:

1. Se comprobó la validez discriminativa de la TAS para el diagnóstico de la alexitimia entre los pacientes de AR y los no-pacientes, tanto en su puntaje total como en los niveles de presencia de alexitimia elevada y ausente. La presencia de Alexitimia Definitiva fue del 38\% entre los pacientes artríticos y estuvo ausente entre los no-pacientes.

2. Se puede afirmar que la categoría alexitimia, evaluada por la TAS, resultó no asociada al nivel socioeconómico y sí, en cambio, a la presencia de enfermedad psicosomática, en este caso AR.

3. La categoría alexitimia evaluada por la TAS, resultó no asociada al mayor nivel de años educativos y sí, en cambio, a la presencia de enfermedad psicosomática, en este caso AR.

4. Se registraron apreciables tendencias significativas entre las muestras en el uso de la fantasía, evaluada por la escala de (RFS). La muestra III exhibió los mejores recursos, mientras que la muestra II, no pacientes de nivel económico medio bajo, la mayor restricción. Los pacientes artríticos (Muestra I ) se situaron en una zona intermedia entre ambas.

La categoría alexitimia evaluada por la TAS, y relacionada con el puntaje total en la Escala de realidad y fantasía, y en los puntajes de la RFS según la distribución de niveles de alexitimia, informó mejor uso de la fantasía asociada al mayor nivel de años educativos y menor en los no-pacientes de nivel socioeconómico medio-bajo. La presencia de enfermedad psicosomática, en este caso AR, mostró la restricción en el uso de la fantasía en menor medida que en los no-pacientes de la muestra II.

Profundizamos en el próximo Capítulo mediante la Técnica Rorschach (S.C.) la comprensión de las características psicológicas de las diferentes muestras utilizadas. 


\title{
Capitulo 5
}

\section{RESUlTADOS OBTENIDOS EN LA TÉCNICA RORSCHACH (S.C.)}

\begin{abstract}
Es decir que veremos y pienso que las presentaciones que vamos a atender lo mostrarán, veremos que en la inmensa mayoría de los casos psicosomáticos, provenientes de un sueño profundo, de un simbolismo psicofisiológico no revelado al ser mismo que los posee, y es allí donde es necesario encontrar la justificación eventual de las pruebas proyectivas, todas ellas métodos susceptibles de objetivar ese lenguaje visceral y de establecer una relación legible entre el inconsciente frustrado y la expresión corporal [...] la enfermedad psicosomática es el conflicto que se expresa por y en el cuerpo y el cual de alguna manera pone a disposición de aquél, sus funciones fisiológicas, cada una diferente de las otras. Y si miramos de cerca constatamos en efecto que la búsqueda no apunta a un órgano solo sino a un conjunto de órganos implicados en una misma función y con un fin concurrente. Fin a dar de las pulsiones normales, pero aquí interdictas entonces en el centro del conflicto profundo- una ejecución que disimule el conflicto y al mismo tiempo lo plasme para sí mismo y para el mundo [...] hace mucho que hemos comparado al enfermo psicosomático con un niño que, escondido detrás de las cortinas, de todos modos las agita para indicar su presencia.
\end{abstract}

A. Morali Daninos (Medicina Psicosomática y Métodos Proyectivos) $)^{1}$

En la introducción al Simposio sobre Medicina Psicosomática y Métodos Proyectivos, que evocamos en el epígrafe, A. Morali Daninos posiciona a dichos métodos, como privilegiados para revelar "el lenguaje visceral" que no se ha logrado representar. Vamos a estudiar a continuación los resultados de la Técnica Rorschach, reconocida entre los métodos proyectivos, según el siguiente desarrollo:

\footnotetext{
${ }^{1}$ Introducción al Simposio de Liège, 19 de octubre de 1974. Société du Rorschach et des Méthodes Projectives de Langue Française.
} 
5.1. Indicadores de Alexitimia en Rorschach (M. W. Acklin y E. Bernat). Resultados.

5.2. Significado de las siglas utilizadas en los cuadros.

5.3. Indicadores ampliados de alexitimia en el Rorschach

5.4. Comparaciones entre las muestras, reagrupándolas según niveles de años educativos

5.5. Investigación de variables asociadas al EA>6

5.6 Discusión de Resultados

5.7. Síntesis de resultados y Conclusión:

\subsection{Indicadores de Alexitimia en Rorschach (M. W. Acklin y E. Bernat). Resultados.}

Comenzaremos por presentar los resultados en la primera agrupación de indicadores de alexitimia en el Rorschach, dada a conocer en 1987 por M. Acklin y E. Bernat. Presenta el interés de proponer los funcionamientos psicológicos esperados en el constructo alexitimia (fantasía disminuida, emoción poco regulada, cognición concreta y recursos adaptativos restringidos) a la izquierda del cuadro. Luego, hacia la derecha, los indicadores Rorschach que permiten evaluar aquellos funcionamientos de la personalidad. Este agrupamiento se investigó en enfermos psicosomáticos, pero no fue aplicado a la enfermedad artritis reumatoidea $(\mathrm{AR})$.

\section{CUADRO V \\ MUESTRA I (AR) Y MUESTRA II (NO-PACIENTES) \\ IGUAL NIVEL SOCIOECONÓMICO MEDIO BAJO \\ Indicadores de Alexitimia en Rorschach ${ }^{2}$ \\ M.W. Acklin, Ph.D. y E. Bernat, $1987^{3}$}

\begin{tabular}{|l|l|l|l|}
\hline \multirow{3}{*}{ Funcionamiento } & $\begin{array}{l}\text { Muestra AR } \\
\text { Indicadores } \\
\text { Rorschach }\end{array}$ & $\begin{array}{l}\text { Muestra } \\
\text { Me60 Nivel } \\
\text { Medio } \\
\text { Bajo=60\% }\end{array}$ & $\begin{array}{l}\text { no-pacientes } \\
\text { N=60 Nivel Medio } \\
\text { Bajo= 53\% }\end{array}$ \\
\hline
\end{tabular}

\footnotetext{
${ }^{2}$ Alexithymia, somatization, and the Rorschach response process,. Rorschachiana XVII.

${ }^{3}$ Department of Psychiatry, University of Hawaii, School of Medicine, Honolulu, Hawái.
} 


\begin{tabular}{|c|c|c|c|}
\hline & & Promedio & Promedio \\
\hline \multirow[t]{2}{*}{ Fantasía } & $\begin{array}{l}\text { Bajo } \mathbf{R} \text { (Productividad } \\
\text { de respuestas) }\end{array}$ & $R=18,46$ & $\begin{array}{l}R=18,45 \\
P=0,982(N / S)\end{array}$ \\
\hline & $\begin{array}{l}\text { Bajo M (movimiento } \\
\text { humano) }\end{array}$ & $M=2,63$ & $\begin{array}{l}M=2,68 \\
P=0,887(N / S)\end{array}$ \\
\hline Emoción & $\begin{array}{l}\text { Respuesta afectiva } \\
\text { restringida } \\
\text { Uso de color } \\
\text { pobremente } \\
\text { adaptativo (Bajo FC) }\end{array}$ & $\begin{array}{l}\text { Sum Pond C 2,56 } \\
\text { FC=2,22 }\end{array}$ & $\begin{array}{l}\text { Sum Pond C 2,60 } \\
P=0,655(N / S) \\
F C=1,97 \\
P=0,377(N / S)\end{array}$ \\
\hline Cognición & $\begin{array}{l}\text { Cognición concreta } \\
\text { (bajo Blend) } \\
\text { Estereotipia (Lambda } \\
\text { elevado) }\end{array}$ & $\begin{array}{l}\text { Blend }=3,52 \\
\text { Lambda }=0,48\end{array}$ & $\begin{array}{l}\text { Blend= 3,12 } \\
P=0,292(N / S) \\
\text { Lambda }=0,69 \\
P=0,436(N / S)\end{array}$ \\
\hline $\begin{array}{l}\text { Recursos } \\
\text { Adaptativos }\end{array}$ & $\begin{array}{l}\text { Deficiencia en } \\
\text { capacidades } \\
\text { ideacionales y } \\
\text { afectivas (Bajo EA) }\end{array}$ & $\mathrm{EA}=5,19$ & $\begin{array}{l}E A=5,37 \\
P=0,665(N / S)\end{array}$ \\
\hline
\end{tabular}

Como vemos en el CUADRO II, no se comprueban diferencias entre los AR y los nopacientes homologados según nivel socio económico medio-bajo respecto del Cluster Rorschach Acklin de alexitimia.

Observemos ahora en el siguiente cuadro las comparaciones entre la muestra I (AR) y los no-pacientes, muestra III, con más años educativos:

\section{CUADRO VI \\ MUESTRA I (AR) Y MUESTRA III (NO PACIENTES) MAYORES AÑOS EDUCATIVOS Indicadores de Alexitimia en Rorschach (M.W. Acklin. Ph.D. y E. Bernat)}

\begin{tabular}{|l|l|l|l|}
\hline $\begin{array}{l}\text { Funciona- } \\
\text { miento }\end{array}$ & $\begin{array}{l}\text { Indicadores } \\
\text { Rorschach }\end{array}$ & $\begin{array}{l}\text { Muestra AR } \\
\text { Años Educ. } \\
\text { Promedio=7, 33 } \\
\mathbf{N}=60\end{array}$ & $\begin{array}{l}\text { Muestra no-pacientes } \\
\text { Años Educ. } \\
\text { Promedio=15, 38 } \\
\text { N=60 }\end{array}$ \\
\hline Fantasía & $\begin{array}{l}\text { Bajo R } \\
\text { (Productividad de } \\
\text { respuestas) }\end{array}$ & $\begin{array}{l}\text { R= } \\
\text { Promedio 18,46 } \\
\text { DS 5,45 }\end{array}$ & $\begin{array}{l}\text { Promedio 19,63 } \\
\text { DS 4,60 } \\
\text { P=0,21 } \\
\text { N/S }\end{array}$ \\
& & & \\
\hline
\end{tabular}




\begin{tabular}{|c|c|c|c|}
\hline & $\begin{array}{l}\text { Bajo M } \\
\text { (movimiento } \\
\text { humano) }\end{array}$ & $\begin{array}{l}\text { M= } \\
\text { Promedio 2,63 } \\
\text { DS } 1,82\end{array}$ & $\begin{array}{l}\text { M } \\
\text { Promedio 5,38 } \\
\text { DS 2,31 } \\
\text { P=0.,000 } \\
\text { A/S }\end{array}$ \\
\hline Emoción & $\begin{array}{l}\text { Respuesta } \\
\text { afectiva } \\
\text { restringida } \\
\text { Uso de color } \\
\text { pobremente } \\
\text { adaptativo (Bajo } \\
\text { FC) }\end{array}$ & $\begin{array}{l}\text { Sum Pond C } \\
\text { Promedio 2,56 } \\
\text { DS 1,66 } \\
\text { FC } \\
\text { Promedio=2,22 } \\
\text { DS 1,75 }\end{array}$ & $\begin{array}{l}\text { Sum Pond C=Promedio } \\
4,43 \\
\text { DS } 1,71 \\
P=0,000 \text { A/S } \\
\text { FC } \\
\text { Promedio }=2,45 \\
\text { DS } 1,92 \\
P=0,494 \\
N / S\end{array}$ \\
\hline \multirow[b]{2}{*}{ Cognición } & $\begin{array}{l}\text { Cognición } \\
\text { concreta } \\
\text { (bajo Blend) }\end{array}$ & $\begin{array}{l}\text { Blend } \\
\text { Promedio=3,51 } \\
\text { DS 2,21 }\end{array}$ & $\begin{array}{l}\text { Blend } \\
\text { Promedio=4,15 } \\
\text { DS } 1,99 \\
P=0,103 \mathrm{~N} / \mathrm{S}\end{array}$ \\
\hline & $\begin{array}{l}\text { Estereotipia } \\
\text { (Lambda } \\
\text { elevado) }\end{array}$ & $\begin{array}{l}\text { Lambda } \\
\text { Promedio=0,48 } \\
\text { DS 0,37 }\end{array}$ & $\begin{array}{l}\text { Lambda } \\
\text { Promedio=0,33 } \\
\text { DS 0,26 } \\
\text { P=0,011 } \\
D / S\end{array}$ \\
\hline $\begin{array}{l}\text { Recursos } \\
\text { Adaptativos }\end{array}$ & \begin{tabular}{|l|} 
Deficiencia en \\
capacidades \\
ideacionales y \\
afectivas (Bajo \\
EA) \\
\end{tabular} & $\begin{array}{l}\text { EA } \\
\text { Promedio=5,19 } \\
\text { DS } 2,54\end{array}$ & $\begin{array}{l}\text { EA } \\
\text { Promedio }=9,81 \\
\text { DS } 1,97 \\
P=0,000 \\
\text { A } / S\end{array}$ \\
\hline
\end{tabular}

En esta comparación, al introducir mayores años educativos, encontramos notables diferencias en los indicadores de alexitimia, en el Rorschach:

Hallamos diferencias significativas D/S en la capacidad para mantenerse distante y objetivo frente a las situaciones (Lambda). Se comprobaron diferencias altamente significativas (A/S) en el uso y la elaboración imaginaria $(\mathrm{M})$, la reactividad emocional (SumpondC) y los recursos ideacionales y afectivos disponibles para afrontar las situaciones (EA), todos ellos muy significativamente inferiores entre los pacientes; mientras que se constatan diferencias no significativas en la productividad, en el uso adaptativo de la afectividad FC y en la capacidad para reconocer asociaciones perceptualmente complejas (Blends).

Corresponde indicar que la propuesta de Acklin respecto de Lambda no evalúa Lambda alto (>99), recurso de distanciamiento racional sí esperable entre los alexitímicos, sino simplemente la aparición de Lambda (comparación de promedios). En ninguna de las muestras que estudiamos el Lambda alto obtuvo suficiente presencia. 


\section{Resultados:}

De la comparación realizada entre la muestra I (AR) y muestra II (no-pacientes) homologadas en igual nivel socioeconómico medio-bajo, no surgen diferencias significativas en las variables para evaluar alexitimia en el Rorschach propuestas por Acklin y Bernat: tanto los pacientes como los no pacientes son igualmente alexitímicos en el Rorschach.

Cuando se introducen mayores años educativos, en la Muestra III en la comparación de los resultados del Rorschach, significativas variables diferencian a los no-pacientes como no alexitímicos: ellas son Movimiento Humano (M), Suma ponderada de respuestas de Color (SumpondC), Lambda y recursos cognitivos y afectivos (EA).

Profundizaremos estos resultados más adelante, en el presente capítulo.

\subsection{Significado de las siglas utilizadas en los cuadros.}

A continuación se presenta una lista de siglas utilizadas en los cuadros que vamos a ilustrar y la significación de éstas a los efectos de agilizar la lectura y la comprensión. Facilitamos como referencia las Medias y Desviaciones Standard obtenidas por la muestra de 506 no-pacientes de la misma región (Gran La Plata), referencia que permite poder apreciar la presencia de desvíos, al comparar con dicha muestra, los resultados de las muestras I, II y III, las que se informan en los cuadros. Designaremos, a continuación, a la muestra normativa de 506 no-pacientes como "muestra argentina de no-pacientes".

\section{Códigos del Rorschach:}

1. R: Cantidad de respuestas que el sujeto ha elaborado durante la administración de la técnica. Es un indicador rápido de su capacidad productiva. La media de la muestra argentina de no-pacientes es $\mathrm{R}=18,66$ y $\mathrm{DS}=4,83$. 
2. M: Movimiento humano, se emplea en respuestas que implican una actividad cenestésica humana. Informa que el sujeto dispone de capacidad ideacional para elaborar sus experiencias, capacidad de empatía, sublimación y creatividad. La media de la muestra argentina de no-pacientes es $\mathrm{M}=3,08$ y $\mathrm{DS}=1,92$.

3. MA \%: Su puntaje incluye $\mathrm{MQ}+\mathrm{MQo}+\mathrm{MQu}$, esto es, la sumatoria de las respuestas de movimiento humano que han logrado una adecuación formal (FQ) de cualidad ordinaria (o), superior $(+)$ o única $(\mathrm{u})$. Informa funcionamientos adaptativos, adecuados de la ideación.

4. FM: Movimiento animal, se emplea en respuestas que implican una actividad cenestésica animal. La media de la muestra argentina de no-pacientes es $\mathrm{FM}=3,46$ y $\mathrm{DS}=1,83$. Estas respuestas son propias de los niños y de las personalidades inmaduras. Si su presencia supera ampliamente a la producción de M, la organización ideacional estará presionada por demandas urgentes y orientadas por el principio del placer.

5. m: Respuesta de movimiento inanimado, implica movimiento de objetos inorgánicos, abstractos o sin la facultad de sentir y dirigir sus propias acciones. La media de la muestra argentina de no-pacientes es $\mathrm{m}=1,18$ y $\mathrm{DS}=1,20$. Refieren tensión y experiencia de conflicto. Deben evaluarse en relación con M y FM.

6. RFS (Reality Fantasy Scale): Se trata de una nueva escala Rorschach desarrollada por S. Tibon y sus colaboradores (2004). La RFS apunta a evaluar la habilidad del sujeto para crear, usar y preservar el espacio transicional entre realidad y fantasía. Se obtiene codificando cada respuesta del protocolo según los polos perceptuales/fantasía. El extremo en el polo fantasía puede mostrar el colapso de la realidad (CR). Cuando el polo de la realidad colapsa en el de la fantasía, los objetos de la fantasía se convierten en cosas en sí mismas. En estos casos se podrían observar fenómenos mentales usualmente manifiestos en la psicosis. Sin embargo, cuando el polo de la fantasía colapsa en la realidad, la realidad le roba a la fantasía su vitalidad y la capacidad para imaginar queda reducida. La escala usa un grupo de 
variables o combinaciones de variables basadas en el Sistema Comprehensivo y un puntaje adicional especial de colapso de la realidad (RC). Los 11 puntos de la escala se distribuyen desde -5 (colapso de la realidad en la fantasía) a +5 (colapso de la fantasía en la realidad), en los que un puntaje de -5 representa el caso más extremo de sostén en la fantasía con mínimo contacto con la realidad externa, y un puntaje de +5 representa un fuerte sostén en los rasgos de la realidad de la lámina con un mínimo ingreso de la fantasía. Un puntaje RFS de 0 en un protocolo representa una combinación equilibrada entre la realidad y la fantasía.

7. W Sum C: Suma ponderada de respuestas de color. La media de la muestra argentina de no-pacientes es $\mathrm{WSumC}=2,98$ y $\mathrm{DS}=1,74$. Evalúa la capacidad de reactividad emocional.

8. FC: Respuesta de forma-color: Se aplica a respuestas que se basan principalmente en las características formales en las que el color se halla naturalmente integrado. Informan el logro de capacidades adaptativas para expresar las emociones. La media de la muestra argentina de no-pacientes es $\mathrm{FC}=2,02$ y $\mathrm{DS}=1,62$.

9. Sum Shad $>$ 3: Agrupación de respuestas C (color acromático puro), T (textura), V (vista), Y (sombreado). Cuando su presencia es $>3$ indica vivencias dolorosas y disfóricas. La media de la muestra argentina de no-pacientes es Sum Shad=3,87 y $\mathrm{DS}=2,52$.

10. Afro: Proporción afectiva, examina el porcentaje de respuestas dadas a las tres últimas láminas, cuyas características cromáticas permiten reconocer el interés y la apertura a la estimulación emocional. Cuando se halla elevado $(>60)$ informa receptividad a la excitabilidad emocional. La media de la muestra argentina de nopacientes es Afro=0,56 y DS=0,22.

11. Lambda: Compara la frecuencia de respuestas de forma pura con el resto de respuestas del protocolo; se relaciona con economía en el uso de recursos y la evitación para implicarse personalmente.También la capacidad de distanciarse de 
situaciones comprometidas. Cuando el Lambda es $>99$ se lo considera elevado. La media de la muestra argentina de no-pacientes es Lambda=0,56 y DS=0,58.

12. Blends o respuestas complejas: Son respuestas en las que se conjugan dos o más determinantes, por ejemplo, Ma FC movimiento humano activo y el uso del color aliado a la forma. Exhibe riqueza de componentes simultáneamente presentes en la percepción de las situaciones. La media de la muestra argentina de no-pacientes es Blends $=3,19$ y DS=2,25; y el porcentaje de respuestas complejas respecto de las respuestas es Blends $/ \mathrm{R}=0,18 \%$ y $\mathrm{DS}=0,12 \%$.

13. R-Eng Alto: Consiste en un puntaje derivado empíricamente por G. Meyer, útil para evaluar la capacidad del sujeto para involucrarse con las demandas perceptuales cognitivas y afectivas de la tarea del Rorschach y la habilidad para articular percepciones y sus determinantes. La fórmula para calcular el índice R-Eng usa puntajes z, ajustados para asignarle distintos pesos a las variables que lo integran: Col Shad Blends $+\mathrm{FY}+\mathrm{FC}+\mathrm{FC}+\mathrm{CF}+\mathrm{C}+\mathrm{Shad}$ Blends $+\mathrm{m}+\mathrm{R}+\mathrm{S}+\mathrm{FM}+\mathrm{FV}+\mathrm{W}+\mathrm{MOR}+\mathrm{M}-$ Lambda (éste último valor se resta). Los puntajes R- Eng. que caen en el rango superior de la distribución de la muestra original $(>0,728)$ sugieren la presencia de un estilo de respuesta abierto o ansiedad general en la conducta del sujeto durante la tarea, mientras que los puntajes que caen en el rango inferior $(<-1,103)$ sugieren una conducta guardada y defensiva durante el test.

14. Sumbr6 CC.EE o SumPond6 CC.EE (Suma bruta 14s códigos especiales y Suma ponderada de diez de ellos: SumPond6: DV, INCOM, DR,y FABCOM, de nivel 1 y 2 más ALOG Y CONTAM): Informa la presencia de códigos especiales en la codificación de la respuesta. Los códigos especiales indican significativas distorsiones o características inusuales en la respuesta. La Sumbr6 CC.EE $>6$ o la SumPond6 CC.EE $>17$ integra en el Sistema Comprehensivo el índice de Trastorno de Pensamiento. Una presencia muy limitada de estos códigos muestra excesiva restricción de la actividad imaginaria. La media de la muestra argentina de nopacientes es Sumbr6=1,97 y DS=1,82; Sumpond6=5,90 y DS=6,02. 
15. Zf: frecuencia de $Z$ (capacidad organizativa): Se asigna puntuación $Z$ a toda respuesta que incluya forma y actividad de procesamiento, es decir, de establecer relaciones de sentido entre distintas áreas de la lámina. La media de la muestra argentina de no-pacientes es $\mathrm{Zf}=9,43$ y $\mathrm{DS}=2,95$ Cuando el $\mathrm{Zf}$ es bajo, muestra la escasa disposición para analizar con riqueza los problemas y experiencias.

16. DQ+: Calidad evolutiva superior, que exhibe capacidad para una adecuada discriminación formal junto con la presencia de recursos para establecer relaciones de síntesis adecuadas. La media de la muestra argentina de no-pacientes es $\mathrm{DQ}+=4,70$ y $\mathrm{DS}=2,23$.

17. A: Respuesta de contenido Animal, implica la percepción de una figura animal completa, constituye una capacidad sencilla, poco elaborada de responder a la tarea. Abunda ( $>50 \%$ de $\mathrm{R})$ en los niños y personas con limitaciones intelectuales. La media de la muestra argentina de no-pacientes es $\mathrm{A}=6,81$ y $\mathrm{DS}=2,41$, lo que representa un porcentaje aproximado del $30 \%$ de $\mathrm{R}$.

18. PSV: Perseveración, cuando se reiteran respuestas casi idénticas en la misma lámina, o se vuelve a decir una respuesta dada anteriormente en otras láminas distintas. Estos tipos de respuesta reflejan una forma de disfunción cognitiva o una marcada preocupación psicológica, que se manifiesta en el fracaso de la integración de los componentes propios de cada lámina. La media de la muestra argentina de no-pacientes es PSV=0,12 y DS=0,42.

19. An: Respuestas de contenido anatómico, referidas a órganos o partes del interior del cuerpo. Manifiestan preocupaciones asociadas con la vulnerabilidad corporal. La media de la muestra argentina de no-pacientes es $\mathrm{An}=1,14$ y $\mathrm{DS}=1,31$.

20. An+Xy: Sumatoria de respuestas de contenido anatómico y de contenido radiografía. Se estudia con sentido similar a la respuesta An. La media de la muestra argentina de no-pacientes es $\mathrm{An}+\mathrm{Xy}=2,10$ y $\mathrm{DS}=2,23$. 
21. P: Respuestas populares, que se dan con una frecuencia elevada en la mayoría de los grupos de sujetos. Para clasificar una respuesta como $\mathrm{P}$, debe aparecer por lo menos una vez cada tres protocolos exactamente en la misma localización, contenido y lámina. Reflejan la capacidad cognitiva para compartir el consenso cultural y también el conformismo social. La media de la muestra argentina de nopacientes es $\mathrm{P}=5,37$ y $\mathrm{DS}=1,63$. En la muestra argentina se halló un total de 10 respuestas populares $(\mathrm{P})$.

22. H: Respuestas que implican la percepción de una figura humana completa. Muestran capacidad para la identificación con seres humanos reales, la integración de la identidad y potencialmente (ya que esto dependerá de otros indicadores en la técnica) buenos recursos para las interacciones interpersonales. La media de la muestra argentina de no-pacientes es $\mathrm{H}=2,31$ y $\mathrm{DS}=1,54$.

23. $\mathbf{T}=\mathbf{0}$ : Respuestas de textura, en las cuales los componentes de sombreado de la mancha se traducen como un fenómeno táctil. Cuando está ausente $(\mathrm{T}=0)$ refleja intensas necesidades de preservar el propio espacio personal y mantenerse a distancia de vínculos íntimos. La media de la muestra argentina de no-pacientes es Sum $\mathrm{T}=0,71$ y $\mathrm{DS}=0,80$; el $47 \%$ de los casos obtuvo $\mathrm{T}=0$.

24. CDI $\geq 4$ : Índice de inhabilidad social. Los sujetos con puntuaciones de 4 o más puntos son proclives a mantener relaciones sociales empobrecidas y tienen dificultades para afrontar a las demandas simples de su entorno. En la muestra argentina de no-pacientes hay un $20 \%$ de $\mathrm{CDI}=4$ y un $9 \%$ de $\mathrm{CDI}=5$.

25. EA: Es la suma de las respuestas de movimiento humano (M), a la izquierda y los valores ponderados de las respuestas de color cromático (FC, CF, C, o sea, Sumpond C) a la derecha. Proporciona un indicador de la medida en que los recursos intelectuales y afectivos están organizados y accesibles para ser usados 
voluntariamente por el sujeto. La media de la muestra argentina de no-pacientes es $\mathrm{EA}=6,06$ y $\mathrm{DS}=2,73$.

26. EB ambigual: Estilo vivencial ambigual. Se refiere a un estilo inconsistente cuando se trata de afrontar decisiones: tanto se puede afirmar sobre las propias experiencias e ideas como alternativamente por los estímulos y respuestas que provienen afectivamente de su entorno, en ensayo-error. Exner lo considera un estilo de afrontamiento poco económico. En la muestra argentina de no-pacientes hay un $49 \%$ de casos con EB ambigual.

27. FD: Respuesta de dimensión basada en la forma. Se aplica a respuestas en las que la impresión de profundidad, perspectiva o dimensión no se ha basado en el sombreado. Indica capacidad para la introspección libre de vivencias irritantes o disfóricas. La media de la muestra argentina de no-pacientes es FD=0,64 y $\mathrm{DS}=0,89$.

28. D o Puntaje D: Se obtiene de la comparación entre los recursos disponibles -EA y las cargas estimulares internas y externas a las que están sometidos (eb). Indica la tolerancia al estrés y la presencia de elementos de control frente al estado de estrés. Los puntajes de $\mathrm{D}=0$ muestran la capacidad de equilibrio y control, cuando se vuelven puntajes negativos el estrés aparece como sobrecarga y a la inversa cuando son positivos. En la muestra argentina de no-pacientes obtuvieron $\mathrm{D}=0$ el $45 \%$ de los casos, $\mathrm{D}>0$ el $8 \%$; $\mathrm{D}<0$ el $46 \%$ y, particularmente $\mathrm{D}<-1$ el $21 \%$ (incluido en el $<0)$.

29. D adj: Es el mismo índice anterior, al cual se le han sustraído los determinantes que están afectados situacionalmente ( $\mathrm{Y}$ y m), lo cual permite reconocer la tolerancia al estrés crónico. En la muestra argentina de no-pacientes el Dadj $>0=11 \% ;=0=54 \%$; $<0=35 \%$ y, puntualmente, $<-1=12 \%$ (incluido en el $<0$ ). 


\subsection{Indicadores ampliados de alexitimia en el Rorschach}

Recientemente se ha desarrollado un repertorio de indicadores, llamados variables entre los rorschachistas, porque sus resultados se modifican según los resultados de otros indicadores, variables que, sometidas a procedimientos estadísticos y empíricos rigurosos han demostrado su asociación con la alexitimia (Porcelli 2004). Ya que igualmente aún se hallan en proceso de investigación, vamos a incorporar también otras variables que en nuestros estudios previos han demostrado alcanzar significación, para analizar su comportamiento. Las llamaremos Otras (cuadro VII b) y se encuentran a continuación del cuadro VII.a 
CUADRO VII a:

COMPARACIONES ENTRE LAS TRES MUESTRAS

RESULTADOS TÉCNICA RORSCHACH S. C.

AGRUPACIÓN DE VARIABLES DE ALEXITIMIA SUGERIDAS POR P. PORCELLI

\begin{tabular}{|c|c|c|c|c|}
\hline \multirow{5}{*}{ Fantasía } & & $\begin{array}{l}\text { MUESTRA I } \\
\text { AR } \\
\text { NivelSoc.M.Bajo } \\
\text { Años ed: } \\
\text { promedio } 7,33 \\
\mathrm{~N}=60\end{array}$ & $\begin{array}{l}\text { MUESTRA II } \\
\text { no-pacientes } \\
\text { NivelSoc.M.Bajo } \\
\text { Años ed: promedio } \\
10,66 \\
N=60\end{array}$ & $\begin{array}{l}\text { MUESTRA III } \\
\text { no-pacientes } \\
\text { Años ed: } \\
\text { promedio } 15,38 \\
\text { N=60 }\end{array}$ \\
\hline & Bajo M & $\begin{array}{l}\text { Prom 2,63 } \\
\text { DS } 1,82\end{array}$ & $\begin{array}{l}\text { Prom 2,68 } \\
\text { DS 2,00 }\end{array}$ & $\begin{array}{l}\text { Prom 5,38 } \\
\text { DS 2,31 }\end{array}$ \\
\hline & Bajo MA\% & $\begin{array}{l}\text { Prom 2,10 } \\
\text { DS 2,18 }\end{array}$ & $\begin{array}{l}\text { Prom 2,02 } \\
\text { DS 1,99 }\end{array}$ & $\begin{array}{l}\text { Prom 3,58 } \\
\text { DS 2,08 }\end{array}$ \\
\hline & $\begin{array}{l}\text { Bajo } \\
M+F M+m\end{array}$ & $\begin{array}{l}\text { Prom 8,17 } \\
\text { DS 5,67 }\end{array}$ & $\begin{array}{l}\text { Prom 7,63 } \\
\text { DS } 3,87\end{array}$ & $\begin{array}{l}\text { Prom 9,92 } \\
\text { DS 5,15 }\end{array}$ \\
\hline & $\begin{array}{l}\text { Reality } \\
\text { Fantasy } \\
\text { Scale } \\
\text { (RFS) } \\
\text { positive }\end{array}$ & $\begin{array}{l}\text { Prom 0,40 } \\
\text { DS 0,85 }\end{array}$ & $\begin{array}{l}\text { Prom 0,73 } \\
\text { DS 0,52 }\end{array}$ & $\begin{array}{l}\text { Prom }-0,17 \\
\text { DS } 0,79\end{array}$ \\
\hline Afecto & Bajo WsumC & \begin{tabular}{|l|} 
Prom 2,56 \\
DS 1,66
\end{tabular} & $\begin{array}{l}\text { Prom 2,60 } \\
\text { DS 1,52 }\end{array}$ & $\begin{array}{l}\text { Prom 4,43 } \\
\text { DS } 1,71\end{array}$ \\
\hline Cognición & Lambda alto & $\begin{array}{l}\text { Prom 0,48 } \\
\text { DS } 0,37\end{array}$ & $\begin{array}{l}\text { Prom 0,69 } \\
\text { DS } 0,76\end{array}$ & $\begin{array}{l}\text { Prom 0,33 } \\
\text { DS } 0,26\end{array}$ \\
\hline \multirow{4}{*}{$\begin{array}{l}\text { Relaciones } \\
\text { Interpersonales }\end{array}$} & Popular alto & $\begin{array}{l}\text { Prom 5,43 } \\
\text { DS 1,86 }\end{array}$ & $\begin{array}{l}\text { Prom 5,40 } \\
\text { DS } 1,80\end{array}$ & $\begin{array}{l}\text { Prom 4,70 } \\
\text { DS } 1,73\end{array}$ \\
\hline & Bajo H Pura & $\begin{array}{l}\text { Prom 1,87 } \\
\text { DS } 1,13\end{array}$ & $\begin{array}{l}\text { Prom 1,95 } \\
\text { DS 1,47 }\end{array}$ & $\begin{array}{l}\text { Prom 3,53 } \\
\text { DS } 1,78\end{array}$ \\
\hline & Alto CDI & $\begin{array}{l}9 \text { (frecuencia) } \\
15 \%\end{array}$ & $\begin{array}{l}8 \text { (frecuencia) } \\
13 \%\end{array}$ & $\begin{array}{l}0 \text { (frecuencia) } \\
0 \%\end{array}$ \\
\hline & $\mathbf{T}=0$ & $\begin{array}{l}\text { 19(frecuencia) } \\
32 \%\end{array}$ & $\begin{array}{l}\text { 20(frecuencia) } \\
33 \%\end{array}$ & $\begin{array}{l}29 \text { (frecuencia) } \\
48 \%\end{array}$ \\
\hline $\begin{array}{l}\text { Otras } \\
\text { características } \\
\text { Afecto }\end{array}$ & Bajo FC & $\begin{array}{l}\text { Prom 2,22 } \\
\text { DS 1,75 }\end{array}$ & $\begin{array}{l}\text { Prom 1,97 } \\
\text { DS 1,38 }\end{array}$ & $\begin{array}{l}\text { Prom 2,45 } \\
\text { DS 1,92 }\end{array}$ \\
\hline \multirow{3}{*}{$\begin{array}{l}\text { Recursos } \\
\text { psicológicos }\end{array}$} & Bajo EA & $\begin{array}{l}\text { Prom 5,19 } \\
\text { DS 2,54 }\end{array}$ & $\begin{array}{l}\text { Prom 5,37 } \\
\text { DS 2,74 }\end{array}$ & $\begin{array}{l}\text { Prom 9,81 } \\
\text { DS 1,97 }\end{array}$ \\
\hline & Bajo FD & $\begin{array}{l}\text { Prom 0,10 } \\
\text { DS 0,35 }\end{array}$ & $\begin{array}{l}\text { Prom 0,42 } \\
\text { DS } 1,14\end{array}$ & $\begin{array}{l}\text { Prom 0,67 } \\
\text { DS 0,82 }\end{array}$ \\
\hline & $\begin{array}{l}\text { EB } \\
\text { Ambiguales }\end{array}$ & $\begin{array}{l}26 \text { (frecuencia) } \\
43 \%\end{array}$ & $\begin{array}{l}26 \text { (frecuencia) } \\
43 \%\end{array}$ & $\begin{array}{l}16 \text { (frecuencia) } \\
27 \%\end{array}$ \\
\hline \multirow{7}{*}{ Cognición } & Bajo Blends & $\begin{array}{l}\text { Prom 3,52 } \\
\text { DS 2,21 }\end{array}$ & $\begin{array}{l}\text { Prom 3,12 } \\
\text { DS } 2,15\end{array}$ & $\begin{array}{l}\text { Prom 4,15 } \\
\text { DS } 1,99\end{array}$ \\
\hline & $\begin{array}{l}\text { Alto R } \\
\text { Engag. }\end{array}$ & $\begin{array}{l}\text { Prom }-0,92 \\
\text { DS } 1,19\end{array}$ & $\begin{array}{l}\text { Prom }-1,10 \\
\text { DS } 0,90\end{array}$ & $\begin{array}{l}\text { Prom }-0,73 \\
\text { DS 0,79 }\end{array}$ \\
\hline & $\begin{array}{l}\text { Bajo Cód. } \\
\text { Esp. }\end{array}$ & $\begin{array}{l}\text { Prom 6,05 } \\
\text { DS 7,52 } \\
\end{array}$ & $\begin{array}{l}\text { Prom 3,42 } \\
\text { DS 4,73 }\end{array}$ & $\begin{array}{l}\text { Prom 8,67 } \\
\text { DS 6,44 } \\
\end{array}$ \\
\hline & Bajo Zf & $\begin{array}{l}\text { Prom } 9,17 \\
\text { DS } 2,44\end{array}$ & $\begin{array}{l}\text { Prom 10,37 } \\
\text { DS 5,66 }\end{array}$ & $\begin{array}{l}\text { Prom 10,48 } \\
\text { DS } 3,18\end{array}$ \\
\hline & Bajo DQ+ & $\begin{array}{l}\text { Prom 4,35 } \\
\text { DS } 2,41\end{array}$ & $\begin{array}{l}\text { Prom 5,10 } \\
\text { DS 2,80 }\end{array}$ & $\begin{array}{l}\text { Prom 6,10 } \\
\text { DS 2,52 }\end{array}$ \\
\hline & Alto A Pura & $\begin{array}{l}\text { Prom } 8,42 \\
\text { DS } 3,06\end{array}$ & $\begin{array}{l}\text { Prom 7,12 } \\
\text { DS 2,50 }\end{array}$ & $\begin{array}{l}\text { Prom 6,02 } \\
\text { DS 2,45 }\end{array}$ \\
\hline & PSV $>0$ & $\begin{array}{l}14 \text { (frecuencia) } \\
23 \%\end{array}$ & $\begin{array}{l}7 \text { (frecuencia) } \\
11,66 \%\end{array}$ & $\begin{array}{l}4 \text { (frecuencia) } \\
6,66 \%\end{array}$ \\
\hline
\end{tabular}




\section{CUADRO VII b: OTRAS VARIABLES DE ALEXITIMIA RESULTADOS TÉCNICA RORSCHACH S.C. COMPARACIONES ENTRE LAS TRES MUESTRAS: SIGNIFICACIÓN ESTADÍSTICA DE LOS RESULTADOS}

\begin{tabular}{|c|c|c|c|}
\hline & $\begin{array}{l}\text { MUESTRA I } \\
\text { AR } \\
\text { NivelSoc. M.Bajo } \\
\text { Años ed: promedio 7,33 } \\
\text { N=60 }\end{array}$ & $\begin{array}{l}\text { MUESTRA II } \\
\text { no-pacientes } \\
\text { NivelSoc.M.Bajo } \\
\text { Años ed: promedio } 10,66 \\
\text { N=60 }\end{array}$ & $\begin{array}{l}\text { MUESTRA III } \\
\text { no-pacientes } \\
\text { Años ed: promedio } \\
15,38 \\
N=60\end{array}$ \\
\hline An $>2$ & $\begin{array}{l}11 \text { (frecuencia) } \\
18,33 \%\end{array}$ & $\begin{array}{l}5 \text { (frecuencia) } \\
8,33 \%\end{array}$ & $\begin{array}{l}5 \text { (frecuencia) } \\
8,33 \%\end{array}$ \\
\hline$A n+X y=>3$ & $\begin{array}{l}3 \text { (frecuencia) } \\
5 \%\end{array}$ & 0 (frecuencia) & $\begin{array}{l}1 \text { (frecuencia) } \\
1,66 \%\end{array}$ \\
\hline Alto Afro & $\begin{array}{l}\text { Prom 0,60 } \\
\text { DS } 0,44\end{array}$ & $\begin{array}{l}\text { Prom 0,62 } \\
\text { DS 0,33 }\end{array}$ & $\begin{array}{l}\text { Prom 0,62 } \\
\text { DS 0,22 }\end{array}$ \\
\hline
\end{tabular}

Consultamos al autor de la agrupación de variables P. Porcelli acerca de cuál era el punto de corte que él establecía para todas aquellas variables donde figura «Bajo». Su respuesta fue que aún se hallan en investigación, pero que necesariamente habrán de establecerse según los diferentes contextos culturales. Nosotros tomaremos como referencia para evaluar la disminución de la aparición, su relación con la media y desviación standard de la muestra argentina de no pacientes de referencia, y también el grado de significación que presente el puntaje al compararlo con las muestras de control. En consecuencia, como se observa en la presentación de nuestros resultados, se informan promedios (media y desviación standard). En el caso de la variable Lambda donde se señala «Alto», igualmente se informan y comparan promedios de Lambda, dado que fueron muy escasas las apariciones de la variable «alto» (Lambda >.99) en las tres muestras. Cuando se trate de comparaciones de porcentajes de frecuencia se aclarará. (indicando que se trató de frecuencias y se comparan porcentajes).

Se ha utilizado el ANOVA para establecer el grado de significación estadística de las comparaciones entre las Muestras I, II y III. Su hipótesis nula propone que el promedio de los tres grupos no difiere. Se empleó la versión Statistics Graphics 6.0, y se aplicó el test de Tukey, para discernir entre qué grupos se establecen las diferencias. En los casos en que interesó establecer la diferencia de porcentajes de frecuencias, se utilizó el test de diferencias de proporciones. 


\section{Resultados $^{4}$ :}

Vamos a continuación a analizar los resultados obtenidos. Hemos comparado, recordamos, Muestra I N=60, pacientes de AR, predominantemente nivel socioeconómico medio bajo (60\%) y promedio de 7,33 de años educativos; Muestra II N=60, no-pacientes nivel socioeconómico medio bajo (50\%) equiparada con Muestra I, años educativos con promedio de 10,66 años y Muestra III, $\mathrm{N}=60$, no-pacientes con mejores recursos intelectuales y afectivos (EA), socioeconómicos y educativos que las muestras anteriores (promedio de años educativos 15,38.

1. Variable M:

El Análisis de la Varianza muestra que existen diferencias significativas entre los promedios de las tres muestras. Al aplicar el test de Tukey, vemos que el menor promedio corresponde a la muestra de AR, en segundo lugar se encuentra la muestra no-pacientes, y con el promedio más alto, los de EA elevado.

Se observa que no existen diferencias significativas entre II y I, mientras que ambos presentan diferencias altamente significativas con III.

\section{Variable MA\%}

El mismo análisis realizado a esta variable arroja resultados similares.

\section{Variable $\mathrm{M}+\mathrm{FM}+\mathrm{m}$}

El mismo análisis realizado a esta variable arroja los mismos resultados que en las dos anteriores: no se observan diferencias significativas entre II y I, mientras que ambos presentan diferencias altamente significativas con III.

\section{Variable W Sum C}

El Análisis de la Varianza muestra que existen diferencias significativas entre los promedios de las tres muestras. Al aplicar el test de Tukey, vemos que el menor promedio

\footnotetext{
${ }^{4}$ En el ANEXO 2 se encontrará el análisis de los resultados de las variables en las tres Muestras, bajo el título Elaboración Estadística.
} 
corresponde a la muestra de artríticos, en segundo lugar se encuentra la muestra de nopacientes, y con el promedio más alto, los de EA elevado.

Se observa que no existen diferencias significativas entre I y II, mientras que ambos presentan diferencias altamente significativas con III.

\section{Variable Lambda}

El Análisis de la Varianza muestra que existen diferencias significativas entre los promedios de las tres muestras. Al aplicar el test de Tukey, vemos que el menor promedio corresponde a la muestra de años educativos elevados, (los que de este modo muestran mayor apertura a la experiencia) en segundo lugar se encuentra la muestra de artríticos, y en el tercer lugar los no-pacientes.

Se observa que no existen diferencias significativas entre III y I, ni entre I y II, pero sí existen diferencias altamente significativas entre III y II, los no-pacientes presentan mayor Lambda (A/S). Los no pacientes de la Muestra II- nivel socioeconómico medio bajoexhiben la mayor restricción o economía en su enfoque de las experiencias.

\section{Variable Popular}

El Análisis de la Varianza muestra que existen diferencias significativas entre los promedios de las tres muestras. Al aplicar el test de Tukey, vemos que el menor promedio corresponde a la muestra de elevados años educativos, en segundo lugar se encuentra la muestra de no-pacientes y en el tercer lugar los artríticos con el mayor. Se observa que existen diferencias significativas entre III con I y II, y no existen diferencias significativas entre II y I.

\section{Variable H Pura}

El Análisis de la Varianza muestra que existen diferencias significativas entre los promedios de las tres muestras. Al aplicar el test de Tukey, vemos que el menor promedio corresponde a la muestra de artríticos, en segundo lugar se encuentra la muestra de nopacientes, y con el promedio más alto, los de años educativos elevados.

Se observa que no existen diferencias significativas entre I y II, mientras que ambos presentan diferencias altamente significativas con III. 


\section{Variable CDI}

El Análisis de la Varianza muestra que existen diferencias significativas entre los promedios de las tres muestras. Al aplicar el test de Tukey, vemos que el menor promedio corresponde a la muestra de educación elevada, en segundo lugar se encuentra la muestra de no-pacientes y en el tercer lugar los artríticos.

Se observa que existen diferencias altamente significativas entre III con I y II, y no existen diferencias entre II y I.

\section{Variable FC}

El Análisis de la Varianza muestra que no existen diferencias significativas entre los promedios de las tres muestras. Los promedios presentan valores similares.

\section{Variable EA}

El Análisis de la Varianza muestra que existen diferencias significativas entre los promedios de las tres muestras. Al aplicar el test de Tukey, vemos que el menor promedio corresponde a la muestra de artríticos, en segundo lugar se encuentra la muestra de nopacientes, y con el promedio más alto, los de educación elevada.

Se observa que no existen diferencias significativas entre I y II, mientras que ambos presentan diferencias altamente significativas con III.

\section{Variable FD}

El mismo análisis estadístico realizado a esta variable arroja resultados similares al anterior: no existen diferencias significativas entre I y II, mientras que ambos presentan diferencias altamente significativas con III (los más altos).

\section{Variable Blend}

El Análisis de la Varianza muestra que existen diferencias significativas entre los promedios de las tres muestras. Al aplicar el test de Tukey, vemos que el menor promedio corresponde a la muestra de no-pacientes, en segundo lugar se encuentra la muestra de artríticos, y con el promedio más alto, los de educación elevada. 
Se observa que no existen diferencias significativas entre II y I, tampoco existen entre I y III, mientras que sí existen entre II y III.

\section{Variable Códigos Especiales}

El mismo análisis estadístico realizado a esta variable arroja los mismos resultados: no existen diferencias significativas entre II y I, tampoco existen entre I y III, mientras que sí existen entre II y III., y los de la muestra II son muy inferiores. En otros términos, la sumatoria de Códigos Especiales, que registran fenómenos de atribución de cualidades especiales a las respuestas, a veces ilógicas y fantaseadas, se muestra significativamente inferior entre los no-pacientes de muestra II, quienes muy escasamente producen respuestas especiales.

\section{Variable Zf}

El Análisis de la Varianza muestra que no existen diferencias significativas entre los promedios de las tres muestras. Los promedios presentan valores muy semejantes.

\section{Variable $\mathrm{DQ}^{+}$}

El Análisis de la Varianza muestra que existen diferencias significativas entre los promedios de las tres muestras. Al aplicar el test de Tukey, vemos que el menor promedio corresponde a la muestra de artríticos, en segundo lugar se encuentra la muestra de No Pacientes, y con el tercer promedio, los de educación elevada.

Se observa que no existen diferencias significativas entre I y II, tampoco se observan entre II y III. Se presentan diferencias altamente significativas entre I y III : los artríticos con inferior nivel de desarrollo de sus respuestas y la muestra III de no-pacientes con los mayores.

\section{Variable A :}

El Análisis de la Varianza muestra que existen diferencias significativas entre los promedios de las tres muestras. Al aplicar el test de Tukey, vemos que el mayor promedio corresponde a la muestra de artríticos, (Muestra I) en segundo lugar se encuentra la muestra 
de no-pacientes,(Muestra II) y con el tercer promedio, los de educación elevada (Muestra III). Se observa que no existen diferencias significativas entre I y II, tampoco se observan entre II y III. Se presentan diferencias altamente significativas entre I y III (AS). Los contenidos Animales están muy significativamente aumentados entre los artríticos.

17. Variable $\mathrm{T}=0$

El método utilizado para evaluar los porcentajes de presencia en cada muestra indica que no se observan diferencias significativas entre las tres muestras.

18. Variable EB Ambiguales

El mismo análisis estadístico realizado a esta variable arroja los mismos resultados: no se observan diferencias significativas entre las tres muestras.

19. Variable $A n>2$

El mismo análisis estadístico realizado a esta variable arroja los mismos resultados: no se observan diferencias significativas entre las tres muestras.

20. Variable PSV $>0$

El método utilizado para evaluar los porcentajes de presencia en cada muestra indica que no se observan diferencias significativas entre I y II, y tampoco entre II y III.

Sólo se observan diferencias significativas entre I y III., presentándose el porcentaje más elevado significativamente entre los artríticos.

21. Variable R-Eng:

No se encuentran diferencias significativas entre las muestras.

22. Variable RFS:

En el puntaje total hay diferencias altamente significativas entre todas las muestras: I y II A/S; entre I y III A/S; y entre II y III A/S (I vs II P=0,009 A/S; I vs III, P=0,000 A/S; II vs III $\mathrm{P}=0,000 \mathrm{~A} / \mathrm{S})$

23. Variables 23: An+Xy>3; 24: Afro y 25: SumShad.

Según el test de Diferencia de Proporciones no se hallaron diferencias significativas. 
Resumamos los resultados Rorschach hallados en los indicadores ampliados de alexitimia, comparando la Muestra I de pacientes con AR, la Muestra II de no-pacientes de igual nivel socioeconómico y la Muestra III de no-pacientes con años educativos $(15,38$ años educativos promedio).

1. La variable RFS dio diferencias altamente significativas entre todas las muestras. En primer lugar los no-pacientes de la Muestra II, con la menor capacidad para usar el espacio transicional; luego los pacientes artríticos, y por último, los no-pacientes de Muestra III, con mejores recursos para el uso de la vida de fantasía.

2. No hubo diferencias significativas entre las muestras I y II en M, MA\%, M+FM+m, P, CDI, Blends, Códigos Especiales,Lambda, H, EA, WSUMC, FD, DQ+, PSV y A. as muestras I y II sólo presentaron diferencias significativas al ser comparadas respecto del RFS.

3. Las muestras I y II presentaron diferencias altamente significativas respecto de la III en M, MA\%, M+FM+m, H y EA (y se halló menor producción en los pacientes).

4. La muestra I de pacientes obtuvo diferencias A/S respecto de la Muestra III en: A y D/S en PSV (con la producción más alta entre los pacientes) y DQ+ (con el valor inferior entre los pacientes).

5. La muestra II (no pacientes de nivel socioeconómico medio bajo) en relación con la Muestra III (no pacientes con un promedio de 15 años educativos) mostró diferencias A/S en Lambda (mayor en la muestra II) y en Blends y Códigos Especiales (inferiores en la muestra II). 
6. Las variables FC, Zf, T=0, R.eng.; An>2; An+Xy; EB ambigual, Afro y Sum shad no mostraron diferencias significativas en la comparación entre las

muestras.

Para profundizar la investigación de la variable años educativos en la Alexitimia tal como evaluada por el Rorschach, hicimos comparaciones de submuestras de la muestra de pacientes artríticos $(\mathrm{N}=60)$ y submuestras del total de los no-pacientes $(\mathrm{N}=120)$, según rangos de años educativos.Utilizamos los rangos 0-7; 8-14 e $\geq 15$. Los resultados de las comparaciones se informan en el siguiente Cuadro VIII.

5.4. Comparaciones entre las muestras, reagrupándolas en 6 submuestras según niveles de años educativos

\section{Cuadro VIII}

comparación según submuestras de años educativos entre los pacientes de AR y los no pacientes5

\begin{tabular}{|c|c|c|c|c|c|c|c|c|c|c|}
\hline $\begin{array}{l}\text { Variable } \\
\text { Rorschach }\end{array}$ & $\begin{array}{c}\text { Promedios } \\
\text { y D. S. }\end{array}$ & $\begin{array}{c}\text { Pac. AR } \\
\text { Años } \\
\text { educ. } \\
0-7\end{array}$ & $\begin{array}{c}\text { No-pac. } \\
\text { Años } \\
\text { educ. } \\
0-7\end{array}$ & $\begin{array}{c}\text { Pac. AR } \\
\text { Años } \\
\text { educ. } \\
8-14\end{array}$ & $\begin{array}{c}\text { No-pac. } \\
\text { Años } \\
\text { educ. } \\
8-14\end{array}$ & $\begin{array}{c}\text { Pac. AR } \\
\text { Años } \\
\text { educ. } \\
\geq 15\end{array}$ & $\begin{array}{c}\text { No-pac. } \\
\text { Años } \\
\text { Educ. } \\
\geq 15\end{array}$ & $\begin{array}{l}\text { Sub } \\
\text { Muest } \\
\text { ras } \\
1 \text { y } 2\end{array}$ & $\begin{array}{l}\text { Sub } \\
\text { Muest } \\
\text { ras } \\
3 \text { y } 4\end{array}$ & $\begin{array}{l}\text { Sub } \\
\text { Muest } \\
\text { ras } \\
5 \text { y } 6\end{array}$ \\
\hline & & $\begin{array}{l}\text { Sub } \\
\text { Muestr } \\
\text { a } 1 \\
N=33\end{array}$ & $\begin{array}{l}\text { Sub } \\
\text { Muestr } \\
\text { a } 2 \\
N=17\end{array}$ & $\begin{array}{l}\text { Sub } \\
\text { Muestr } \\
\text { a } 3 \\
N=20\end{array}$ & $\begin{array}{l}\text { Sub } \\
\text { Muestr } \\
\text { a } 4 \\
N=49\end{array}$ & $\begin{array}{l}\text { Sub } \\
\text { Muestr } \\
\text { a } 5 \\
N=7\end{array}$ & $\begin{array}{l}\text { Sub } \\
\text { Muestr } \\
\text { a } 6 \\
\mathrm{~N}=54\end{array}$ & $\begin{array}{l}\text { Dif. } \\
1 Y 2\end{array}$ & $\begin{array}{l}\text { Dif. } \\
3 \text { Y } 4\end{array}$ & $\begin{array}{l}\text { Dif. } \\
5 \text { Y } 6\end{array}$ \\
\hline \multirow[t]{2}{*}{ M } & PROMEDIO & 2,20 & 1,76 & 2,7 & 3,63 & 4,30 & 5,06 & 0,843 & 0,744 & 0,778 \\
\hline & D.S. & 1,98 & 1,15 & 1,42 & 2,33 & 1,11 & 2,54 & 0,403 & 0,460 & 0,440 \\
\hline \multirow[t]{2}{*}{ MA\% } & PROMEDIO & 2,10 & 1,71 & 2,40 & 2,47 & 3,70 & 3,69 & 0,805 & 0,146 & 0,014 \\
\hline & D.S. & 1,81 & 1,16 & 1,50 & 1,91 & 1,25 & 1,89 & 0,425 & 0,884 & 0,989 \\
\hline \multirow[t]{2}{*}{$M+F M+f m$} & PROMEDIO & 7,80 & 7,00 & 8,70 & 6,47 & 8,70 & 9,31 & 0,760 & 3,614 & 0,547 \\
\hline & D.S. & 3,98 & 2,37 & 2,46 & 2,27 & 2,75 & 2,78 & 0,451 & 0,000 & 0,587 \\
\hline \multirow[t]{2}{*}{ RFS } & PROMEDIO & 0,33 & 0,96 & 0,60 & 0,40 & 0,06 & $-0,06$ & $-2,42$ & 1,233 & 0,000 \\
\hline & D.S. & 0,99 & 0,56 & 0,50 & 0,65 & 0,67 & 0,83 & 0,019 & 0,222 & 1,000 \\
\hline \multirow[t]{2}{*}{$\mathrm{R}$} & PROMEDIO & 18,2 & 17,94 & 18,6 & 18,04 & 19,6 & 19,69 & 0,192 & 0,417 & $-0,04$ \\
\hline & D.S. & 4,99 & 3,49 & 4,17 & 5,38 & 10,10 & 4,99 & 0,849 & 0,978 & 0,969 \\
\hline \multirow[t]{2}{*}{ WsumC } & PROMEDIO & 2,50 & 2,53 & 2,80 & 2,89 & 1,90 & 4,39 & $-0,067$ & $-0,199$ & $-3,488$ \\
\hline & D.S. & 1,63 & 1,23 & 1,85 & 1,64 & 1,21 & 1,83 & 0,947 & 0,843 & 0,000 \\
\hline
\end{tabular}

\footnotetext{
${ }^{5}$ Se han tratado las diferentes proporciones numéricas entre las muestras con métodos estadísticos, para controlar el efecto de sus diferencias.
} 


\begin{tabular}{|c|c|c|c|c|c|c|c|c|c|c|}
\hline \multirow[t]{2}{*}{ Lambda } & PROMEDIO & 0,50 & 0,53 & 0,40 & 0,62 & 0,40 & 0,41 & $-0,253$ & $-1,149$ & $-0,075$ \\
\hline & D.S. & 0,43 & 0,32 & 0,23 & 0,84 & 0,42 & 0,32 & 0,801 & 0,255 & 0,940 \\
\hline \multirow[t]{2}{*}{ Popular } & PROMEDIO & 5,40 & 5,24 & 5,20 & 5,11 & 6,30 & 4,94 & 0,267 & 0,189 & 1,992 \\
\hline & D.S. & 1,94 & 2,14 & 1,82 & 1,79 & 1,60 & 1,71 & 0,791 & 0,851 & 0,050 \\
\hline \multirow[t]{2}{*}{ H Pura } & PROMEDIO & 1,60 & 1,71 & 1,90 & 2,90 & 2,60 & 3,07 & $-0,362$ & $-2,230$ & $-0,675$ \\
\hline & D.S. & 1,03 & 0,99 & 1,27 & 1,83 & 1,13 & 1,71 & 0,719 & 0,029 & 0,503 \\
\hline \multirow[t]{2}{*}{ CDI } & PROMEDIO & 3,30 & 3,12 & 3,30 & 2,63 & 2,60 & 1,91 & 0,471 & 2,009 & 1,992 \\
\hline & D.S. & 1,21 & 1,41 & 1,17 & 1,29 & 0,79 & 0,87 & 0,640 & 0,049 & 0,050 \\
\hline \multirow[t]{2}{*}{ FC } & PROMEDIO & 2,20 & 2,00 & 2,30 & 2,16 & 2,10 & 2,31 & 0,393 & 0,309 & $-0,300$ \\
\hline & D.S. & 1,78 & 1,54 & 1,83 & 1,66 & 1,57 & 1,76 & 0,696 & 0,759 & 0,765 \\
\hline \multirow[t]{2}{*}{ EA } & PROMEDIO & 4,80 & 4,29 & 5,50 & 6,68 & 6,20 & 9,44 & 0,770 & $-1,504$ & $-1,077$ \\
\hline & D.S. & 2,46 & 1,63 & 2,79 & 3,02 & 1,98 & 2,65 & 0,445 & 0,137 & 0,286 \\
\hline \multirow[t]{2}{*}{ FD } & PROMEDIO & 0,10 & 0,06 & 0,20 & 0,73 & 0,10 & 0,52 & 0,558 & $-1,760$ & $-1,450$ \\
\hline & D.S. & 0,24 & 0,24 & 0,52 & 1,31 & 0,38 & 0,75 & 0,579 & 0,083 & 0,152 \\
\hline \multirow[t]{2}{*}{ Blend } & PROMEDIO & 3,40 & 2,35 & 3,60 & 3,04 & 3,70 & 4,57 & 1,568 & $-1,524$ & $-1,018$ \\
\hline & D.S. & 2,42 & 1,84 & 2,09 & 1,71 & 1,60 & 2,18 & 0,124 & 0,132 & 0,313 \\
\hline \multirow[t]{2}{*}{ E.Eng. } & PROMEDIO & $-1,12$ & $-1,20$ & $-0,68$ & 0,40 & $-0,63$ & $-0,06$ & $-0,260$ & $-4,827$ & 1,408 \\
\hline & D.S. & 1,16 & 0,71 & 1,20 & 0,65 & 1,27 & 0,83 & 0,796 & 0,000 & 0,165 \\
\hline \multicolumn{11}{|l|}{ Wgd } \\
\hline \multirow[t]{2}{*}{ Sum6 } & PROMEDIO & 5,20 & 2,53 & 6,50 & 5,02 & 9,11 & 8,04 & 1,562 & 0,849 & 0,378 \\
\hline & D.S. & 6,74 & 2,74 & 7,72 & 6,05 & 10,29 & 6,50 & 0,125 & 0,399 & 0,707 \\
\hline \multirow[t]{2}{*}{$Z f$} & PROMEDIO & 8,7 & 7,82 & 9,30 & 10,88 & 11,30 & 10,83 & 1,181 & $-1,208$ & 0,331 \\
\hline & D.S. & 2,58 & 2,32 & 1,97 & 5,69 & 1,98 & 3,67 & 0,244 & 0,231 & 0,742 \\
\hline \multirow[t]{2}{*}{$\mathrm{DQ}+$} & PROMEDIO & 3,80 & 3,88 & 4,60 & 5,24 & 6,40 & 6,46 & $-0,122$ & $-1,113$ & $-1,058$ \\
\hline & D.S. & 2,47 & 1,54 & 1,79 & 2,30 & 2,76 & 3,00 & 0,904 & 0,270 & 0,295 \\
\hline \multirow[t]{2}{*}{ A } & PROMEDIO & 8,60 & 7,29 & 8,50 & 6,78 & 7,60 & 6,15 & 1,824 & 2,136 & 1,404 \\
\hline & D.S. & 2,54 & 2,11 & 3,82 & 2,66 & 3,26 & 2,48 & 0,074 & 0,036 & 0,165 \\
\hline \multirow[t]{2}{*}{$A n+X y$} & PROMEDIO & 1,30 & 0,24 & 1,00 & 1,18 & 2,70 & 0,94 & 2,460 & $-0,565$ & 2,991 \\
\hline & D.S. & 1,74 & 0,44 & 1,15 & 1,22 & 0,345 & 1,02 & 0,018 & 0,574 & 0,004 \\
\hline \multirow[t]{2}{*}{ Punt D } & PROMEDIO & $-1,80$ & $-1,35$ & $-1,70$ & $-0,49$ & $-0,70$ & 0,31 & $-0,981$ & $-3,191$ & $-2,364$ \\
\hline & D.S. & 1,69 & 1,17 & 1,98 & 1,14 & 1,38 & 1,01 & 0,331 & 0,002 & 0,022 \\
\hline \multirow[t]{2}{*}{ D Adj } & PROMEDIO & $-1,30$ & $-1,06$ & $-1,20$ & $-0,36$ & $-0,70$ & 0,52 & $-0,607$ & $-2,405$ & $-2,980$ \\
\hline & D.S. & 1,36 & 1,25 & 1,88 & 1,01 & 1,38 & 0,97 & 0,547 & 0,019 & 0,004 \\
\hline \multirow[t]{2}{*}{ DEPI } & PROMEDIO & 3,80 & 3,18 & 3,40 & 3,16 & 2,90 & 3,54 & 1,760 & 0,671 & $-1,437$ \\
\hline & D.S. & 1,35 & 0,73 & 1,39 & 1,33 & 0,90 & 1,13 & 0,085 & 0,504 & 0,156 \\
\hline \multirow[t]{2}{*}{ Afro } & PROMEDIO & 0,70 & 0,6 & 0,50 & 0,64 & 0,60 & 0,61 & 0,702 & $-1,639$ & 0,518 \\
\hline & D.S. & 0,57 & 0,18 & 0,14 & 0,37 & 0,16 & 0,21 & 0,486 & 0,106 & 0,606 \\
\hline
\end{tabular}

En este nuevo análisis de las muestras, destinado a investigar pormenorizadamente la posible influencia de la variable años educativos, hemos incorporado nuevas variables que podrían permitirnos observaciones complementarias. Ellas son R, DEPI, puntaje D y Dadj. Resaltados en negrita se observan las diferencias significativas.

\section{Resultados:}

SUB-Muestra 1, artríticos de 0-7 años educativos y SUB-Muestra 2, no-pacientes de igual nivel educativo. Se hallaron D/S en RFS. Los no pacientes se acercaron significativamente 
al nivel en el cual la fantasía colapsa en la realidad, es decir, que el uso de la vida imaginaria es muy limitado:

a) Se hallaron D/S en RFS, los no-pacientes punturaron en el rango normótico o sobreadaptado, propio de los alexitímicos (RFS>+.65). Los no-pacientes se acercaron significativamente al nivel en el cual la fantasía colapsa en la realidad, es decir, que el uso de su vida imaginaria es muy limitado, predomina el pensamiento operatorio y la cognición concreta. Es importante señalar que esta diferencia se constata independientemente de variables educativas, ya que están homologados los pacientes con los pacientes.

b) También se hallaron en esta comparación D/S en An+Xy. Los pacientes $(1,30)$ puntuaron más alto que los no-pacientes $(0,24)$, mostrando su mayor preocupación por el interior del cuerpo y la vulnerabilidad al enfermar.

SUB-Muestra 3, artríticos de entre 8 y 14 años educativos y SUB-Muestra 4, no-pacientes de igual nivel educativo:

a) Se hallaron diferencias $\mathrm{A} / \mathrm{S}$ en $\mathrm{M}+\mathrm{FM}+\mathrm{m}$ (mayor entre los artríticos $8,70 \mathrm{y}$ 6,47), los no-pacientes presentaron mucha menos tensión asociada a representación de impulsos y registro de demandas intrusivas y urgentes.

b) También se encontraron diferencias A/S en R-eng, que indican mayor capacidad en los pacientes para involucrarse en las respuestas al Rorschach y mayor dificultad o resistencia defensiva a hacerlo por parte de los no-pacientes. Esta diferencia significativa fue entre las muestras 3 y 4 . El R-Eng fue más alto (0.40) en los NPs con 7-14 años de educación comparados con los AR (-0,68), de igual educación. Si bien se marca la tendencia de los pacientes hacia un pensamiento concreto y simplista, ambos puntajes se encuentran dentro de niveles señalado como normativos para esta variable. Sin embargo, se observa en todos las muestras una asociación entre menor nivel educativo y puntajes R- 
Eng más bajos, lo que otorgaría interés para examinar especialmente esta asociación en nuevas muestras.

c) Se hallaron $\mathrm{D} / \mathrm{S}$ en producción de $\mathrm{H}$, menor entre los pacientes $(1,90 \mathrm{y}$ no-pac. $2,90)$; también $\mathrm{D} / \mathrm{S}$ en producción de $\mathrm{A}$, mayor entre los pacientes $(\mathrm{AR}=8,50$; no-pac. 6,78 ) y también hallamos $\mathrm{D} / \mathrm{S}$ en producción de D y en Dadj (en ambos casos mayor entre los artríticos). Aún con años educativos entre 8 y 14 los pacientes exhiben la disminución de las representaciones humanas y simbolización $(\mathrm{H})$, pobreza ideacional (A), y presencia de estrés crónico y situacional.

SUB-Muestra 5, artríticos de $\geq 15$ años educativos y SUB- Muestra 6, no-pacientes de igual nivel educativo(promedio $\geq 15$ ):

a) Hallamos diferencias $\mathrm{A} / \mathrm{S}$ en WSUMC, producción mucho menor en muestra 5 (AR: 1,90 y no-pac. muestra 6: 4,94), que refleja la importante restricción de la respuesta emocional en los artríticos, aun con muchos años educativos.

b) También nuevamente informamos diferencias $\mathrm{A} / \mathrm{S}$ en $\mathrm{An}+\mathrm{Xy}>3$, muy superior en los pacientes.

c) Con diferencias significativas $(\mathrm{D} / \mathrm{S})$ la producción de Populares, el D y el Dadj (mayor en los pacientes).

d) Numerosos indicadores no evidenciaron modificaciones significativas al realizar comparaciones según nivel de años educativos entre pacientes y no-pacientes. Ellos fueron M, MA\%, R, Lambda; FC, EA, FD, Blend, Wpond6, Zf, DQ+ y Afro.

Vemos que introducir comparaciones de submuestras según años educativos, favoreció claramente poder reconocer como independientes de los años de educación recibidos a las características de los pacientes. Tales son, la escasez de respuestas con identificaciones humanas $(\mathrm{H})$ entre los pacientes como expresión de su limitación en la integración de la identidad y el desarrollo de vínculos interpersonales escasamente diferenciados, es decir, fundamentalmente primarios. En este mismo sentido, también, la elevada producción de 
respuestas de contenido animal (A) subraya la pobreza de su mundo representacional y vincular. Esta tendencia a la estereotipia cognitiva y social también se acentúa por sus diferencias significativas $(\mathrm{D} / \mathrm{S})$ en la producción de Populares. Las frecuencias significativas de los índices de Estrés Situacional (D) y Crónico (Dadj) entre los pacientes de AR refiere la importante sobrecarga emocional a la que están sometidos, en las que son altamente significativas sus preocupaciones por la vulnerabilidad corporal (An $+\mathrm{Xy}>3$, muy superior en los pacientes).

Las diferencias A/S en WSUMC, producción mucho menor en muestra 5 (AR: 1,90 y no-pacientes muestra 6: 4,94) reflejan la importante restricción de la respuesta emocional en los artríticos, aun cuando padecen una importante sobrecarga emocional (D y Dadj), mayor en los pacientes -aún con muchos años educativos-, que exhibe la penosa situación de, a la vez, padecer una gran carga emocional y estar restringido para manifestarla.

Continuando con la comparación de sub-muestras de años educativos entre pacientes y no pacientes, fue apropiado examinar la aparición de algunas variables que a continuación informamos, cuadro IX, en su frecuencia y porcentaje y no en el promedio.

\section{Cuadro IX}

6 Sub muestras comparadas según niveles de años educativos Variables evaluadas según porcentajes

\begin{tabular}{|c|c|c|c|c|c|c|c|c|}
\hline $\begin{array}{l}\text { DEPI } \geq 5 \\
\text { Sub } \\
\text { Muestra } 1 \\
N=33 \\
27,3 \%\end{array}$ & $\begin{array}{l}\text { Sub } \\
\text { Muestra } \\
2 \\
\mathrm{~N}=17 \\
0 \%\end{array}$ & $\begin{array}{l}\text { Sub } \\
\text { Muestra } \\
3 \\
N=20 \\
15 \%\end{array}$ & $\begin{array}{l}\text { Sub } \\
\text { Muestra } \\
4 \\
N=49 \\
16,3 \%\end{array}$ & $\begin{array}{l}\text { Sub } \\
\text { Muestra } \\
5 \\
\mathrm{~N}=7 \\
0\end{array}$ & $\begin{array}{l}\text { Sub } \\
\text { Muestra } \\
6 \\
N=54 \\
16,17 \%\end{array}$ & $\begin{array}{l}\text { Sub } \\
\text { Muestras } \\
1 \text { y } 2 \\
P=\mathbf{0 , 0 4 8}\end{array}$ & $\begin{array}{l}\text { Sub } \\
\text { Muestras } \\
3 \text { y } 4 \\
P=0,819\end{array}$ & $\begin{array}{l}\text { Sub } \\
\text { Muestras } \\
5 \text { y } 6 \\
P=0,570\end{array}$ \\
\hline $\begin{array}{l}\text { CDI } \geq 4 \\
\text { Sub } \\
\text { Muestra } 1 \\
42,4 \%\end{array}$ & $\begin{array}{l}\text { Sub } \\
\text { Muestra } \\
2 \\
41,1 \%\end{array}$ & $\begin{array}{l}\text { Sub } \\
\text { Muestra } \\
3 \\
55 \%\end{array}$ & $\begin{array}{l}\text { Sub } \\
\text { Muestra } \\
4 \\
26,6 \%\end{array}$ & $\begin{array}{l}\text { Sub } \\
\text { Muestra } \\
5\end{array}$ & $\begin{array}{l}\text { Sub } \\
\text { Muestra } \\
6 \\
3,7 \%\end{array}$ & $\begin{array}{l}\text { Sub } \\
\text { Muestras } \\
1 \text { y } 2 \\
P=0,830\end{array}$ & $\begin{array}{l}\text { Sub } \\
\text { Muestras } \\
\begin{array}{l}3 \text { y } 4 \\
P=0,049\end{array}\end{array}$ & $\begin{array}{l}\text { Sub } \\
\text { Muestras } \\
5 \text { y } 6 \\
P=0,533\end{array}$ \\
\hline $\begin{array}{l}\text { Sum } \\
\text { Shad }>3\end{array}$ & Muestra & Muestra & Muestra & Muestra & Muestra & $\begin{array}{l}\text { Sub } \\
\text { Muestras }\end{array}$ & $\begin{array}{l}\text { Sub } \\
\text { Muestras }\end{array}$ & $\begin{array}{l}\text { Sub } \\
\text { Muestras }\end{array}$ \\
\hline
\end{tabular}




\begin{tabular}{|c|c|c|c|c|c|c|c|c|}
\hline $\begin{array}{l}\text { Muestra } 1 \\
63,3 \%\end{array}$ & $\begin{array}{l}2 \\
64,7 \%\end{array}$ & $\begin{array}{l}3 \\
65 \%\end{array}$ & $\begin{array}{l}4 \\
40,7 \%\end{array}$ & $\begin{array}{l}5 \\
71,4 \%\end{array}$ & $\begin{array}{l}6 \\
57,4 \%\end{array}$ & $\begin{array}{l}1 \text { у } 2 \\
P=0,831\end{array}$ & $\begin{array}{l}3 \text { y } 4 \\
P=0,117\end{array}$ & $\begin{array}{l}5 \text { y } 6 \\
P=0,764\end{array}$ \\
\hline $\begin{array}{l}\text { PSV >0 } \\
\text { Muestra } 1 \\
30,3 \%\end{array}$ & $\begin{array}{l}\text { Muestra } \\
2 \\
5,9 \%\end{array}$ & $\begin{array}{l}\text { Muestra } \\
3 \\
20 \%\end{array}$ & $\begin{array}{l}\text { Muestra } \\
4 \\
12,1 \%\end{array}$ & $\begin{array}{l}\text { Muestra } \\
5 \\
0 \%\end{array}$ & $\begin{array}{l}\text { Muestra } \\
6 \\
7,4 \%\end{array}$ & $\begin{array}{l}\text { Sub } \\
\text { Muestras } \\
1 \text { y } 2 \\
P=0,107\end{array}$ & $\begin{array}{l}\text { Sub } \\
\text { Muestras } \\
3 \text { y } 4 \\
P=0,638\end{array}$ & $\begin{array}{l}\text { Sub } \\
\text { Muestras } \\
5 \text { y } 6 \\
P=0,938\end{array}$ \\
\hline $\begin{array}{l}\text { Sum T=0 } \\
\text { Muestra } 1 \\
24,24 \%\end{array}$ & $\begin{array}{l}\text { Muestra } \\
2 \\
35,29 \%\end{array}$ & $\begin{array}{l}\text { Muestra } \\
3 \\
55 \%\end{array}$ & $\begin{array}{l}\text { Muestra } \\
4 \\
38,77 \%\end{array}$ & $\begin{array}{l}\text { Muestra } \\
5 \\
0\end{array}$ & $\begin{array}{l}\text { Muestra } \\
6 \\
46,2 \%\end{array}$ & $\begin{array}{l}\text { Sub } \\
\text { Muestras } \\
1 \text { y } 2 \\
P=0,623\end{array}$ & $\begin{array}{l}\text { Sub } \\
\text { Muestras } \\
3 \text { y } 4 \\
P=0,334\end{array}$ & $\begin{array}{l}\text { Sub } \\
\text { Muestras } \\
\begin{array}{l}5 \text { y } 6 \\
P=\mathbf{0 , 0 5 0}\end{array}\end{array}$ \\
\hline $\begin{array}{l}\text { An>2 } \\
\text { Muestra } 1 \\
18,22 \%\end{array}$ & $\begin{array}{l}\text { Muestra } \\
2 \\
0\end{array}$ & $\begin{array}{l}\text { Muestra } \\
3 \\
15 \%\end{array}$ & $\begin{array}{l}\text { Muestra } \\
4 \\
14,28 \%\end{array}$ & $\begin{array}{l}\text { Muestra } \\
5 \\
42,85 \%\end{array}$ & $\begin{array}{l}\text { Muestra } \\
6 \\
5,55 \%\end{array}$ & $\begin{array}{l}\text { Sub } \\
\text { Muestras } \\
\begin{array}{l}1 \text { y } 2 \\
P=0,160\end{array}\end{array}$ & $\begin{array}{l}\text { Sub } \\
\text { Muestras } \\
\begin{array}{l}3 \text { y } 4 \\
P=0,764\end{array}\end{array}$ & $\begin{array}{l}\text { Sub } \\
\text { Muestras } \\
\begin{array}{l}5 \text { y } 6 \\
P=\mathbf{0 , 0 1 5}\end{array}\end{array}$ \\
\hline $\begin{array}{l}\text { Ambiguales } \\
36 \%\end{array}$ & $59 \%$ & $45 \%$ & $20 \%$ & $14 \%$ & $54 \%$ & $\begin{array}{l}\text { Sub } \\
\text { Muestras } \\
1 \text { y } 2 \\
P=0,211\end{array}$ & $\begin{array}{l}\text { Sub } \\
\text { Muestras } \\
3 \text { y } 4 \\
P=0,069\end{array}$ & $\begin{array}{l}\text { Sub } \\
\text { Muestras } \\
5 \text { y } 6 \\
P=0,112\end{array}$ \\
\hline
\end{tabular}

Nota: las correlaciones que están resaltadas en negrita obtuvieron Diferencias Significativas (D/S)

La comparación de los porcentajes obtenidos por las variables, según niveles educativos, entre las muestras de pacientes y no pacientes nos permiten notar que cuando comparamos artríticos y no-pacientes de escasos años educativos (muestras 1 y 2) la única variable que informa diferencias significativas es el índice de Depresión (DEPI) positivo $(\geq 5)$, ausente en la muestra de no-pacientes.

Al comparar pacientes y no-pacientes con años educativos entre 8 y 14 años (muestras 3 y 4), la única variable que mostró diferencias significativas fue el Índice de Desvalimiento Social (CDI) positivo ( $\geq 4)$, ausente entre los no-pacientes.

Dos variables informan diferencias significativas cuando comparamos las muestras 5 y 6 (pacientes con artritis y no-pacientes, ambos con educación $>15$ años). Ellas son: $a$ ) SUM $\mathrm{T}=0$, ausente entre los pacientes de $\mathrm{AR}$ y $b$ ) An $>2$, con porcentaje de aparición muy importante entre los pacientes de AR. 
Los resultados mencionados nos permiten afirmar que, equiparando los años educativos entre los pacientes y los no-pacientes según los porcentajes de frecuencia de aparición, se establecen diferencias significativas entre los pacientes de AR, que presentan índice de depresión positivo (DEPI), índice de desvalimiento social positivo (CDI), An>2, y refieren su preocupación con la vulnerabilidad corporal y su necesidad de vínculos íntimos y de continencia (ausencia de $\mathrm{T}=0$ ).

Por su parte, los no-pacientes no presentan índice de depresión positivo (DEPI), índice de desvalimiento social positivo (CDI), An>2, y refieren carencia de preocupación por la vulnerabilidad corporal y que son capaces de establecer distancia de relaciones cercanas y de vínculos íntimos y de continencia (presencia significativa de $\mathrm{T}=0$ ).

Ya hemos comprobado que comparando pacientes y no pacientes en sub-muestras de años educativos, las diferencias de años educativos no intervinieron significativamente. Para definitivamente, despejar la posibilidad de que en los pacientes de AR, la diferencia de años educativos dentro de la propia muestra, pudiera estar interviniendo con diferencia en los indicadores del Rorschach realizamos el siguiente estudio de submuestras desdobladas dentro de la muestra I de pacientes y las comparamos entre sí, según sus años educativos.

Observemos los resultados en el siguiente cuadro X. 


\section{Cuadro X}

Muestra I (pacientes de AR $\mathbf{N}=60$ )

COMPARACIÓN SEGÚN AÑOS EDUCATIVOS ENTRE LOS PACIENTES DE ARTRITIS REUMATOI DEA

COMPARA SUB MUESTRA 1 (0-7 AÑOS EDUCATIVOS $\mathbf{N}=33$ ) CON SUBMUESTRA 3 ( 8-14 AÑOS EDUCATIVOS, $N=20$ ) CON SUBMUESTRA 5 ( $\geq 15$ AÑ̃S EDUCATIVOS $\mathrm{N}=7$ )

\begin{tabular}{|c|c|c|c|}
\hline & Comparación sub muestras & Comparación sub muestras & Comparación sub \\
\hline VARIABLE & $1 Y 3$ & 1 y 5 & muestras 3 y 5 \\
\hline M & 0,36 & 0,01 & 0,012 \\
\hline MA $\%$ & 0,536 & 0,033 & 0,051 \\
\hline$M+F M+m$ & 0,367 & 0,574 & 1 \\
\hline RFS & 0,263 & 0,497 & 0,033 \\
\hline $\mathrm{R}$ & 0,765 & 0,584 & 0,714 \\
\hline WSumC & 0,54 & 0,365 & 0,244 \\
\hline Lambda & 0,343 & 0,578 & 1 \\
\hline Popular & 0,716 & 0,26 & 0,169 \\
\hline H Pura & 0,351 & 0,027 & 0,21 \\
\hline CDI & 1 & 0,153 & 0,156 \\
\hline FC & 0,845 & 0,891 & 0,799 \\
\hline EA & 0,344 & 0,167 & 0,548 \\
\hline FD & 0,345 & 1 & 0,646 \\
\hline Blend & 0,76 & 0,757 & 0,91 \\
\hline R - Engagement & 0,1 & 0,324 & 0,926 \\
\hline W Sum 6 & 0,522 & 0,213 & 0,486 \\
\hline $\mathrm{Zf}$ & 0,376 & 0,017 & 0,029 \\
\hline $\mathrm{DQ}+$ & 0,213 & 0,018 & 0,058 \\
\hline A & 0,909 & 0,373 & 0,567 \\
\hline$A n+X y$ & 0,497 & 0,042 & 0 \\
\hline Punt D & 0,846 & 0,116 & 0,231 \\
\hline D Adj & 0,823 & 0,297 & 0,527 \\
\hline DEPI & 0,306 & 0,102 & 0,637 \\
\hline \multirow[t]{3}{*}{ Afro } & 0,131 & 0,651 & 0,129 \\
\hline & \multicolumn{2}{|c|}{ Comparaciones entre porcentajes } & \\
\hline & $1 Y 3$ & 1 y 5 & 3 y 5 \\
\hline $\mathrm{DEPI}>=5$ & 0,485 & 0,282 & 0,704 \\
\hline $\mathrm{CDI}>=4$ & 0,544 & 0,09 & 0,036 \\
\hline Sum Shad $>3$ & 0,865 & 0,978 & 0,876 \\
\hline PSV $>0$ & 0,615 & 0,232 & 0,511 \\
\hline Sum $T=0$ & 0,049 & 0,352 & 0,036 \\
\hline An $>2$ & 0,94 & 0,358 & 0,319 \\
\hline AMBIGUAL & 0,719 & 0,492 & 0,314 \\
\hline
\end{tabular}

Metodología

Para las variables continuas, se utilizó el ANOVA. En aquellos casos que dio diferencia entre los tres promedios se continuó con el test de Tukey, comparando todos los datos contra todos. Cuando se trató de porcentajes se usó el test de diferencia de proporciones. 
En negrita se destacan las diferencias significativas y altamente significativas

\section{Resultados}

Diferencias significativas entre submuestras de AR con 0-7 años educ (submuestra 1) y 8-14 (submuestra 3) en SUM T = 0 . Entre las 31 variables comparadas, solamente Sum $\mathrm{T}$, fue significativamente superior entre los pacientes con más años educativos. De éste modo, los pacientes más educados, muestran mayor capacidad para mantenerse a distancia de relaciones interpersonales y afectivas de tipo íntimo o cercano.

Diferencias significativas entre submuestras de AR con 0-7 años educ(submuestra 1) y ( $\geq 15$ AÑOS ) (submuestra 5) : variables M, MA\%;Zf, DQ+, An+Xy

Cuando los pacientes artríticos tienen mayor educación su producción de M, MA\%, Zf, $\mathrm{DQ}+\mathrm{y} \mathrm{An}+\mathrm{Xy}$, es mejor.

Diferencias significativas entre submuestras de AR con 8-14años educ(submuestra 3) y ( $\geq 15$ AÑos ) (submuestra 5): variables M, SUMT=0, Zf, An+Xy, RFS,CDI Los pacientes con mayores años educativos, produjeron mayor M, SumT,Zf, An+Xy, RFS y menor CDI

De las comparaciones de 31 variables Rorschach solo en 8 variables fueron significativas, y no se hallaron diferencias en las restantes 23. La mayor educación en esas variables se asoció con mejores recursos psicológicos. Dentro de las variables significativas y respecto de la agrupación original de Acklin y Bernat (Acklin, 1997) solamente la M (respuesta de movimiento humano) se mostró asociada con mayores años educativos, los cuales favorecerían su producción. 


\subsection{Investigación de variables asociadas al EA>6}

Al estudiar, como ilustramos antes en este capítulo, la comparación entre las muestras I y II (Cuadro IV) de Acklin, comprobamos el amplio cumplimiento de los indicadores de alexitimia esperados en ambas muestras. Nos llamó la atención que uno de los indicadores Rorschach de Acklin muy importante de alexitmia, el EA obtuvo un resultado por debajo de lo normativo (EA 6.06)en ambas. El EA resulta de la sumatoria de todas las respuestas de Movimiento Humano, más la Suma ponderada de las respuestas de color. Para Exner, el EA, "la experiencia accesible", muestra las capacidades en uso activo por el sujeto. El EA, informa la disponibilidad de recursos ideacionales y afectivos para afrontar las situaciones vitales: en este caso informa en su falencia las deficiencias ideacionales y afectivas. En un caso, podríamos pensar de modo preliminar, que la Muestra I se correspondería con la presencia de alexitmia en la AR asociada a la reconocida restricción cognitiva y afectiva. Podríamos, también atribuir la diferencia de EA entre las muestras I (60\% nivel medio bajo) y II al nivel socioeconómico medio-bajo,(presente en un 51,33 \% en esta muestra) ya que está equiparado y podría afectar su producción. No podríamos, sin embargo, atribuirla a menores recursos educativos en la muestra II, ya que está presentó diferencias significativas con mayores años educativos que los pacientes. Nuestra pregunta es: ¿cómo podíamos explicar el EA bajo en la muestra de no-pacientes?. Tomemos en cuenta que esta restricción de recursos, se encuentra en la muestra II de no-pacientes adaptativos, que desempeñan normalmente sus trabajos y vida familiar, que nunca demandaron atención psicoterapéutica por ningún problema y que cuentan con más años educativos que los pacientes. Sobre todo nos interesa la asociación entre EA y alexitimia. Este punto, entonces, nos plantea interrogantes que intentaremos elucidar a continuación.

Al analizar la muestra III, con aún mayores años educativos y diferencias en nivel socioeconómico, encontramos que invariablemente el EA es normativo $(>6)$, por ello, la pregunta que nos planteamos es si la capacidad de disponer recursos ideacionales y afectivos $(E A>6)$ para afrontar las demandas vitales estará asociada con el nivel socioeconómico o con los mayores años educativos. Estudiaremos continuación, cómo varía el porcentaje de EA $>6$ a medida de analizamos la asociación con años educativos y niveles socioeconómicos medios, ya sean altos, medios o bajos. 
Para responder a esta pregunta analizamos los datos que se presentan en el siguiente cuadro:

\section{Cuadro: XI}

\section{Comparación entre muestras de pacientes y no-pacientes con EA>6}

$\mathrm{EA}>6=\quad 60$

Años Educativos

$0-7$

8-15

$>15$

Total

$\mathrm{EA}>6=$

16

Años Educativos

$0-7$

8-15

$>15$

Total

$\mathrm{EA}>6=19$

Años Educativos

$0-7$

8-15

$>15$

Total
NO PACIENTES DE AR CON EA $\geq 6$

Niv. Soc.

$\%$

$0,00 \%$

$48,33 \%$

$51,67 \%$

$100,00 \%$

Alto
Medio
Bajo
Total

N $\%$

$16 \quad 26,67 \%$

$39 \quad 65,00 \%$

$5 \quad 8,33 \%$

$60 \quad 100,00 \%$

NO PACIENTES DE AR

Niv. Soc.

$\%$

$6,25 \%$

$56,25 \%$

$37,50 \%$

$100,00 \%$

Alto
Medio
Bajo

N \%

$2 \quad 12,50 \%$

$10 \quad 62,50 \%$

$4 \quad 25,00 \%$

$16 \quad 100,00 \%$

CASOS DE AR

Nil. Soc.

$\%$
$52,63 \%$
$42,11 \%$
$5,26 \%$
$100,00 \%$

$\begin{array}{rrr}\text { N } & \% \\ 1 & 5,26 \% \\ 14 & 73,68 \% \\ 4 & 21,05 \% \\ 19 & 100,00 \%\end{array}$

Se usó el test Chi-2 que determina si existe independencia entre las variables que se contrastan. Los resultados son: para años educativos chi- $2=43,15 \mathrm{P}=0,000$, hay diferencias altamente significativas. Para nivel socioeconomico Chi-2=7,56 $\mathrm{P}=0,109$, no hay diferencias.

Por lo tanto, el estudio permite afirmar que la variable EA, disposición de recursos ideacionales y afectivos adecuados para afrontar las demandas vitales, está afectado por los 
años educativos recibidos y no lo está por pertenecer a algún nivel socioeconómico sea este medio-bajo, medio-medio o medio-alto. En consecuencia, ya que la muestra II de nopacientes contaba con más años educativos $(\mathrm{D} / \mathrm{S})$ que los pacientes, deberemos comprender la deficiencia de sus recursos ideacionales y afectivos como característica propia del grupo.

\subsection{Discusión de Resultados}

Vamos a comenzar la discusión de nuestros resultados en relación a los reportados o propuestos como esperables en las investigaciones de la alexitimia mediante el Rorschach (S.C.).

La agrupación de indicadores Rorschach de alexitimia de Acklin y Bernat, en los funcionamientos de fantasía, cognición, emoción y recursos adaptativos.

: se cumple en su gran mayoría en la AR. Nuestro estudio permite corroborar como válidos para el diagnóstico de la alexitimia la producción baja de M, Sumpond C, FC, Blends y EA. No comprobamos, confirmando estudios nuestros anteriores, el Lambda alto. Es oportuno indicar que R no facilitó diferencias significativas en nuestra investigación, y por lo tanto, se afirmaría la propuesta de Porcelli de no considerarla como indicador.

Respecto de FC, si bien apareció bajo entre los alexitímicos en el Rorschach (muestra I y II), también su producción fue baja y sin diferencias significativas en los no alexitímicos, Rorschach (Muestra III). Lo mismo sucede respecto de Blends.

Nuestro estudio discrepa con lo informado por Diaz Curiel en artríticos juveniles, ya que no hallamos al FC con capacidad discriminativa. Tampoco hallamos el Afro bajo significativo como propone. Corresponde mencionar al respecto que si bien se trata de la misma enfermedad (AR) las muestras no son comparables : en aquel caso son niños y jóvenes y nuestra muestra comienza en el rango de edad 18, con un promedio de edad de 44,43 años.

En nuestras investigaciones previas habíamos informado entre los pacientes de AR, presencia significativa de Indice de Desvalimiento (C.D.I), Estrés crónico (Dadj), Estrés Situacional (D) e índice de Depresión (DEPI). Luego del presente estudio, los hemos hallado a todos confirmados, especialmente cuando se equiparan años educativos entre 
pacientes y no-pacientes. Respecto del An>2 que habíamos informado significativo en muestras psicosomáticas, igualmente lo corroboramos en la AR.

Examinando la propuesta de variables ampliadas de alexitimia de Porcelli, se comprobó la eficacia altamente significativa de las variables $\mathrm{MA} \%, \mathrm{M}+\mathrm{FM}+\mathrm{m}, \mathrm{H}, \mathrm{DQ}+\mathrm{y}$ Códigos especiales, con producción baja entre los pacientes. En cambio, se comprobaron, con producción mayor entre los pacientes de AR, también las variables A, P y PSV.

Las variables FC, Zf, EB ambigual, Afro y Sumshad no informaron diferencias significativas. Al analizar las variables homologando muestras según años educativos se hallaron diferencias en R-Eng, $\mathrm{An}>2$ y $\mathrm{An}+\mathrm{Xy}>3$.

Un hallazgo realmente destacado es la variable RFS, la única que mostró validez discriminatoria consistentemente entre las tres muestras, y que por lo tanto se aconseja utilizar para el diagnóstico cualitativo de la alexitimia.

Excluimos de nuestro comentario a las variables de Akclin y Bernat, incluídas en la propuesta ampliada de Porcelli, ya que nos hemos referido a ellas al comienzo de la discusión de resultados. Encontramos avalada la exclusión realizada por Porcelli y Meyer de la variable número de Respuestas( R) que constaba en el cluster original de Acklin, pero que no ha probado ser significativa en los estudios de Porcelli ni en los nuestros.

La discusión de los resultados hallados en nuestra investigación, comparando muestras de pacientes y no pacientes, investigando un repertorio ampliado de variables de alexitmia, que incluyó otras surgidas de nuestros propios trabajos previos y la investigación del análisis de las muestras de pacientes y no pacientes homologados en submuestras según años educativos, nos permiten puntuar las siguientes observaciones:

Primera observación muy importante, al no hallarse diferencias significativas entre la muestra I (AR) y la muestra II de no-pacientes demográficamente equivalentes y de igual nivel socioeconómico medio-bajo, en ninguna de las variables del cluster de alexitmia de 
Acklin encontramos que según el Rorschach, la muestra II es igualmente alexitímica. Casi aún más alexitímica, ya que una serie de variables como RFS, de nivel en rango normótico (alexitímico-sobreadaptado) y mayor Lambda puntuaron significativamente más alto que los no alexitímicos (Muestra III) y significativamente más bajo que éstos en Blends y Códigos Especiales, exhibiendo así la restricción de su vida emocional y cognitiva.

Estos resultaron impulsaron estudios especiales, tratando de establecer alguna asociación estadísticamente significativa que permitiera comprender este rasgo alexitímico entre los no-pacientes (Muestra II). Tal como se ha detalladamente informado no puede asociarse ni a menores años educativos, ya que portan $\mathrm{D} / \mathrm{S}$ en mayores años respecto de los pacientes, ni tampoco al nivel socioeconómico, ya que se comprobó la falta de asociación de esta variable y el déficit cognitivo y afectivo característico de la alexitimia. Tales resultados nos plantean reconocer que en la población general adaptativa, y no sólo en los pacientes psicosomáticos, también se presenta significativamente la alexitimia según el Rorschach. Dicho rasgo alexitímico, es reconocible en los no pacientes que evitan experimentar conflictos y se orientan y adaptan, según la deseabilidad social. Estas afirmaciones se aclararán mejor, pensamos, cuando reunamos la información conjunta de nuestras técnicas, en el Capítulo siguiente.

\subsection{Síntesis de resultados y Conclusión:}

De la comparación realizada entre la muestra I (AR) y muestra II (no-pacientes) de igual nivel socioeconómico, no surgen diferencias significativas en las variables para evaluar alexitimia en el Rorschach propuestas por Acklin y Bernat: tanto los pacientes como los no pacientes son igualmente alexitímicos en el Rorschach.

Cuando se introducen mayores años educativos en la Muestra III, en la comparación de los resultados al Rorschach, significativas variables diferencian a los no-pacientes como no alexitímicos: M, SumpondC, Lambda y EA.

Los resultados Rorschach hallados en los indicadores ampliados de alexitimia, comparando las Muestras I, II y III son: diferencias altamente significativas entre todas las 
muestras en RFS. No hubo diferencias significativas entre las muestras I y II en M, MA\%, $\mathrm{M}+\mathrm{FM}+\mathrm{m}, \mathrm{P}, \mathrm{CDI}$, Blends, Códigos Especiales,Lambda, H, EA, WSUMC, FD, DQ+, PSV y A. Las muestras I y II sólo presentaron diferencias significativas al ser comparadas respecto del RFS. Las muestras I y II presentaron diferencias altamente significativas respecto de la III en M, MA\%, M+FM+m, H y EA (menor producción en los pacientes). La muestra I (AR) tuvo A/S respecto de la Muestra III en A y D/S en PSV (más alta entre los pacientes) y DQ+ (inferior entre los pacientes). La muestra II (no pacientes de nivel socioeconómico medio-bajo) en relación con la Muestra III (no-pacientes con un promedio de 15 años educativos) mostró diferencias A/S en Lambda (mayor en la muestra II) y en Blends y Códigos Especiales (inferiores en la muestra II).

Las variables FC, Zf, T=0, R.eng., An>2, An+Xy, EB ambigual, Afro y Sum shad no mostraron diferencias significativas en la comparación entre las muestras.

La variable RFS dio diferencias altamente significativas entre todas las muestras, reagrupándolas según nivel de años educativos. En primer lugar, los no-pacientes de la Muestra II, con la menor capacidad para usar el espacio transicional; luego los pacientes artríticos, y por último, los no-pacientes de mayores años educativos.

Equiparando los años educativos entre los pacientes y los no-pacientes según los porcentajes de frecuencia de aparición, se establecen diferencias significativas entre los pacientes de AR, los que presentan índice de depresión positivo (DEPI), índice de desvalimiento social positivo (CDI), An>2, y refieren su preocupación con la vulnerabilidad corporal y su necesidad de vínculos íntimos y de continencia (ausencia de $\mathrm{T}=0)$.

Señalamos que la mayoría de las variables del agrupamiento de Acklin para el diagnóstico de la alexitimia se hallaron comprobadas, en la AR. Se refuta en los resultados de nuestras muestras tanto de pacientes como de no pacientes la producción significativa de Lambda Alto. El R no discrimina alexitímicos de no alexitímicos. 
Numerosas variables ampliadas de alexitmia probaron su eficacia para el diagnóstico de la alexitimia, ellas son: MA\%, M+FM+m, H, DQ+ , Códigos Especiales (Wpond6), A, P , PSV, R-Eng, An>2 y An+Xy>3.

Especialmente la variable RFS probó su eficacia para el diagnóstico cualitativo de la alexitmia, según se la estudió asociada a la presencia de alexitimia Definitiva, Indeterminada y Ausente en las tres Muestras.

La variable EA ( $>6)$, que indica recursos ideacionales y afectivos disponibles dentro de valores normativos, mostró asociación significativa con los años educativos y no significativa con el nivel socioeconómico.

Los pacientes de AR y una de las muestras de la población no-paciente (Muestra II, nivel socioeconómico medio bajo) claramente portan el rasgo alexitimia como limitación ideacional y afectiva en la estructura y funcionamiento de su personalidad, de modo muy significativo. La comparación con la muestra III de no-pacientes en cambio, al hallarse compuesta por niveles socioeconómicos más variados y mejores años educativos, permitió discriminar en la población no-paciente a los no alexitímicos. 


\section{Capitulo 6: El empleo de multimétodos y el entrecruzamiento de resultados.}

Yo sé que por el cuerpo andan pensamientos descalzos.

FILIBERTO HERNÁNDEZ, Nadie encendía las

lámparas

El empleo de multi métodos en Psicodiagnóstico, consiste en un criterio teórico y técnico básico. Autores seminales en la disciplina, como D. Rapaport, ya en 1950 o R. Schafer en 1954, planteaban la necesidad de utilizar, no una sola técnica sino una batería de técnicas, junto con las entrevistas para la evaluación de la personalidad. La diferencia y complementareidad de los diferentes instrumentos en sus procesos de consistencia a través de la recurrencia y convergencia de información (Lunazzi, 1992), proveen el recurso para captar las diferentes dimensiones y niveles de funcionamiento de la personalidad.

Organizaciones de personalidad, tales como las estructuras borderline, pueden reconocerse mediante el interjuego de técnicas estructuradas y no estructuradas. Como señaló O. Kernberg, en alusión a la "regla básica", para el diagnóstico del borderline, postulada por P.Gunderson y a.Singer: "Los estados borderline permanecen adaptativos y coherentes frente a las técnicas estructuradas, pero son las Proyectivas las que ponen de manifiesta la perturbación profunda de sus relaciones objetales” (Kernberg. 1979).

Anticipamos estos conceptos para explicitar que no es esperable encontrar coincidencia de los mismos resultados entre técnicas de naturaleza distinta: más bien cada una desde su propiedad iluminará distintas caras de una personalidad o constructo psicológico.

A continuación desarrollaremos el tema mediante el siguiente plan: 
6.1 Ventajas de la Aplicación conjunta de la Escala Toronto de Alexitimia (TAS26) y la Técnica Rorschach (S.C.) para la evaluación concurrente del constructo alexitmia.

6.2 Los perfiles psicológicos.

6.3. Perfil psicológico de la Muestra I (Pacientes de artritis reumatoidea-AR), alexitímicos tanto en TAS26, como en el Rorschach (S.C.)

6.4. Perfil psicológico de la Muestra II (No-Pacientes de nivel socioeconómico medio bajo), no alexitímicos en la TAS26, y alexitímicos en el Rorschach (S.C.)

6.5. Perfil psicológico de la Muestra III (No-Pacientes con años educativos iguales o superiores a 15 años), no alexitímicos en la TAS26,y no alexitímicos en el Rorschach (S.C.)

\subsection{Ventajas de la Aplicación conjunta de la Escala Toronto de Alexitimia (TAS26) y la Técnica Rorschach (S.C.) para la evaluación concurrente del constructo alexitmia.}

Numerosos autores en el presente, se ocupan y destacan la importancia del empleo de multimétodos en investigación (Ganellen, 1996, Masling, 1997 a y b; Meyer, 1997; Weiner, 1999; Matlar, 2004; Petot, 2005). Por ejemplo, I Weiner al respecto manifiesta: "Los instrumentos de evaluación psicológica varían según la estructura que ellos mismos tienen y en cuan claros y manifiestos son sus propósitos. El Método Rorschach de las manchas de tinta (RIM) es un instrumento relativamente inestructurado, mientras que el MMPI-2, es un instrumento relativamente estructurado: los sujetos responden a estos dos instrumentos con diferentes niveles de conocimiento conciente respecto del significado posible de sus respuestas. Debido a su naturaleza relativamente inestructurada, el RIM, es menos susceptible que el MMPI-2 para permitir que se marque la dirección de la respuesta. Esta complementareidad hace posible que los hallazgos del Rorschach enriquezcan las evaluaciones clínicas, especialmente cuando los esfuerzos para fingir buenos resultados en los protocolos del MMPI-2, proveen información poco confiable. Hay una sólida base 
conceptual en psicología, para emplear evaluación multimétodo y aplicaciones clínicas en las cuales los datos del Rorschach contribuyen a formulaciones más completas o más exactas, que por otra vía, hace posible dar testimonio del incremento de validez que puede derivar de la inclusión de medidas relativamente inestructuradas en una batería de test" (Weiner, 1999)

Principalmente, por nuestra parte, fue la consideración de dos criterios, teóricometodológicos los que fundamentaron que hayamos implementado en nuestra investigación un dispositivo de multimétodos: $a$ ) ningún método podrá por sí solo comunicar la riqueza de resultados que devienen de la aplicación de varios, los que así se complementarían y $b$ ) utilizar un sólo método en la evaluación de la alexitimia podría hacernos incurrir en falsas ecuaciones semánticas, como suponer que todos los psicosomáticos en consecuencia serían alexitímicos, si se utiliza solamente la Técnica Rorschach, o suponer que puntuar en el rango de alexitimia definitiva en la TAS implicaría de suyo contar con estructura de personalidad y funcionamiento alexitímicos. O también, lo opuesto, puntuar en ausencia de alexitmia en la TAS y, por lo tanto, no ser psicológicamente alexitímico.

Nuestros resultados nos han otorgado interesantes pruebas sobre la utilidad del empleo de multimétodos, como veremos de inmediato:

Comencemos por revisar los principales cuadros que ilustran los resultados obtenidos mediante la aplicación de una y otra técnica: el Cuadro II (Cap. 4: Resultados mediante la TAS) y el Cuadro V (Cap.5: Agrupamiento de indicadores de alexitimia en el Rorschach). Como se observará, en los dos cuadros, que ahora renumeramos XII y XIII, se están comparando las mismas muestras.

\section{CUADRO XII \\ MUESTRAS I y II \\ Compara artríticos $(n=60)$ con no-pacientes $(n=60)$ \\ homologados según nivel socioeconómico medio-bajo}

\begin{tabular}{|l|l|l|l|}
\hline & $\begin{array}{l}\text { Artríticos } \\
\mathbf{N}=\mathbf{6 0}\end{array}$ & $\begin{array}{l}\text { No-pacientes } \\
\mathbf{N}=\mathbf{6 0}\end{array}$ & Significación \\
\hline Edad & Promedio $=46,88$ & Promedio $=44,43$ & $\mathrm{P}=0,258$ \\
\hline
\end{tabular}




\begin{tabular}{|c|c|c|c|}
\hline & D.S. $=11,55$ & D.S. $=12,05$ & N./S. \\
\hline Años educativos & $\begin{array}{l}\text { Promedio }=7,36 \\
\text { D.S. }=5,29\end{array}$ & $\begin{array}{l}\text { Promedio }=10,66 \\
\text { D.S. }=3,64\end{array}$ & $\begin{array}{l}P=0,000 \\
\text { A. } / S .\end{array}$ \\
\hline Nivel socioeconómico & $\begin{array}{l}\text { Nivel medio-bajo } \\
60 \%\end{array}$ & $\begin{array}{l}\text { Nivel-medio bajo } \\
50 \%\end{array}$ & $\begin{array}{l}P=0,359 \\
\text { N./S. }\end{array}$ \\
\hline Alexitimia definitiva & $\begin{array}{l}\text { Promedio }=84,04 \\
\text { D.S. }=5,62 \quad N=23\end{array}$ & $\mathrm{~N}=0$ & $\begin{array}{l}P=0,000 \\
\text { A./S. }\end{array}$ \\
\hline Alexitimia indeterminada & $\begin{array}{l}\text { Promedio }=68,7 \\
\text { D.S. }=2,9 \quad N=31\end{array}$ & $\begin{array}{l}\text { Promedio }=64,33 \\
\text { D.S }=1,92 \quad N=24\end{array}$ & $\begin{array}{l}P=0,000 \\
A / S .\end{array}$ \\
\hline Ausencia de Alexitimia & $\begin{array}{l}\text { Promedio }=57,33 \\
\text { D.S. }=1,03 \quad N=6\end{array}$ & $\begin{array}{l}\text { Promedio }=54,22 \\
\text { D.S. }=3,98 \quad N=36\end{array}$ & $\begin{array}{l}P=0,067 \\
N / S\end{array}$ \\
\hline Puntaje Total TAS & $\begin{array}{l}\text { TAS } \\
\text { Promedio }=73,45 \\
\text { D.S. }=9,90\end{array}$ & $\begin{array}{l}\text { TAS } \\
\text { Promedio }=58,26 \\
\text { D.S. }=5,99\end{array}$ & $\begin{array}{l}P=0,000 \\
\text { A./S. }\end{array}$ \\
\hline
\end{tabular}

N/S: Diferencias no significativas; S: Diferencias significativas; A/S: Diferencias altamente significativas.

Los hallazgos importantes que comunica este cuadro son: $a$ ) que en dos muestras homologadas demográficamente que comparan pacientes y no pacientes, los pacientes presentaron un puntaje total muy alto (alexitimia definitiva) en la TAS, con diferencias altamente significativas respecto de los no-pacientes, cuyo puntaje total promedió en ausencia de alexitimia. $b$ ) Tambien se observan diferencias altamente significativas en los niveles de alexitimia (definitiva, indeterminada y ausente), y entre los pacientes es mayor la definitiva y menor la ausencia.

Examinemos ahora los resultados que nos informó el Rorschach (S.C.) comparando las mismas muestras. 


\section{CUADRO XIII \\ MUESTRA I (AR) Y MUESTRA II (NO-PACIENTES) \\ IGUAL NIVEL SOCIOECONÓMICO \\ Indicadores de Alexitimia en Rorschach \\ M.W. Acklin, Ph.D. y E. Bernat, 1987}

\begin{tabular}{|c|c|c|c|}
\hline Funcionamiento & Indicadores Rorschach & $\begin{array}{l}\text { Muestra AR } \\
\mathrm{N}=60 \\
\text { Promedio }\end{array}$ & $\begin{array}{l}\text { Muestra } \\
\text { no-pacientes } \\
\mathrm{N}=60 \\
\text { Promedio }\end{array}$ \\
\hline Fantasía & $\begin{array}{l}\text { Bajo } R \text { (Productividad de } \\
\text { respuestas) } \\
\text { Bajo M (movimiento } \\
\text { humano) }\end{array}$ & $\begin{array}{l}R=18,46 \\
M=2,63\end{array}$ & $\begin{array}{l}R=18,45 \\
P=0,982(N / S) \\
M=2,68 \\
P=0,887(N / S)\end{array}$ \\
\hline Emoción & $\begin{array}{l}\text { Respuesta afectiva } \\
\text { restringida } \\
\text { Uso de color pobremente } \\
\text { adaptativo (Bajo FC) }\end{array}$ & $\begin{array}{l}\text { Sum Pond C 2,56 } \\
F C=2,22\end{array}$ & $\begin{array}{l}\text { Sum Pond } C 2,60 \\
P=0,655(N / S) \\
\text { FC=1,97 } \\
P=\mathbf{0 , 3 7 7}(\mathbf{N} / \mathbf{S})\end{array}$ \\
\hline Cognición & $\begin{array}{l}\text { Cognición concreta (bajo } \\
\text { Blend) } \\
\text { Estereotipia (Lambda } \\
\text { elevado) }\end{array}$ & $\begin{array}{l}\text { Blend }=3,52 \\
\text { Lambda }=0,48\end{array}$ & $\begin{array}{l}\text { Blend }=3,12 \\
\mathrm{P}=0,292(\mathrm{~N} / \mathrm{S}) \\
\text { Lambda }=0,69 \\
\mathbf{P}=\mathbf{0 , 4 3 6}(\mathbf{N} / \mathbf{S})\end{array}$ \\
\hline $\begin{array}{l}\text { Recursos } \\
\text { Adaptativos }\end{array}$ & $\begin{array}{l}\text { Deficiencia en capacidades } \\
\text { ideacionales y afectivas } \\
\text { (Bajo EA) }\end{array}$ & $E A=5,19$ & $\begin{array}{l}E A=5,37 \\
P=0,665(N / S)\end{array}$ \\
\hline
\end{tabular}

Como vemos en el Cuadro V, no se comprueban diferencias entre los AR y los nopacientes homologados de igual nivel socio económico medio-bajo respecto del Cluster Rorschach Acklin de Alexitimia.

En otros términos, la TAS informa que los pacientes son alexitímicos y los no-pacientes no, mientras que el Rorschach informa que las dos muestras son alexitímicas. Si bien se han incorporado otras variables a este cluster, permanece en el curso de las investigaciones que posterioremente se desarrollaron en la base válida del diagnóstico Rorschach de alexitimia. 
Dejando de lado que cuando sometemos a una comparación más exhaustiva de las variables entre muestras y agrupamientos de submuestras, como vimos en el Cap. 5, se encontraron una serie de variables, en cambio, que sí son muy significativas en sus diferencias, tales como CDI, D y Dadj, An+Xy>3, PSV y A, en todos los casos superiores en los artríticos, que podrían atribuirse a la presencia de enfermedad psicosomática, lo que ahora debemos destacar es que la estructura y funcionamiento básico de la alexitimia se encuentra tanto en los pacientes como en los no-pacientes, empleando el Rorschach.

Volviendo a la confrontación entre los resultados contradictorios de la TAS y del Rorschach, ¿cómo explicamos que para la una los no-pacientes no son alexitímicos mientras que el Rorschach informa que tanto los pacientes como los no-pacientes, según la cualidad de su cognición, de su actividad afectiva, de sus recursos adaptativos, junto con la del uso que hacen de su vida de fantasía son semejantemente alexitímicos?

¿Alguna de las técnicas no es válida? Definitivamente, no: ambos son instrumentos válidos y eficaces para evaluar la alexitimia, pero creemos que contestan o revelan distintas dimensiones psicológicas propias de los alexitímicos.

En el caso de la TAS, introduce su particularidad en cuanto consiste en un cuestionario de autoinforme, contestado con control voluntario por parte de los sujetos, y de acuerdo con la deseabilidad social que las respuestas conllevan. Además, con honestidad, los sujetos pueden desconocer o no interesarse por los propios rasgos de personalidad y orientar las respuestas según lo socialmente conveniente y esperable. Creemos que esta es una explicación adecuada para comprender por qué en la TAS los no-pacientes no son alexitímicos. Cuentan con buena adaptación y conformismo social, no padecen ni han padecido problemas psiquiátricos ni psicológicos, y son suficientemente capaces como para responder un cuestionario con preguntas personales de modo convencional y esperable. Debemos tomar en cuenta, entonces, el tipo de datos que se obtienen mediante una y otra técnica: en el caso de la TAS, informa lo que el sujeto sabe de sí y está dispuesto a comunicar. En el Rorschach obtenemos la estructura y funcionamiento de su personalidad por medios indirectos al control del sujeto.

Si exploramos la estructura y funcionamiento de la personalidad mediante el Rorschach, los no-pacientes (Muestra II), efectivamente tienen las características de los alexitímicos, 
llamados «normóticos» por J. McDougall, o «sobreadaptados» por D. Liberman: sus intereses cognitivos están orientados a tareas concretas que se desenvuelven en el mundo externo (pensamiento operatorio) y les permiten desentenderse de su propia vida introspectiva e imaginaria. Su comportamiento está orientado a la evitación de conflictos, especialmente las defensas de racionalización y negación los protegen de la experiencia de angustia. Su conducta es, en gran medida, estereotipada, previsible, al igual que los vínculos interpersonales en los que se mueven. Bien adaptados socialmente, superficialmente comunicativos, no se comprometen con situaciones complejas o ambiguas.

Pero ahora podemos formularnos todavía otra pregunta: ¿por qué si los pacientes (Muestra I)y los no pacientes (Muestra II) son igualmente alexitímicos en el Rorschach, en la TAS sólo los pacientes son significativamente alexitímicos, y los no pacientes no lo son?

Creemos que la respuesta posiblemente se halla en la estructura de su personalidad y en la organización defensiva. Organización defensiva primitiva, con fallas y sometida a gran sobrecarga emocional de características crónicas en los pacientes, y efectiva y de nivel superior en los no-pacientes.

Los no-pacientes (Muestra II) refirieron en su discurso al completar las preguntas de la TAS «quien supongo soy, muestro ser o debo ser». Su discurso es una herramienta de los no-pacientes, que posiciona socialmente su identidad y a la vez los configura en una representación de sí mismos. Pensamos que asistimos a la eficacia adaptativa de la represión defensiva, que les permite capacidad de afrontamiento aunque en el fondo sean alexitímicos, lo que no saben o no les interesa.

Los pacientes artríticos, con su sobrecarga emocional, confusión y desvalimiento social, refirieron verídicamente, y sin saberlo, su disregulación afectiva, que se recogió en la TAS y se confirmó y precisó en relevantes variables del Rorschach.

En cuanto a la Muestra III de no-pacientes, con niveles medios socioeconómicos, medios bajos, medios altos y medios medios más variados que la muestra II, ( ésta, predominantemente $51,33 \%$ nivel socioeconómico medio bajo) y con años educativos 
superiores (promedio 15 años), pensamos que sus mejores recursos socioeconómicos y educativos que se expresaron en disponibilidad de experiencias para afrontar ricamente las demandas vitales $(\mathrm{EA}>6)$, estuvieron como grupo exentos de alexitimia tanto en la TAS como en el Rorschach. Es preciso mencionar, sin embargo, que no existe una regla simple que permita asociar mejores recursos socioeconómicos o educativos con ausencia de alexitimia. Hallamos en la muestra III dos casos con alexitimia definitiva y también, a la inversa, dentro de los artríticos, aún de nivel educativo y económico medio alto ausencia de alexitimia. Una ecuación corriente entre alexitimia y “déficit de simbolización”, puede conducir a error. Hay alexitímicos con muy buenos recursos de simbolización cuyo déficit específico no se plantea en los procesos de simbolización n general, sino en la mentalización de sus propios estados afectivos.

El entrecruzamiento de los resultados de ambas técnicas nos permite avanzar algunos postulados. La investigación con multimétodos está especialmente indicada cuando se realizan estudios nomotéticos, es decir, cuando se intentan descubrir las leyes generales que pueden regular determinados funcionamientos psicológicos o constructos teóricos. Pero en la práctica clínica, al abordar la singularidad de cada caso es imprescindible que debamos implementar criterios técnicos, como los de recurrencia y convergencia dinámica, para la proposición de hipótesis que permitan explicar las aparentes discrepancias entre indicadores. (Lunazzi, 1992). Ninguna técnica por sí sola cubre el amplio espectro de cuestiones y variables que atraviesan y se entrecruzan en los casos. Veamos ejemplos: una investigación realizada en Francia, en el año 1996, que ya comentamos en el Cap. 2, en la cual se administró conjuntamente la TAS26 y el Rorschach a estudiantes universitarios de literatura. Al hallar que el Rorschach desacreditaba el diagnóstico de alexitimia, se llegó a concluir que los resultados contradecían lo teóricamente esperable (Teorías de P. Marty, De M Uzan y Sifneos). Los casos habian puntuado alto en Alexitmia en la TAS, y para el Rorschach no lo eran. Observemos que en este caso los resultados son opuestos a los hallados por nosotros con los no-pacientes, en los que el Rorschach reveló que sí eran alexitímicos, mientras que la TAS no. Nuevamente, ambas técnicas son válidas, y también la teoría. Lo que no se tomaba en consideración es que numerosos casos dela población nopacientes puntúan alto en alexitmia, sin serlo estructuralmente, como en el ejemplo francés que comentamos. Y es cierto también lo contrario, numerosos no-pacientes pueden puntuar 
en la TAS como ausencia de alexitimia y según su funcionamiento psicológico evaluado mediante el Rorschach, ser alexitímicos.

Si bien se espera que las técnicas psicológicas que miden el mismo constructo mutuamente correlacionen, capacidad que se denomina validez convergente, es necesario que revisemos nuestras expectativas. Respecto de la validez convergente entre el Rorschach y los cuestionarios de autoinforme, será naturalmente baja cuando las muestras son heterogéneas y no se controlan ciertas variables que afectan los instrumentos. La investigación de las relaciones entre el Rorschach y las TAS están en un estado incipiente, mientras que se ha profundizado la investigación entre el MMPI-2 y el Rorschach (Ganellen, 1996; Meyer 1996, 1997, 1999). La baja validez convergente en investigación puede determinar preocupación o duda sobre la validez singular de cada instrumento, pero en la práctica clínica, tradicionalmente se aborda la evaluación de la personalidad mediante multimétodos (Batería Psicodiágnóstica que incluye como técnica a las entrevistas) y se reúne información de diferentes niveles de funcionamiento psicológico, que se integra con el juicio clínico (Lunazzi, 1992, 1995).

Revisaremos brevemente algunas de las razones de la falta de convergencia entre el Rorschach y los cuestionarios autoadministrados: $a$ ) una de las cuestiones se refiere a si los instrumentos de evaluación están cubriendo las mismas o diferentes dimensiones de la personalidad, o si abarcan la completa complejidad del conjunto de la personalidad; por ejemplo, si recogen rasgos conscientes o inconscientes de la personalidad; $b$ ) pueden ser el resultado de diferencias entre sus opciones metodólogicas respecto de validez y confiabilidad. Ganellen (1996), por ejemplo, informó que es alta la correlación entre el MMPI-2 y el psicótico, porque aparecen muchos falsos positivos; $c$ ) también debe tomarse en cuenta la heterogeneidad de las variables del Rorschach que se expresa tanto en puntajes brutos o en porcentajes y en proporciones, especialmente cuando se realizan investigaciones hay ciertas variables que deben ser tomadas en cuenta, pues modifican los resultados (R, Lambda y EB). Al respecto, G. Meyer (1999) realizó un estudio en el que demostró que los protocolos con bajas respuestas en el Rorschach (R entre 14 y 17) presentaron correlación baja con el MMPI-2, pero en los protocolos más largos, positiva (Petot, Djuric Jocic, 2005). 
En nuestro trabajo hemos analizado especialmente la falta de correlación hallada entre los resultados de la TAS26 y el Rorschach (SC), comparando la muestra I de pacientes (AR) y la muestra II (demográficamente homologada), desde el foco de el tipo de datos que cada una provee, la actitud frente a la administración de las técnicas y el estilo de respuesta propio de los sujetos en estudio. De un modo sumamente sintónico con nuestro análisis del aparente problema de la falta de concordancia entre los instrumentos administrados, presentamos el siguiente párrafo, que pertenece a un trabajo reciente que abordó el tema: «En el contexto clínico la discrepancia de variables de dos instrumentos puede ser el resultado de diferencias entre el "conjunto de respuestas conscientes" dadas por los pacientes, dependientes de los mecanismos de defensa y de la extensión del impacto de los procesos inconscientes sobre el funcionamiento consciente de los sujetos. Reconocer a tales pacientes tiene implicancias terapéuticas, puesto que son incapaces de reconocer o atribuir importancia a sus síntomas y problemas (negación o simulación). De esta manera lo que aparece como una debilidad estadística, en el contexto clínico, resulta en una importante información diagnóstica y terapéutica» (Petot, Djuric Jocic, 2005: 113). En realidad representan dos niveles psíquicos, de modo amplio, podemos decir, concientes e inconcientes, que se interrelacionan, dando cuenta de los procesos y estructuras que los subyacen

En la revisión del marco teórico (Cap. 1) y en la del estado de la cuestión (Cap. 2), señalamos dos conceptos propicios para recordar ahora:

1. La alexitimia es un desorden cognitivo y de la regulación de los afectos, reconocible en enfermos psicosomáticos y en numerosas organizaciones psicopatológicas y no psicopatológicas que se caracterizan por la escasa integración de los afectos a la identidad y la tendencia a la acción. En tanto rasgo de la personalidad, entonces, presenta una distribución poblacional que no se limita solamente a los pacientes psicosomáticos.

2. La alexitimia consiste en un constructo teórico que ha de establecerse reconociendo su naturaleza idiosincrásica en cada sujeto pasible de portarla. Esto destaca el abordaje de la heterogeneidad de los casos que puedan compartir, sin embargo, una descripción común y un puntaje alto, bajo o similar en las Escalas TAS y TAS-20. No es por ende adecuado evaluar sólo lo manifiesto sin someterlo a mayor dispositivo de interpretación. 
En el desarrollo de nuestro trabajo sometimos numerosas veces a estudio las variables, reagrupando las muestras según submuestras identificadas por criterios homogéneos, por ejemplo la presencia de alexitimia definitiva o los años educativos. Fueron justamente esos estudios más particularizados de los casos y de las variables que los atraviesan los que junto con afirmar la esperable heterogeneidad, nos van a otorgar a continuación, la posibilidad de describir los perfiles psicológicos de las muestras estudiadas.

\subsection{Los perfiles psicológicos}

El trazado de los perfiles que proponemos, como todo perfil, sólo muestra la silueta que abarca una determinada corporeidad, la cual queda omitida en sus detalles y especificaciones. Sin embargo, el perfil no es fortuito, sino que muchas veces capta y revela la forma esencial de presentación de un fenómeno. En el perfil sólo se recogen los rasgos homogéneos o comunes de un grupo, pero no comprenden los matices ni las singularidades propias de cada caso.

Para elaborar los perfiles hemos estudiado cuantitativa y cualitativamente el entrecruzamiento de resultados TAS/Rorschach, y las diferencias halladas - $\mathrm{O}$ no- en la comparación entre las muestras I (AR), II (no-pacientes de semejante nivel económico) y III (con recursos normales y años educativos superiores), y las comparaciones entre submuestras seleccionadas según control de variables.

Vamos a basarnos en los datos obtenidos al comparar los resultados de la TAS y el Rorschach en las tres muestras (I, AR; II, no-pacientes homologados; III, no-pacientes con recursos normales y educación $>8$ años), ellos son:

\section{Técnica TAS26:}

Muestra I:

Alexitimia definitiva 38\%

Alexitimia indeterminada $52 \%$

Ausencia de alexitimia 10\%

Puntaje total: alexitimia con diferencias altamente significativas respecto de las muestras II y III. 
Muestra II:

Alexitimia definitiva $0 \%$

Alexitimia indeterminada $40 \%$

Ausencia de alexitimia $60 \%$

Muestra III:

Alexitimia definitiva 3, 3\%

Alexitimia indeterminada $33 \%$

Ausencia de alexitimia 63,3\%

\section{Rorschach (S.C.)}

1. La variable RFS dio diferencias altamente significativas entre todas las muestras. En primer lugar, los no-pacientes de la Muestra II con la menor capacidad para usar el espacio transicional; luego los pacientes artríticos, y por último, los no-pacientes de Muestra III, con mejores recursos para el uso de la vida de fantasía.

2. No hubo diferencias significativas entre las muestras I y II en M, MA\%, $\mathrm{M}+\mathrm{FM}+\mathrm{m}, \mathrm{P}, \mathrm{CDI}$, Blends, Códigos Especiales, Lambda, H, EA, WSUMC, FD, DQ+, PSV y A. Las muestras I y II sólo presentaron diferencias significativas al ser comparadas respecto del RFS.

3. Las muestras I y II presentaron diferencias altamente significativas por su menor producción respecto de la III en M, MA\%, M+FM+m, H y EA. La muestra I de pacientes obtuvo diferencias A/S respecto de la Muestra III en A y D/S en PSV (con la producción más alta entre los pacientes) y DQ+ (con el valor inferior entre los pacientes).

4. La muestra II (no pacientes de nivel socioeconómico medio-bajo) en relación con la Muestra III (no pacientes con un promedio de 15 años educativos) mostró diferencias A/S en Lambda (mayor en la muestra II) y en Blends y Códigos Especiales (inferiores en la muestra II).

Las variables FC, Zf, T=0, R- Eng.; An>2; An+Xy; EB ambigual, Afro y Sum shad no mostraron diferencias significativas en la comparación entre las muestras.

Los resultados que obtuvimos al hacer comparaciones de submuestras según cortes por años educativos, en algunos casos modifican los anteriores y son: 
1. Muestra 1, artríticos de 0-7 años educativos y Muestra 2, no-pacientes de igual nivel educativo: Se hallaron D/S en RFS. Los no-pacientes se acercaron significativamente al nivel en el cual la fantasía colapsa en la realidad, es decir, que el uso de la vida imaginaria es muy limitado. También se hallaron D/S en An+Xy. Los pacientes $(1,30)$ puntuaron más alto que los no-pacientes $(0,24)$, mostrando su mayor preocupación por el interior del cuerpo y la vulnerabilidad al enfermar.

2. Muestra 3, artríticos de entre 8 y 14 años educativos y Muestra 4, no-pacientes de igual nivel educativo: Se hallaron diferencias $\mathrm{A} / \mathrm{S}$ en $\mathrm{M}+\mathrm{FM}+\mathrm{m}$ (mayor entre los artríticos 8,70 y 6,47), los no-pacientes presentaron mucha menos representación de impulsos y registro de demandas intrusivas y urgentes. También diferencias A/S en R-Eng, que indican mayor capacidad en los pacientes para involucrarse en las respuestas al Rorschach y mayor dificultad o resistencia defensiva a hacerlo por parte de los no-pacientes. Se hallaron D/S en producción de $\mathrm{H}$, siendo menor entre los pacientes (1,90 y no-pac. 2,90$)$; también $\mathrm{D} / \mathrm{S}$ en producción de $\mathrm{A}$, mayor entre los pacientes $(\mathrm{AR}=8,50$; no-pac. 6,78 ) y también hallamos D/S en producción de D y en Dadj (en ambos casos mayor entre los artríticos).

3. Muestra 5, Artríticos de $>14$ años educativos y Muestra 6, no-pacientes de igual nivel educativo. Hallamos diferencias A/S en WSUMC, producción mucho menor en la muestra 5 (AR: 1,90 y no-pac. muestra 6, 4,94), que refleja la importante restricción de la respuesta emocional en los artríticos, aun con muchos años educativos. También $\mathrm{A} / \mathrm{S}$ en $\mathrm{An}+\mathrm{Xy}>3$, muy superior en los pacientes. Con diferencias significativas $(\mathrm{D} / \mathrm{S})$ la producción de Populares, D y Dadj (mayor en los pacientes).

4. Numerosos indicadores no evidenciaron modificaciones significativas al realizar comparaciones según niveles de años educativos entre pacientes y nopacientes. Ellos fueron M, MA\%, R, Lambda; FC, EA, FD, Blend, Wpond6, Zf, DQ+ y Afro.

En síntesis, destacamos que: 
Comparando Artríticos y No pac.II, vemos que hay D/S en producción de D y en Dadj (en ambos casos mayor entre los artríticos).D y Dadj<-1 AR 42\%; Dadj<-1 no pac 22\%; $\mathrm{D}<-150 \%$; D<-1 27\%; DEPI D/S entre I y II: DEPI $\geq 5$ 20\%; No-pac. DEPI $\geq 5$ \% Blends y Códigos Especiales: A/S entre II Y III (inferiores en los no-pac. II). Diferencias significativas en RFS entre II y III, y los II son menos creativos.

Diferencias no significativas N/S entre I, II y III en FC, T=0, EB ambigual, R-Eng, An $>2$, Zf, An+Xy>3; Afro y SumShad.

$\mathrm{M}, \mathrm{MA} \%, \mathrm{M}+\mathrm{FM}+\mathrm{m}, \mathrm{CDI}, \mathrm{LAMBDA}, \mathrm{P}, \mathrm{H}, \mathrm{EA}, \mathrm{WSUMC}, \mathrm{FD}, \mathrm{FQ}+$, PSV, A: con

Diferencias A/S entre las muestras I y III; diferencias N/S entre las muestras I y II.

RFS A/S II y III; II y I A/S, los no pacientes de nivel medio bajo son menos creativos.

\subsection{Perfil Psicológico de la Muestra I, pacientes de AR (alexitímicos en TAS y Rorschach).}

Los artríticos difieren de los no-pacientes II y III por la presencia de mayor conformismo social (P) junto con mayor carga emocional crónica y situacional (D y Dadj), presencia de depresión (DEPI) y desvalimiento social como déficit de afrontamiento (CDI) que no pueden considerarse, a juzgar por la cualidad de estas variables estructurales Rorschach, como adaptaciones a la enfermedad. Corrobora esta afirmación que numerosos pacientes artríticos puntuaban alto en alexitimia (definitiva) ya al comienzo de la enfermedad. La limitación alexitímica para mentalizar, o sea, regular estos montos emocionales e integrarlos saludablemente a una representación eficaz es reconocible, lo que convierte su situación psíquica en penosamente reiterativa. Caracterizó a los artríticos una mayor pobreza fantasmática y estereotipia del pensamiento (PSV) y la falencia en la capacidad de introspección. La ausencia de Lambda alto se vuelve esperable, por cuanto representa la eficacia de la defensa racional (racionalización) para disociarse de estímulos complejos tanto internos como externos, capacidad que en este grupo está significativamente restringida. Se vuelven explicativas a estas alturas las teorizaciones de los modelos de déficit a los que hicimos referencia (Cap. 1), déficit que determinaría carencia de la vida fantasmática, vida operatoria (Pensamiento Operatorio) y desorganización somática, objetivables en los resultados de los artríticos reumatoideos, recogidos por cada técnica de modo independiente. Podemos entender la escasez de respuestas con identificaciones humanas $(\mathrm{H})$ entre los pacientes como expresión de sus limitaciones para la integración de la identidad y para el desarrollo de vínculos 
interpersonales escasamente diferenciados, es decir, fundamentalmente primarios. En este mismo sentido, la elevada producción de respuestas de contenido animal (A) subraya la pobreza de su mundo representacional y vincular. Esta tendencia a la estereotipia cognitiva y social también se acentúa por sus diferencias significativas $(\mathrm{D} / \mathrm{S})$ en su alta producción de Populares. La evaluación diferencial de la presencia de las características mencionadas en los artríticos, y en especial las frecuencias significativas en ellos de los índices de Estrés Situacional (D) y Crónico (Dadj), DEPI, CDI y la ausencia de T=0 como necesidad de vínculos íntimos y de continencia, proponen reflexiones asociadas con las intervenciones psicoterapéuticas. Los pacientes artríticos, con considerables limitaciones para hacerse cargo de sí mismos e intensas preocupaciones por la vulnerabilidad corporal $(\mathrm{An}+\mathrm{Xy}>3)$ requieren sostén, contención y orientación. Estas necesidades difícilmente sean verbalmente comunicadas, ya que también están muy restringidos en la expresión afectiva (A/S en WSUMC). El padecimiento sufrido y el alto conformismo social son factores que podrían intervenir positivamente para favorecer la adherencia a los tratamientos.

\section{Perfil de los pacientes (AR)}

1. Padecen crónica y situacionalmente de notable sobrecarga emocional (estrés).

2. Están muy limitados para organizarse adaptativamente.

3. Los afectos se «descargan» en sus discursos catárticos, manifestaciones de padecimiento y simultáneo desvalimiento social.

4. No diferencian sus afectos para poder comunicarlos ni para regularlos.

5. Se someten a los estereotipos cognitivos del buen deber adaptativo social.

6. Presentan pobreza del repertorio de identificaciones y roles.

7. Requieren vínculos de contención y orientación pero no saben pedirlas.

8. Vivencian vulnerabilidad corporal e indefensión.

\subsection{Perfil Psicológico de la Muestra II, no- pacientes de nivel socioeconómico medio bajo (alexitímicos en el Rorschach).}

Al comparar pacientes y no-pacientes, las variables que mostraron diferencias significativas fueron el Índice de Desvalimiento Social (CDI) positivo, An $>2$, índice de depresión positivo (DEPI), ausente entre los no-pacientes, y la presencia significativa de 
$\mathrm{T}=0$ en los no-pacientes, lo que muestra su capacidad de establecer distancia de relaciones cercanas y de vínculos íntimos de continencia.

Los no-pacientes de nivel socioeconómico medio bajo presentan escasos recursos internos para mentalizar y regular afectos $(\mathrm{EA}<6)$, su pensamiento es más simple y carente de actividad imaginativa (bajo Códigos Especiales, RFS positiva) respecto de la población general, predominantemente de nivel socioeconómico medio medio.(muestra III). Presentan significativamente menor estrés crónico (D adj), estrés situacional (D) y depresión (DEPI) que los artríticos. Su capacidad de mentalizar (M) también es menor que la de los pacientes, aunque recibieron significativamente más años educativos. Comparten con los AR numerosas variables asociadas con alexitimia, particularmente la orientación del pensamiento a lo externo (falta de introspección, pensamiento operatorio), la cognición concreta (Bajo Blend), la respuesta afectiva restringida y la baja expresión afectiva regulada $(\mathrm{FC})$.

Sin embargo, a pesar de compartir muchas limitaciones y deficiencias, hemos visto que obtuvieron diferencias $\mathrm{A} / \mathrm{S}$ con valores más bajos y normativos en alexitimia definitiva y en puntaje total TAS de alexitimia respecto de los artríticos.

\section{Perfil:}

1. Evitan los conflictos: carecen de preocupaciones por problemas existenciales, o por la vulnerabilidad corporal.

2. Con recursos afectivos e ideacionales limitados, muestran una buena adaptación social.

3. Tienen un pensamiento simple, lógico y ordenado. Son poco reflexivos.

4. Se valen de sí mismos y no requieren vínculos de continencia y sostén.

5. Orientan su interés y preocupaciones a la resolución o participación en actividades concretas.

6. Eluden participar de conflictos y situaciones ambiguas o no predecibles.

7. Cuentan con defensas de negación y racionalización útiles para lidiar con cuestiones potencialmente angustiantes.

8. La deseabilidad social de los actos y roles regula principalmente su comportamiento. 
Esta muestra de no-pacientes nos ha permitido entonces, acceder a un gran grupo poblacional adaptativo, sin alexitimia aparente, que se manifestara en ansiedad intensa o síntomas corporales. Los no pacientes de Muestra II, podrían ser exponentes de los procesos de aculturación o colectivización, sin traumas afectivos registrados. Dichos rasgos de personalidad, podrían también ofrecerle "beneficio" de eludir la experiencia de conflicto psíquico, hallando en los roles de los que es socialmente esperado y deseable, (y que no se cuestiona) las referencias necesarias para la conducta. Este es un tema muy vasto que escapa a nuestro presente cometido.

\subsection{Perfil Psicológico de la Muestra III, no- pacientes con años educativos promedio 15 y mejores y variados niveles socioeconómicos (ausencia de alexitimia en TAS y Rorschach).}

Esta muestra III, no-pacientes con recursos adaptativos (ideacionales y afectivos) normales $(E A>6)$ y años educativos $>8$, resultó muy valiosa, porque puso de manifiesto diferencias altamente significativas con las otras muestras, las que pudimos caracterizar.

Su buen funcionamiento se comprobó en la ausencia de alexitimia elevada en la TAS y en la mejor mentalización que informan las variables del Rorschach: H (identidad integrada), $\mathrm{M}, \mathrm{MA} \%, \mathrm{M}+\mathrm{FM}+\mathrm{m}$, (todas ellas refieren a capacidades ideacionales, fantasmáticas y cognitivas), EA (recursos ideacionales y afectivos), FD (capacidad de introspección), Blends y DQ+ (complejidad y riqueza cognitiva). Se diferencian de las otras muestras por su mayor M, la SUMpond C, mayor Blend, MA\%, RFS, EA>6, la ausencia de estrés situacional y crónico (D y Dadj), aunque la variable FC (respuesta afectiva regulada) fue baja, en comparación con las otras muestras. No muestran preocupación por la integridad corporal (An>2). La escala de Realidad/Fantasía (RFS) de signo negativo muestra la mayor disponibilidad de fantasía, o sea de uso de recursos imaginarios, por parte del grupo III. El porcentaje de aparición de $\mathrm{T}=0$ en esta muestra fue muy significativo. 
Hemos visto que los mejores niveles educativos se asociaron con la producción de ciertas variables Rorschach que muestran buena capacidad intelectual y afectiva. Al menos podemos constatar un interjuego entre buena dotación natural en este grupo y mayores estímulos educativos. La capacidad de afrontamiento de problemas y situaciones vitales del grupo es buena, pero cabe marcar una fuerte tendencia que podríamos llamar "individualista o autoabastecida" dado que su producción muy significativa de $\mathrm{T}=0$ muestra la prescindencia de vínculos interpersonales íntimos o muy cercanos.

\section{Perfil:}

1. Cuentan con recursos ideacionales y afectivos para afrontar las demandas vitales.

2. Son capaces de usar su introspección para orientar la satisfacción de sus necesidades.

3. Cuentan con recursos imaginarios para filtrar el impacto de los sucesos problemáticos y enriquecer su comportamiento.

4. Pueden tolerar situaciones complejas y ambiguas sin desorganizarse ni evitarlas.

5. Su pensamiento puede ser complejo, pero eficaz, para resolver la sobrecarga emocional.

6. Presentan capacidad normal para la expresión adaptativa de las emociones.

7. Se apoyan más en sus propios objetivos y necesidades que en la deseabilidad social.

En gran medida, pueden desenvolverse satisfactoriamente, prescindiendo de vínculos íntimos y de continencia.

Pensamos que la posibilidad de haber obtenido este trazado de los perfiles diferenciales de las muestras confrontadas mediante la aplicación de las dos técnicas nos otorgará las referencias empíricas para desarrollar en nuestra siguiente revisión del recorrido realizado. 


\title{
Capitulo 7
}

\section{CONCLUSIÓN}

\author{
Verdad: Pilatos dijo entonces: ¿Luego sois rey? \\ Jesús le respondió: Como vos decís, y por eso \\ nací y vine al mundo, para dar este testimonio de \\ verdad, y todos los hombres que aman la verdad \\ oyen mi voz. Pilatos le replicó: ¿qué es la \\ verdad? y después de decir esto, salió» (San Juan, \\ cap. xviii).
}

VOLTAIRE, Diccionario filosófico.

A continuación, ya terminado, presentamos la revisión y síntesis final, en los siguientes puntos:

7.1. Revisión de las problemáticas desarrolladas previamente y de los respuestas obtenidas, mediante la aplicación de los instrumentos de evaluación de la alexitmia.

7.2. Síntesis.

\subsection{Revisión de las problemáticas desarrolladas previamente y de los respuestas obtenidas, mediante la aplicación de los instrumentos de evaluación de la alexitmia.}

Vamos a retomar conceptos generales con acuerdo o en estado controversial, revisados previamente, en el Estado de la cuestión (cap.2) a los que daremos respuesta a la luz de nuestros resultados, en la investigación sobre la AR:

\section{Afirmación General 1:}

Los afectos son los adjetivos de las experiencias, los que le dan significado, y las experiencias dejan el rastro de su significado afectivo. Son objeto de acciones regulatorias y juegan un importante rol en la organización saludable del funcionamiento mental y conductual. Hay importante acuerdo, dentro de los marcos teóricos que plantean que la 
escasa mentalización afectiva estaría asociada con enfermedades psicosomáticas, con cuadros de estrés postraumático, personalidades actuadoras y estilo comportamentales orientados al locus de control externo. El constructo alexitimia informa la dificultad en distinguir sentimientos de sensaciones corporales, de comunicarlos, de utilizar creativamente la vida de fantasía y la tendencia al pensamiento concreto, operatorio. Se postula la presencia de mecanismos defensivos primitivos en los alexitímicos.

\section{Respuesta a la afirmación 1:}

Hemos comprobado empíricamente en nuestros resultados con multimétodos la fuerte asociación estadísticamente significativa entre presencia de alexitmia y la enfermedad psicosomática, conocida como artritis reumatoidea (AR). Todas las dimensiones propias de la alexitimia se encontraron verificadas en los distintos indicadores de las técnicas. Ha sido posible verificar la vinculación entre la presencia de características alexitímicas y algunos mecanismos de defensa yoicos primitivos, como la negación, la disociación y el acting-out.

\section{Afirmación General 2:}

Las investigaciones han encontrado una relación negativa entre el status social de clase baja y la alexitimia. La orientación hacia los hechos externos, un estilo de pensamiento concreto, poco mentalista, de las clases populares y menos educadas parece reforzar la expresión somatizada de las emociones.

Respuesta a la afirmación 2:

Se comprobó que el nivel socioeconómico bajo esta asociado negativamente con alexitimia, al evaluar la alexitimia con la TAS26: los no-pacientes de nivel económico medio-bajo puntuaron negativamente en alexitimia. El Rorschach, en cambio, puso de relieve el funcionamiento psicológico alexitímico de esta muestra. Las clases populares con menor mentalización y pensamiento concreto mostraron la expresión somatizada de las emociones sólo cuando habían puntuado en la TAS26 en alta alexitimia. Los no-pacientes no exhibieron expresión somatizada de las emociones, aun perteneciendo a las mismas clases populares.

\section{Afirmación General 3:}


Los años educativos proveen a las personas del vocabulario necesario para hablar mejor sobre las emociones. Existe una relación entre la riqueza del lenguaje y el desarrollo cognitivo de la vivencia emocional. Sin embargo, las investigaciones preliminares sobre la relación de la alexitimia y esas variables han mostrado escasa o baja asociación con el nivel socioeconómico bajo, bajo nivel educativo y baja inteligencia. La alexitimia no es resultante sólo de las diferencias culturales en la expresividad emocional: este resultado es homogéneo y estable culturalmente.

Respuesta a la afirmación 3:

Se comprobó presencia de alexitimia definitiva (TAS) tanto en pacientes como en nopacientes de elevados años educativos (promedio 15 años educativos).

\section{Afirmación General 4:}

La alexitimia se postula como un rasgo y no un estado. Investigaciones longitudinales han permitido comparar la estabilidad de esta dimensión de la personalidad. Los puntajes altos en la TAS estuvieron asociados fuertemente con afectividad negativa. Se ha encontrado el más alto nivel de distress en pacientes con elevada alexitimia. La alexitimia aparece asociada con estrategias de afrontamiento (coping) relacionadas con la evitación cognitiva, emocional y conductual Las personas alexitímicas muestran una frecuencia alta de activación displacentera indiferenciada que no pueden simbolizar en palabras.

Respuesta a la afirmación 4:

Las características psicológicas de los pacientes con AR preceden al diagnóstico y no pueden considerarse una mera adaptación a la enfermedad (estado). Remitimos al lector al cuadro I, del Cap.3 donde puede observarse que en el comienzo o corto tiempo de desarrollo de la enfermedad, se registran puntajes de alexitimia definitiva.( $>74)$. Se obtuvieron altos puntajes en alexitimia en la TAS y la evaluación positiva en los indicadores ampliados de alexitimia en el Rorschach al comienzo de la enfermedad. Tampoco se comprobó que la alexitmia aumentara según la duración de la enfermedad o el impedimento físico. De acuerdo con los puntajes altos en la TAS, también los indicadores del Rorschach verifican la presencia de significativo distress, déficit de afrontamiento o 
desvalimiento social y activación displacentera indiferenciada no expresada ni regulada entre los pacientes alexitímicos.

\section{Afirmación General 5:}

Hay afirmaciones controvertidas respecto de presencia de alexitimia elevada entre los pacientes de AR.

Respuesta a la afirmación 5:

Tanto el Rorschach como la TAS confirmaron la significativa presencia de alexitimia elevada entre los pacientes de AR respecto de los no-pacientes. Se comprobó la validez discriminativa de la TAS para el diagnóstico de la alexitimia entre los pacientes de AR y los no-pacientes, tanto en su puntaje total como en los niveles de presencia de alexitimia.

\section{Afirmación General 6:}

Se puede cometer una «falsa ecuación semántica» si se supone que todos los psicosomáticos son alexitímicos o que todos los artríticos son sujetos homogéneos. Es indicado evaluar con un criterio externo la presencia de alexitimia, por ejemplo con la TAS. No obstante, la TAS ha dado resultado alto en sujetos no alexitímicos según el Rorschach. Es imprescindible el uso conjunto de multimétodos para su completa evaluación. Las relaciones entre alexitimia, inteligencia y nivel social o educativo son controvertidas y no se han investigado en la AR.

Respuesta a la afirmación 6:

Efectivamente hallamos que es imprescindible el uso conjunto de multimétodos para la completa evaluación del constructo alexitimia. La TAS puede informar puntajes altos o bajos en alexitimia y no ser o ser efectivamente alexitímico respectivamente en el Rorschach. Nuestra investigación con el uso conjunto de la TAS y el Rorschach informó que el nivel social no está asociado con la presencia de alexitimia. Los mayores años educativos se hallaron relacionados con buenos recursos ideacionales y afectivos $(\mathrm{EA}>6)$, es decir, lo opuesto a lo encontrado en los alexitimicos, pacientes y no-pacientes (Rorschach). La categoría alexitimia evaluada por la TAS resultó no asociada al mayor nivel de años educativos (variable independiente) y sí, en cambio, a la presencia de 
enfermedad psicosomática, en este caso AR. Los pacientes y no-pacientes de bajo nivel socioeconómico (medio-bajo) fueron igualmente alexitímicos en los indicadores de alexitimia (Acklin y Bernat). Cuando se introducen mayores años educativos, significativas variables diferencian a los no- pacientes como no alexitímicos: M, SumpondC, Lambda y EA. El contexto cultural medio bajo apareció fuertemente asociado con la limitación de los recursos adaptativos, ideacionales y de regulación afectiva.

\section{Afirmación General 7:}

Caracteriza a los alexitímicos la pobreza de su mundo de fantasía, su pensamiento concreto y la falta de introspección.

Respuesta a la afirmación 7:

Los resultados obtenidos mediante la RFS y la TAS en las comparaciones entre las muestras I, II y III informaron tendencias significativas en el uso de la fantasía. La muestra III exhibió los mejores recursos, mientras que la muestra II la mayor restricción. Es decir, mejor uso de la fantasía asociada al mayor nivel de años educativos y menor en los no pacientes de nivel socioeconómico medio-bajo. Hay coincidencia con una investigación que llevamos a cabo previamente en el nivel socioeconómico medio-bajo.

\section{Afirmación General 8:}

Es esperable estadísticamente alta validez convergente entre la TAS y el Rorschach (SC) para la evaluación conjunta del constructo alexitimia.

Respuesta a la afirmación 8:

Si bien ambos instrumentos tienen probada validez para la evaluación de la alexitimia su convergencia fue baja, estadísticamente. Esto se atribuye a cuestiones teóricas y metodológicas. Hubo convergencia entre la TAS y el Rorschach al evaluar las muestras I (pacientes artríticos) y III (no-pacientes de mejores recursos cognitivos, afectivos y educativos). En cambio hubo discrepancia entre la TAS26 y el Rorschach en la evaluación de la muestra II (no-pacientes de nivel socioeconómico medio-bajo, demográficamente homologada con la muestra I) no alexitímicos para la TAS y alexitímicos para el Rorschach. Hemos además, analizado especialmente la falta de correlación hallada entre 
los resultados de la TAS26 y el Rorschach (SC), desde el foco del tipo de datos que cada una provee, la actitud frente a la administración de las técnicas y el estilo de la respuesta.

\section{Afirmación General 9:}

Obtener una evaluación cuantitativa del puntaje total de alexitimia en la TAS permite la adecuada evaluación diagnóstica.

Respuesta a la afirmación 9:

Sin duda, el puntaje total de alexitimia evaluado mediante la TAS permite de modo apropiado discriminar pacientes alexitímicos de no-pacientes. Presentó, sin embargo, también, interés comprobado la discriminación de los niveles de distribución de la alexitimia según según sus puntos de corte: definitiva, indeterminada o ausente, $\mathrm{y}$ correlacionarlos con otras variables.

\section{Afirmación General 10:}

La alexitimia consiste en un déficit de la regulación afectiva, visible en las enfermedades psicosomáticas.

Respuesta a la afirmación 10:

Respondemos afirmativamente, ya que la muestra de pacientes claramente volvió observable su padecimiento emocional y las dificultades para el afrontamiento. Respecto de la muestra II de no-pacientes, para el Rorschach, también alexitímicos, consideramos que no podría afirmarse que se trata de un déficit o en cambio, más apropiadamente, un estilo o rasgo de personalidad. Estos no-pacientes no se interesan por la búsqueda de la verdad, ni en su interior afectivo ni el cuestionamiento de la realidad externa, y representan una considerable proporción de la distribución poblacional normal. Estos no-pacientes adaptativos, sin índice de estrés o depresión, sin enfermedades psíquicas o somáticas, con escaso uso de la introspección, la imaginación y la experiencia de conflicto, orientados al sometimiento a los estereotipos sociales y organizados según la deseabilidad social, no 
parecen experimentar un déficit. Tal vez una cuestionable postura evaluativa que tenga en mente un ideal desarrollo pleno, saludable y creativo de la propia subjetividad podría estimar en ellos un déficit. En una investigación (Lunazzi, 2000), en la que estudiamos en 550 casos la intervención de diversas variables en el puntaje de alexitimia de la TAS26, tales como genero, nivel socioeconómico, presencia de enfermedad psicosomática, los cambios sobre la personalidad del ejercicio profesional prolongado, hallamos estadísticamente muy significativos los puntajes de ausencia de alexitimia (hiperlexitimia) entre los profesionales psicólogos (promedio 20 años de ejercicio profesional). ¿Deberíamos estimar como un déficit a la hiperlexitimia de quienes hacen continuamente énfasis en la diferenciación de sus estados emocionales y en comunicarlos? Nuevamente creemos que esta respuesta remite al carácter idiosincrásico de la alexitimia o la hiperlexitimia: sólo tal vez en casos particulares de no-pacientes cuidadosamente evaluados pueda constituir un déficit.

\subsection{Síntesis}

- Se verificó una importante y significativa presencia de alexitmia en los pacientes de Artritis Reumatoidea. La TAS26 resultó válida: discriminó efectivamente pacientes de no-pacientes según presencia y nivel de alexitimia en la AR. Las variables nivel socio-económico y años educativos resultaron independientes de la presencia de alexitimia. El puntaje total obtenido en la escala es un buen predictor; también comprobamos la utilidad de investigar los niveles de presencia definitiva, indeterminada o ausente de alexitimia en relación a otras variables.

- Acklin y Bernat proponen 7 variables Rorschach para evaluar la alexitimia: bajo R, bajo M, Bajo SumpondC, bajo FC, bajo Blends, bajo EA y alto Lambda. La mayoría de las variables Rorchach del agrupamiento de Acklin para el diagnóstico de la alexitimia se hallaron comprobadas en la AR. Los resultados de nuestras muestras, tanto de pacientes como de no-pacientes refutan la variable de Acklin: producción significativa de Lambda Alto. Tampoco, ( R ), la producción de respuestas discrimina alexitímicos de no alexitímicos. La variable EA (>6), dentro de valores normativos, mostró asociación significativa con los años educativos (variable dependiente) y no significativa con el nivel socioeconómico (variable independiente). 
- P.Porcelli propone 15 variables, además de las originales, para ampliar la evaluación de la alexitimia: ellas son Bajos MA\%, M+FM+m, H, RFS, FD, DQ+, Wsumpond6, Zf ,ausencia de T=0, PSV $>0$ y altos R-Eng, EBambigual, A, P y CDI. Diez de sus variables ampliadas de alexitmia probaron eficacia para el diagnóstico de la alexitimia, en la $\mathrm{AR}$ ellas son: $\mathrm{MA} \%, \mathrm{M}+\mathrm{FM}+\mathrm{m}, \mathrm{H}$, DQ+, Códigos Especiales (Wpond6), A, P, PSV, R-Eng, RFS.

- Basados en nuestros propios estudios, propusimos otras 7 variables capaces de examinar la alexitimia: ellas son $A n>2$ y $A n+X y>3$, Afro alto, Sum $\operatorname{shad}>3$, DEPI, D y Dadj. Obtuvimos diferencias significativas en 5 de las variables exploradas en la comparación de las tres muestras y en las submuestras reagrupadas según años educativos: ellas son $\mathrm{An}>2$ y $\mathrm{An}+\mathrm{Xy}>3$, DEPI, D y Dadj.

- Según nuestra investigación 20 indicadores son válidos para la investigación de la alexitimia mediante el Rorschach: 1. Bajos M, 2. SumpondC, 3. FC, 4. Blends, 5. EA, 6. MA\%, 7. M+FM+m, 8. H, 9. DQ+ , 10. Códigos Especiales (Wpond6), 11. Altos A, 12. P, 13. PSV, 14. R-Eng, 15. RFS, 16. An>2, 17. An+Xy>3, 18. DEPI, 19. D y 20 Dadj. (estos dos últimos con puntajes negativos).

Como puede observarse, comenzamos nuestra investigación revisando las contribuciones y advertencias sobre errores metodológicos o de concepto sobre el tema, ya que aspirábamos a ofrecer hallazgos que pudieran considerarse representativos de un estudio válido, con los instrumentos TAS-Rorschach del constructo alexitimia, en la enfermedad artritis reumatoidea (AR). Obtuvimos los estadísticos descriptivos de referencia normativos poblacionales, para realizar la adecuada comparación de muestras obtenidas en el mismo contexto cultural. Sometimos a análisis variables educativas y socioeconómicas para establecer su independencia o dependencia en la evaluación del constructo. 
Adoptamos la metodología de multimétodos porque la reconocemos como la más indicada. Al llegar a este punto del recorrido realizado, estamos en condiciones de dar respuesta al problema que nos planteamos en la formulación de las hipótesis, y de haber alcanzado los objetivos que propusimos.

Recordamos en principio las hipótesis:

\section{Hipótesis 1:}

Los pacientes diagnosticados con artritis reumatoidea presentarán un déficit reconocible en la regulación de los afectos llamado alexitimia, evaluada mediante el empleo de multimétodos, tales como la Escala Toronto de Alexitimia (TAS26) y la técnica Rorschach (Sistema Comprehensivo).

\section{Hipótesis 2:}

De acuerdo al constructo teórico alexitimia, entendido como déficit de la regulación de los afectos, y por la naturaleza de los instrumentos de evaluación utilizados, (TAS26) y Rorschach (SC) a través de su uso conjunto o independiente, se podrán observar distintas asociaciones entre la alexitimia y el nivel socioeconómico o entre la alexitimia y los años educativos.

Respondemos:

\section{Hipótesis 1}

Pudo establecerse la asociación estadísticamente significativa desde el punto de vista probabilístico entre la alexitimia y la artritis reumatoidea (AR), evaluada por la TAS26 y por el Rorschach (SC).

1.- Los pacientes presentaron un déficit reconocible de la regulación de los afectos, mediante la evaluación de las técnicas Escala Toronto de Alexitimia (TAS) y Rorschach (Sistema Comprehensivo). 
2.- Tal déficit pudo claramente objetivarse con el uso de las técnicas, cada una de inestimable valor para establecer la presencia o no del déficit e informar sobre su estructura y funcionamiento.

\section{Hipótesis 2}

Nuestros estudios comparando los 180 casos que integran las tres muestras utilizadas y además comparando submuestras seleccionadas según niveles socioeconómicos y de años educativos informan que:

3.- Los resultados de la $\mathrm{TAS}_{26}$, en la artritis reumatoidea fueron independientes a la intervención de variables socioeconómicas y de años educativos.

4.-Los resultados del Rorschach, en la AR tampoco se hallaron asociados con el nivel socioeconómico. Los mayores años educativos intervinieron en cambio, en los resultados de significativas variables del Rorschach. Sin embargo, también los mayores años educativos se hallaron presentes en no-pacientes que contaban con mejores recursos ideacionales y afectivos, en su personalidad

\section{En cuanto a nuestros objetivos:}

1. Contribuir a la precisión del diagnóstico de la alexitimia en la AR.

2. Validar el uso de dos técnicas destinadas para el diagnóstico de la alexitimia: la TAS26 y el Rorschach (Sistema Comprehensivo) y evaluar su funcionamiento (convergente o no) en el diagnóstico de la alexitimia.

\section{Respondemos:}

5.- El empleo de multimétodos es relevante en el estudio de la alexitmia. Aún cuando la convergencia concurrente estadística no sea siempre completa, aporta riquísima información para fundamentar el juicio clínico del evaluador. 
6.- Corresponde señalar la capacidad de la TAS para operacionalizar la evaluación del constructo alexitimia y poner de manifiesto las diferencias entre pacientes (detecta presencia de enfermedad psicosomática) y no pacientes.

7.- Se comprobaron y refutaron indicadores tradicionales y ampliados para la evaluación Rorschach de la alexitimia.Propusimos 7 indicadores originales Rorschach surgidos de nuestros propios estudios para investigar la presencia de alexitimia, de los cuales se verificó la validez de 5 .

8.- Se verificaron 20 indicadores Rorschach de alexitimia válidos para su diagnóstico en la AR. Entre ellos, se destaca la capacidad discriminativa de la RFS.

Retomando, ahora, las ricas reflexiones de J.Grostein, coincidimos en que el significado de la alexitimia es el de la excepción que prueba la regla: esto es, que desde esta perspectiva todo un completo escenario se vuelve manifiesto y se logra una perspectiva más vasta sobre la importancia de la vida emocional en un sentido amplio. «Sabemos ahora lo que antes se había sólo intuido: que los afectos son el servidor silencioso de nuestra autoorganización y nuestros procesos de supervivencia, que interactúan en el cuerpo y en la mente y los comprenden holísticamente al mismo tiempo».

Según pudimos comprobar, la alexitimia refleja, en tanto rasgo de personalidad, un desorden importante en la regulación de los afectos y constituye un importante factor de riesgo en las enfermedades del tipo que fueran, pues al reducir la circulación y significación de la información proveniente de las señales del mundo interno y del mundo externo, interfiere con el proceso de autoorganización y reorganización del organismo en su historia y ambiente. Establecer diferencialmente su presencia en los casos precisará el diagnóstico y orientación psicoterapéutica por parte del equipo de salud. Aspiramos, en el caso de la AR, contribuir con nuestro trabajo a ese cometido.

Helena Lunazzi

20 de abril de 2006 


\title{
Tabla de Contenidos
}

\author{
Cuadro I a \\ Muestra I: Artríticos Reumatoideos ( $\mathrm{N}=60$ pacientes)
}

Características de la Muestra.

pág. 145

Cuadro I b

Muestra I: Artríticos Reumatoideos ( $\mathrm{N}=60$ pacientes)

Características de la Muestra: distribución de la composición pág.146

Cuadro II a

MUESTRAS I y II

Compara artríticos $(N=60)$ con no-pacientes ( $N=60)$

homologados según nivel socioeconómico medio-bajo pág. 153

\section{Cuadro II b}

Nivel socioeconómico y Alexitimia Muestra I

Compara artríticos $(N=60)$, mediante submuestras, según niveles socioeconómicos medio-alto, medio medio y medio-bajo............pág. 155

\section{Cuadro III}

Muestras I y III: Compara Artríticos $(N=60)$ con no-pacientes $(N=60)$ con años educativos promedio $>15$.

\section{Cuadro IV a}

Muestra I (pacientes AR) $\mathbf{N}=60$ Distribución de presencia de alexitimia, según niveles socioeconómicos y de años educativos...........................................................................pág. 159

\section{Cuadro IV b}

Años educativos y Alexitimia .pág. 160

Muestra I (pacientes AR) $N=60$ Comparación de presencia de alexitimia, según submuestras de años educativos 
Cuadro IV c

Comparaciones entre Puntaje Total y niveles de Alexitimia y la RFS, en las Muestras I, II y III.....................................................pág. 163

Cuadro V

Muestra I (AR) y Muestra II (no-pacientes)

igual nivel socioeconómico medio bajo

Indicadores de Alexitimia en Rorschach (M. W. Acklin, Ph. D. y E. Bernat,

1987) pág. 172

\section{CuadroVI}

Muestra I (AR) y Muestra III (no-pacientes) mayores educativos. Indicadores de Alexitimia en Rorschach

(M. W. Acklin. Ph. D. y E. Bernat) pág. 173

Cuadro VII a

Comparaciones entre las tres muestras

Resultados técnica Rorschach S. C. agrupación de variables de alexitimia sugeridas por $\mathbf{P}$. Porcelli pág. 183

Cuadro VII b

Otras variables de alexitimia. Resultados Técnica Rorschach S. C. comparaciones entre las tres muestras:

significación estadística de los resultados............................ pág. 184

Cuadro VIII

Comparación según submuestras de años educativos entre los pacientes de AR y los no pacientes..................................... pág. 191

Cuadro IX

6 Sub muestras comparadas según niveles de años educativos. Variables evaluadas según porcentajes. pág 195 
Cuadro $\mathbf{X}$

Muestra I (pacientes de AR $\mathbf{N}=60$ )

Comparación según años educativos entre los pacientes de artritis reumatoidea: compara submuestra $1(0-7$ años educativos $n=33)$ con submuestra 3 (8-14 años educativos, $n=20)$ con submuestra 5 ( $\geq 15$ años educativos $n=7$ ) pág. 197

Cuadro XI

Comparación entre muestras de pacientes y no-pacientes con EA > 6 pág. 201

Cuadro XII

Muestras I y II

Compara artríticos $(N=60)$ con no-pacientes $(N=60)$

homologados según nivel socioeconómico medio-bajo pág. 209

\section{Cuadro XIII}

Muestra I (AR) Y Muestra II (No Pacientes)

Igual nivel socioeconómico

Indicadores de Alexitimia en Rorschach

M. W. Acklin, Ph.D. y E. Bernat, 1987

pág. 211 


\section{BIBLIOGRAFÍA}

Acklin, M. W. y Bernat, E. (1987). Depression, Alexithymia and pain-prone disorder: a Rorschach study. Journal of Personality Assessment, 51 3, 462-479.

Acklin, M. (1990). Alexithymia, somatization and the Rorschach Response Process. Rorschachiana, XVII, 180-187.

Acklin, M. (1994). Some Contributions of Cognitive Science to the Rorschach Test. Rorschachiana, XIX, 129-145.

Acklin, M. y McDowell, C.J. II (1995). Statistical Power in Rorschach Research. Rorschach Research: Issues and Methods Edited by John Exner Jr., Rorschach Workshops, New Jersey: Lawrence Erlbaum, 181-194.

Acklin M., C. J. McDowell II (1995). Statistical Power in Rorschach Research. Rorschach Research: Issues and Methods. Edited by John Exner Jr. Rorschach Workshops Lawrence Erlbaum Publ. Mahwah. New Jersey.

Ahrens, S. y Deffner, G. (1986). Empirical study of alexithymia: methodology and results. American Journal of Psychotherapy, 40, 430-47.

Andronikof - Sanglade, A. (1983). Image du Corps et Image de Soi au Rorschach. Techniques Projectives II, tome 28.2.

Andronikof - Sanglade, A. (1990). La Répresentation de Soi: un concept fecond pour la Psychologie Clinique et Proyective. Bull. de la Soc. du Rorschach et des Méth. Proj. de Langue Française, 34, 9-15.

Alexander, F. (1950). La médecine psychosomatique. París: Payot, Allinson, J.; Blatt, S. y Zimet, N. (1988). The Interpretation of Psychological test. New York: Taylor \& Francis.

Allen, J. \& Walsh, J. A. (2000). A construct - based approach to equivalence: methodologies for cross-cultural/ multicultural personality assessment research. In R. H.

Allen, J.; Dana, R. (2004). Methodological Issues in Cross-Cultural and Multicultural

Rorschach Research. Journal of Personality Assessment, 82 (2), 189-206. Lawrence

Erlbaum Publ. Mahwah. New Jersey.

Apfel, R. J. y Sifneos, P. E. (1979). Alexithymia: concept and measurement. Psychotherapy and Psychosomatics,32, 180-90.

Bagby, R. M.; Taylor, G. J.; Parker, J. D. A. y Loiselle, C. (1990). Cross validation of the factors structure of the Toronto Alexithymia Scale. Psychotherapy and Psychosomatics, 50, 29-34. 
Baker, G. H. B. (1982). Life events before the onset of rheumatoid arthritis. Psychotherapy and Psychosomatics, 38, 173-7.

Baker, G. H. B. (1987). Psychological factors and immunity. Journal of Psychosomatic research, 31, 1-10.

Bash, K. W. (1986). Psychosomatic diseases and the Rorschach test. Journal of Personality Assessment, 50, 350-357.

Bash, K. W. (1995). Psychosomatic Diseases and the Rorschach Test. Rorschachiana, XX, $16-28$.

Battagliotti, C.; Gentiletti, A. y Pons-Estel, B. (1992). Lupus eritematoso sistémico: aspectos clínicos y terapéuticos. Madrid: VDB.

Bergeret, J. (1992). Psychologie pathologique. París: Masson.

Bekei, M. (1991). Lecturas de lo psicosomático. Buenos Aires: Lugar Editorial.

Bion, W. (1965). Transformations. Londres: Heinemann.

Bion, W. (1992). Cogitations. Londres: Karnac Books.

Camara, E. G. y Danao, T. C. (1989). The Brain and the immune system: a psychosomatic network. Psychosomatics, 30, 140-6.

Canteros, J. (2003). El «cuerpo propio»" y la «representación» en psicoanálisis. Crítica a la metáfora cerebral. Trabajo inédito, 1-19.

Casullo, M. M. (1990). Alexitimia: consideraciones teóricas y empíricas. Buenos Aires: CONICET.

Casullo, M. M. (1994). Alexitimia: ¿síntoma o patrón cultural? Psicodiagnóstico de Rorschach y otras Técnicas Proyectivas, Año 16, 1, 65-70.

Chevnik, M. (1992). La clínica del paciente con daño somático: Diagnóstico y Abordaje Psicoterapéutico. Revista Argentina de Psiquiatría, 8, 126-132.

Costantino, G.; Flanagan, R.; Malgady, R. (1995) The history of the Rorschach: Overcoming bias in multicultural projective assessment. Rorschachiana, vol. 20, pp. 148 171. Bern, Hogrefe \& Huber Publishers.

Crofford, L. y Demitrack, M. (1996). Evidence that abnormalities of central neurohormonal systems are key to understanding fibromyalgia and chronic fatigue syndrome. Controversies in fibromyalgia and related conditions. Rheumatic disease clinics of North America, Volume 22, 2, 267-284.

Crofford, L. y Casey, K. (1999). Central modulation of pain perception. Pain management in the rheumatic diseases. Rheumatic disease clinics of North America, Volume 25, $1,1-13$.

Crown, S.; Crown, J. M. y Fleming, A. (1975). Aspects of the psychology and epidemiology of rheumatoid disease. Psychological Medicine, 5, 291-299.

Crown, S. y Crisp, A. H. (1979). Manual of the Crown. Crisp Experiential Index. Londres: Hodder \& Staughton. 
Damasio, A. (1996). El error de Descartes: la emoción, la razón y el cerebro humano. Barcelona: Crítica.

Damasio, A. (2003). Looking for Spinoza. Joy, sorrow, and the feeling brain. San Diego: Harcourt.

Dana, R. H. (1993) Multicultural assessment perspectives for professional psychology. Boston. Allyn \& Bacon.

Dana, R. (Ed), (1995) Handbook of cross-cultural and multicultural personality assessment (pp. 63-85). Mahwah, NJ: LEA Associates, Inc.

Dana, R. H. (1998) Projective assessment of Latinos in the United States: Current realities, problems, and prospects. Cultural Diversity and Mental Health, 4, 165-184.

Dana, R. (2002) Special series: Multicultural Assessment: Teaching methods and Competence Evaluations. Journal of Personality Assessment, 79 (2), 195-199.

Daruna, J. H. y Morgan, J. E. (1990). Psychosocial effects on immune function: neuroendocrine pathways. Psychosomatics, 31, 4-12.

Debray, R. (1991). Apport du TAT et du Rorschach a la recherche en Psychosomatique. Rorschachiana, XVII, 206-216.

Debray, R. (1996). Clinique de l'expression somatique. París: Delachaux et Niestlé.

De Jours, C. (1990). Choix de l'organe et indication "therapeutique". Revue Française de Psychosomatique, 17, 15-24.

De Mol, J. (1990). Les Modifications post-traumatiques de la Répresentation de Soi au Test de Rorschach. Bull. de la Soc. du Rorschach et Meth. Proj. de langue Francaise, 34, 77-84.

Dolto, F. (1986). La imagen inconciente del cuerpo. Buenos Aires: Paidós.

Dunbar, F. (1955). Mind and Body: Psychosomatic Medicine. New York: Random House.

Engel, G. (1955). Studies of Ulcerative Colitis III, The nature of the Psychologic Process, Amer. J. Med, 19, 231.

Exner, J. Jr. (1970). Las respuestas de Rorschach como índice de narcisismo. El Ro. En la Argentina, Año 2, n. ${ }^{\circ} 1$.

Exner, J. Jr. (1994). El Rorschach un Sistema Comprehensivo. Vol. I. Fundamentos Básicos. Rorschach Workshops, 3. ${ }^{\circ}$ ed. Madrid: Psimática.

Exner, J. Jr. y Sendin, M. C. (1995). Manual de Interpretación del Rorschach para el Sistema Comprehensivo. Madrid: Psimática.

Exner, J. Jr. (2000). Alumni Newsletter, November, 1-20. Asheville: Rorschach Workshops.

Exner, J. Jr. (2000). A Primer for Rorschach Interpretation. Asheville: Rorschach Workshops. 
Felten, D. L.; Felten, S. Y.; Bellinger, D. L. y Madden, K. S. (1993). Fundamental aspects of neuro-immune signalling. Psychotherapy and Psychosomatics, 60, 46-56.

Fernandez, A.; Sriram, T. G.; Rajkumar, S. y Chanraskar, A. N. (1989). Alexithimic characteristics in rheumatoid arthritis: a controlled study. Psychotherapy and Psychosomatics, 51, 45-50.

Fifield, J.; Tennen, H.; Reisine, S. y McGuillam, J. (1998). Depression and the long term risk of pain, fatigue and disability in patients with Rheumatoid Arthritis. Arthritis \& Rheumatism, Vol. 41, n. ${ }^{\circ} 10$, October 1998, 51-57.

Flanagan, R. (1996). History of the Rorschach. Jour. Per. Ass., Vol. 70 n. ², 315-334.

Franchi, V.; Sanglade, A. (1999) Methodological and Epistemological Issues Raised by the use of Rorschach Comprehensive System in Cross - Cultural Research. Rorschachiana, vol. 23, pp. 118 - 134. Bern, Hogrefe \& Huber Publishers.

Freud, S. (1968). Lecciones de introducción al psicoanálisis (artículo de 1916-1917), en Obras Completas. Madrid: Biblioteca Nueva.

Freud, S. (1968). Historia de una neurosis infantil (1918), en Obras Completas. Madrid: Biblioteca Nueva.

Freyberger, H. (1977). Supportive psychotherapeutic techniques in primary and secondary alexithymia. Psychotherapy and Psychosomatics, 28, 33742.

Friedman, H. S. y Booth-Kewley, S. (1987). The disease prone personality: a metanalytic view of the construct. American Psychologist, 42, 539-55.

Fukunishi, I.; Moroji, T. y Okabe, S. (1995). Alexithymia and coping with stress in healthy persons: alexithymia as a personality trait is associated with low social support and poor response to stress. Psychological Reports, 76, 1299-304.

Ganellen, R. (1996a). Exploring MMPI-Rorschach relationships Journal of Personality Assessment, 67, 529-542.

Ganellen, R. (1996b). Integrating the Rorschach and the MMPI-2 in personality assessment. Mahwah, N.J.: Erlbaum N.Y.

Gianella, A. (1995). Introducción a la Epistemología y a la Metodología de la Ciencia. La Plata: Editorial Universidad de La Plata.

Gray, J. (1993). La Psicología del miedo y el estrés. Barcelona: Labor.

Grotstein, J. S. (1986). The psychology of powerlessness: disorders of self - regulation and interactional regulation as a newer paradigm for psychopathology.

Psychoanalitic Inquiry, 6, 93-118.

Grotstein, J. S. (1990). Nothingness, meaningless, chaos, and the 'black hole' II: The 'black hole'. Contemporary Psychoanalysis, 26, 377-407. 
Haviland, M.; Sonne, J. y Kowert, P.(2004). Alexithymia \& Psychopathy: comparison and application of California Q-set-Prototypes. J. P. Ass., Vol. 82, n. ${ }^{\circ} 3$, June 2004, 307318.

Herbert, T. B.; Cohen, S.; Marsland, A. L.; Bachen, E. A.; Rabin, B. S.; Muldoon, M. F. y Manuck, S. B. (1994). Cardiovascular reactivity and the course of the immune response to an acute psychological stressors. Psychosomatic Medicine, 56, 37-44.

Horowitz, D. A. (1982). Evidence of three mononuclear populations in cellular immunity. Scientific Basis of Rheumatology. Nueva York: G. Panayi.

Hunsley, J. y Meyer, G. J. (2003). The incremental validity of psychological testing and assessment: Conceptual, methodological, and statistical issues. Psychological Assessment, 15, 446-455.

Intebi, A. y Zukerfeld, R. Z. (2000). CRH en neurociencias. Neuropsiquiatría y Neurociencia cognitiva, 14-26.

Jordan, M. S. y Lumley, M. A. (1993). Alexithymia and rheumatoid arthritis: Poster presented at the annual meeting of the American Psychosomatic Society.

Keltinkangas - Jarvinen, L. (1987). Concept of Alexithymia II: the consistency of Alexithymia. Psycotherapy and Psychosomatics, 47, 2, 113-20.

Kernberg, O. (1977). La Teoría de las Relaciones Objetales y el Psicoanálisis Clínico. Paidós. Bs. As.

Kernberg, O. (1979). Desórdenes Fronterizos y Narcisismo Patológico. Buenos Aires: Paidós.

Kernberg, O. (1987). Trastornos graves de personalidad. México: Editorial Taller.

Keiger, J. H. y Kinsman, R .A. (1980). The development of an MMPI Alexithymia Scale. Psychotherapy and Psychosomatics, $34,17-24$.

Kielcolt - Glaser, J. K. y Glaser, R. (1995). Psychoneuroimmunology and health consequences: data and shared mechanism. Psychosomatic Medicine, 57, 269-74.

Kielcolt - Glaser, J.; McGuire, L.; Robles, T. y Glaser, R. (2002). Physical \& Somatoform and Psychogenic Disorders. Psychosomatic Medicine, 64, 1, 3290-32.

Kinder, B. y Curviss, G. (1990). Alexithymia among empirically derived of Subgroups of chronic pain back patients. Journal of Personality Assessment, 54, 1-2.

Kirmayer, L. J. (1987). Languages of suffering and healing. Transcultural Psychiatric Research Review, 24, 119-36.

Kirmayer, L. J.; Robbins, J. M. y Paris, J. (1994). Somatoform Disorders: personality and the social matrix of somatic distress. Journal of Abnormal Psychology, 103, 12536.

Klein, M. (1940). Mourning and its relation to manic-depressive state. Contributions to psycho-analysis. Londres: Hogarth Press.

Klimovsky, G. (1971). Estructura y validez de las teorías científicas, en D. Ziziemsky (comp.): Métodos de investigación en psicología y psicopatología. Buenos Aires: Nueva Visión. 
Klimovsky, G. (1995). Las Desventuras del Conocimiento Cientifico. Buenos Aires: A-Z.

Klimovsky, G. e Hidalgo, C. (1998). La inexplicable sociedad. Buenos Aires: AZ.

Krystal, H. (1993). Integration and self healing: affect, trauma, Alexithymia. Hillsdale (Nueva Jersey): Analytic Press.

Lacan, J. (1997). Escritos 2. Barcelona: Siglo XXI Editores.

Laplanche, J. y Pontalis, F. (1971). Diccionario de Psicoanálisis. Barcelona: Labor.

Lerner, P. (1991). Psychoanalytic Theory and the Rorschach. Londres: The Analytic Press.

Liberman, D. (1991). Del cuerpo al símbolo. Buenos Aires: Nueva Visión.

Liberman, D. (1966). La comunicación en terapéutica psicoanalítica. Buenos Aires: Eudeba.

Lolas, F.; Von Rad, M. y Scheibler, D. (1981). Situational influencies on verbal affective expression of psychosomatic y psychoneurotic patients. Journal of Nervous and Mental Disease, 169-619-23.

Lunazzi, H. (1992). Lectura del Psicodiagnóstico. Buenos Aires: Editorial Universidad de Belgrano.

Lunazzi, H. (1994). The Battery as perceptual hold in Structural Diagnosis. Rorschachiana XIX, 112-128.

Lunazzi, H.; García de la Fuente, M.; Elías, D. y Kosak, V. (1997). Alexitimia y Sobrepeso Crónico. Psicodiagnosticar, vol. 8, 23-34.

Lunazzi, H.; García de la Fuente, M.; Elías, D.; Kosak, V. y Rossi Casé, L. (1997). Investigación sobre los Factores del Constructo Alexitimia (póster). IV Jornadas de Investigación, Facultad de Psicología, Universidad de Buenos Aires.

Lunazzi, H. (1999). Lambda and very high Alexithymia. XVI International Rorschach Congress, Amsterdam.

Lunazzi, H. (1999). La alexitimia como factor de riesgo psicosomático. Segundo Congreso Iberoamericano de Evaluación Psicológica AIDEP, Caracas.

Lunazzi, H. (1999). L'indice d'egocentrisme dans les patients psychosomatiques. XVI International Rorschach Congress, Ámsterdam.

Lunazzi, H.; García de la Fuente, M.; Elías, D. y Kosak, V. (1999). Investigación sobre variables en el constructo Alexitimia según puntaje total y factores en 550 casos (póster). IV Congreso Iberoamericano de Evaluación Psicológica, Caracas.

Lunazzi, H.; Lojo, M. y Lazzarino, R. (1999). Artritis Reumatoidea y Alexitimia (póster). XV Jornadas Instituciones Hospital Rossi, La Plata.

Lunazzi, H. (2000). Investigación de variables en el constructo Alexitimia en 550 casos. Rev. Ibearoam. de Ev. Psic, vol. 10, n. ${ }^{\circ}$, 101-119.

Lunazzi, H. (2000). El Índice de Angustia: un exceso imposible de tramitar. Abreletras Psicodiagnóstico, III, 79-90. 
Lunazzi, H. (2001). Los obesos de perfil. Revista de la Sociedad Española de Rorschach y Métodos Proyectivos, n. ${ }^{\circ} 13-14,99-121$.

Lunazzi, H. (2001). Aportes al Campo Psicodiagnóstico. La Plata: Editorial de la Universidad Nacional de La Plata, 135-210.

Lunazzi, H. (2002). Ampliando Nuestro Estudio del Rorschach. Cap. X Ro. ¿Método cognitivo-psicodinámico o Sistema Comprehensivo?). La Plata: Editorial de la Universidad Nacional de La Plata.

Lunazzi, H. y col. (2002). Acerca de los sesgos en la construcción de estudios normativos: ¿La muestra de no pacientes constituye un sesgo?. Psicodiagnosticar. Revista de la Asociación Argentina de Estudio e Investigación en Psicodiagnóstico. Vol. 12. pag. 21 -31

Lunazzi, H.; Urrutia, M. I. (2005). Re-visitando el Lambda elevado. XVIII International Congress of Rorschach and P.M., Barcelona.

Lunazzi, H. y col. (2006). El Rorschach en sujetos No pacientes. Tablas Normativas (Rorschach of Nonpatient subjects. Normative Data), edición bilingüe. Madrid: Psimática (en prensa).

Lunazzi, H. (2006). May the Rorschach say when high Alexithymia means a psychosomatic risk? Rorschachiana, 26 (en prensa).

Luraguiz, L. (1992). Lo Psicosomático: Apertura y Encrucijada. Revista Argentina de Psiquiatría, Vertex, Vol. III, 8, 107-115.

Lutgendorf, S. K. y Constanzo, E. S. (2003). Psychoneuroimmunology and health psychology. An integrative model. Brain Behavior and Immunity, 17, 225-232.

Masling, J. M. (1997): On the nature and utility of projective test and objective test. Journal of Personality Assessment, 9 , 113-121.

Ma Tous Ral, J. (2000). La evaluación de la personalidad mediante la integración de tres sistemas de conducta, en Cordero, A. (Comp): La evaluación psicológica en el año 2000. Madrid: TEA.

Maldavsky, D. (1977). Teoría de las Representaciones, sistemas y matrices, transformaciones y estilos. Buenos Aires: Nueva Visión.

Maldavsky, D. (1988). Psicosomática Buenos Aires. Actualidad Psicológica, Año XIII, $1,49,2-5$.

Maldavsky, D. (1992). Teoría y Clínica de los Procesos Tóxicos. Buenos Aires: Amorrortu. On the nature and utility of projective test and objective test,

Maldavsky, D. (1992). Sobre la relación entre psicosis y procesos tóxicos. Psicoanálisis ApdeBA, Vol. XIV, n. ${ }^{\circ} 2,303-330$.

Márquez Lopez - Mato, A. (2004). Psiconeuroinmunoendocrinología II. Nuevos dilemas para viejos paradigmas. Viejos dilemas para neoparadigmas. Buenos Aires: Polemos.

Marty, P. y de M’Uzan, M. (1963). La “pensée opératoire”. Revue Francaise de Psychanalyse, 27, 1345-56. 
Marty, P. (1990). La Psicosomática del Adulto. Buenos Aires: Amorrortu.

Marty, P. y Nicolaïdes, N. (1990). Psychosomatique. París: L’esprit du temps.

Masling, J. (2002). How Do I Score Thee? Let Me Count the Ways. Or Some Different Methods of Categorizing Rorschach Responses. Journal of Personality Assessment, $79,3,399-421$.

Mattlar, C.E.(2004) The Rorschach Comprehensive System is Reliable, Valid, and cost effective Rorschachiana XXVI-158-186 . Hans Huber.Berna

Mc Cain, G. (1996). A cost - effective approach to the diagnosis and treatment of fibromyalgia. Controversies in fibromyalgia and related conditions. Rheumatic disease clinics of North America, Volume 22, n. ${ }^{\circ} 2,323-349$.

Mc Dougall, J. (1982). Alegato por cierta Anormalidad. Barcelona: Petrel.

Mc Dougall, J. (1987). Teatros de la Mente. Madrid: Technocomunicaciones.

Mc Dougall, J. (1991). Teatros del cuerpo. Barcelona: Julián Yebenés.

Mc Grath, R. y Ratliff, K. (1993). Using Self- Report Measures to corroborate theories of depression: the Specificity Problem. Journal of Personality Assessment, 61, 1, 156168.

Meltzer, D. (1993). Implicaciones Psicosomáticas en el Pensamiento de Bion. Rev. $A P D E B A$, Vol. XV, 2, 117-129.

Meyer, G. (1996). The Rorschach and MMPI. Toward a more scientifically differentiated understanding of cross-method assessment. Journal of Personality Assessment, Vol. 67, $\mathrm{N}^{\mathrm{o}} 3,558-578$.

Meyer, G. (1997). On the integration of Personality assessment methods: the Rorschach and the MMPI. Journal of Personality Assessment, 68, 297-330.

Meyer, G. J. (1999). The convergent validity of MMPI and Rorschach scales: An extension using profile scores to define response/character styles on both methods and a re-examination of simple Rorschach response frequency. Journal of Personality Assessment, 72, 1-35.

Meyer, G. J.; Riethmiller, R. J.; Brooks, G. D.; Benoit, W. A. y Handler, L. (2000). A replication of Rorschach and MMPI-2 convergent validity. Journal of Personality Assessment, 74, 175-215.

Meyer, G. J. (2001).. Evidence to correct misperceptions about Rorschach norms. Clinical Psychology: Science and Practice, 8, 389-396.

Meyer, G. J.; Viglione, D. J. y Exner, J. E. Jr. (2001). Superiority of Form \% over Lambda for research on the Rorschach Comprehensive System. Journal of Personality Assessment, 76, 68-75.

Meyer, G. J. (2002). Exploring Possible Ethnic Differences and Bias in the Rorschach Comprehensive System. Journal of Personality Assessment, 78, (1) pp. 104 - 130. LEA Publishers. 
Meyer, G. J. (2004).. The reliability and validity of the Rorschach and TAT compared to other psychological and medical procedures: An analysis of systematically gathered evidence, en M. Hilsenroth y D. Segal (Eds.): Personality assessment, Volume 2, en M. Hersen (Ed.-in-Chief): Comprehensive handbook of psychological assessment.. Hoboken (Nueva Jersey): John Wiley \& Sons, 315-342.

Montreuil, M. (1995). Le fonctionnement Alexithymique: de l'observation clinique à l’evaluation quantitative. Pratiques Psychologiques, 54, 123-138.

Mora, G. (1967). History of Psychiatry, en Kaplan (Ed.): Comprehensive Textbook of Psychiatry. Londres: Williams and Wilkins, 2-34.

Morali-Daninos, A. (1978). Les Methodes Projectives en Medecine Psychosomatique. Introduction Au Symposium de Liège. Bull. de la Societé Française du Rorschach et des Methodes Projectives, 31, 7-9.

Musaph, H. (1974). The role of aggression in somatic symptom formation. International Journal of Psychiatry and Medicine, 5, 449-460.

Nemiah, J. C. y Sifneos, P. E. (1970). Affect and fantasy in patients with psychosomatics disorders, en O.W. Hill (Ed): Modern trends in psychosomatic medicine, vol. 2, 2634.

Nossal, G. J. V. (1987). The basic components of the immune system. N. Engl. J. Med., 316- 328.

Páez, D.; Basabe, N.; Valdoseda, M. e Iraurgi, I. (1995). Confrontation: inhibitionalexithymia and health, en J.F. Penenbaker (Ed): Emotions, disclosure and health. Washington: A.P.A.

Páez, D. y Casullo, M. M. (2000). Cultura y Alexitimia. Buenos Aires: Paidós.

Pandey, R.; Mandal, M.; Taylor, G. y Parker, J. (1996). Cross Cultural Alexithymia: Development and validation of a hindi translation of the 20- item Toronto Alexithymia Scale. Journal of Clinical Psychology, Vol. 52, № 2.

Parker, J. D. A.; Bagby, R. M. y Taylor, G. J. (1991). Alexithymia and depression: distinct of overlapping constructs? Comprehensive Psychiatry, 32, 387-94.

Petot, D. (1996). Alexithymie: Psychological Poverty or Psychological Richness?: A Rorschach study. Rorschachiana, Vol. 21, 153-168.

Petot, J. M. y Djuric Jocic, D. (2005). Discrepancies Between the Rorschach Inkblot Method and Self-Report Measures of Personality. Rorschachiana, XXVII, 101-116.

Porcelli, P.; Zaka, S.; Leoci, C.; Centonze, S. y Taylor, G. J. (1995). Alexithymia in inflammatory bowel diseases. Psychotherapy and Psychosomatics, 64, 49-53.

Porcelli, P. y Meyer, G. (2002). Construct validity of Rorschach variables of Alexithymia. Psychosomatics: Journal of consultation Liaison Psychiatry, 43, 360369.

Porcelli, P. (2004). Psychosomatic Medicine and the Rorschach Test. Madrid: Psimática.

Prazeres, N. (1996). Ensajo de um estudo sobre alexitimia com o Rorschach e a escala de alexitmia de Toronto (TAS-20). Disertación presentada en la Facultad de Psicología y Educación, Universidad de Lisboa, Portugal. 
Quintana, G. (1996). La psicología de la personalidad y sus trastornos. Madrid: CCS.

Quiñónez, M. P.; Ahuja, S. K.; Jiménez, F.; Schaefer, J.; Garavito, E.; Rao, A.; Chenaux, G.; Reddick, R. L.; Kuziel, W. A. y Ahuja, S. S. (2004). Experimental arthritis in $\mathrm{CC}$ chemokine receptor $2-$ null mice closely mimics severe human rheumatoid arthritis. J. Clinical. Investigation, 113, 856-866.

Rather, L. J. (1965). Mind and Body in eighteen century medicine. Londres: Historical Medical Library.

Rausch de Traubenberg, N. y Sanglade, A. (1984). Representation de Soi et Rélation d' Object au Rorschach: Grille de Répresentation de Soi. Revue de Psychologie Appliquée, $\mathrm{N}^{\mathrm{o}} 34, \mathrm{n}^{\circ}{ }^{\mathrm{a}} 1,1 .^{\circ}$ trimestre.

Rausch de Traubenberg, N. (1990). La Répresentation de Soi et Rélation d'object au Rorschach. Bull. de la Soc. du Rorschach et des Meth. Proj. de langue Franç., n. ${ }^{0} 34,3-16$.

Rausch de Traubenberg, N. (1990). Elaboration de la Grille de Répresentation de Soi au Rorschach. Bull. de la Soc. du Rorschach et des Meth. Proj. de langue Franç., n. ${ }^{\circ} 34,17-26$.

Ricart, F.; Cohen, M. A.; Alfonso, C.; Hoffman, R.; Quiñónez, N.; Cohen, A. e Indyk, D. (2002). Understanding the psychodinamics of non-adherence to medical treatment in persons with HIV infection. Mount Sinai Hospital, New York. General Hospital Psychiatry, 24, 176-185.

Rice, J. y Pisetsky, D. (1999). Pain in the Rheumatic Diseases: Practical aspects of diagnosis y treatment. Pain Management in the Rheumatic Diseases, 0889-857 X/99, vol 25, n. ${ }^{\circ}$ 1, Feb. 1999, 15-32.

Rimon, R. (1969). A Psychosomatic approach to rheumatoid arthritis: a clinical study of 100 female patients. Acta rheumatica Scandinavia, suppl 15, 1-154.

Rimon, R. y Laakso, R. L. (1985). Life stress and rheumatoid arthritis. Psychotherapy and Psychosomatics, 43, 38-43.

Rosmond, R. (2005). Role of stress in the pathogenesis of the metabolic syndrome. Psychoneuroendocrinology, 30, 1-10.

Sami - Ali, M. (1979). Cuerpo real, cuerpo imaginario. Para una epistemología psicoanalítica. Buenos Aires: Paidós.

Sami - Ali, M. (1993). El cuerpo, el espacio y el tiempo. Buenos Aires: Amorrortu.

Sampieri Hernández, R.; Collado Fernández, C. y Lucio Baptista, P. (1998). Metodología de la Investigación. Segunda edición. Madrid: McGraw Hill.

Sang - Ahm, L. y Young-Joo, N. (2005). Perceived self control of seizures in patients with uncontrolled partial epilepsy. Seizure, 14, 100-105.

Schanberg, L. y Sandstrom, M. (1999). Causes of pain in children with arthritis. Pain management in the rheumatic diseases. Rheumatic disease clinics of North America, Vol. 25, n. ${ }^{\circ} 1,31-53$.

Schwartz, L. (1995). Hablar lo verbal. Hacia una epistemología de las Técnicas Proyectivas verbales. Buenos Aires: Tekne. 
Schwartz, L. (1998). Algunas problemáticas epistemológicas relacionadas con el Psicodiagnóstico. Psicodiagnosticar, Vol. VIII, 26-33.

Schwartz, L. (2003). Operativización para la validación de las Técnicas Proyectivas. Revista del Instituto de Investigaciones de la Facultad de Psicología de la Universidad de Buenos Aires, Vol. 2.

Selye, H. (1992). Panorama general de la Etiopatogenia de las Enfermedades de Adaptación y ¿Qué es el stress?. Conferencias Pronunciadas en el 2do Congreso Iberoamericano en 1956, Buenos Aires. Vertex, Vol. III, 8, 157-168.

Sendín, M. C. (2000). Diagnóstico Psicológico: bases conceptuales y guía práctica en los contextos clínico y educativo. Madrid: Psimática.

Sendín, M. C. y Esbert, M. (2000). Reflexiones en torno a la complejidad del proceso diagnóstico, variables intervinientes y posibles fuentes de error. Ponencia presentada en el IV Congreso Nacional de Psicodiagnóstico, XI Jornadas Nacionales ADEIP.

Sepa, A.; Frodi, A. y Ludvigsson, J. (2002). Could parenting stress and lack of support / confidence function as mediating mechanisms between certain environmental factors and the development of autoimmunity in children? Ann. New York Academy of Sciences, 958, 431-436.

Shoenfeld, Y. y Schwartz, R. S. (1984). Immunologic and Genetic factors in autoimmune diseases. New England Journal of Medicine, 311, 1019-29.

Sifneos, P. E. (1973). The prevalence of "Alexithymic" characteristics in psychosomatics patients. Psychotherapy and Psychosomatics, 22, 255-62.

Sifneos, P. E. (1995). Psychosomatique, Alexithymie et Neurosciencies. Revue Francaise de Psychosomatique, 7, 27-36.

Sivak, R. y Wiater, A. (1997). Alexitimia: la dificultad para verbalizar los afectos. Buenos Aires: Paidós.

Smadja, C. (1995). Le Modèle Psychosomatique de Pierre Marty. Revue Française de Psychosomatique, 7, 7-26.

Smith, B. (1994). The Object Relations Theory and the Integration of Empirical and Psychoanalitycal approaches to Rorschach Interpretation. Rorschachiana, XIX, 6178.

Soler, B. (1997). Immunologie. V. III, 8, 107-115. París: Presses Universitaires de France.

Sorribas, E. y Burde, L. (1993). Enfermos Psicosomáticos: Personalidades Míticas. Buenos Aires: Lugar.

Taylor, G. J.; Bagby, M.; Ryan, D.; Parker, J. D. A.; Doody, K. y Keefe, P. (1988). Criterion Validity of Toronto Alexithymia Scale. Psychosomatic Medicine, Vol. 50, 54-72.

Taylor, G. J. (1994). El constructo Alexitimia: conceptualización, validación y relación con dimensiones básicas de la personalidad. New Trends in Experimental and Clinical Psychiatry, Vol.X, n. ${ }^{\circ} 2,94$. 
Taylor, G. J.; Parker, J.y Fanelli, M. (1995). Alexithymia in essential hypertensive and psychiatric outpatient: a comparative study. Jour. Of Psychosom. Research, Vol. 39, N. ${ }^{\circ} 8,987-994$.

Taylor, G. J.; Parker, J.; Bagby, M. y Bourke, M. (1996). Relationships between Alexithymia and Psychological Characteristics Associated with eating Disorders. Journal of Psychosomatic Research, Vol. 41, N 6, 561-568.

Taylor, G. J.; Bagby, M. y Parker, J. (1997). Disorders of affect regulation: Alexithymia in medical and psychiatric illness. Cambridge: University Press.

Taylor, G. J.; Parker, J. y Bagby, M (1998). Alexithymia: Relationship with Ego defense and Coping Styles. Comprehensive Psychiatry, Vol. 39, N. ${ }^{\circ} 2,91-98$.

Taylor, G. J.; Bagby, M. y Parker, J. (2003). The 20- Item Toronto Alexithymia Scale IV Reliability and factorial validity in different languages and cultures. Journal of Psychosomatic Research, 55, 277-283.

Tibon, S.; Handelzalts, J. E. y Weinberger, Y. (2002, September). The effectiveness of the Reality - Fantasy Scale (RFS). in normative and clinical samples. Paper presented at the 17th Congress of the International Rorschach Society, Rome, Italy.

Tibon, S.; Porcelli, P. y Weinberger, Y. (2005). The Ego Impairment Index and the Reality - Fantasy Scale: Comment on Viglione, Perry and Meyer (2003). Journal of Personality Assessment, 84, 3, 315-317.

Timsit, M. (1978). Test de Rorschach et Pathologie Psychosomatique. Bull. Soc. Franç. du Rorschach et des Meth. Proj., 31, 11-31.

Timsit, M. (1990). Distorsions des réponses kinestesiques au Rorschach et Somatizations. Revue de Psychol. Appliquée, Vol 40, 2, 261-283.

Tuset Bertran, A. M. (1996). The Rorschach in the study of coronary heart disease. Rorschachiana, Vol. 21, 18-27.

Unanue, E. R. y Allen, P. M. (1987). The basis of the immunoregulatory role of macrophages and other accessory cells. Science, 236-551.

Vaillant, G. E. (1994). Ego mechanisms of defense and personality psychopathology. Journal of Abnormal Psychology, 103, 44-50.

Viglione, D. (1996). Data and issues to Consider in Reconciling Self-Report and the Rorschach. Journal of Personality Assessment, 67 3, 579-87.

Vollhardt, B. R.; Ackerman, S. H.; Rrayzel, A. I. y Barland, P. (1982). Psychologically distinguishable groups of R.A. Patients. Psychosom. Medicine, 44, 353-62.

Vollhardt, B. R.; Ackerman, S. H. y Shindledecker, R. D. (1986). Verbal expression of affect in A.R. and Alexithymia. Acta Psychiatrica Scandinavica, 74, 73-9.

Wallace, E. R. (1988). Mind-body. Monistic dual aspect interactionism. Journal of Nervous and Mental Disease, 176, 4-21.

Wallace, E. R. (1988). What is "truth"? Some philosophical contributions to psychiatric issues. American Journal of Psychiatry, 145, 137-47. 
Weiner, I. (1995). Consideraciones Metodológicas en la Investigación Rorschach. Psychological Assessment, Vol. 7, N. ${ }^{\circ} 3,330-337$.

Weiner, I. (1998). Principles of Rorschach Interpretation. Nueva York: LEA.

Weiner, I.(1999). Lo que el Rorschach puede hacer por usted. Incremento de su validez en aplicaciones clínicas. Journal of Psychological Assessment,6-(4) 327-336

Weiner, I. (2000). Status Actual del Rorschach inkblot method-RIM- P. 13. Journal of Personality Assessment, 1997, 68, 1, 5-19.

Weiner, I. (2000). Conferencia Magistral: Haciendo una Interpretación del Rorschach tan buena como se pueda. Journal of Personality Assessment, 74, 2, 164-174.

Weiner, I. (2002). On the Future of Rorschach Assessment. Conference XVIII International Rorschach Congress, Septiembre, Roma

Weiner, I.; Spielberger, C. y Abeles, N. (2002). Psicología Científica y Método Rorschach. Boletín Informativo ADEIP, Año 14, n. ${ }^{\circ 34,34-39 .}$

Weiner, I. B. (2004a). Rorschach assessment: Current status, en M. J. Hilsenroth y D. L. Segal (Eds.): Personality assessment, vol.2, 343-355) en M. Hersen (Ed.-in-Chief): Comprehensive handbook of psychological assessment. Hoboken (Nueva Jersey): Wiley.

Wetzler, S. y Marlowe, D. (1993). The diagnosis and Assessment of Depression, Mania and Psychosis, by Self-Report. Journal of Personality Assessment, 60, 1, 1-31.

Winnicott, D. W. (1953). Transitional objects and transitional phenomena. International Journal of Psychoanalysis, 34, 89-97.

Winnicott, D.W. (1978). Donald W. Winnicott. Buenos Aires: Trieb.

Winnicott, D. W. (1979). Realidad y Juego. Barcelona: Gedisa.

Winnicott, D. W. (1991). Exploraciones Psicoanalíticas I. Buenos Aires: Paidós.

Wolfe, F. y Potter, J. (1996). Fibromyalgia and work disability. Is fibromialgia a disabling disorder?. Controversies in fibromyalgia and related conditions. Rheumatic disease clinics of North America, Vol. 22., n. ${ }^{\circ} 2,369-391$. 


\section{ANEXOS}

Anexo 1: Planillas de composición demográfica y variables Rorschach de las tres muestras utilizadas: muestra I, muestra II y muestra III.

Anexo 2: Elaboración estadística

Prof. María Inés Urrutia (CesPI - Centro de estudios estadísticos para la Investigación. Universidad Nacional de la Plata)

Anexo 3: La Escala de Realidad y Fantasía (RFS)

Resultados en las muestras I, II y III, según niveles de presencia de alexitimia definitiva, indeterminada y ausente.

Anexo 4: El involucramiento en las respuestas ( $R$ - Engagement) evaluado en cada protocolo.

Resultados en las muestras I, II y III

Anexo 5: La Confiabilidad de la codificación entre codificadores de la muestra de 506 no-pacientes argentinos. elaborada por Thomas Shaffer, Ph. D., A.B.P.P. 